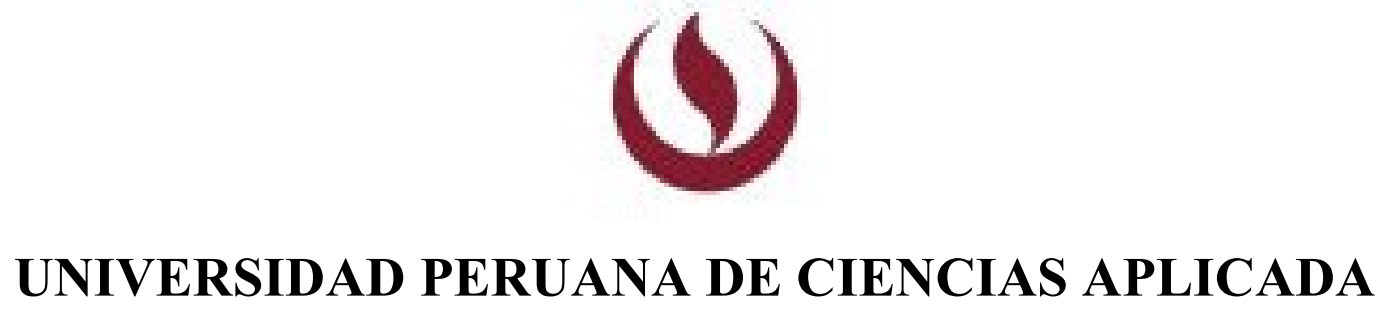

FACULTAD DE INGENIERÍA CARRERA DE INGENIERÍA INDUSTRIAL

\title{
PROPUESTA DE MEJORA DEL PROCESO DE UNA PLANTA DE PRODUCCIÓN DE FIDEOS
}

TESIS

PARA OPTAR POR EL TÍTULO DE INGENIERO INDUSTRIAL

\author{
AUTOR \\ LLERENA MANRIQUE, RUBÉN DARÍO (0000-0002-1155-9075)
}

ASESOR

HUMBERTO REYES ROCHA (0000-0002-3646-446X)

Lima, 19 de julio 2018 


\section{RESUMEN}

La presente tesis explica la situación actual de una planta de manufactura de fideos, que es parte de una compañía que se dedica a la manufactura de alimentos de consumo masivo. La planta está ubicada en Lima, facturó 376 millones de soles en el año 2015 y consta de 9 líneas de producción con una capacidad instalada de 35 toneladas por hora. La programación de la producción es en base a la demanda del cliente, el cual es decodificada semanalmente, por el área de planeamiento, en toneladas por cada Stock Keeping Unit (SKU) y está es entregada al área de producción bajo un contrato, donde ambas partes dan conformidad para cumplir con el cliente. El cumplimiento de programa es importante porque evita tener desperdicios de sobreproducción, inventarios y además de ventas pérdidas. Para ello se debe lograr producir dentro del $90 \%$ al $110 \%$ del volumen planificado por SKU. Entonces, el cumplimiento de la producción semanal es igual a la sumatoria de todos los SKU's cumplidos entre la sumatoria de todos los SKU's programados. En el primer capítulo se presenta el marco teórico a aplicar, los cuales servirán como base para poder identificar la problemática del proceso de fabricación de fideos, así como las posibles soluciones. En el segundo capítulo se describe la situación actual de la compañía, específicamente en la planta de fabricación de fideos, donde se describe los procesos actuales, el planteamiento de la problemática y el análisis de las causas con las herramientas del diagrama de Ishikawa, análisis de árbol de falla, diagrama de Pareto, análisis de la capacidad del proceso e histogramas. En el tercer capítulo se plantea una propuesta para mejorar el proceso de producción de fideos mediante la aplicación de la herramienta de la manufactura Esbelta, con el fin de obtener una producción más eficiente y eficaz acorde a las exigencias de los clientes. Finalmente, en el cuarto capítulo, se presentan las conclusiones y recomendaciones para la propuesta de mejora del presente trabajo.

Palabras Clave: Lean Manufacturing, A3, Poka Yoke, mejora de procesos 


\begin{abstract}
This thesis explains the current situation of a noodle manufacturing plant, which is part of a company that is dedicated to the manufacture of food for human consumption. The plant is in Lima, invoiced 376 million soles in 2015 and consists of 9 production lines with an installed capacity of 35 tons per hour. The production schedule is based on customer demand, which is decoded weekly, by the planning, in tons for each Stock Keeping Unit (SKU) and is delivered to the production under a contract, where both parts give conformity to meet the customer. Program compliance is important because it avoids waste of overproduction, inventories and sales losses. For this, it must be possible to produce $90 \%$ to $110 \%$ of the volume planned by SKU. Then, the accomplishment of the weekly production is equal to the sum of all the SKUs accomplished between the sum of all the SKUs programmed. In the first chapter the theoretical framework to be applied is presented, which will serve as a basis to identify the problems of the noodle manufacturing process, as well as the possible solutions. The second chapter describes the current situation of the company, specifically in the noodle manufacturing plant, where the current processes are described, the problematic approach and the analysis of the causes with the tools of the Ishikawa diagram, analysis of fault tree, Pareto diagram, process capacity analysis and histograms. In the third chapter a proposal is presented to improve the noodle production process through the application of the Lean manufacturing tool, to obtain a more efficient and effective production according to the customers' requirements. Finally, in the fourth chapter, the conclusions and recommendations for the improvement proposal of the present work are presented.
\end{abstract}

Keywords: Lean Manufacturing, A3, Poka Yoke, process improvement 


\section{Tabla de contenido}

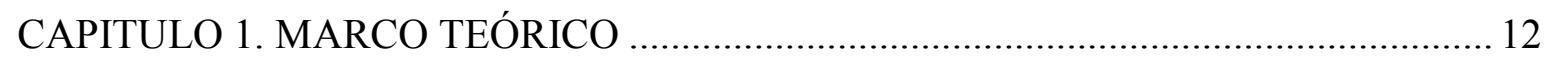

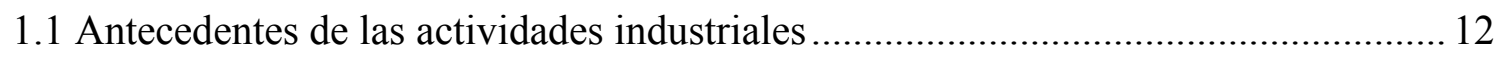

1.2 Estrategias para el mejoramiento Continuo de procesos productivos para las

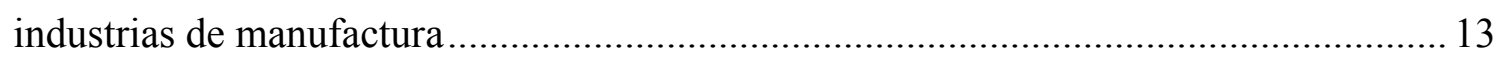

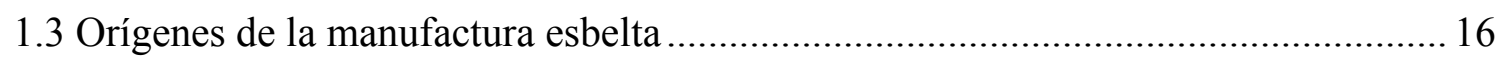

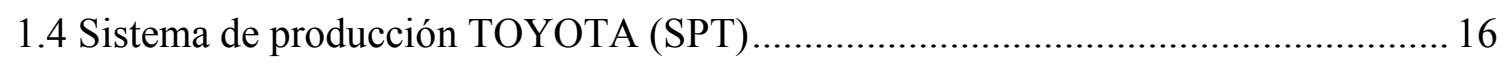

1.4.1 Los 14 Principios del Método Toyota.............................................................. 17

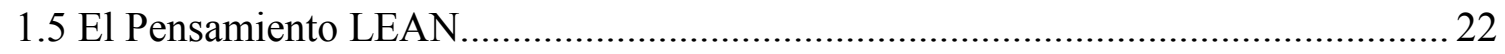

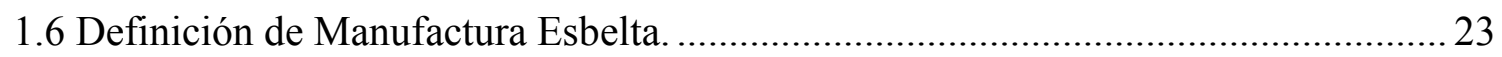

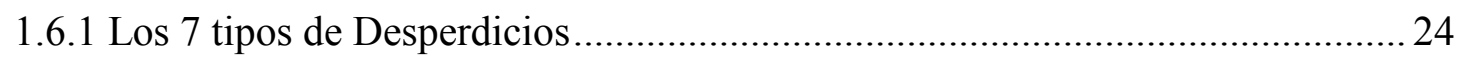

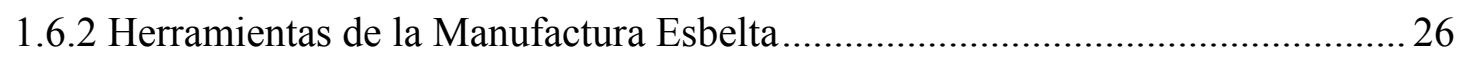

1.6.3 Enfoque estratégico de la producción desde la perspectiva de la gestión de

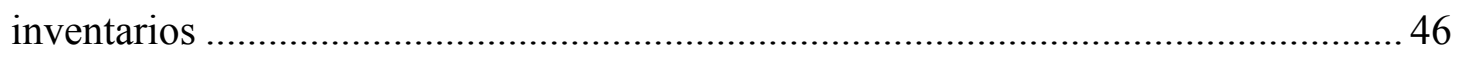

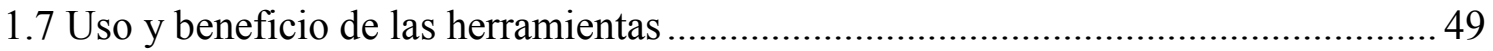

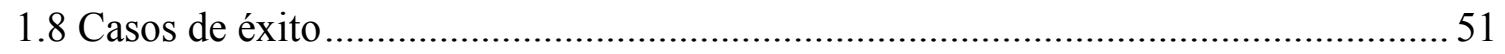

Caso de éxito Maheso e ICE Consultants................................................................ 51

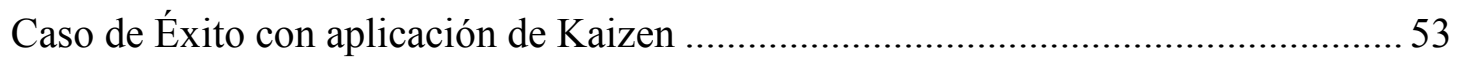

CAPITULO 2. ANÁLISIS Y DIAGNÓSTICO DEL PROCESO ACTUAL ......................57

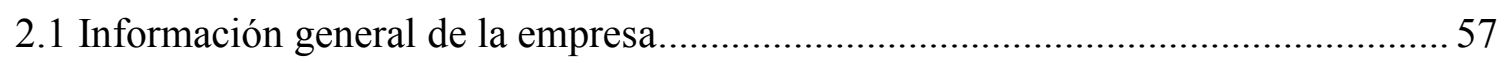

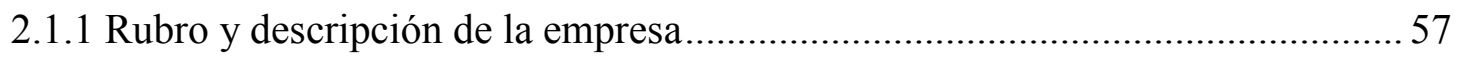

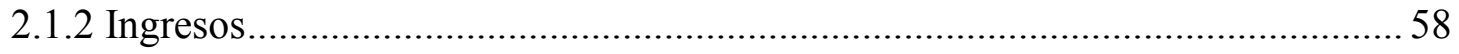

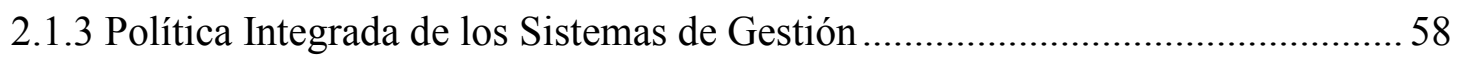

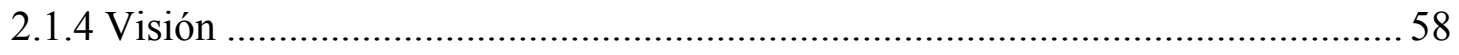

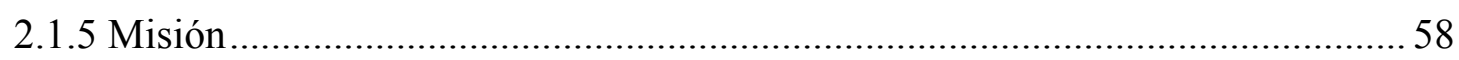

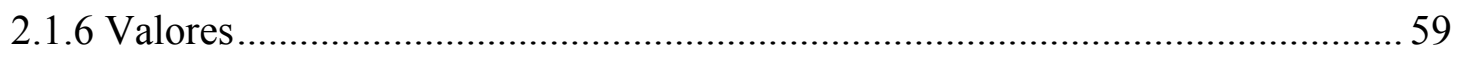

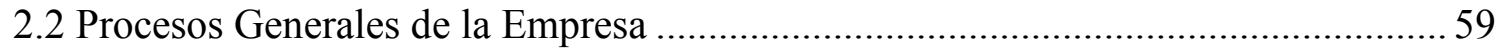

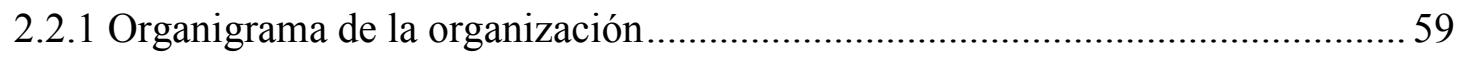

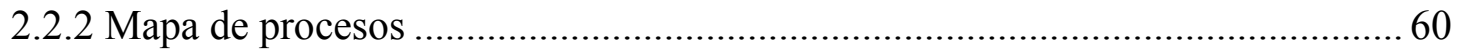

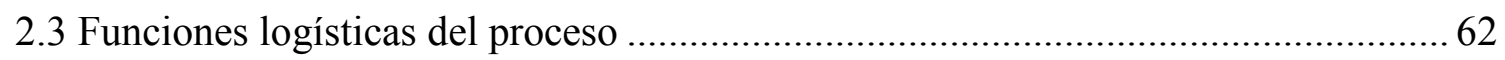

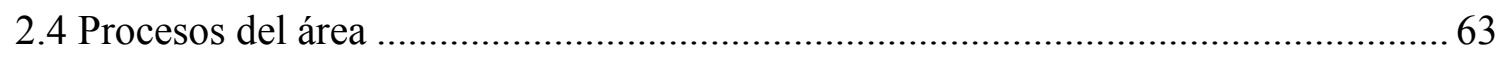

2.4.1 Diagrama SIPOC del área de producción de fideos .........................................63 63

2.4.2 Descripción del Proceso de fabricación de fideos ............................................... 64 


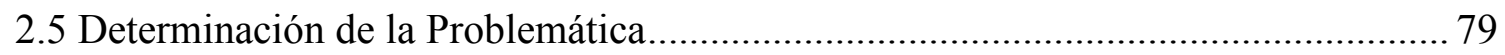

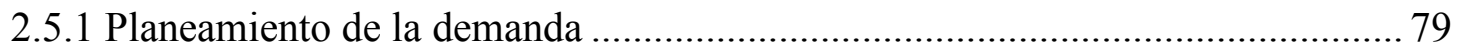

2.5.2 Preparación ejecución y cumplimiento del programa de producción.................. 85

2.5.3 Metodología de estimación del proceso productivo .......................................... 86

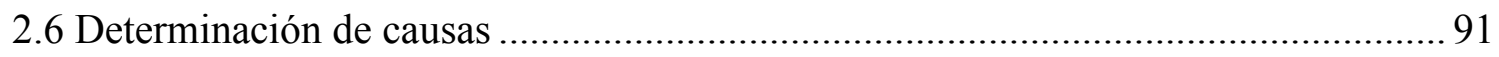

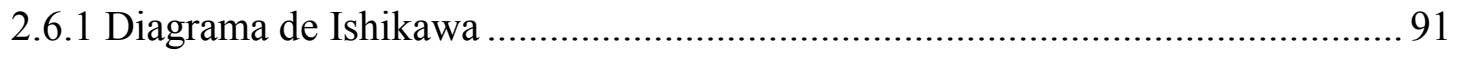

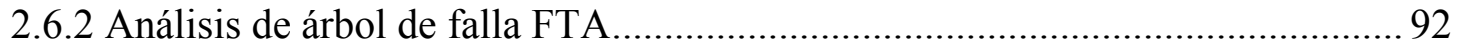

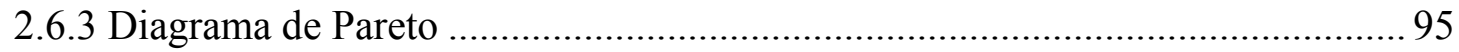

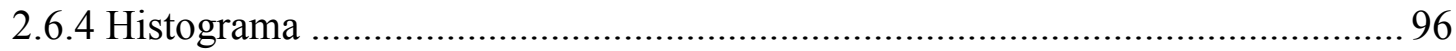

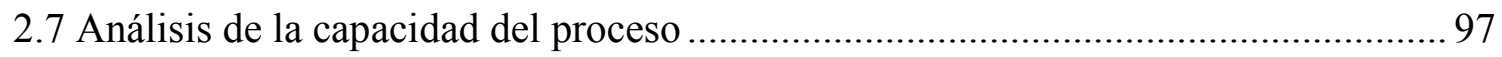

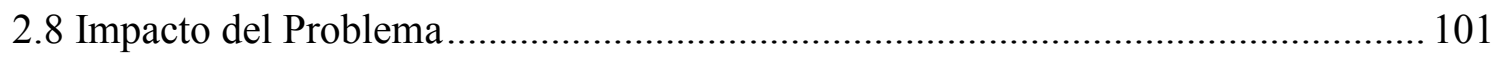

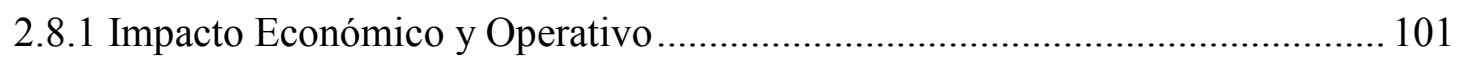

CAPITULO 3. METODOLOGÍA SOLUCIÓN AL PROBLEMA .................................... 103

3.1 Evaluación de aplicación de herramientas de Manufactura Esbelta........................ 103

3.2 Plan de mejora del proceso de Producción ................................................................. 109

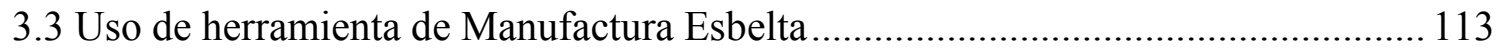

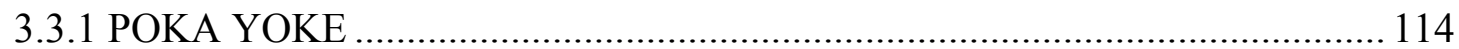

3.3.2 Implementación de mecanismos Poka - Yoke.................................................. 114

3.3.3 Método para desarrollar dispositivos Poka - Yoke.......................................... 115

3.3.4 Sistema de distribución de materia prima ..................................................... 117

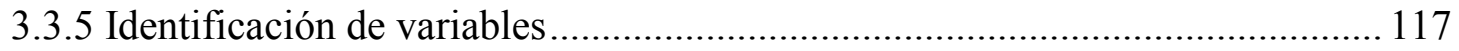

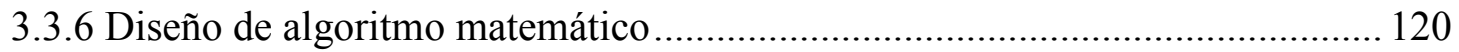

3.3.7 Propuesta diseño de la lógica de control ....................................................... 121

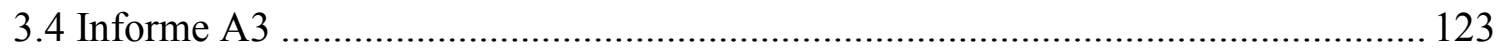

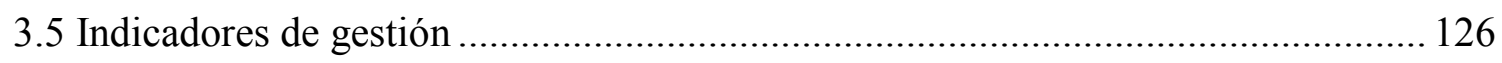

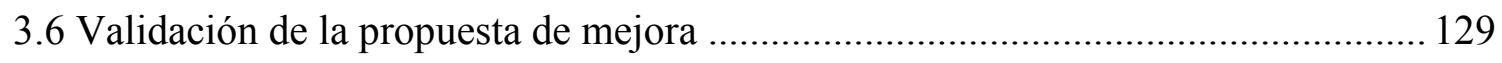

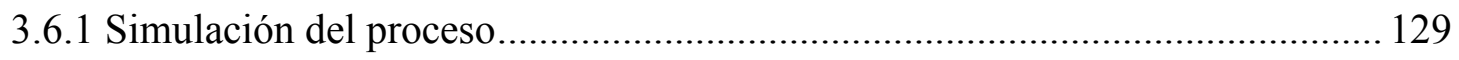

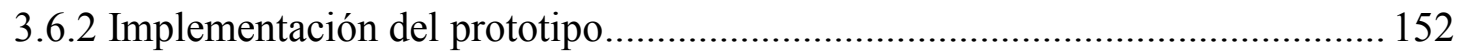

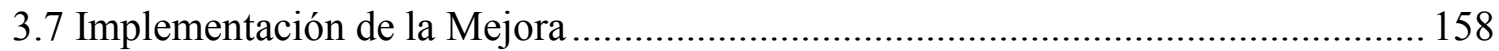

3.7.1 Medición de resultado de la implementación del prototipo .............................. 162

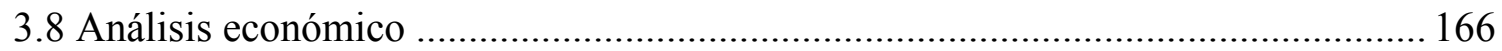

CAPITULO 4. CONCLUSIONES Y RECOMENDACIONES ..................................... 175

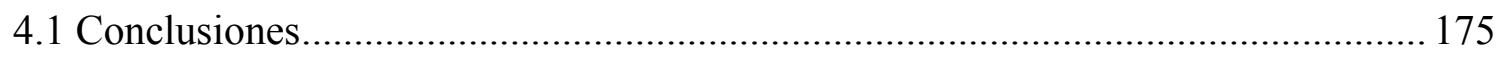


4.2 Recomendaciones

176

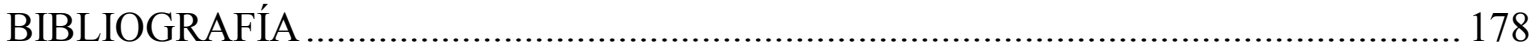

Anexos 


\section{Índice de tablas}

Tabla 1: Comparación de la cadena de valor dinámico y estático.......................................2 28

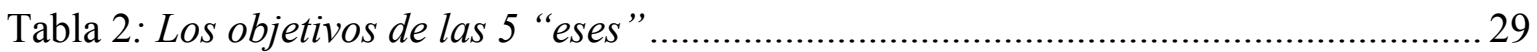

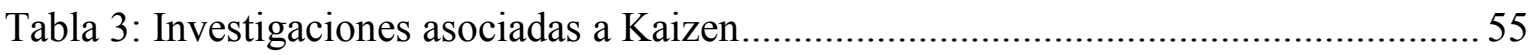

Tabla 4: Distribución del porcentaje de cumplimiento por SKU ........................................ 98

Tabla 5: Etapa de aplicación de Herramientas de Manufactura Esbelta ............................ 104

Tabla 6: Oportunidades que ofrece las Herramientas de Manufactura Esbelta................. 107

Tabla 7: Aplicación de herramientas de Manufactura Esbelta por problema..................... 108

Tabla 8: Numero de eventos que afectan el cumplimiento del programa de producción . 115

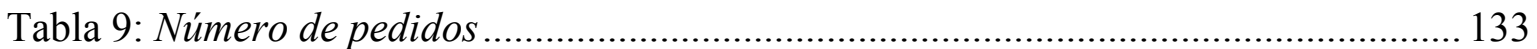

Tabla 10: Cantidad de toneladas por órdenes de producción ............................................ 135

Tabla 11: Tiempos para procesar una tonelada ................................................................. 136

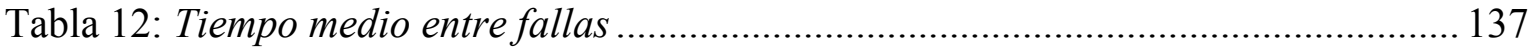

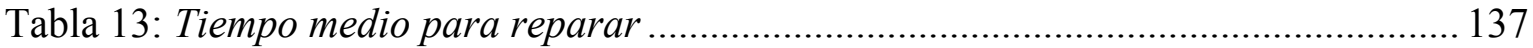

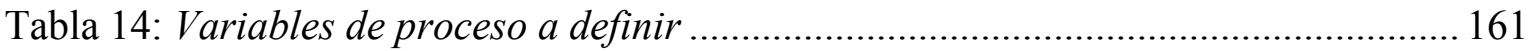

Tabla 15: Registro de Variables de proceso........................................................................ 162

Tabla 16: Registro de cumplimiento de programa de producción...................................... 164

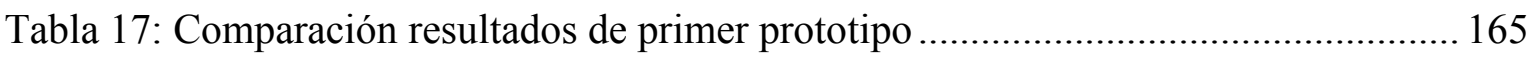

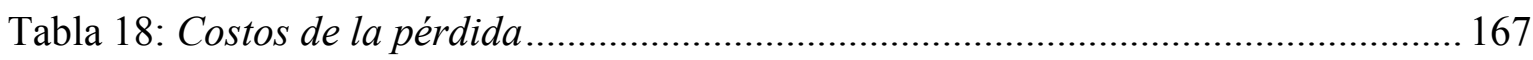

Tabla 19: Costos de la pérdida por sobre producción ..................................................... 167

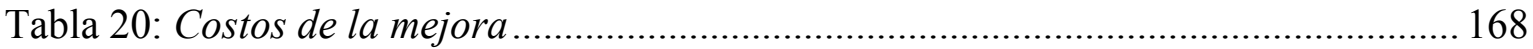

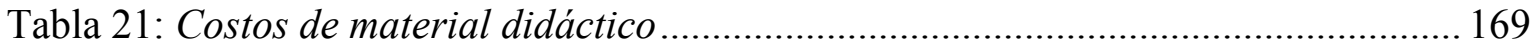

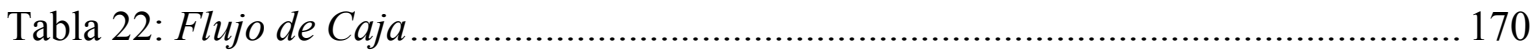

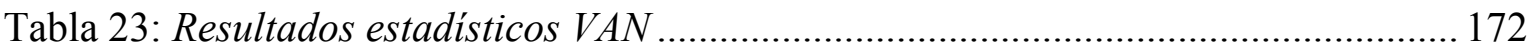

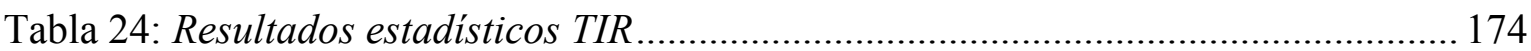

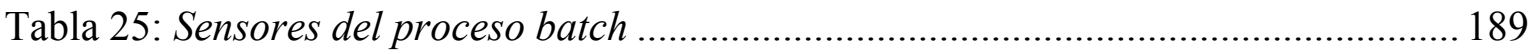




\section{Índice de figuras}

Figura 1: Principales metodologías de mejoramiento en manufactura en el mundo........... 15

Figura 2: Conceptos Fundamentales del Método Toyota................................................... 17

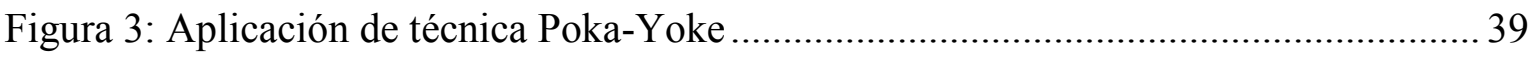

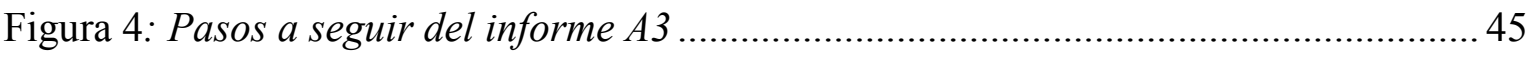

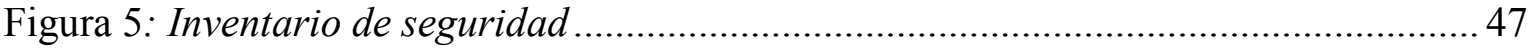

Figura 6: Relación entre Nivel de servicio y el factor $\mathrm{z}$.................................................... 48

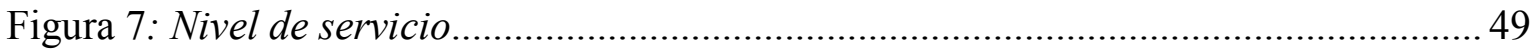

Figura 8: Pareto para cada actividad de las empresas ..................................................... 50

Figura 9: Empresas que en los últimos tres años han usado herramientas, según tamaño .. 51

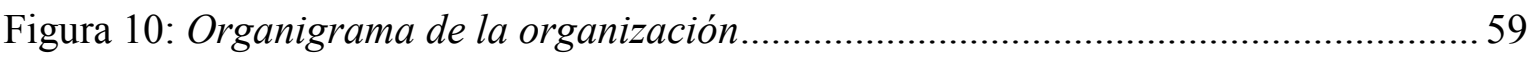

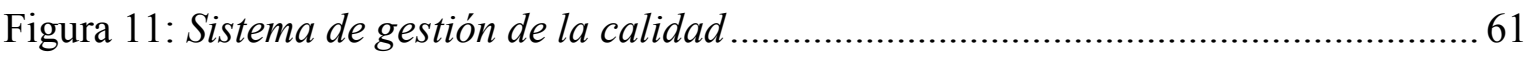

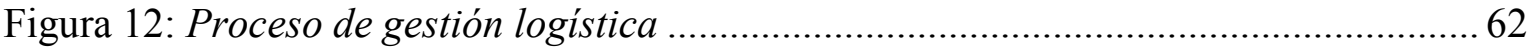

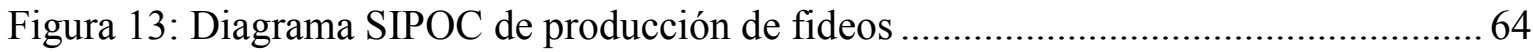

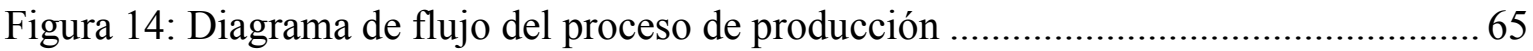

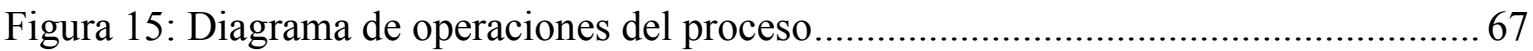

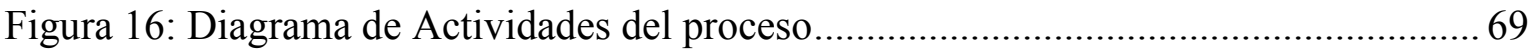

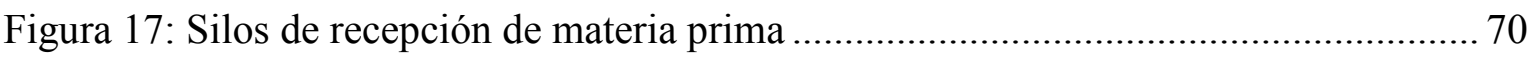

Figura 18: Sistema de distribución de macro y microcomponentes ................................... 70

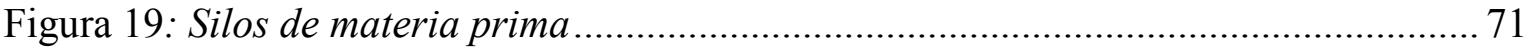

Figura 20: Sistema de dosificación de agua y sémola ....................................................... 72

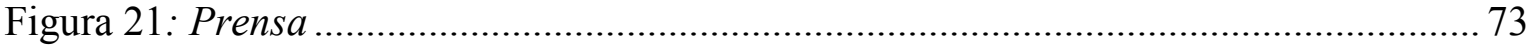

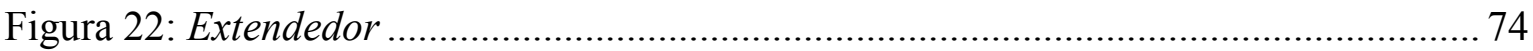

Figura 23: Diagrama de secado para pasta larga …......................................................... 75

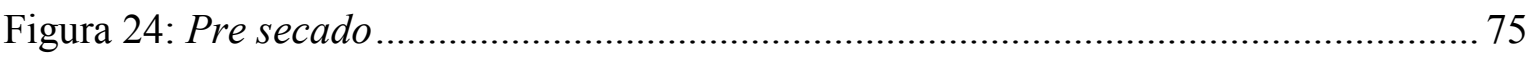

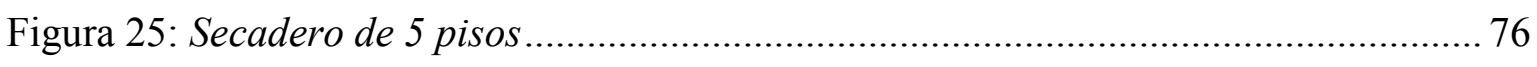

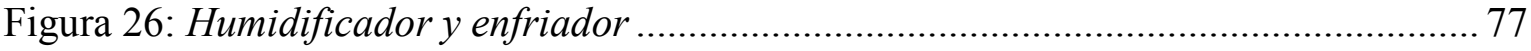

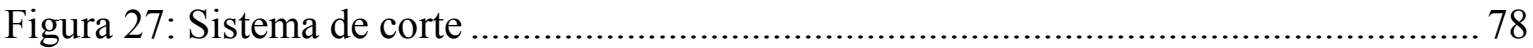

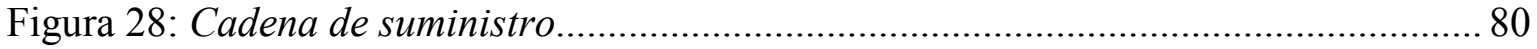

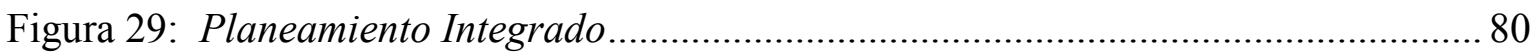

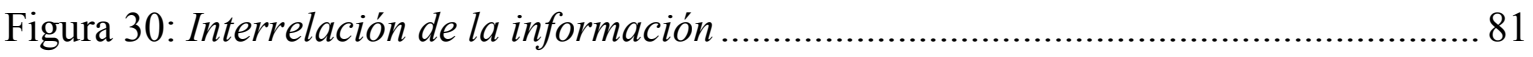

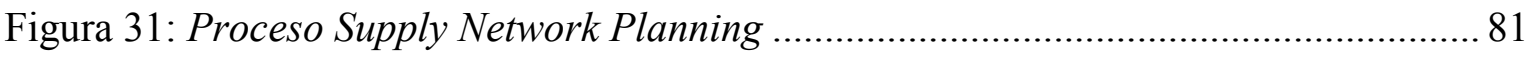

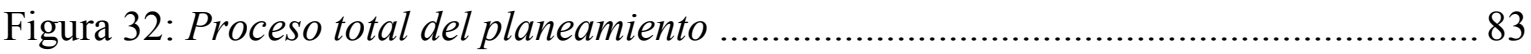




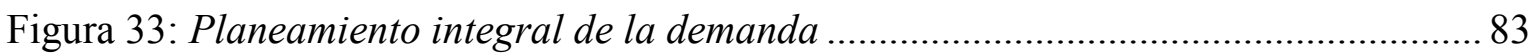

Figura 34: Proceso de elaboración del plan de producción ................................................. 84

Figura 35: Eficacia del cumplimiento de la producción...................................................... 87

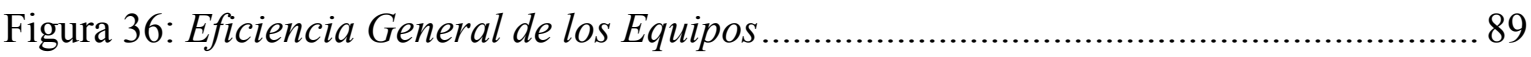

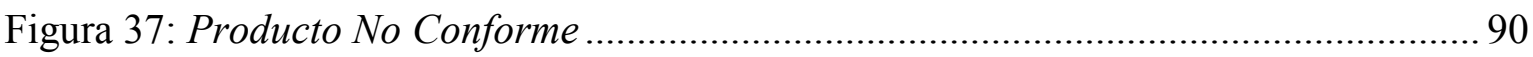

Figura 38: Diagrama de Ishikawa de la eficiencia del cumplimiento de la producción...... 93

Figura 39: FTA Incumplimiento del programa de producción ........................................... 94

Figura 40: Problemas por áreas que ocasionan el no cumplimiento de la producción........ 95

Figura 41: Factores de que afectan el cumplimiento de la producción ................................96

Figura 42: Distribución del porcentaje de cumplimiento por SKU ..................................... 97

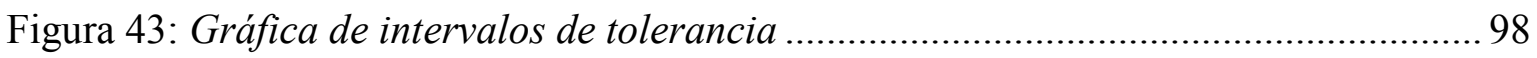

Figura 44: Gráfica de Capacidad de Proceso .................................................................. 100

Figura 45: Relación de secuencia de implementación herramientas de Manufactura Esbelta 106

Figura 46: Propuesta de Diagrama SIPOC de producción de fideos................................. 109

Figura 47: Proceso de implementación de lean................................................................... 111

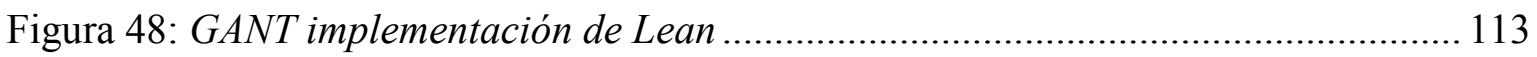

Figura 49: Impacto de las herramientas en la solución de la problemática........................ 116

Figura 50: Proceso de Recepción Materia Prima ............................................................. 117

Figura 51: Propuesta Lógica de Control ........................................................................ 122

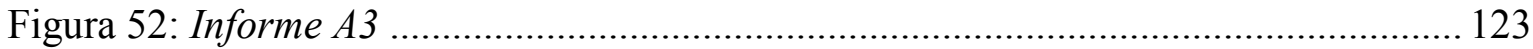

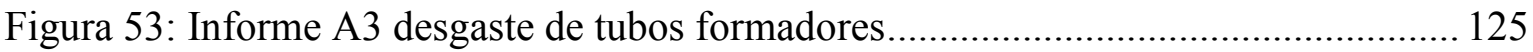

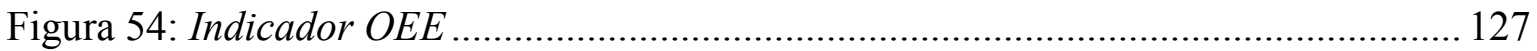

Figura 55: Indicador Cumplimiento de Producción ............................................................. 128

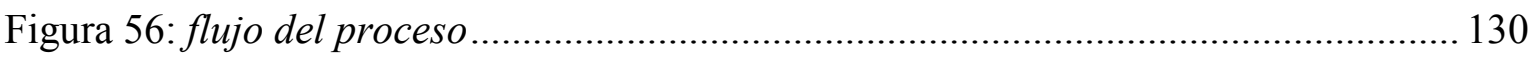

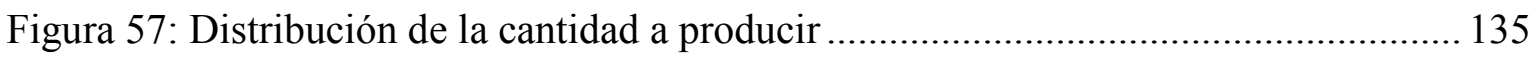

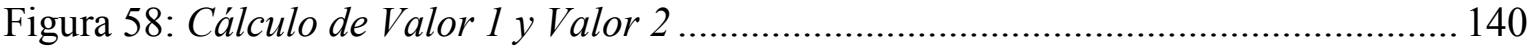

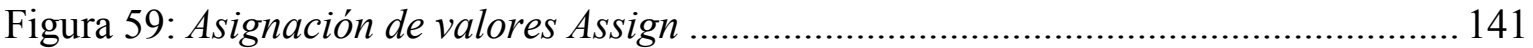

Figura 60: Asignación de valores Separate ..................................................................... 142

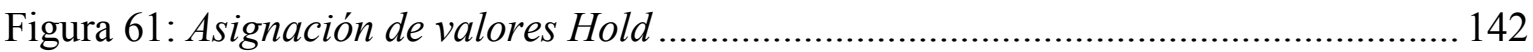

Figura 62: Asignación de valores Decide ........................................................................ 143

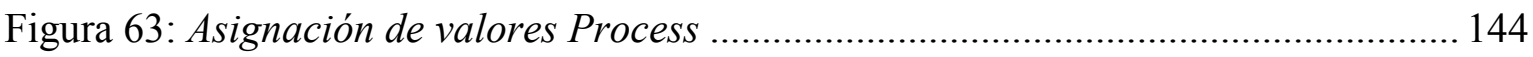

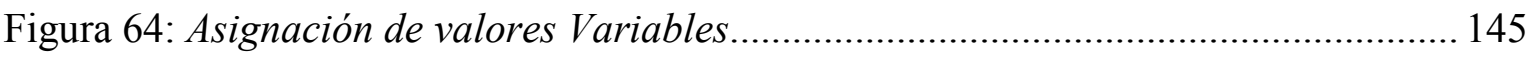


Figura 65: Diagrama de bloques para el cálculo.

Figura 66: Asignación de variables para calcular indicador principal

Figura 67: Asignación de condiciones de simulación

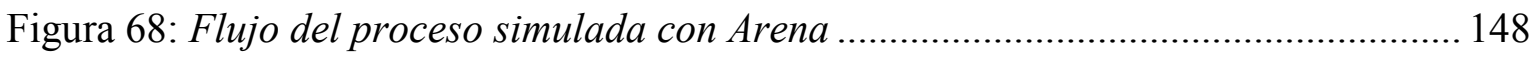

Figura 69: Ingreso de variables en Assign al nuevo diagrama mejorado .......................... 151

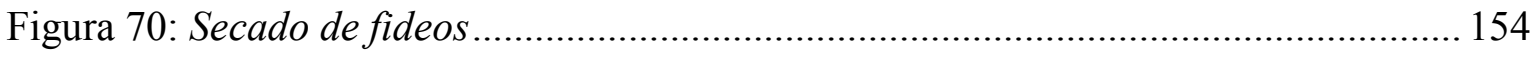

Figura 71: Balance de masa del proceso de producción de fideos .................................... 155

Figura 72: Estimación del volumen de harina .................................................................... 157

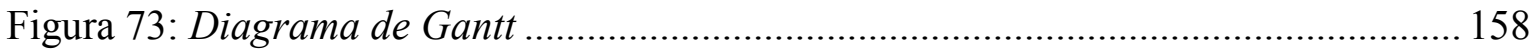

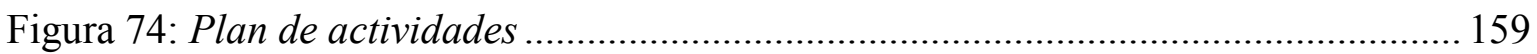

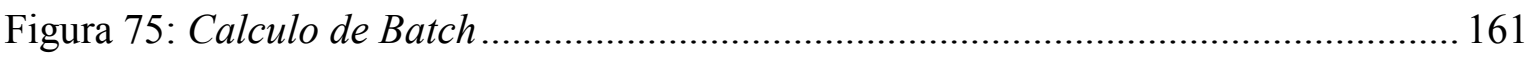

Figura 76: Gráfica de distribución del Análisis del Valor Actual Neto ............................. 171

Figura 77: Gráfica Acumulativa ascendente del Análisis del Valor Actual Neto ............. 171

Figura 78: Gráfica de distribución del Análisis de la Tasa de Retorno Interno ................ 173

Figura 79: Gráfica Acumulativa ascendente del Análisis de la Tasa de Retorno Interno. 173

Figura 80: Gráfica de sistema de control de Batch........................................................... 188

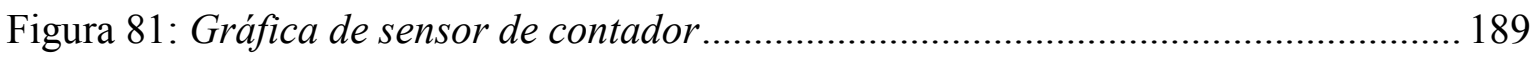

Figura 82: Gráfica de pantallas de control de Batch ...................................................... 190 


\section{INTRODUCCIÓN}

La globalización es un fenómeno que empuja a las empresas industriales a que deban asumir nuevos retos, puesto que la competencia en el mercado está cada vez más exigente debido a la gran velocidad de los avances de la tecnología, las comunicaciones, el transporte y la industria. En ese sentido, para lograr sobrevivir a este nivel de competencia las empresas tienen que desarrollar estrategias que les permita ser eficientes y flexibles para tener la capacidad de afrontar los cambios y ser competitivas en este mercado globalizado donde los clientes cada vez son más críticos, exigentes y esperan satisfacer sus expectativas con productos y servicios de excelente calidad que tengan un valor agregado y a un precio justo.

Muchas empresas ya han logrado interiorizar la necesidad de emplear estrategias y herramientas para el mejoramiento continuo de sus procesos productivos que les permites optimizar sus costos y tener más flexibilidad en sus procesos. Una de estas principales estrategias utilizadas es la herramienta Manufactura Esbelta, porque les permites a las organizaciones identificar sus principales oportunidades de mejora y les facilita herramientas para eliminar los desperdicios logrando mejoras tanto en calidad, procesos de producción y métodos de trabajo. Además, les permite conocer profundamente el fin y trabajo de la compañía con mira de adoptar un cambio cultural que les permita ser más competitivas.

El presente trabajo emplea la filosofía Lean para mejorar el proceso de fabricación de fideos, mediante el poder identificar las mudas que actualmente generan un impacto negativo y proponer un plan que permita lograr un importante beneficio para la compañía, tanto en costo, calidad y flexibilidad. 


\section{CAPITULO 1. MARCO TEÓRICO}

\subsection{Antecedentes de las actividades industriales}

Antiguamente las políticas proteccionistas de los países facilitaron que el mercado sea dominado por el fabricante. Los consumidores tenían que pagar precios altos y no se satisfacía la demanda, había escasez de productos. En esa época las fabricas producían en masa sin programas de producción porque el mercado lo cautivaba todo, la demanda no era cubierta. Además, para las empresas los costos de fabricación y las ineficiencias productivas no han sido un problema del que preocuparse, puesto que al costo total de fabricación sólo le agregaban el valor que deseaban obtener como utilidad. La economía actual ha cambiado y el mercado tiene mayor oferta porque hay más competencia no sólo a nivel local y nacional, sino que también internacional. Este incremento de oferta da oportunidad a los clientes de comparar precios, calidad y valor agregado de los productos y servicios. ${ }^{1}$

Ahora la economía actual se encuentra globalizada y el cliente es quien domina al fabricante. En consecuencia, está obligando a las organizaciones a reaccionar y adaptarse a estos cambios porque la globalización se está intensificando por el aporte significativo de la tecnología de las comunicaciones, internet y la informática; también por el crecimiento de las denominadas economías emergentes y la proliferación de los tratados de libre comercio que impulsan la competitividad en costos y precios de las

\footnotetext{
${ }^{1}$ Cfr. Ruiz 2007:15-17
} 
empresas. Además, a nivel geopolítico, en el que la geografía aporta conocimiento de territorios y la política aporta el conocimiento de las relaciones de poder, por los cambios en las nuevas relaciones de poder mediante los procesos de integración de los países. $^{2}$

En ese sentido, las organizaciones industriales deben tener la visión de buscar ser la mejor no sólo a nivel del mercado local ni a nivel nacional sino a nivel internacional, por lo tanto, el esfuerzo debe orientarse en buscar una estrategia que les permita evolucionar ser más competitivas, eficientes y productivas. En consecuencia, las empresas deben implementar las mejores herramientas de gestión que le permitan brindar productos de calidad que cubran la demanda y que puedan satisfacer las expectativas de los clientes y consumidores con el objetivo de ser reconocidos como una organización de clase mundial.

\subsection{Estrategias para el mejoramiento Continuo de procesos productivos para las industrias de manufactura}

En estas últimas décadas, para las industrias de manufactura han surgido una variedad de estrategias para la mejora continua de los procesos productivos.

Los más importantes son los siguientes:

- TQM (Total Quality Management),

- $\quad$ BPR (Business Process Reengineering),

- Ventajas competitivas de Porter.

- Manufactura Esbelta, constituida por diferentes técnicas:

- Las 5S es la técnica utilizada para el mejoramiento de las condiciones de orden y limpieza en el trabajo de la empresa.

\footnotetext{
${ }^{2}$ Cfr. Cardozo y otros 2011: 40
} 
- Los sistemas SMED: técnica empleada para la disminución de los tiempos de cambio de referencia.

- Los sistemas Poka Yoke: técnica empleada con el fin de disminuir los errores en la operación del sistema.

- La administración visual: técnica al alcance de todo el personal para presentar visualmente los indicadores de desempeño.

- Los grupos Kaizen: técnica que busca el mejoramiento continuo

- Los procesos de mejoramiento basados en 6 sigma

- El desarrollo de células de manufactura: técnica de nuevos flujos de producción

- Los sistemas TPM: Implementación del mantenimiento productivo total

- El análisis de valor del proceso: (Value Stream Mapping): técnica para detectar los mayores desperdicios ${ }^{3}$

En general, las empresas manufactureras industriales se enfrentan a la necesidad de mejorar su productividad. En consecuencia, deben utilizar menor cantidad de recursos para producir más. Lo que significa, que deben decidir que herramientas deben aplicar para el mejoramiento de los procesos productivos; y si consideran evaluar la manufactura esbelta, qué técnicas deben aplicar. Las organizaciones deben tener claridad y evaluar su situación actual, las oportunidades de mejora y sus objetivos para implementar exitosamente una de estas estrategias y técnicas.

\footnotetext{
${ }^{3}$ Cfr. Arrieta y otros 2010: 142
} 
Figura 1: Principales metodologías de mejoramiento en manufactura en el mundo

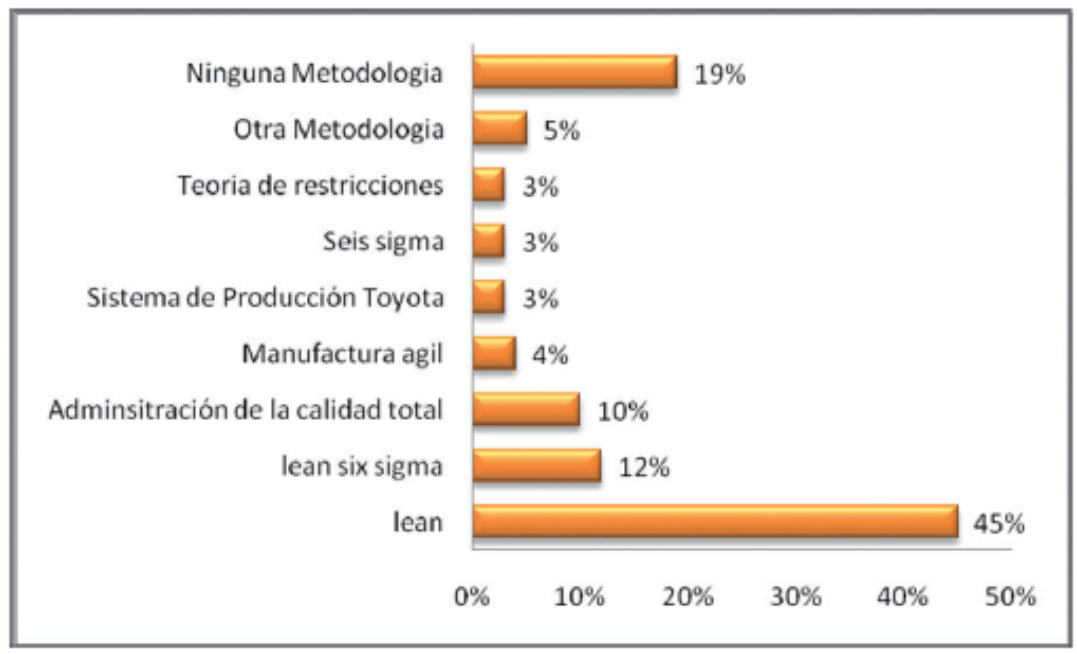

Fuente: Manufacturing Performance Institute citado en Piuzzi 2009

En la figura 1, se muestra las principales metodologías utilizadas en el mundo donde se observa que la metodología Lean tiene el $45 \%$ de participación, posicionándose como la metodología más utilizada como una herramienta de mejora continua. Esta mayor participación muestra que las empresas que han implementado dicha metodología han logrado obtener resultados verificables como la reducción en los costos de fabricación, en los inventarios de materia prima, en los tiempos de atraso, en el tiempo de mano de obra por consiguiente un aumento de la productividad, mayor eficiencia, uso óptimo de equipos e instalaciones de planta y mejora en la calidad de los productos.

En los últimos años, los investigadores de la metodología Lean han desarrollado una mejora continua de estas herramientas buscando obtener mayores beneficios y que además sean aplicables de acuerdo con las necesidades particulares de cada sector de la industria. Para ello, consideran las diferentes variables logísticas, de producción, financieras y estratégicas. ${ }^{4}$ En ese sentido, la selección de la metodología más

\footnotetext{
${ }^{4}$ Cfr. Delgado y Gallo 2011: 119,120.
} 
adecuada a ser empleada en las empresas dependerá de la estrategia y variables a las cuales estén afectas.

\subsection{Orígenes de la manufactura esbelta}

La Manufactura Esbelta es una metodología que surge como una respuesta a la necesidad de las empresas para obtener mayores beneficios haciendo uso de menores recursos. A principios del siglo XIX se logró los inicios de este modo de trabajar con Henry Ford, cuando estableció el concepto de producción en masa, donde el modelo T pasó a producirse en masa en una línea de montaje móvil, que lograron en la producción el incremento de la productividad y la reducción de los precios de venta. ${ }^{5}$

\subsection{Sistema de producción TOYOTA (SPT)}

Después de la segunda guerra mundial, Toyota sufre una serie de adversidades tanto económicas, políticas, de mercado y de recursos lo cual conlleva a sus líderes a buscar soluciones. En el año 1950 Eiji Toyoda fue a visitar una planta de Ford en los Estados Unidos para analizar el sistema de producción en masa. Luego de estudiarla queda convencido que este modelo de producción no puede ser implantado en Japón, ya que el mercado era pequeño. Taiichi Ohno al analizar estas restricciones se dedicó a desarrollar un nuevo enfoque en la producción, el cual mejoró y se logró el sistema de producción Toyota (SPT), que es una mejora diseñada para minimizar todas las formas de perdidas, incrementando la calidad y productividad, permitiendo la reducción de los costos en los procesos de producción. Esta mejora más tarde sería Lean Manufacturing, filosofía de trabajo que ha sido difundida en todo el mundo; y

\footnotetext{
${ }^{5}$ Cfr. Aldape y otros 2011: 3
} 
diferentes sectores productivos lo han adoptado y puesta en práctica. ${ }^{6}$ Los beneficios que se pueden percibir por la implementación de esta metodología puede apalancar los resultados de una organización y por consiguiente puede ser aplicado al caso específico del sector de fabricación de pastas.

\subsubsection{Los 14 Principios del Método Toyota.}

Los 14 principios del método Toyota están organizados en 4 conceptos fundamentales:

filosofía, proceso, gente y socios; y resolución de problemas. Figura 2

Figura 2: Conceptos Fundamentales del Método Toyota

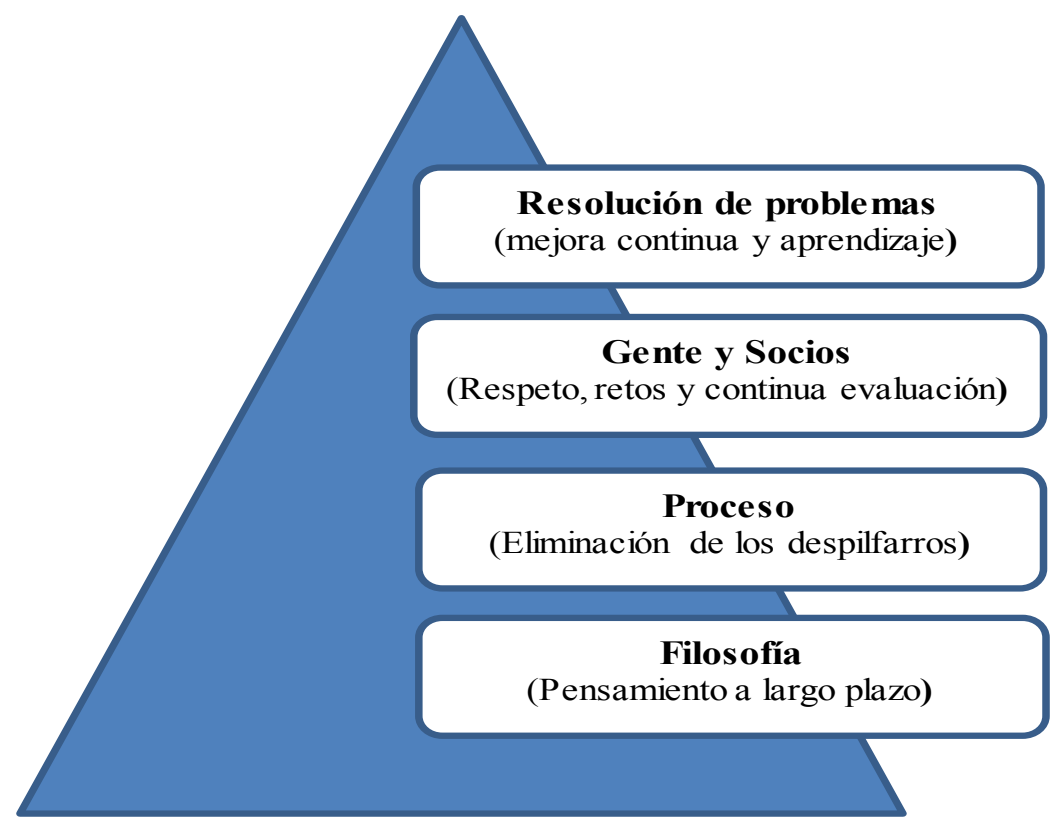

Fuente: Las claves del éxito Toyota. Lean, más que un conjunto de herramientas y técnicas citado en Toledano 2009

\section{CONCEPTO I: FILOSOFÍA (Pensamiento a largo plazo)}

Principio 1. Base sus decisiones de gestión en una filosofía a largo plazo, a expensas de lo que suceda con los objetivos financieros a corto plazo.

\footnotetext{
${ }^{6}$ Cfr. Tejada 2011: 281-283
} 
Toyota fidelizó al cliente ofreciéndole un producto de calidad a costa de perder en el corto plazo, porque es una situación que le permite lograr su auténtica misión de un mejor futuro económico y crecimiento de la organización, sus miembros y su país.

\section{CONCEPTO II: PROCESO (Eliminación de los despilfarros)}

Si los procesos son correctos se lograrán resultados correctos, por eso es importante la excelencia operacional.

Principio 2. Cree procesos en flujo continuo para hacer que los problemas sean evidentes.

Este principio busca identificar y minimizar lo inútil (MUDA $\left.{ }^{7}\right)$. Estos despilfarros que se hacen evidentes al crear el flujo continuo son: Sobreproducción, defectos, transportes, esperas, operaciones innecesarias, movimientos innecesarios, stock y creatividad desaprovechada. Una herramienta de ayuda en este principio es el Value Stream Mapping (Mapa del flujo de valor)

Principio 3. Utilice sistemas PULL (tirar) para evitar la sobreproducción.

El cliente, interno o externo, debe tirar de la producción, el ideal de flujo es el flujo pieza a pieza con inventarios cero y fabricados al ritmo que marca el cliente. Toyota utiliza el sistema KANBAN para controlar el compromiso entre la necesidad de inventarios y el MUDA. KANBAN significa señal, y puede ser de cualquier tipo mediante el sistema KANBAN, se consigue que el proceso aguas arriba produzca un pequeño lote de nuevas piezas sólo cuando el proceso aguas abajo le mande una señal.

\footnotetext{
${ }^{7}$ MUDA es un término que en el sistema TPS se refiere a lo conocido en japonés como despilfarro en los procesos,
} 
El sistema de producción PUSH es opuesto y se utiliza en la producción en masa, esto significa que empujan el material aguas abajo sin importar su necesidad; las áreas buscan su máxima eficiencia local, sin importar los resultados del flujo global.

Principio 4. Nivele la carga de trabajo (HEIJUNKA)

Un nuevo concepto de flujo ideal formula un cierto desacoplamiento del PULL del cliente para minimizar otros dos tipos de despilfarros, el MURI (sobrecarga del personal o de las máquinas) y el MURA (irregularidad o variabilidad). Este propone nivelar la carga de trabajo con planes que utilicen los inventarios y las previsiones de demanda. Esto, junto con lotes de fabricación pequeños, con el objetivo de tener una alta flexibilidad con respecto a los requerimientos del cliente.

Principio 5. Cree una cultura de parar a fin de resolver los problemas, para lograr una buena calidad a la primera.

Hay que detectar el problema en el momento que se produce, involucrar la participación del equipo que realiza la tarea para asegurar el éxito; ayudan a encontrar la causa raíz de los problemas herramientas como los «5 por qué» o el «diagrama de Ishikawa»y a partir de ello implementar contramedidas para que el problema no se repita, como el Poka-Yoke (sistemas anti-error). Lo importante es anticipar los problemas y hacer medidas preventivas.

Principio 6. Las tareas estandarizadas son el fundamento de la mejora continua y de la autonomía del empleado. 
El SPT plantea que los estándares están para «matarlos», pero mientras están vigentes, representan la mejor práctica conocida. Los estándares deben ser creados por los propios miembros de cada área de trabajo y no por departamentos ajenos que, en su afán de estandarizar toda la empresa, la colapsan y la llenan de MUDA.

Principio 7. Utilice el control visual de modo que no se oculten los problemas.

Lo más usual son las 5 eses. Pero, a veces, se olvida que sólo son la base del sistema de gestión visual, característica fundamental de los sistemas LEAN. A partir de esta base, se colocan una serie de elementos visuales (paneles, KANBAN), que permiten al equipo auto gestionarse.

Principio 8. Utilice sólo tecnología fiable absolutamente probada que dé servicio a su personal y a sus procesos

El éxito de Toyota se basa en sus procesos y su gente, por lo que sólo incorpora tecnología absolutamente probada, los sistemas de información son el apoyo de sus procesos.

\section{CONCEPTO III: GENTE Y SOCIOS (Respeto, retos y continua evolución)}

Toyota localiza a las personas en el corazón de su sistema y mantiene una relación de mutuo beneficio con los socios y suministradores.

Principio 9. Haga crecer a líderes que comprendan perfectamente el trabajo, vivan la filosofía y la enseñen a otros.

Los líderes nacen en la misma organización porque están familiarizados con el método, la cultura, los valores y el conocimiento de cada uno de los departamentos, por consiguiente, una mayor efectividad en la toma de decisiones. 
Hay otras tres características del sistema Toyota que se consideran claves para poder crear líderes y equipos excepcionales:

- Proyecto a largo plazo, que les libera de los continuos cambios de tendencias que venden soluciones a corto plazo.

- Tolerancia al error como fuente de aprendizaje. Se busca crear una organización que aprende, que utiliza el error como experiencia de aprendizaje

- Equipos multifuncionales alineados con la creación de valor, que permiten que las personas tengan una visión más completa de lo que se necesita para entregar un producto al cliente.

Principio 10. Desarrollar personas y equipos excepcionales que sigan la filosofía de la empresa.

Crear equipos orientados al flujo de valor, que trabajen de manera autónoma y que se soporten en la responsabilidad individual y autonomía. Esta forma de organización hace innecesaria la presencia de departamentos de control, ya que ellos deben tener la función de autocontrol.

Principio 11. Respete a su red extendida de socios y proveedores, desafiándoles y ayudándoles a mejorar.

El concepto es la «empresa extendida». Relaciones de largo plazo, respeto, beneficio mutuo y mejora continua.

\section{CONCEPTO IV: RESOLUCIÓN DE PROBLEMAS (Aprendizaje organizativo)}

Principio 12. Vaya a verlo por sí mismo para comprender a fondo la situación (GENCHI GENBUTSU). 
La gestión de los procesos y de las personas (gestión del conocimiento). «Los datos son, por supuesto importantes en fabricación, pero yo pongo el mayor énfasis en los hechos (Taiichi Ohno, 1988)». Los datos no dejan de ser puros «indicadores» de lo que sucede, pero es necesario que los hechos sean verificados en el escenario por la persona que toma las decisiones, o por sus personas de confianza.

Principio 13. Tome decisiones por consenso lentamente, considerando concienzudamente todas las opciones; impleméntelas rápidamente.

La toma de decisiones debe contener los siguientes cinco elementos:

- Averiguar lo que realmente está pasando (GENCHI GENBUTSU)

- Averiguar las causas raíz (5 por qué)

- Considerar una gama de soluciones alternativas y explicar la solución elegida

- Crear un consenso dentro del equipo

- Usar vehículos de comunicación eficaces para ejecutar los pasos anteriores

Principio 14. Conviértase en una organización que aprende mediante la reflexión constante (HANSEI) y la mejora continua (KAIZEN)

La mejora continua permitirá buscar la excelencia y hace que la organización se convierta en una «organización que aprende». ${ }^{8}$

\subsection{EI Pensamiento LEAN.}

La filosofía Lean Thinking aplica una serie de métodos y herramientas con el objetivo de entregar un producto que cumpla estrictamente con las necesidades del cliente,

\footnotetext{
${ }^{8}$ Cfr. Liker 2010: 44-250
} 
eliminando aquellas características que no agregan valor al producto y que el cliente no puede apreciarlas. El objetivo es definir qué es de valor desde el punto de vista del cliente. Esta filosofía fue desarrollada por Toyota a finales de la segunda guerra mundial para competir en la industria del automóvil. Esta metodología fue documentada Womack, Roos y Jones (1990). Algo más tarde, Womack y Jones (1996) definieron una metodología de implantación que incluye los siguientes 5 principios:

- Definir el valor desde la perspectiva del cliente.

- Identificar la cadena de valor. Esta agrupa todas las actividades necesarias para entregar el producto al cliente. Obviamente, existen actividades que no agregan valor al producto a estas se las considera desperdicios, y se clasifican en dos grupos:

- Desperdicios relativos: actividades que no pueden ser percibidas por el cliente como valor, pero que son necesarias.

- Desperdicios absolutos ("Muda", en la terminología japonesa): actividades que no son percibidas por el cliente como de valor y no son necesarias para completar otras, que deben eliminarse; entre los que se encuentran: procesos innecesarios, movimientos innecesarios, elementos no deseados por el cliente, demoras y errores.

- Optimizar el flujo de valor: hacer que el flujo de actividades fluya sin retrasos, eliminar las colas y esperas.

- Estudiar al cliente acerca de sus necesidades exactas e identificar qué considera él de valor.

- Perseguir la Mejora continua ${ }^{9}$

\subsection{Definición de Manufactura Esbelta.}

La manufactura esbelta fue introducida por el Dr. James P. Womack en 1990 en occidente con la publicación del libro "la máquina que cambio el mundo" (Womack et al., 1990) basado en el estudio del Sistema de Producción Toyota, el concepto esbelto

\footnotetext{
${ }^{9}$ Cfr. Sánchez 2012: 215
} 
y la manufactura esbelta buscan mejoras importantes en el desempeño operacional que se traduce en ventajas competitivas como: costo, calidad, velocidad de entrega, precio, innovación, consistencia en la entrega y flexibilidad. Esto solo es posible lograr a través de la identificación y eliminación sistemática de los desperdicios. Sin lugar a duda, la participación de los empleados en proyectos de mejora continua es vital para eliminar las "mudas" como: sobre producción, tiempo de espera, transporte, procesos innecesarios, inventarios, movimientos y defectos. Este conjunto de técnicas aplicadas con disciplina conducirá eventualmente a las empresas al camino de la producción esbelta lo que les permitirá capturar los beneficios de la eficiencia operacional y las ventajas competitivas. La manufactura esbelta se apoya en una serie de herramientas como son: los sistemas Kanban, el mantenimiento productivo total (TPM), los sistemas Kaizen, las 5's, Seis Sigma, Poka Yoke, Jidokas, entre otros ${ }^{10}$.

\subsubsection{Los 7 tipos de Desperdicios}

Los desperdicios de los procesos son conocidos como la Muda y hacen referencia aquellas actividades que no agregan valor para el cliente, T. Ohno las clasifica en:

1. Sobreproducción

Utilización de recursos en momentos y en cantidades que realmente no se requieren para satisfacer el consumidor, es conocida como madre de las Mudas es la más peligrosa y está asociada a las decisiones tácticas y estratégicas de las organizaciones.

- Tiempo de Espera.

\footnotetext{
${ }^{10} \mathrm{Cfr}$. Monge y otros 2013: 18
} 
Agrupa los tiempos en que los recursos se encuentran sin ser utilizados, esto debe a falta nivelación de cargas, fallas de equipos o demás eventos que demanden paro en algún dispositivo del proceso.

- Transporte.

Desplazamiento innecesario de elementos, materiales, herramientas, producto en proceso o terminado de un lado a otro, que no modifican alguna característica del producto, incluso cuando son distancias cortas.

- Procesos innecesarios.

Todas aquellas actividades que solo existen por el diseño de procesos poco robustos e ineficientes, o por presencia de defectos.

- Inventario.

Las existencias de inventario son necesarias como medio de protección ante situaciones imprevistas de demanda, su sostenimiento prologando y excesivo genera situaciones no deseadas para la organización. Naturalmente, estos excesos generan sobre costos de almacenaje, obsolescencia, defectos.

- Movimientos innecesarios.

Cualquier movimiento que el operario realice aparte de generar valor agregado al producto por ejemplo personas subiendo y bajando por documentos, buscando, escogiendo, agachándose, etc.

- Defectos.

Producir productos que no cumplen con las especificaciones del cliente interno o externo, genera procesos innecesarios. Está asociada a los costos de no calidad, afecta no solo la parte productiva o la económica, sino la misma satisfacción del cliente $^{11}$.

\footnotetext{
${ }^{11}$ Cfr. Pérez 2011: 175,176.
} 


\subsubsection{Herramientas de la Manufactura Esbelta}

\subsubsection{EI Mapeo de la Cadena del Valor (VALUE STREAM MAPPING).}

La cadena de valor es una herramienta de visualización que permite crear mapas de flujo de información y materiales muy útiles para los procesos administrativos y de manufactura, recientemente también se usa en el campo de los servicios. Los mapas reflejan una visión de conjunto del proceso, existen dos tipos de mapeo de la cadena de valor la estática y dinámica.

\section{Mapeo de la cadena de valor estático}

La versión estática es creada usando un papel y un lápiz con un conjunto de símbolos estandarizados, se debe empezar con graficar un mapa de estado actual e identificar las MUDAS más importantes. Después de terminar con tu estado actual, continúas con el estado futuro el cual te ayuda a ver hacia donde te diriges y como se va a lograr ese recorrido que plasmaste en tu mapa, los pasos a seguir son los siguientes:

- Selección de la línea de producto a examinar, designación del gestor de la cadena de valor

- Creación del mapa de valor actual

- Marcar los problemas en el mapa del estado actual

- Creación del mapa del estado futuro

- Realización del estado futuro

\section{$\underline{\text { Mapeo de la cadena de valor dinámico }}$}

El mapa del flujo de valor dinámico se basa en el principio de la simulación de modelos, donde el estado actual y el futuro se crean en un sistema de simulación. Es 
natural, que antes de realizar el mapa actual se debe conocer los procesos examinados y recoger los datos más importantes este tipo de mapeo tiene los siguientes pasos:

- Asignación de los sistemas logísticos a examinar, designación del gestor de la cadena de valor

- Creación del mapeo de flujo de valor dinámico

- Análisis de los problemas, el nombramiento de los problemas en el mapa

- Creación del mapa del estado futuro

- Realización del estado futuro

La aplicación de alguno de estos métodos dependerá de las características del proceso en la siguiente tabla 1 se realiza una comparación. 
Tabla 1: Comparación de la cadena de valor dinámico y estático

\begin{tabular}{|c|c|}
\hline de valor estático & Mapeo de la cadena de valor dinámico \\
\hline $\begin{array}{l}\text { - La aplicación de este método tiene más } \\
\text { ventaja en casos de procesos de flujo } \\
\text { simple. } \\
\text { - Es aplicable en una línea de proceso. } \\
\text { - La creación del flujo del valor se hace } \\
\text { - La interacción de más líneas de } \\
\text { productos no puede ser examinada. } \\
\text { Efectos de los eventos estocásticos no } \\
\text { pueden ser examinados. }\end{array}$ & $\begin{array}{l}\text { - La aplicación de este método tiene más } \\
\text { ventaja en casos de procesos de flujo } \\
\text { complejo. } \\
\text { - Es aplicable en relación con la mejora } \\
\text { conjunta de más líneas de proceso. } \\
\text { - La creación del mapeo de la cadena de } \\
\text { valor se hace en un sistema de } \\
\text { simulación. } \\
\text { La interacción de más líneas de } \\
\text { productos puede ser examinada. } \\
\text { Efectos de los eventos estocásticos } \\
\text { pueden ser examinados. }\end{array}$ \\
\hline
\end{tabular}

Fuente: Application of Value Stream Mapping at flexible Manufacturing Systems Tamás 2016

Estas son algunas de las propiedades más importantes del mapeo de la cadena de valor estática y dinámica. $^{12}$

\subsubsection{Las cinco "eses"}

La metodología de las $5 \mathrm{~S}$ se compone de cinco pasos, cada uno de ellos provienen de la etimología japonesa, para conocerla se incluye su descripción en español, indicando los variados conceptos que se han usado para su traducción (Sousa, 2013). Cada

\footnotetext{
${ }^{12}$ Cfr. Tamás 2016: 168-171
} 
término tiene un significado importante para la creación de un lugar digno y seguro donde trabajar. La Tabla $\mathrm{N}^{\circ} 2$ resume la información de los objetivos de las $5 \mathrm{~S}$.

Tabla 2: Los objetivos de las 5 "eses"

\begin{tabular}{|c|c|c|c|c|}
\hline $\mathbf{N}^{\circ}$ & $\begin{array}{l}\text { Palabra en } \\
\text { Japonés }\end{array}$ & $\begin{array}{c}\text { Concepto en } \\
\text { español }\end{array}$ & $\begin{array}{l}\text { Frase en } \\
\text { español }\end{array}$ & Objetivo \\
\hline 1 & Seiri & $\begin{array}{l}\text { Clasificación } \\
\text { Selección } \\
\text { Preparación }\end{array}$ & $\begin{array}{c}\text { Separar } \\
\text { innecesarios }\end{array}$ & $\begin{array}{l}\text { Eliminar del espacio o área de trabajo lo que } \\
\text { no sea necesario }\end{array}$ \\
\hline 2 & Seiton & $\begin{array}{l}\text { Orden } \\
\text { Organización }\end{array}$ & $\begin{array}{l}\text { Situar } \\
\text { necesarios }\end{array}$ & $\begin{array}{c}\text { Organizar u ordenar el área de manera } \\
\text { eficiente }\end{array}$ \\
\hline 3 & Seiso & Limpieza & $\begin{array}{l}\text { Suprimir } \\
\text { Suciedad }\end{array}$ & Realizar la limpieza del lugar adecuadamente \\
\hline 4 & Seiketsu & $\begin{array}{l}\text { Normalización } \\
\text { Estandarización } \\
\text { Sistematización } \\
\text { Control visual }\end{array}$ & $\begin{array}{l}\text { Señalizar } \\
\text { anomalías }\end{array}$ & $\begin{array}{l}\text { Estandarizar los procesos que permitan } \\
\text { prevenir el orden y falta de limpieza }\end{array}$ \\
\hline 5 & Shitsuke & $\begin{array}{l}\text { Unificación } \\
\text { Mantener la } \\
\text { disciplina y } \\
\text { compromiso }\end{array}$ & $\begin{array}{c}\text { Seguir } \\
\text { mejorando }\end{array}$ & $\begin{array}{l}\text { Asegurar de que se mantengan los cuatro } \\
\text { posos anteriores }\end{array}$ \\
\hline
\end{tabular}

Fuente: Eficiencia con las 5'S Limpieza y orden eficientes, clave del desarrollo japonés Sousa 2014

\section{Objetivo de SEIRI:}

Consiste en retirar del área de trabajo o estación todos aquellos elementos que no son parte del proceso con el objetivo de ganar espacios y eliminar la basura, guardar sólo lo necesario para realizar las diferentes labores. Se debe eliminar los equipos obsoletos y no pensar en un probable uso en el futuro. Cuando se logre este objetivo, se podrá dedicar recursos a lo que realmente es importante se debe tener algunas reglas básicas para realizar esta actividad.

- Ante la duda si se debe conservar, elimine el objeto

- Tiene tiempo sin uso si la respuesta es afirmativa elimine.

- Recicle siempre que sea posible 
- Establezca un cronograma para realizar esta actividad

- Cada espacio o área debe pasar por una evaluación

\section{Objetivo de SEITON:}

El objetivo de Seiton es que cada artículo u objeto tenga un espacio definido, y este debe ser visible y además correctamente marcado o identificado, lo que permitirá ejecutar las tareas o actividades de trabajo porque los artículos estarán listos y disponibles para ser utilizados. Durante este proceso se podrá identificar y descartar los objetos innecesarios, ordenar, clasificar y seleccionar los artículos de trabajo de acuerdo con el lugar de trabajo. Para ello se ha de considerar los aspectos de visibilidad, fácil acceso y correcta identificación.

\section{Objetivo de SEISO:}

En esta etapa se tiene el objetivo de estandarizar o mantener el área de trabajo limpio. Luego de haber logrado retirar los artículos u objetos innecesarios y de definir un espacio para cada cosa es más fácil limpiar el área de trabajo, en el que se debe considerar todos los muebles, equipos, piso, paredes y todos los espacios del entorno de trabajo. Además, se debe comprometer a que todo el personal sea responsable de cuidar y limpiar las instalaciones, aprovechando de inspeccionar las herramientas, equipos, fugas, focos de suciedad y posibles problemas que a la larga les da más conocimiento y compromiso del personal sobre su área de trabajo.

\section{Objetivo de Seiketsu:}

Desarrollar estándares de trabajo que permitan mantener en las primeras tres $\mathrm{S}$, implica seguir procedimientos que permitan mantener las tres primeras S. para generar esta cultura es necesario utilizar diferentes tipos de herramientas como las visuales para recordar las condiciones óptimas. Es importante, que la organización diseñe 
sistemas y procedimientos para cada empleado con funciones específicas para que se asegure la continuidad de Seiri, Seiton y Seiso.

\section{Objetivo de Shitsuke:}

Ésta es la etapa más difícil, hace referencia a la disciplina que se debe tener para evitar que se pierda los procedimientos establecidos. Este paso sólo es posible si se realizan todos los pasos anteriores de forma constante e integrada. Las 5S son un conjunto de pasos y son parte de un mismo proceso los cuales deben trabajarse en forma permanentemente de acuerdo con las normas establecidas. La clave para lograr el éxito es la disciplina, es decir interiorizar el hábito de ejecutar correctamente todos los procedimientos. $^{13}$

\subsubsection{Kaizen}

Kaizen es un concepto de gestión japonesa lanzada por Masaaki Imai, que resultó ser la clave para el éxito competitivo japonés. El significado de este concepto es: KAI = cambio y ZEN = para mejor, y la traducción es "mejora continua", que significa pequeñas mejoras en forma constante. A diferencia de la Concepción occidental, que implica un cambio total en grandes intervalos de tiempo, el uso de grandes cantidades de recursos y un alto costo, Kaizen busca mejoras continuas en forma diaria, gradual, y a un costo mínimo. La estrategia del mensaje Kaizen es que no debe pasar un día sin que se haya hecho alguna mejora en cualquier lugar de la compañía. La Gestión del Kaizen se centra en la mejora de cada proceso, el objetivo principal es la eliminación de las pérdidas y minimizar costos. La mejora de procesos garantiza la eficiencia de la producción. En este sentido, Las

\footnotetext{
${ }^{13}$ Cfr. Sousa 2014: 39-51
} 
actividades de tipo Kaizen aseguran la maximización del valor del producto y una diferenciación cualitativa. ${ }^{14}$

\subsubsection{Mantenimiento Productivo Total (TPM).}

Las empresas para aumentar su productividad y conseguir ser competitivas deben plantear estrategias de mantenimiento que les permita tener una alta confiabilidad en sus procesos. El mantenimiento productivo total TPM es el sistema japonés de mantenimiento industrial, se define como un programa de fabricación diseñado para maximizar la efectividad de los equipos de fabricación en toda su vida útil a través de la participación integral de todos los recursos humanos de la empresa (Nakajima, 1988). La gestión de los activos tiene una vital importancia para garantizar la continuidad de la operación.

Espolita-Carreño (2000) afirma que:

“donde quiera que existan activos físicos, se generan actividades de restauración consecuencia de las averías, y ello ocasiona costos de reparar, indisponibilidad de los equipos y riesgos de daños a personas, a las cosas y al medio ambiente". ${ }^{15}$

Esta gestión está asociada principalmente a garantizar que los activos de forma permanente tengan una atención transfiriendo la responsabilidad del mantenimiento rutinario de los equipos del departamento de mantenimiento al personal de producción propietario del proceso el objetivo apunta a la mejora de la productividad, costos, calidad, seguridad, medio ambiente, y moral. ${ }^{16}$ Los resultados de esta gestión del proceso productivo deben ser medidos con indicadores que permitan evaluar el desempeño integral.

\section{Eficiencia Global de los Equipos (OEE)}

Las máquinas están diseñadas desde la base de una capacidad ideal de producción. En la realidad, esto no se cumple por diferentes motivos por lo que la producción siempre

\footnotetext{
${ }^{14}$ Cfr. Rof 2011: 105

${ }^{15}$ Cfr. Sanchis y otros 2011: 649

${ }^{16}$ Cfr. Marín-García y Martínez 2013: 825
} 
es menor que la de diseño. La eficiencia Global de los Equipos (OEE), fue introducido por Nakajima, es una matriz integral de evaluación del rendimiento de los activos para mejorar la productividad de la empresa. Son tres factores que definen OEE la disponibilidad del sistema, el rendimiento del equipo y la calidad de la producción, considerando la eliminación de seis grandes pérdidas (averías, instalación y ajustes, pequeñas paradas, la reducción de velocidad, la puesta en marcha y rechazos de producción). La medición del $\mathrm{OEE}$ es un punto de referencia para comparar el rendimiento de un determinado activo de fabricación con los estándares de la industria, para activos similares en la empresa. Sin embargo, la medida OEE también es útil como una base para seguir el progreso a través del tiempo en la eliminación de los residuos procedentes de un activo determinado de fabricación inherente al compromiso de la organización para la sostenibilidad ${ }^{17}$. Los tres factores que miden del OEE la disponibilidad, el rendimiento y la calidad proporcionan información importante y de actualidad para la toma de decisiones y es un punto de partida para la mejora continua.

\subsubsection{Metodología SMED (Single Minute Exchange of Die)}

Las empresas tienen la necesidad de atender al consumidor dentro los plazos establecidos lograr este objetivo cada vez es más complicado porque los mercados están en un constante cambio exigiendo más variedad de productos, plazos de entrega más reducidos, pedidos de menor tamaño. Estas condiciones requieren optimizar los tiempos productivos. La metodología SMED Single Minute Exchange of Die (Cambio de herramienta en menos de diez minutos) concepto introducido por Shigeo Shingo ingeniero japonés que contribuyó en el sistema de producción Toyota. La

\footnotetext{
${ }^{17}$ Cfr. Hasrulnizzam 2015: 555
} 
configuración o cambio de herramientas en referencia a la productividad de proceso de fabricación es entendida como una pérdida. Es el resultado del hecho de que durante el momento en que la máquina no produce no genera beneficios. SMED se refiere a la teoría y técnicas utilizadas para la reducción de los tiempos de preparación del equipo. La metodología SMED se utiliza como un elemento de mantenimiento Productividad Total (TPM) y "proceso de mejora continua" en diversos estudios para llegar a la manufactura esbelta. El SMED permite reducir la configuración del equipo al mínimo mediante la separación de acciones internas y externas. ${ }^{18}$ Es claro que los beneficios obtenidos por la implementación de esta técnica es transformar el tiempo improductivo en productivo, así como la estandarización de las actividades.

\section{$\underline{\text { Herramientas de la calidad }}$}

En la actualidad el control de la calidad es un factor importante que las empresas deben temar en cuenta ya que está ligado estrechamente con la satisfacción del cliente. Por lo tanto, un adecuado control de calidad estará directamente relacionado con el aumento de la productividad y los consiguientes beneficios económicos para las organizaciones. Las diferentes herramientas estadísticas permiten mejorar y controlar consecutivamente los procesos el uso habitual y correcto de las herramientas de la calidad permitirá resolver el $95 \%$ de los problemas. En este sentido, el control estadístico de los procesos (SPC) combina las herramientas básicas llamadas las siete herramientas de Ishikawa con otras más avanzadas como el análisis de la varianza (ANOVA). ${ }^{19}$ En el presente trabajo se desarrollarán las siguientes:

- Diagrama de flujo

\footnotetext{
${ }^{18}$ Cfr. Grzybowska y Gajdzik 2012: 556

${ }^{19}$ Cfr. López y López 2014: 74-76
} 
El diagrama de flujo es una herramienta que permite representar de forma gráfica la secuencia cronológica de los pasos que conforman el proceso, permitirá conocer e identificar problemas potenciales.

- Hoja de control o comprobación

Para realizar un proceso de investigación será necesario acopiar datos de forma sencilla, concisa y estructurada los cuales se registrarán en formato llamado hoja de control o comprobación, los cuales posteriormente permitirán el análisis.

- Diagrama de Pareto

Una herramienta estadística de uso frecuente es el diagrama de Pareto que permite analizar y detectar las causas principales del problema objeto de estudio. El objetivo de este análisis es identificar y focalizar los esfuerzos para la solución de las principales causas del problema. Vilfredo Pareto economista italiano encontró que la riqueza en Europa distaba de una equidistribuciòn. Puesto que, el 20 \% de la población poseía el $80 \%$ de la riqueza. Más tarde, Joseph Juran reconoció este concepto el cual podría ser utilizado en varios campos y estableció la regla del 80/20 en honor a Pareto.

- Gráficos de control

En la actualidad los procesos productivos son controlados a través del control estadístico. Los gráficos de control son herramientas prácticas que permiten reducir la variabilidad y mejorar los procesos, enfocan la atención hacia las causas especiales de variación cuando estas aparecen y reflejan la magnitud de la variación debida a las causas comunes. Además, determinan si estos procesos se encuentran bajo condiciones controladas. Los gráficos de control por lo general tienen tres líneas paralelas y horizontales; línea central (LC) corresponde al valor promedio del parámetro que se desea controlar, y otras dos se denominan límite de control superior (LCS) y límite de control inferior (LCI) que marcan el intervalo dentro del cual se espera se encuentren 
el $99,73 \%$ de las observaciones para que un proceso se considere bajo control estadístico asimismo no se debe observar ningún comportamiento anómalo ( ciclos, rachas, inestabilidad...). No obstante, cuando un punto se encuentra por encima del LCS o por debajo del LCI, el proceso estará fuera de control. Una característica medible de calidad $(\mathrm{X})$ solo es considerada si sigue una distribución Normal con media $\mu$ y desviación estándar $\sigma^{20}$. Estos graficas se clasifican de acuerdo con el tipo de variable analizar.

\section{$\underline{\text { Gráficas de control por variables }}$}

El control por variables vigila el valor medio de la característica de calidad y su variabilidad (Shewhart, 1980). En realidad, variable se designa a una característica de la calidad "medible" tal como presión, temperatura, peso, humedad relativa, etc. En este sentido, el gráfico X-barra permite controlar el promedio las desviaciones respecto al objetivo y el gráfico $\mathrm{R}$ los rangos muéstrales permite medir variaciones del proceso y detectar posibles causas especiales.

\section{Gráfica de control por atributos}

Las gráficas de control por atributos es otra forma de representar la calidad es tipo de graficas son menos costosas, además, algunas de las características cualitativas de calidad convenientemente no pueden representarse con valores numéricos. En este sentido, los productos se clasifican en conforme o disconforme respecto a las especificaciones técnicas establecidas. El gráfico de control tipo p mide el porcentaje de los elementos defectuosos de la producción y permitirá determinar si los elementos defectuosos se encuentran bajo control.

\footnotetext{
${ }^{20}$ Cfr. López y López 2014: 76,77.
} 


\section{$\underline{\text { Capacidad del proceso }}$}

La capacidad del proceso permite verificar si un proceso se encuentra bajo control y cuán capaz de cumplir con las especificaciones. Para realizar este cálculo es necesario definir los límites de control del proceso LCS y LCI donde X es una característica de calidad medible con media $\mu$ igual al valor objetivo. Los índices de capacidad potencial y real tienen las siguientes expresiones.

$$
\begin{gathered}
C p=\frac{L C S-L C I}{6 \sigma} \\
C p k=\min \left(\frac{L C S-\mu}{3 \sigma}, \frac{\mu-L C I}{3 \sigma}\right)
\end{gathered}
$$

Donde:

Índice de Capacidad potencial $\mathrm{Cp}$

Índice de Capacidad real $\quad \mathrm{Cpk}$

Límite de control superior LCS

Limite control inferior LCI

Media $\mu$

Desviación estándar $\quad \sigma$

El índice de la capacidad del proceso Cp deberá ser mayor que 1.33 para considerar que el proceso es capaz desde el punto de vista de la calidad ${ }^{21}$. Es indudable, que estas herramientas formalizadas $\mathrm{y}$ bien establecidas ayudaran a gestionar la calidad disminuyendo la variabilidad. Sin embargo, el tratamiento adecuado de las causas

\footnotetext{
${ }^{21}$ Cfr. López y López 2014: 78-81
} 
comunes y especiales requiere la atención de otras herramientas que permitan eliminarlas o mitigarlas.

\subsubsection{POKA - YOKE}

Los procesos industriales tienen una gran variedad de actividades y estas están sujetas a errores debido a diferentes factores y causas. Metodología de corrección de error Poka-Yoke es un término japonés que significa "error- revisar. Este concepto fue formalizado y el término adoptado por Shigeo Shingo como parte del sistema de producción Toyota. El objetivo es evitar las piezas mal ensambladas, piezas faltantes, procesamiento incorrecto y piezas incorrectas. La definición de Poka-Yoke $=$ Error Revisar y tiene las siguientes características:

- Poka-Yoke es un dispositivo que impide que se pueda cometer un error durante el proceso (predicción) o un defecto se transmita al usuario (detección).

- Cuando se pronostica un defecto o se detecta un error, el proceso se detiene o un control evita que el proceso siga adelante o se envía una advertencia.

- Son sencillas y baratas

- Son parte del proceso, la aplicación de lo que Shingo llama "inspección 100\%".

- Se colocan cerca de donde ocurren los errores, proporcionando retroalimentación rápida a los trabajadores, de modo que los errores pueden ser corregidos.

La metodología de verificación de errores, Poka-Yoke, elimina la causa de un error en la fuente mediante la detección de cualquier error mientras se está realizando o poco después de que ha sido hecho, pero antes de que llegue la próxima operación. PokaYoke ayuda a construir la calidad en procesos y productos. Poka-Yoke es un programa de capacitación para los empleados con el fin de desarrollar una mentalidad Poka-Yoke y adquirir experiencia práctica en la aplicación. ${ }^{22}$ El error es mejor controlarlo antes de

\footnotetext{
${ }^{22}$ Cfr. Schmidt 2013: 27
} 
que se produzca de lo contrario se perderá tiempo, materiales, mano de obra etc. La siguiente figura 3 muestra que la técnica de Poka-Yoke puede aplicarse antes o una vez que ocurra el problema, y en ambos casos se puede proponer mejoras acciones para mitigar o eliminar el error

Figura 3: Aplicación te técnica Poka-Yoke

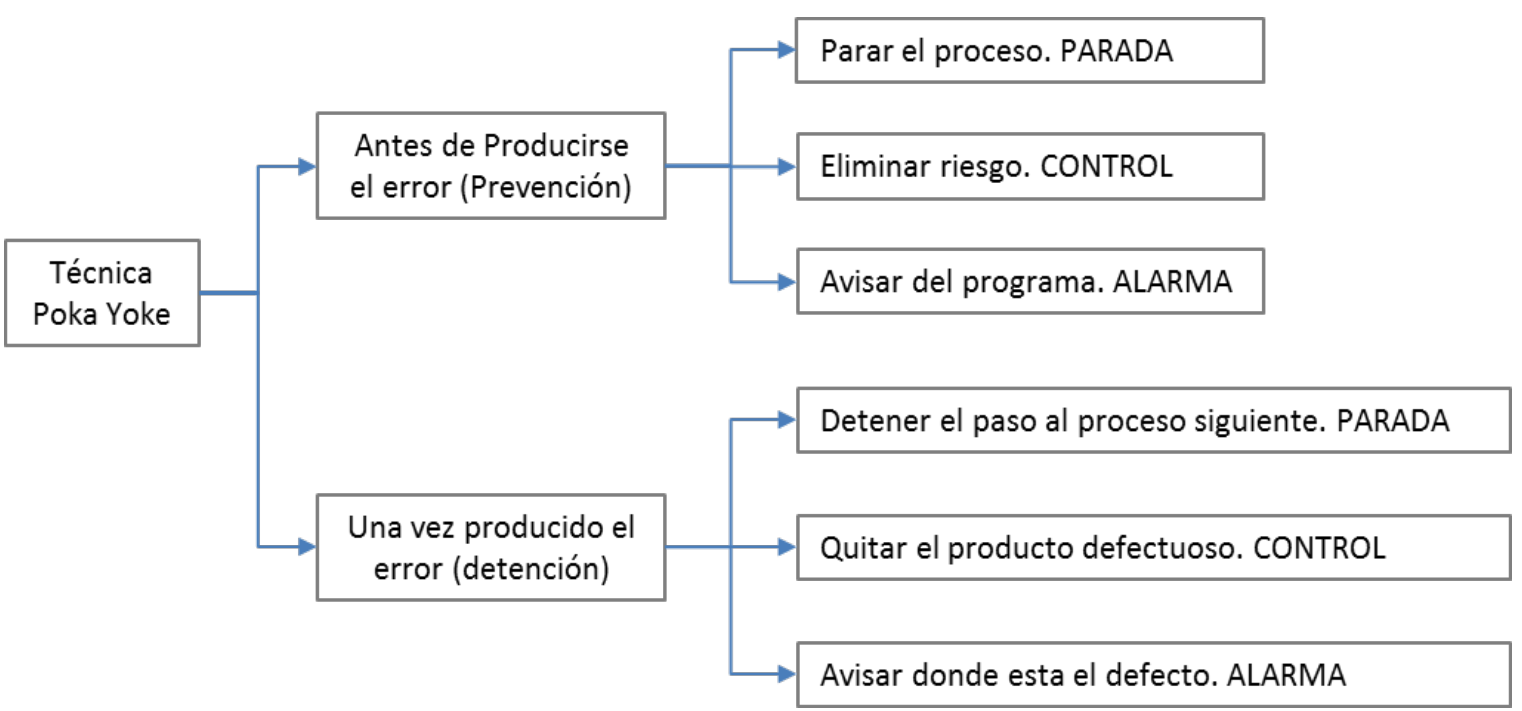

Fuente: Implementación del método anti-errores: Poka Yoke 2012

\subsubsection{Six Sigma}

Conseguir reducir o eliminar los defectos o fallos en los productos o servicios que se ofrece al cliente es una constante en las organizaciones. Six Sigma es una metodología desarrollada por el ingeniero Bill Smith, de la división de comunicaciones de la Motorola, en 1988 (WATSON; DEYONG, 2010). El método estandarizó la manera de contar los defectos y definió un punto, próximo a la perfección, los elementos básicos del Six Sigma son: Control Estadístico del Proceso (CEP), Análisis del Modo y Efecto de los Fallos (FMEA), PDCA (Planear, Realizar, Verificar, Actuar), entre otras herramientas. El Six Sigma es una forma de afrontar la mayoría de las operaciones de las organizaciones para mejorar o crear procesos y productos, eliminando todo aquello 
que no agregue valor. Se puede decir en pocas palabras, que es un método, basado en datos, para llevar la Calidad hasta niveles próximos a la perfección, diferente de otros enfoques ya que también corrige los problemas antes de que se presenten. Más específicamente se trata de un esfuerzo disciplinado para examinar los procesos repetitivos de las empresas. Esta metodología tiene una serie de principios entre los principales:

- Foco genuino en el cliente

- Gestión dirigida para datos y hechos

- Foco en proceso, gestión y mejoras

- Gestión proactiva

- Colaboración sin fronteras

- Impulso a la perfección

MODELO DMAIC (Definir-Medir-Analizar-Implementar-Controlar)

La metodología Six Sigma utiliza como herramienta de dirección el modelo DMAIC este en forma estructurada tiene como objetivo lograr la mejoría del proceso está compuesta por los cinco pasos o fases donde cada paso está conectado lógicamente e interrelacionado con el paso anterior, así como el posterior. Es decir, el DMAIC es un proceso que permite la mejora continua de la metodología utilizada en Six Sigma. Bajo la filosofía del Six Sigma, los cinco pasos para la ejecución de trabajos son establecidos por el ciclo DMAIC:

1. D -Define (Defina): defina con precisión las metas y objetivos estratégicos a mejorar.

2. M -Measure (Medir): la existencia de un sistema de medición de desempeño estructurado es un punto de partida crucial en esta fase, para identificar los puntos críticos y posibles de mejoría

3. A-Analyse (Analizar): analice el sistema para identificar manera de eliminar los fallos del desempeño actual del sistema o proceso y la meta deseada. Normalmente en este paso se utiliza la herramienta FMEA. 
4. I -Improve (Implemente): creatividad para hacer las cosas mejor, de forma más rápida y económica, es mirar el proceso, los datos y encontrar la causa raíz.

5. C -Control (Controle): institucionalizar, la mejora de los sistemas de remuneración, incentivos, políticas, procedimientos, de planificación de las necesidades de material, presupuesto, instrucciones de operación y otros sistemas de gestión. ${ }^{23}$

\subsubsection{Justo a Tiempo (JIT)}

La competitividad por la globalización de los mercados exige que las organizaciones trabajen en la eficiencia en cada uno de sus elementos (procesos productivos, personal, clientes, proveedores) esto significa que todos ellos deben estar comprometidos en el objetivo de la mejora continua. Según lo establecido en Monden (1990), el fin del sistema de producción de Toyota es aumentar los beneficios mediante la reducción de costos a través de la completa eliminación de despilfarros tales como el exceso de existencias o de personal. Para lograr este objetivo, la producción debe adaptarse rápida y flexiblemente a las variaciones de la demanda del mercado, y esto se logra aplicando la filosofía del JIT: Optimizar un sistema de producción de manera que se logre producir los elementos necesarios en las cantidades necesarias y en el momento necesario. Los objetivos del JIT pueden resumirse mediante la "Teoría de los cinco ceros", que son (Visconti et al. (2006)):

- Cero averías.

- Cero defectos en los productos

- Cero pérdidas de tiempo

- Cero burocracias

- Cero stocks

La filosofía de producción JIT se orienta a la mejora de la atención de la demanda. Una vez desarrollada esta herramienta la ventaja competitiva que se logrará es optimizar la capacidad de la empresa permitiendo dar una respuesta más económica y rápida al cambio

\footnotetext{
${ }^{23}$ Cfr. Medianeira 2014: 5,6.
} 
de la demanda. ${ }^{24}$ La participación y compromiso del capital humano es un aspecto importante en la implementación de esta metodología de producción, la identificación de las oportunidades de mejora y gestión de las mismas permitirá que se apalanquen los resultados.

\subsubsection{KANBAN}

El sistema Kanban es una herramienta que funciona como sistema de información como uno de los principales elementos de la filosofía JIT. Kanban es una palabra japonesa que significa "tarjeta". Este sistema emplea tarjetas que sirven como administradores visuales de las ordenes de fabricación, donde se indica las actividades a realizar sin la necesidad de consultar al operario de la etapa anterior o al encargado de supervisar el trabajo. Las tarjetas pueden ser de colores, tener información precisa de producir, recoger y transportar productos; y deben estar visibles al operador. Este sistema ayuda a minimizar inventarios porque evita producir en exceso por estaciones de trabajo, sirve como ordenes de trabajo, ayuda a identificar productos defectuosos y evita que pasen a la siguiente etapa de fabricación; facilita el termino de ordenes con mayor prioridad y es útil para el control de inventarios en cata etapa del proceso.

La información típica de las tarjetas kanban es el número de referencia y nombre; nombre del proceso donde se utilizó; el número de unidades del contenedor; el número de tarjetas kanban emitidas; el proceso de donde procede y el proceso subsiguiente. El proceso se inicia con el pedido del cliente, la primera tarjeta kanban se genera al almacén de producto terminado, que debe entregar lo requerido, si almacén no tiene el stock, tiene que generar otra tarjeta kanban al operador de la operación precedente en el que autoriza y solicita la fabricación la cantidad del pedido. Si el operador no tiene todos los materiales necesarios para iniciar la producción, tiene que generar otra tarjeta

\footnotetext{
${ }^{24}$ Cfr. Yacuzzi y otros 2012: 24,25
} 
kanban de movimiento de materiales en el proceso anterior, y de esta manera se van generando las tarjetas kanban que pueden llegar hasta los proveedores de materiales. ${ }^{25}$ Tener la trazabilidad del producto permitirá producir la cantidad de requerida en el tiempo especificado, el uso de las nuevas tecnologías electrónicas y de sistemas de información permite la aplicación de esta herramienta de una manera eficiente y eficaz.

\subsubsection{TAKT TIME}

Conocer los factores que intervienen en la atención de la demanda es importante para cumplir con los requerimientos de los clientes las capacidades instaladas, los tiempos de proceso y el volumen de venta tiene una estrecha relación. El Takt Time es una herramienta de medida primaria en el trabajo estandarizado. El origen de la palabra Takt proviene del idioma alemán utilizada para el metro musical o ritmos. El objetivo de la Takt Time es sincronizar la producción con la demanda del cliente. En consecuencia, se debe calcular la cantidad de tiempo que debe tomar terminar una parte o trabajo completo, basado en los volúmenes de venta.

Para determinar el Takt Time se debe calcular primero el tiempo de producción diaria. Esto quiere decir, del tiempo total disponible se debe restar todos los tiempos no productivos y dividirlo entre el requerimiento de producción total diario ${ }^{26}$. Determinar el tiempo por unidad requerida permitirá evaluar y ajustar la cantidad de equipos a operar o trabajar horas extra para cumplir con el requerimiento. En este sentido, será necesario tener una estrategia para la gestión de inventarios.

\footnotetext{
${ }^{25}$ Cfr. Sánchez y otros 2012: 63,64.

${ }^{26}$ Cfr. Miguel 2013: 28
} 


\subsubsection{Reporte A3}

El reporte A3 es una herramienta que esencialmente es la documentación del proceso Planificar-Hacer-Verificar-Actuar (PDCA) del circulo de Deming, que un equipo de personas utilizó para resolver un problema y mejorar un proceso. Un aspecto clave e importante del reporte A3 es porque captura toda la información relevante en un solo lado de un papel de 11 por 17 pulgadas. Esto obliga a la persona que crea el A3 a sintetizar la información y plasmar los hechos más importantes y relevantes en la asignación de espacio de papel. En la siguiente figura se muestra el proceso de gestión A3 para resolver problemas. 
Figura 4: Pasos a seguir del informe A3

Title: What are you talking about?

\begin{tabular}{l} 
I. Background \\
Why are you talking about it? \\
II. Current Conditions \\
- Show visually using charts, graphs, \\
drawings, maps, etc. \\
What is the problem? \\
III. Goals/Targets \\
\hline What specific outcomes are \\
required?
\end{tabular}

IV. Analysis

What is the root cause(s) of the problem?

- Choose the simplest problem- analysis tool that clearly shows the cause-andeffect relationship.

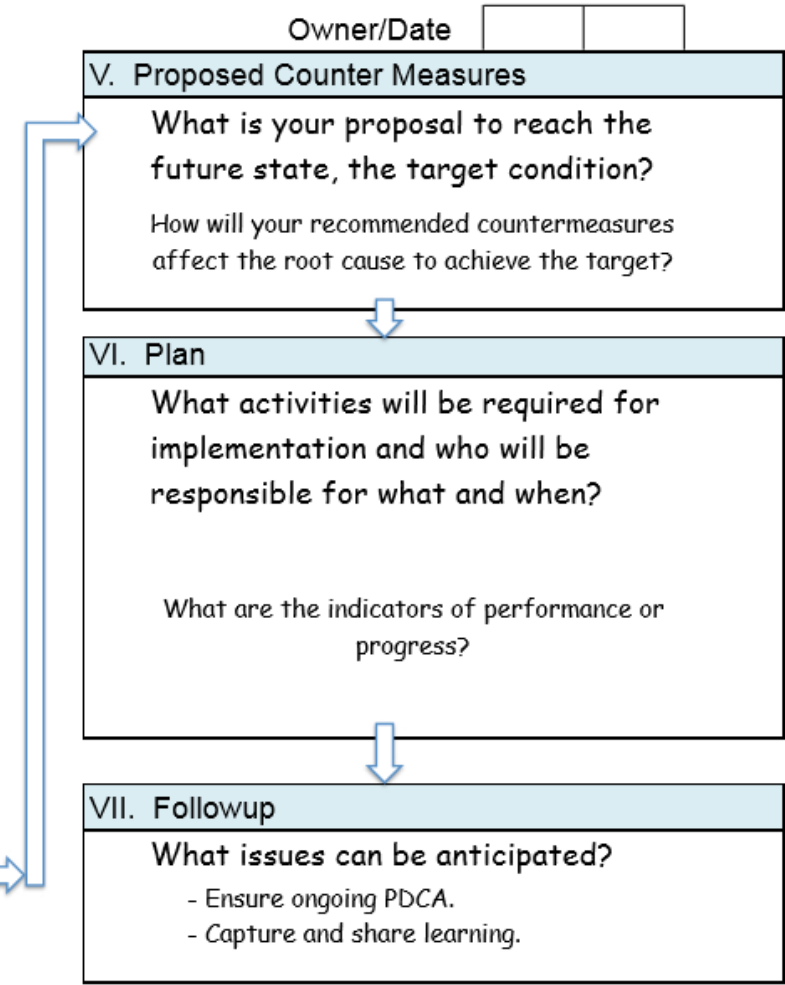

Fuente: Using the A3 management process to solve problems, gain agreement, mentor, and lead Shook, 2008

El primer paso del reporte A3 es la base que proporcionara la información para el resto de la lógica en la solución del problema esta debe tener congruencia con la perspectiva de la organización. ${ }^{27}$ Desarrollar un reporte A3 requiere de una lógica y una estructura formalizada que permita afrontar la diversidad de problemas que se puede encontrar en un proceso productivo.

\subsubsection{Diagrama de bloques}

Los sistemas físicos pueden tener varios tipos de representaciones gráficas entre ellas se tienen diagramas de circuitos, diagramas de bloque, gráficos de flujo. Los

\footnotetext{
${ }^{27}$ Cfr. Olsen y otros 2014: 3,4.
} 
diagramas de bloques sirven para simplificar sistemas y de ayuda para las simulaciones de cálculo del proceso. Un diagrama de bloques es una forma convencional de representar las interrelaciones entre las variables significativas del sistema, así como las características de los componentes que lo conforman. En cada bloque se representan los aspectos esenciales y tienen un flujo de interconexión de acuerdo la secuencia del proceso, cada bloque individual puede representar un modelo globalizado o como uno distribuido. La unión lineal de estos bloques forma un sistema de elementos globalizados ${ }^{28}$. El análisis de un proceso productivo en bloques permite realizar cálculos parciales e integrales del proceso, este cálculo es conocido como balance de masa.

\subsubsection{Enfoque estratégico de la producción desde la perspectiva de la gestión de inventarios}

Uno de los grandes retos de las organizaciones de manufactura respecto a la planificación y el control de los inventarios se convertido en la actualidad en un punto importante debido a que estos se convierten en un activo en el balance general de las empresas y estos generan costos. El inventario se ha convertido en un amortiguado entre la oferta y la demanda y el tamaño dependerá de que tan larga es la cadena. Entonces aparece el concepto conocido como "inventario de seguridad" este método de esta asociado a la distribución de los datos de la demanda real, la explicación de la necesidad de inventario se explica en la figura 5

\footnotetext{
${ }^{28}$ Cfr. Roca 2014: 2
} 
Figura 5: Inventario de seguridad

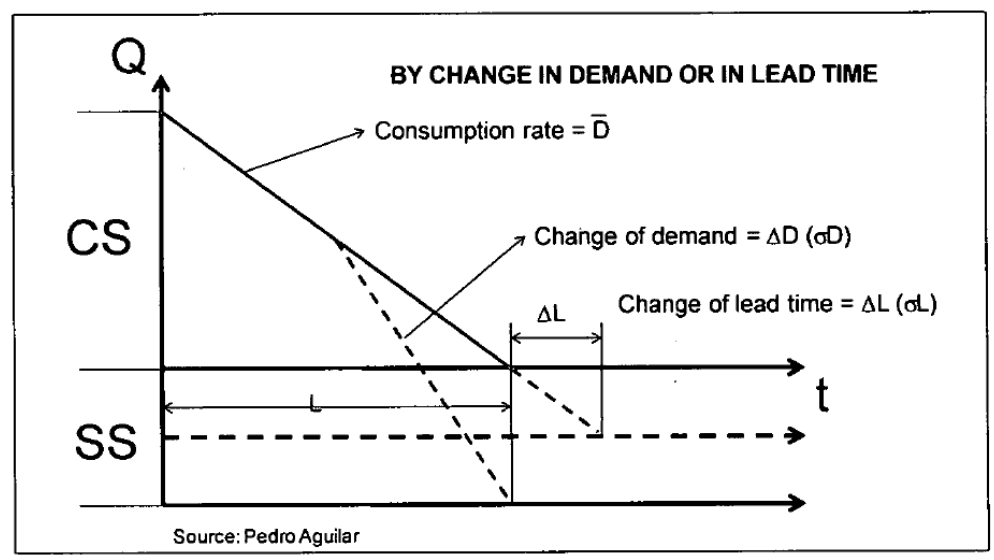

Fuente: Modelo de clasificación de inventarios para incrementar el nivel de servicio al cliente y la rentabilidad de la empresa (2012)

La variación de la demanda como el tiempo de aprovisionamiento obligan a tener un inventario adicional que absorba estas variaciones y es conocido como inventario de seguridad.

$$
\mathrm{SS}=\mathrm{z} \sigma \mathrm{D}
$$

En condiciones en las cuales solo existe variación de la demanda. Cuando se presentan variación en el tiempo de aprovisionamiento y variación en la demanda el valor del inventario de seguridad se define así

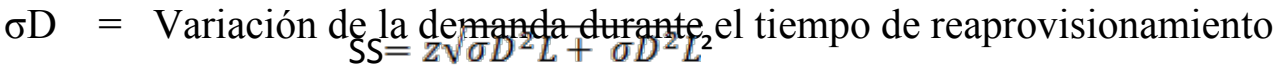

$$
\begin{aligned}
& \mathrm{L}=\text { Es el "Lead Time" o tiempo de aprovisionamiento } \\
& \sigma \mathrm{L}=\text { Variación del tiempo de aprovisionamiento } \\
& \mathrm{D}=\text { Promedio de la demanda durante el tiempo de reaprovisionamiento } \\
& \mathrm{z}=\text { Valor de la normal tipificada }
\end{aligned}
$$

El valor z depende del nivel de servicio que se desee brindar en la siguiente figura 6 se observa la interrelación entre las dos variables. 
Figura 6: Relación entre Nivel de servicio y el factor z

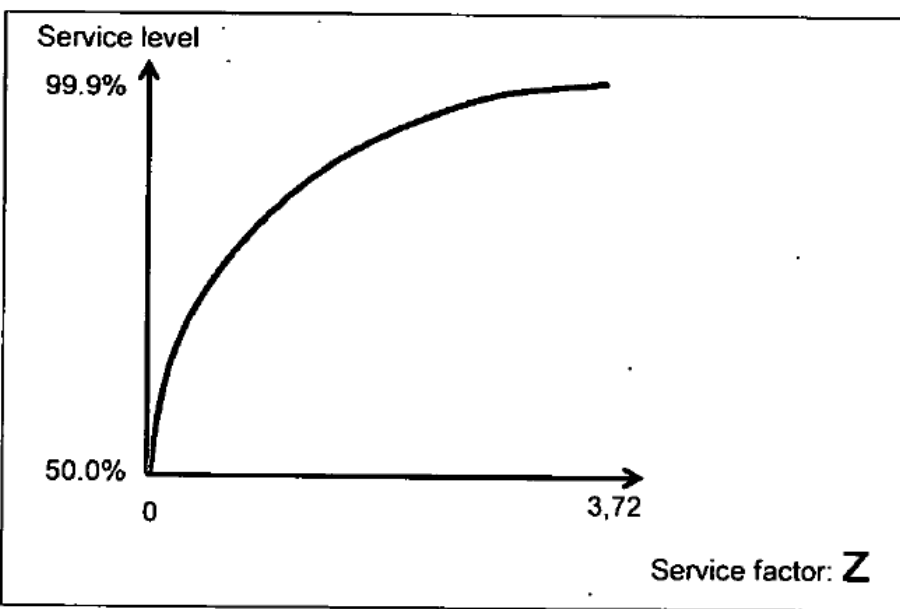

Fuente: Modelo de clasificación de inventarios para incrementar el nivel de servicio al cliente y la rentabilidad de la empresa (2012)

Se puede inferir que a mayor nivel de servicio mayor inventario de seguridad esta condición lleva a las empresas a evaluar los costos asociados. Estas condiciones llevan a evaluar y encontrar el punto óptimo relacionando el costo de la venta perdida y el costo de mantener inventarios para un nivel de servicio en la siguiente figura 7 la correlación. 
Figura 7: Nivel de servicio

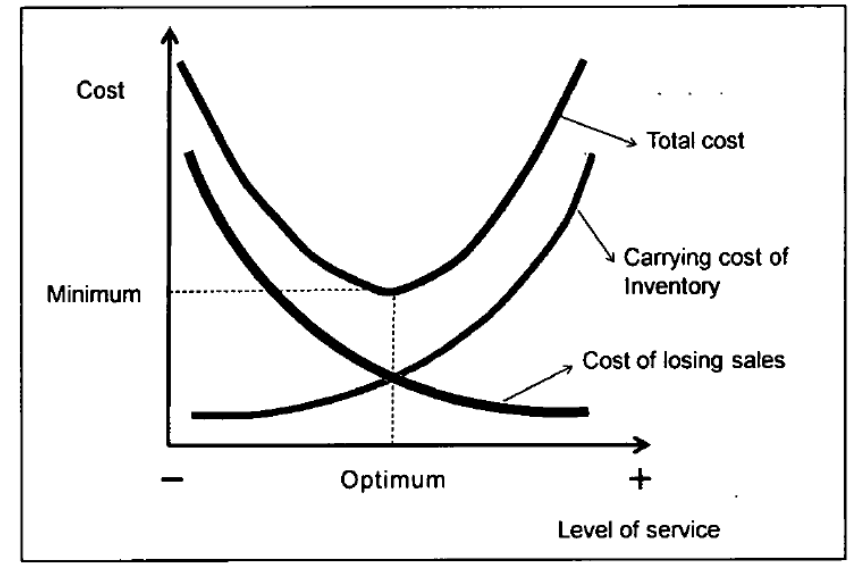

Fuente: Modelo de clasificación de inventarios para incrementar el nivel de servicio al cliente y la rentabilidad de la empresa (2012)

Una evaluación de los costos permitirá definir cuál es el nivel de servicio optimiza estos $\operatorname{costos.}^{29}$ La evaluación de los inventarios de seguridad dependerá de la estrategia organizacional para atender un mercado cada vez más informado y exigente

\subsection{Uso y beneficio de las herramientas}

Una investigación respecto al uso de las herramientas de mejoramiento comunes en la literatura empresarial en la ciudad de Antioquia - Colombia demuestra que entre los resultados se encuentra que las empresas "grandes" hacen mayor uso de herramientas de mejoramiento que las "medianas", y también perciben más beneficios; en la figura 8 se muestra la participación de los diferentes sectores productivos.

${ }^{29}$ Cfr. Aguilar 2012: 152-156 
Figura 8: Pareto para cada actividad de las empresas

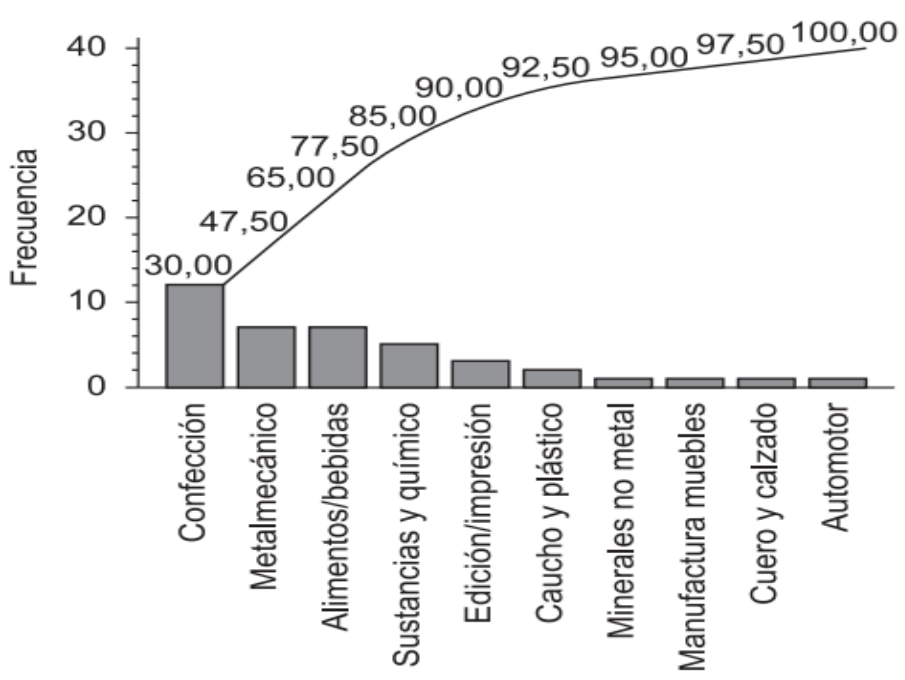

Fuente: Gest. Prod. São Carlos 2010

En el gráfico de Pareto muestras los sectores que utilizan las herramientas de mejoramiento que representan el $80 \%$ empresas dedicadas a la Confección, Metalmecánica y Alimentos/bebidas.

La selección de las empresas para el estudio fue realizada al azar con el siguiente criterio de clasificación la industria mediana y grande. Está definición es otorgada por la cámara de comercio de Medellín y tiene como criterios la cantidad de empleados y los niveles de facturación el objetivo identificar que prácticas de manufactura utilizaron en los últimos tres años el resultado Control estadístico de procesos (75\%), Benchmarking (73\%), Sistema de gestión ISO 9000:2000 (68\%) y las 5'S (64\%), y las menos utilizadas: Seis sigma, Mantenimiento Productivo Total (TPM) y SMED, con iguales porcentajes (31\%) en la figura 9 se muestran los resultados de las 13 herramientas más utilizadas. 
Figura 9: Empresas que en los últimos tres años han usado herramientas, según tamaño

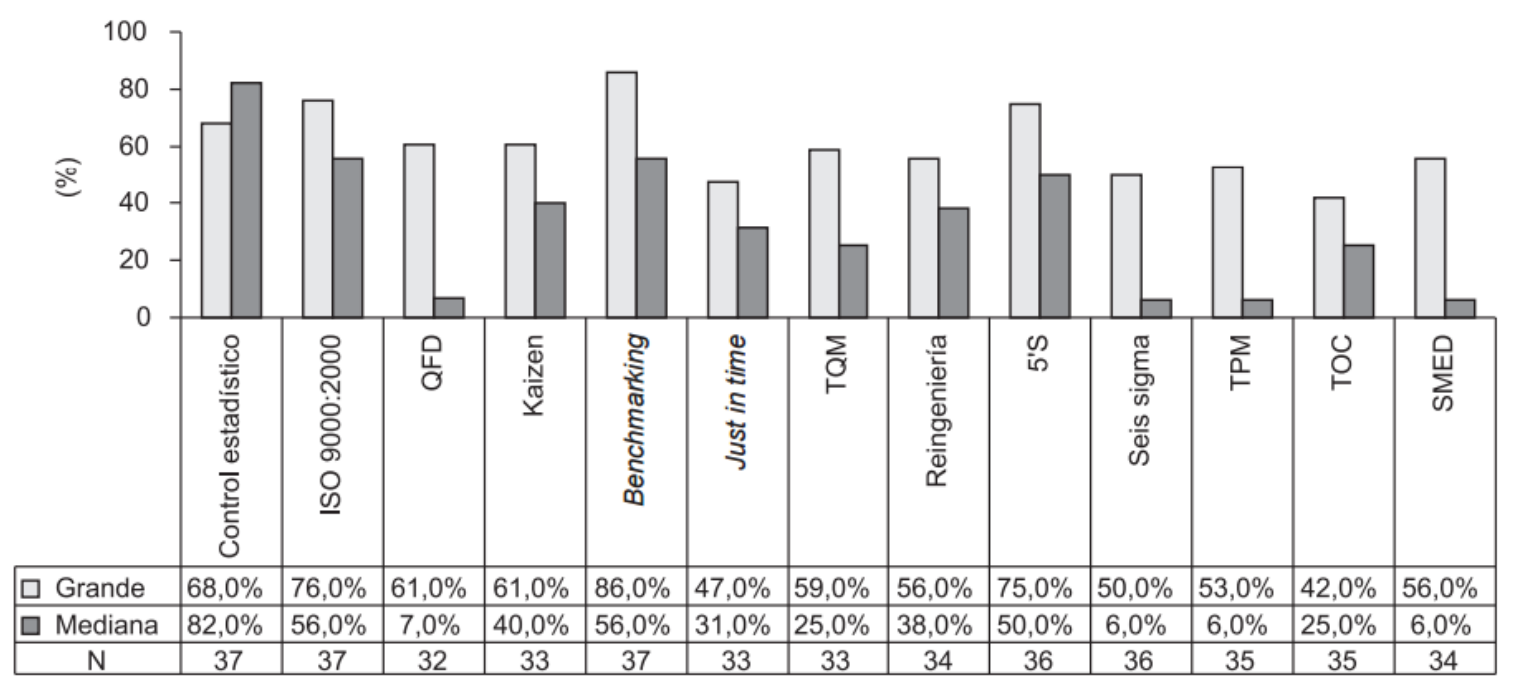

Fuente: Gest. Prod. São Carlos 2010

En el gráfico se observa que, a excepción de Control estadístico de procesos, las empresas grandes reflejaron mayor uso que las medianas. Las diferencias estructurales entre las empresas grandes y medianas suponen que no todos los casos de implementación de las herramientas para el mejoramiento han tenido éxito esto se debe principalmente al compromiso de la alta dirección, liderazgo, sensibilización del talento humano y falta de conocimiento de la técnica. Las herramientas más utilizadas en las empresas grandes en la ciudad de Medellín el Benchmarking, Sistemas de Calidad ISO 9000:2000, 5'S y el Control Estadístico. Los factores de éxito el servicio post venta, la calidad del producto y la flexibilidad. ${ }^{30}$ La selección de la herramienta a utilizar dependerá de las características de la organización y de los objetivos y metas a cumplir.

\subsection{Casos de éxito}

\section{Caso de éxito Maheso e ICE Consultants}

Un caso importante de éxito de la implementación del Lean relacionado con la fabricación de pastas y tema de estudio se desarrolló en España. La relación entre Maheso e ICE Consultants empieza a mediados de 2008, cuando la dirección de Maheso se plantea implementar técnicas y herramientas Lean durante tres días a

\footnotetext{
${ }^{30}$ Cfr. Pérez y otros 2010: 592-595
} 
personas clave de la organización. Para la formación, además de abordar cuestiones teóricas, ICE Consultants realiza una toma exhaustiva de datos en planta que se discute durante las sesiones del curso y que permite, entre todos, identificar las oportunidades de mejora y definir un plan de acciones orientado a la mejora de eficiencia de las líneas de producción. Tras una evaluación más detallada utilizando herramientas de diagnóstico, Maheso decide focalizar sus esfuerzos en dos de las áreas que presentaban la mayor oportunidad estas son las líneas Pasta Rellena y Frituras. La decisión estratégica de apoyarse con una empresa de consultoría ICE Consultants para el análisis y rediseño de las secciones mediante la implantación de los principios y técnicas Lean fue un factor clave. Para la realización del proyecto se definió un equipo mixto Maheso-ICE trabajando como un equipo integral de proceso con una dedicación a tiempo completo de ingeniería de proceso, un soporte puntual del resto de departamentos y el apoyo y liderazgo de la dirección. Gracias a esta labor, el proyecto transcurrió según lo planificado sin desvíos ni imprevistos de ningún tipo. Tras la consolidación de las medidas implantadas, las dos líneas de Maheso experimentaron las siguientes mejoras:

- Incrementos de eficiencia

- Incrementos importantes en la productividad

- Reducción importante en las mermas en la línea de Pasta Rellena.

Estas mejoras se lograron con pequeñas inversiones y retornos de la inversión de pocos meses. Los ahorros debido a estos resultados y la disminución de los costos productivos, fue acompañada por aspectos cualitativos encaminados a garantizar mejoras adicionales en un futuro:

- Procesos productivos más robustos.

- Mejor control y gestión de la planta. 
- Desarrollo de indicadores y organización orientados a la mejora continua.

- Mayor participación del personal de planta y dirección en los resultados operativos.

- Este piloto permitió hacer extensivo la metodología a las demás áreas de la organización.

El éxito de este proyecto, la colaboración entre Maheso e ICE Consultants se alargó por un periodo mayor con el objetivo de generalizar estas técnicas al resto de las áreas, incluso el servicio de comida de la empresa, con la misma metodología empleada que en las líneas de producción $^{31}$. El caso de éxito demuestra que la implementación de la metodología Lean teniendo en cuenta factores importantes como el compromiso de la alta dirección, la participación de una empresa consultora, la designación recursos, la utilización de herramientas de diagnóstico y la participación del personal se logra obtener con inversiones pequeñas grandes resultados.

\section{Caso de Éxito con aplicación de Kaizen}

Es imperativo determinar cuáles son los factores que intervienen en el éxito de la implementación de un evento Kaizen. Farris et al. (2008) presenta una investigación de 51 eventos Kaizen realizados en seis organizaciones de manufactura, el objetivo determinar el conjunto de las variables y los factores del proceso que tienen mayor impacto en relación con el desarrollo de la actitud del empleado y la capacidad del mismo. El informe concluye que, de acuerdo con los resultados arrojados de su investigación para obtener el máximo impacto en la actitud del empleado y la habilidad de resolver problemas, la organización debe tomar en cuenta lo siguiente:

1. La organización debe buscar la motivación y dinamismo de su equipo de trabajo con mecanismos estructurados y de un facilitador.

2. La organización debe mantener el compromiso y apoyo constante durante el evento.

3. La organización debe tener claro que a mayor complejidad de los objetivos se tendrá que aumentar el conocimiento del equipo de trabajo. Además, que es imperativo que el personal tenga un alto grado de autonomía y mecanismos que ayuden a gestionar la participación.

${ }^{31}$ Cfr. Hernández y otros 2013: 138,139. 
4. La organización debe reconocer que la complejidad del área de trabajo disminuye el aprendizaje del equipo y que la experiencia del líder no soluciona esta condición, por lo que se debe compensar con otros mecanismos.

El resultado de la investigación determina el éxito de Kaizen partiendo del impacto que el evento genera en los miembros del equipo, como la capacidad de resolver problemas, y su aprendizaje. Más aun, es importante mencionar que existen factores personales del recurso humano que toman vital importancia en la participación, el deseo y la motivación del personal para volver a participar en eventos futuros. Los principales factores claves del éxito que se han determinado a lo largo de diferentes investigaciones de Kaizen son los que se ilustran en la tabla 3 
Tabla 3: Investigaciones asociadas a Kaizen

\begin{tabular}{|c|c|}
\hline et al. (1998) & $\begin{array}{l}\text { Tiempo de duración, el enfoque específico, inversión de capital, la } \\
\text { naturaleza basada en el equipo, orientación a la acción, el uso de } \\
\text { indicadores específicos y verificables. }\end{array}$ \\
\hline $\begin{array}{l}\text { Bateman y Rich } \\
(2003)\end{array}$ & $\begin{array}{l}\text { La disponibilidad de recursos, el reconocimiento de la necesidad de } \\
\text { un cambio, la cultura que apoya el cambio, la coherencia de } \\
\text { enfoque en la mejora, la calidad Kaizen y programa de campeón, la } \\
\text { calidad del líder del equipo, apoyo a la gestión, la rotación de } \\
\text { personal, calidad de la comunicación, la alineación del sistema de } \\
\text { medición, la capacidad para justificar económicamente los eventos. }\end{array}$ \\
\hline Patil (2003) & $\begin{array}{l}\text { Involucramiento de los trabajadores, seguridad en el empleo, la } \\
\text { formación, las encuestas de necesidades de los empleados, los } \\
\text { procedimientos operativos estándar (SOP), seguimiento fallas, el } \\
\text { tiempo para la finalización de los elementos de acción, la alineación } \\
\text { estratégica, intercambio de conocimientos }\end{array}$ \\
\hline $\begin{array}{l}\text { Bradley } \\
\text { Willett (2004) }\end{array}$ & $\begin{array}{l}\text { Complejidad del problema, los conocimientos del equipo de } \\
\text { herramientas, el conocimiento del proceso del equipo, la } \\
\text { experiencia líder del equipo, la experiencia de facilitador, procesos } \\
\text { internos eficaces, claridad de metas, la estabilidad de la } \\
\text { organización, la heterogeneidad equipo funcional, el alcance de } \\
\text { eventos, la falta de la manipulación, la falta de competencia, } \\
\text { recompensas por la participación, la flexibilidad en el enfoque, la } \\
\text { lista de los rubros, los datos históricos de rendimiento. }\end{array}$ \\
\hline Miller (2004) & $\begin{array}{l}\text { Esperanza de las creencias, las creencias, los comportamientos de } \\
\text { tareas de valor de rendimiento }\end{array}$ \\
\hline Bateman (2005) & $\begin{array}{l}\text { 5S, la medición del desempeño, los empleados de resolución de } \\
\text { problemas de sistemas, soporte del área de trabajo gerente, } \\
\text { empleado, el coordinador de la potenciación plena Kaizen } \\
\text { hora del evento, la capacitación en nuevos métodos de trabajo, la }\end{array}$ \\
\hline
\end{tabular}




\begin{tabular}{|l|l|}
\hline & $\begin{array}{l}\text { gestión de área de trabajo, la participación en eventos Kaizen, el } \\
\text { apoyo a la alta dirección de IP, la alineación estratégica }\end{array}$ \\
\hline Montabon (2005) & Equipo funcional de la heterogeneidad \\
\hline Doolen et al (2008) & Dificultad de la meta, apoyo a la gestión \\
\hline Farris et al (2008) & $\begin{array}{l}\text { Objetivo con claridad, la representación del equipo funcional, la } \\
\text { autonomía del equipo }\end{array}$ \\
\hline
\end{tabular}

Fuente: GARCÍA, Jorge y otros 2012

No obstante, la implantación de la técnica de Kaizen no siempre logra los resultados esperados, y muchas veces durante la etapa de implementación estos proyectos se abandonan. Por ello, es necesario y se requiere de una planeación que sea bien estructurada, completa y que sea sólida, para que esta pueda garantizar el éxito de la herramienta ${ }^{32}$. Es claro que se debe conocer profundamente los factores claves que aseguren el éxito de la técnica Kaizen además la organización debe tener estrategias motivacionales con el recurso humano para garantizar una constante participación.

32 Cfr. García y otros 2012: 344,345. 


\section{CAPITULO 2. ANÁLISIS Y DIAGNÓSTICO DEL PROCESO ACTUAL}

\subsection{Información general de la empresa}

\subsubsection{Rubro y descripción de la empresa}

Empresa dedicada al rubro de manufactura de alimentos para Consumo Masivo tales como aceites domésticos, fideos, margarinas, galletas entre otros. La empresa cuenta con casa matriz en el Perú con operaciones en otros países Latino Americanos: Argentina, Brasil, Colombia y Ecuador. A lo largo de los años ha construido una historia de crecimiento y mejora. Su estrategia se basa en la consolidación del negocio actual, lanzamiento de nuevos productos, búsqueda de expansión internacional y adquisiciones. La compañía fue constituida en el año 1928. Al inicio fabricaban aceites, jabones y mantecas. Durante los siguientes años se dedicaron a comprar varias empresas en Perú, Ecuador, Colombia, Argentina y Brasil, con el correr de los años ha tenido un importante crecimiento en los rubros de consumo masivo, nutrición animal y productos industriales. Han logrado alcanzar estándares internacionales de calidad y competitividad. Además, han elevado sus niveles de liderazgo en diversas categorías de productos. La compañía tiene presencia en casi todos los departamentos del Perú, a través de sus diferentes instalaciones como almacenes, plantas industriales, plataformas logísticas, oficinas de venta y distribuidoras exclusivas. La organización cuenta con más de 4,500 colaboradores en sus operaciones en el Perú. Las acciones comunes y de inversión se encuentran listadas en la Bolsa de Valores de Lima. 


\subsubsection{Ingresos}

Los ingresos estimados de la empresa por el negocio de pastas para el año 2015 fue más de S/. $360000000 .^{33}$

\subsubsection{Política Integrada de los Sistemas de Gestión}

En la empresa, todos contribuimos con la sostenibilidad de nuestros negocios y del entorno, comprometiéndonos a:

"Crecer, excediendo las expectativas de nuestros clientes y consumidores ofreciéndoles productos y servicios elaborados con la aplicación de los más exigentes estándares de calidad, inocuidad y eficiencia.

Prevenir la contaminación ambiental, asegurando el uso adecuado de recursos y promover el comportamiento seguro para evitar que las personas sufran lesiones o daños a su salud en nuestras instalaciones.

Cumplir con los requisitos legales aplicables y voluntarios que la Empresa asuma y proteger nuestras actividades contra su posible uso por organizaciones ilícitas.

Desarrollar a nuestro personal y promover activamente su participación en los procesos del Sistema de Gestión, como base para mejorar continuamente los resultados de la empresa.” La Empresa (2014)

\subsubsection{Visión}

"Hacia el 2021 vamos a triplicar el valor de la compañía"

La Empresa (2014)

\subsubsection{Misión}

"Creamos marcas líderes que transforman mercados generando experiencias extraordinarias en nuestros consumidores. Estamos en constante movimiento buscando innovar para generar valor y bienestar en la sociedad."

\footnotetext{
${ }^{33}$ Cfr. La empresa (2015)
} 
La Empresa (2014)

\subsubsection{Valores}

Lideramos con pasión

Estamos conectados

Actuamos con agilidad y flexibilidad

Confiamos

Respetamos

La Empresa (2014)

\subsection{Procesos Generales de la Empresa}

\subsubsection{Organigrama de la organización}

El actual organigrama de la organización es matricial, el objetivo es consolidar la gestión comercial, la gestión de las marcas y acelerar el crecimiento del negocio en el Perú, mediante la acción de desarrollar, coordinar y garantizar los procesos con toda la organización para la ejecución de la estrategia corporativa en el corto, mediano y largo plazo. En la figura 10 se representa el organigrama de toda la organización, la propuesta de mejora de este proyecto de mejora se enfocará en la unidad de negocios de farináceos en la planta de fabricación de fideos.

Figura 10: Organigrama de la organización 


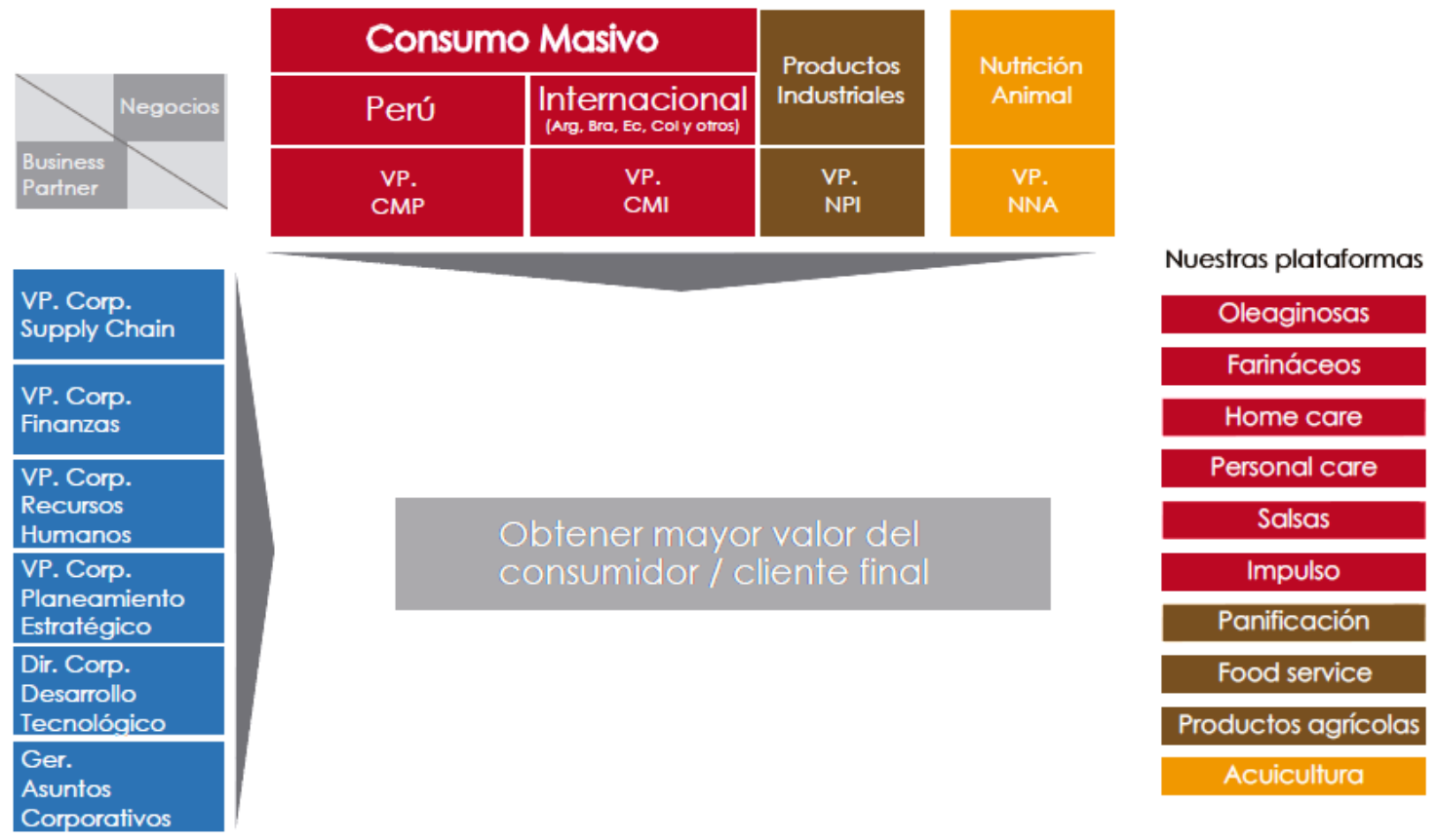

Fuente: La empresa

\subsubsection{Mapa de procesos}

El sistema de calidad actual de la planta de producción de fideos empieza con un input que es el requerimiento de consumidores y clientes, esta información de demanda pasa por las áreas de Marketing, Venta, Planeamiento Industrial y Servicio al Cliente la cual tiene un tratamiento acorde con las estrategias de la organización. El siguiente proceso el proceso productivo donde intervienen diferentes subprocesos que se interrelacionan para garantizar un producto de calidad. El proceso gestión de la calidad tiene un círculo que implica la responsabilidad de la dirección, gestión de recursos, medición, análisis y mejora continua. Finalmente, el output del proceso son los productos que se entregaran a los clientes y consumidores, dentro de ellos están las distribuidoras industriales, supermercados y mayoristas, la figura 11 representa el proceso. 
Figura 11: Sistema de gestión de la calidad

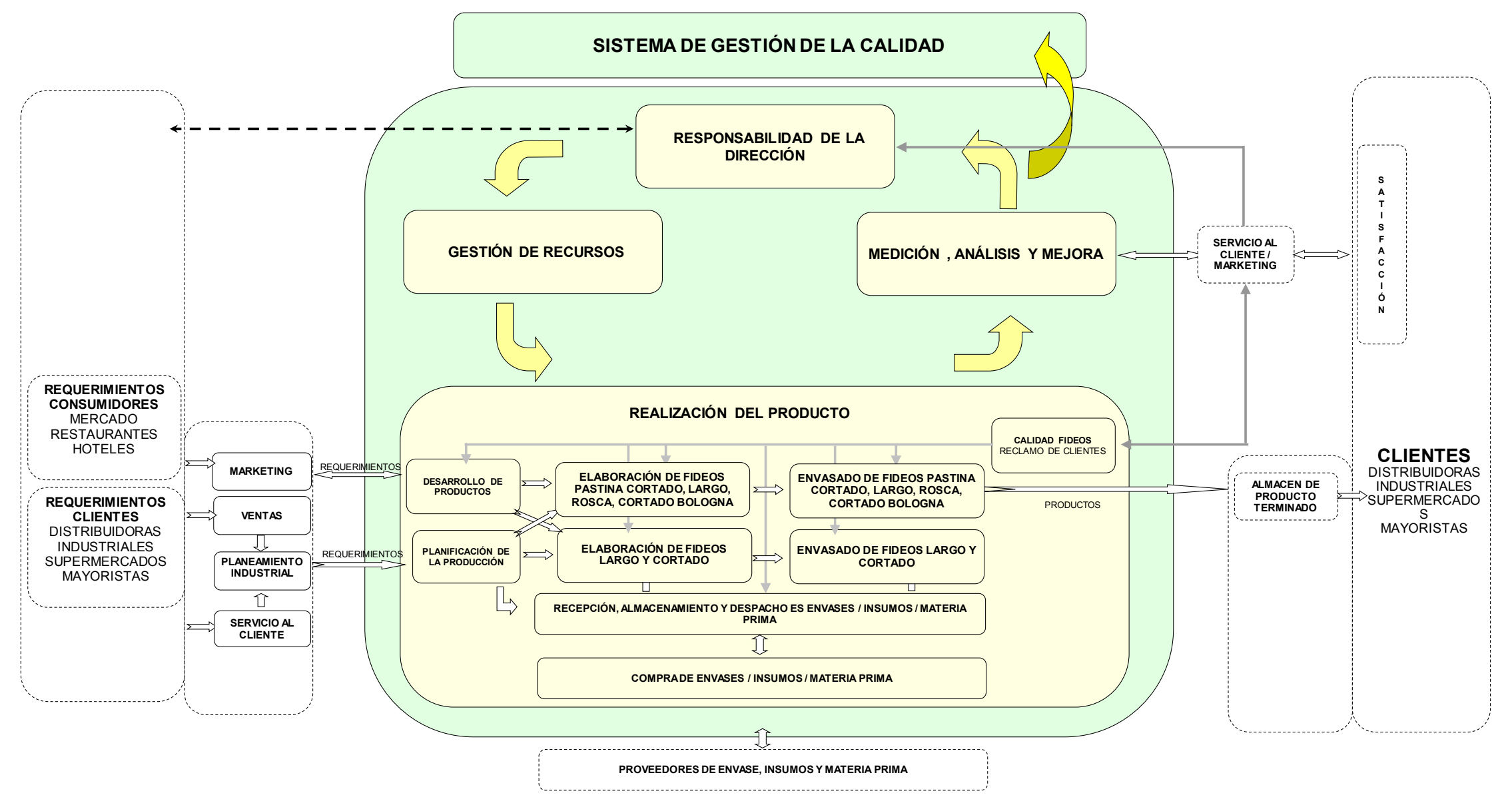

Fuente: La empresa 


\subsection{Funciones logísticas del proceso}

La organización tiene un sistema logístico diseñado acorde con la estrategia de crecimiento y ha establecido que la ejecución de las funciones logísticas sea realizada por el área de compras, el área de materias prima, almacén y distribución de producto terminado. Con la finalidad de graficar la sinergia entre las áreas se presenta un esquema grafico de la logística de ingreso y salida en la figura 12.

Figura 12: Proceso de gestión logística

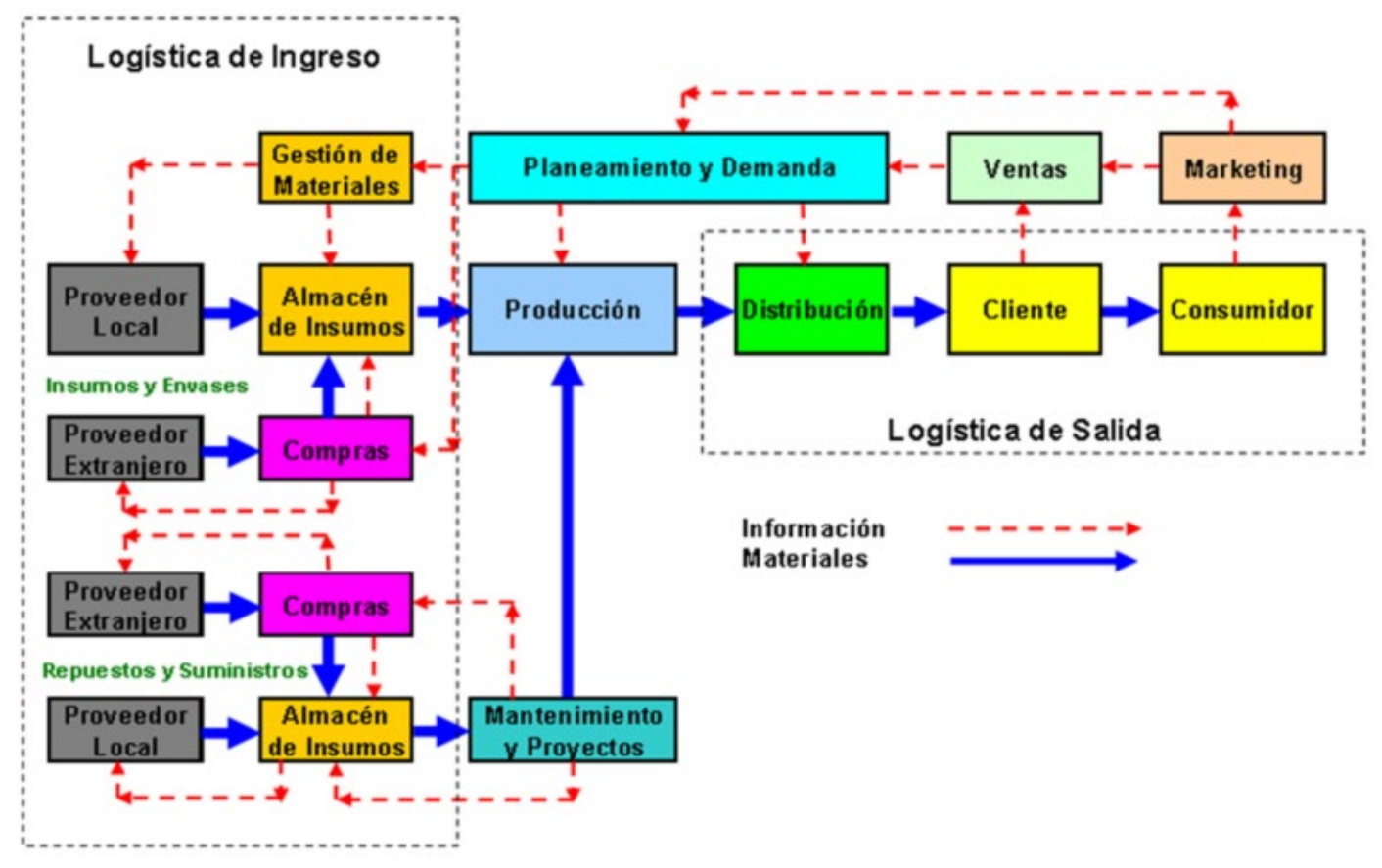

Fuente: La empresa

La empresa se enfoca en consolidar el liderazgo de sus plataformas claves, y mantener un sólido crecimiento orgánico e inorgánico. La estrategia se sustenta en la amplia participación de mercado con la que cuenta en los mercados en los que opera, así como en la creación de valor agregado a sus productos para conseguir un crecimiento sostenido, y 
una alta recordación de sus marcas. La Compañía se basa en cinco ventajas competitivas para impulsar el liderazgo de sus marcas y obtener una sólida y creciente rentabilidad.

Mediante su estrategia de crecimiento orgánico, la empresa logra obtener un sólido posicionamiento de sus líneas de negocio, lo cual junto con la adecuada segmentación de mercado. A nivel internacional ostenta un posicionamiento sólido debido a su estrategia de penetración con marcas reconocidas en mercados locales, lo cual facilita la implementación de sinergias en compras, cadena de abastecimiento, operaciones, tecnología e infraestructura; asimismo, facilita su expansión, mayor acceso, y fortalece su plataforma de distribución.

\subsection{Procesos del área}

\subsubsection{Diagrama SIPOC del área de producción de fideos}

El área de producción es el responsable del proceso de producción de fideos que busca optimizar la productividad en términos de eficiencia, eficacia, calidad y costos. En este sentido, gestionar la producción y cumplir con la entrega de los productos de acuerdo con la demanda del mercado estimada por la empresa es su responsabilidad. En la figura 13 se muestra el diagrama SIPOC de producción de fideos. Donde es importante resaltar la importancia que tiene el subproceso 1 "Process" porque tiene cinco factores críticos como es la mano de obra, materiales, método, maquinaria y medición. 
Figura 13: Diagrama SIPOC de producción de fideos

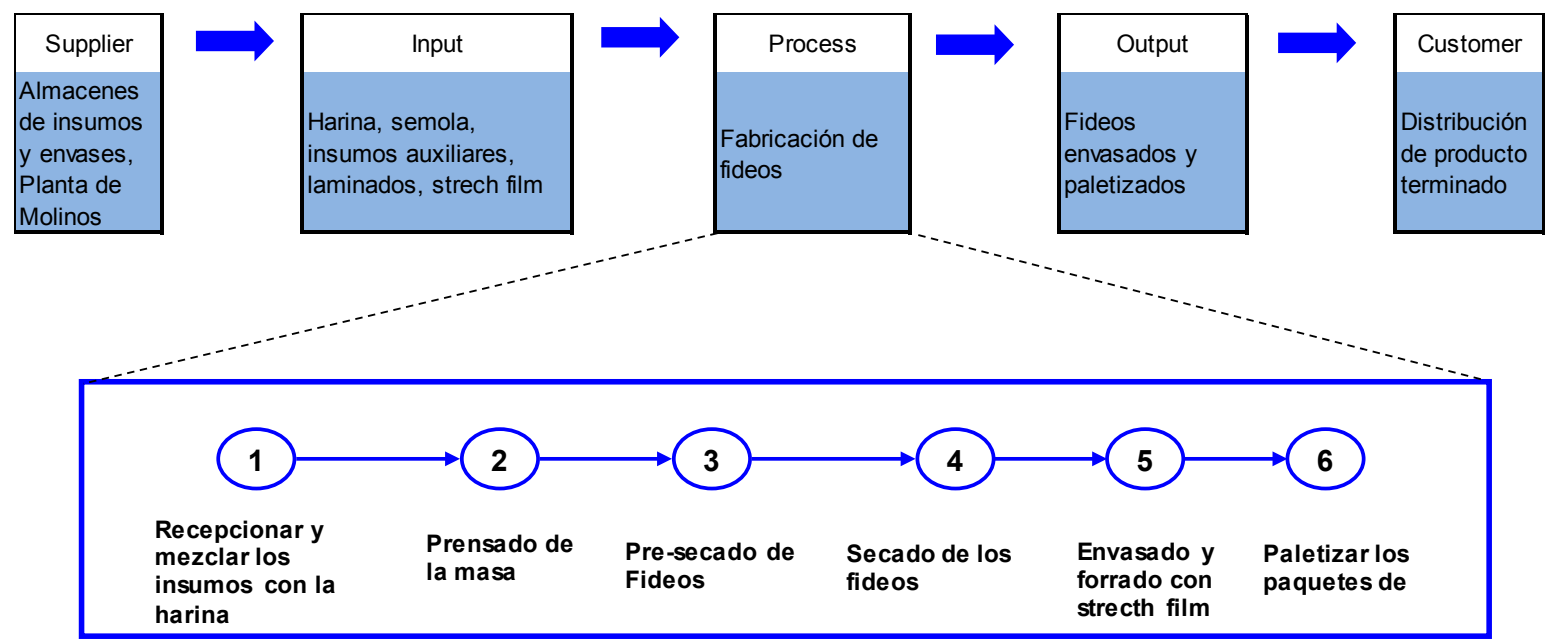

\begin{tabular}{|ccccccc|}
\hline \multicolumn{2}{c}{ Factores Criticos } & & & & \\
& MO & MAT & MET & MAQ & MED & MA \\
1 & $\mathrm{x}$ & $\mathrm{x}$ & $\mathrm{X}$ & $\mathrm{x}$ & $\mathrm{x}$ & \\
2 & & & $\mathrm{X}$ & $\mathrm{x}$ & $\mathrm{x}$ & \\
3 & & & $\mathrm{X}$ & $\mathrm{x}$ & $\mathrm{x}$ & \\
4 & & $\mathrm{x}$ & $\mathrm{x}$ & $\mathrm{x}$ & $\mathrm{x}$ & \\
5 & $\mathrm{x}$ & $\mathrm{X}$ & $\mathrm{x}$ & & \\
6 & $\mathrm{x}$ & & $\mathrm{X}$ & & \\
\hline
\end{tabular}

\begin{tabular}{|clll|}
\hline Leyenda & & & \\
MO & Mano de Obra & MAQ & Maquinaria \\
MAT & Materiales & MED & Medición \\
MET & Método & MA & Medio Ambiente \\
\hline
\end{tabular}

Fuente: Elaboración propia basado en la información de la empresa

\subsubsection{Descripción del Proceso de fabricación de fideos}

La producción de fideos es una unidad de negocio importante para la organización y ha sumado esfuerzos para centralizar la producción en la planta principal con la instalación de nuevas máquinas con el objetivo de buscar eficiencias operativas. La planta tiene máquinas de producción de alta capacidad y última tecnología. Este nivel de automatización de última generación permite procesos continuos y totalmente automatizados. Por lo que, en esta planta 
se pueden fabricar fideos de diferentes marcas y tipos tales como spaghetti; tallarín grueso y delgado; cabello de ángel; coditos; aritos; tornillo; canuto grueso y delgado; corbatas; etc., existen dos modelos de máquina para la fabricación de estos tipos de fideos y son: máquinas que fabrican pasta larga y máquinas que fabrican pasta corta. Las diferentes variedades o formas se logran cambiando los moldes y tipo de empaque, la figura 14 describe el proceso productivo, en la figura 15 el Diagrama de Operaciones del Proceso y en la figura 16 el Diagrama de actividades del Proceso, estos gráficos nos ayudaran a tener una mejor perspectiva del proceso productivo desde la recepción de materia prima hasta el paletizado del producto terminado.

Figura 14: Diagrama de flujo del proceso de producción 
Materia Prima
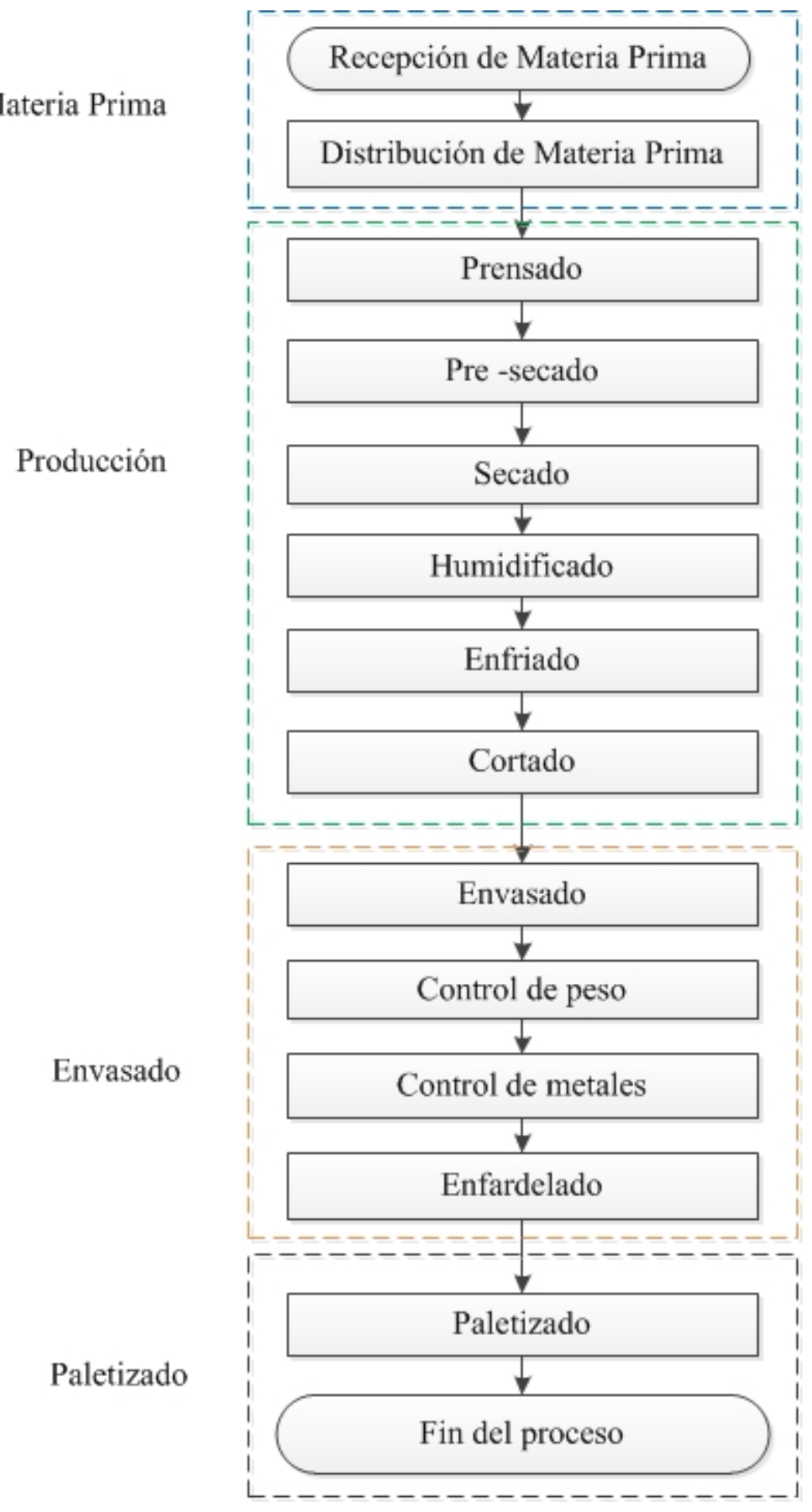

Fuente: Elaboración propia basado en la información de la empresa 
Figura 15: Diagrama de operaciones del proceso

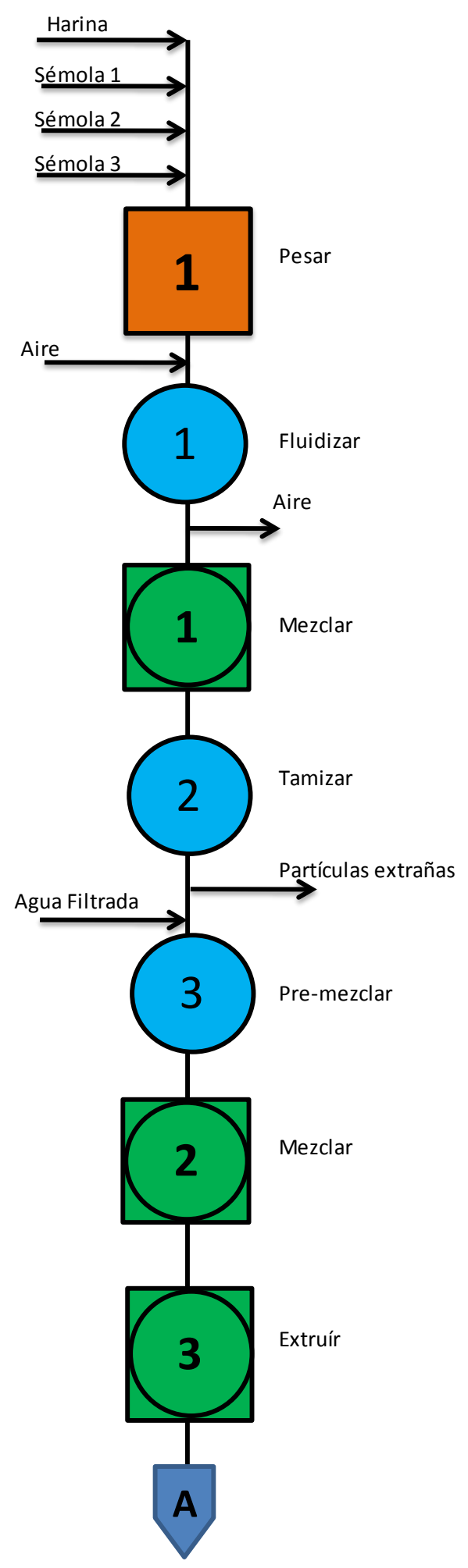




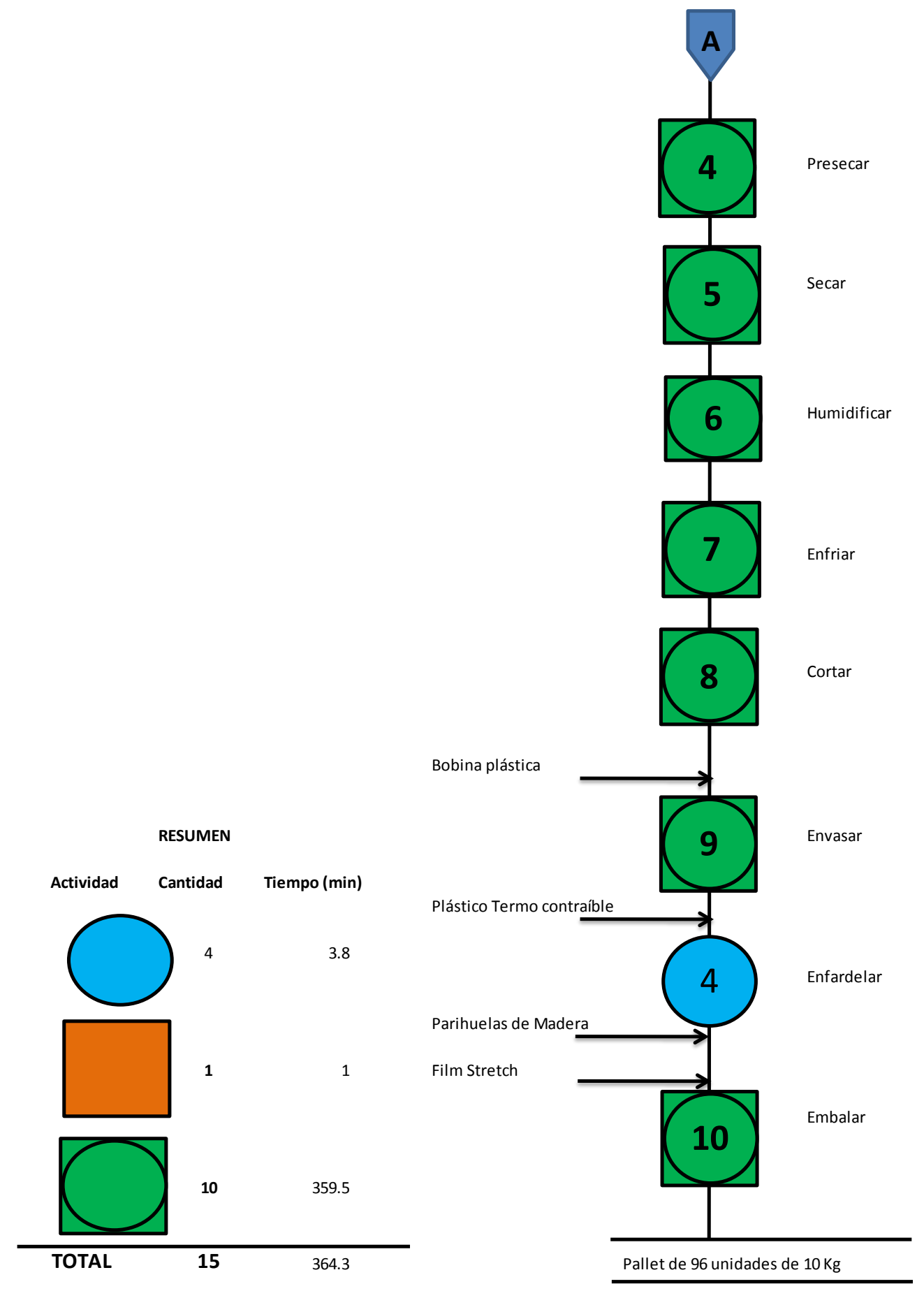

Fuente: Elaboración propia basado en la información de la empresa 
Figura 16: Diagrama de Actividades del proceso

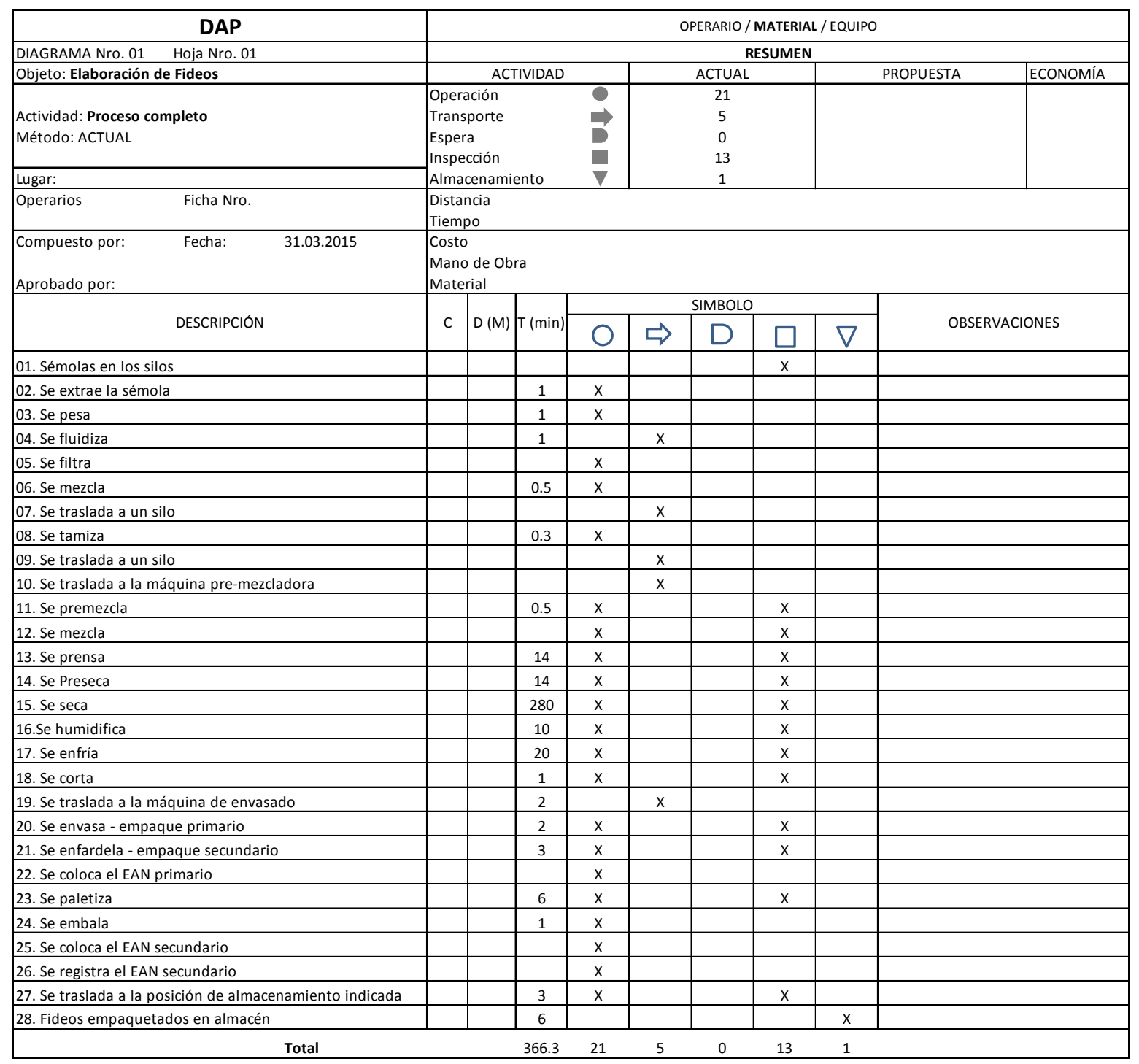

Fuente: Elaboración propia basado en la información de la empresa 


\section{Almacenamiento de materia prima}

El almacenamiento de la materia prima se realiza en silos de 100 toneladas, estos son abastecidos de la planta de molino por un sistema de transporte neumático. Cada tipo de producto es identificado y almacenado en un silo y a través de sensores y un sistema de supervisión control y acceso de datos (SCADA) se gestiona el stock y el abastecimiento. La figura 17 muestra la distribución.

Figura 17: Silos de recepción de materia prima

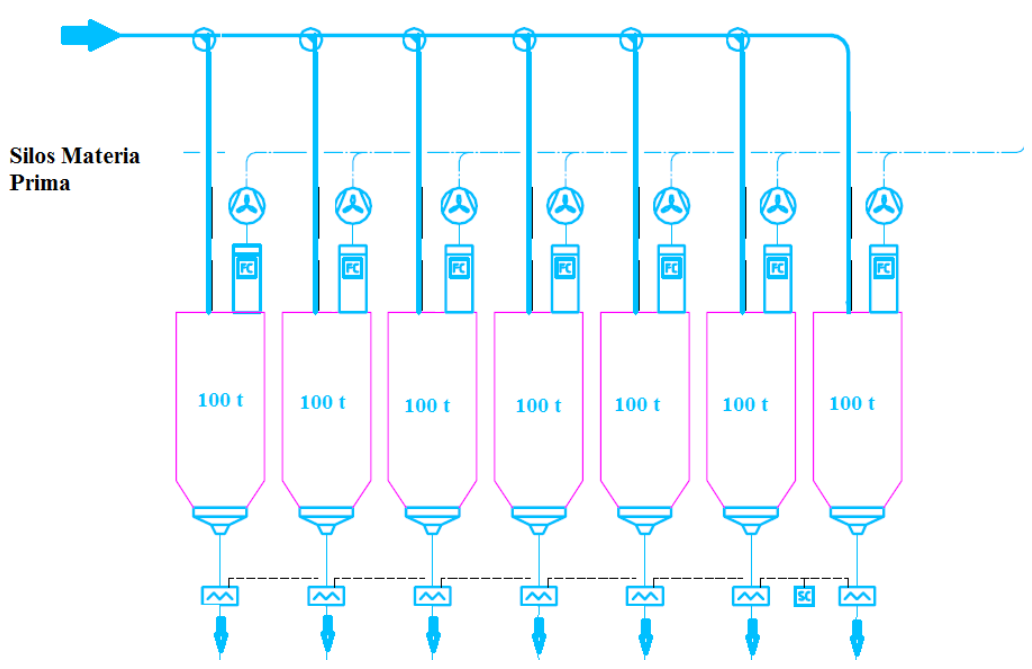

Fuente: La empresa

\section{Sistema de distribución de materia prima}

El sistema de distribución se encarga de formular y enviar las materias primas y los microingredientes a cada línea de proceso. Los diferentes productos tienen recetas específicas que son formuladas por el sistema de distribución. Esta se realiza por batch de 1 tonelada, la proporción de cada materia prima y micro ingrediente se encuentra previamente establecido en el sistema. Una vez formulado el batch es enviado por un sistema de transporte neumático a cada línea de proceso, la figura 18 muestra las balanzas que pesan los insumos mayores e insumos; y el sistema de envío.

Figura 18: Sistema de distribución de macro y microcomponentes 


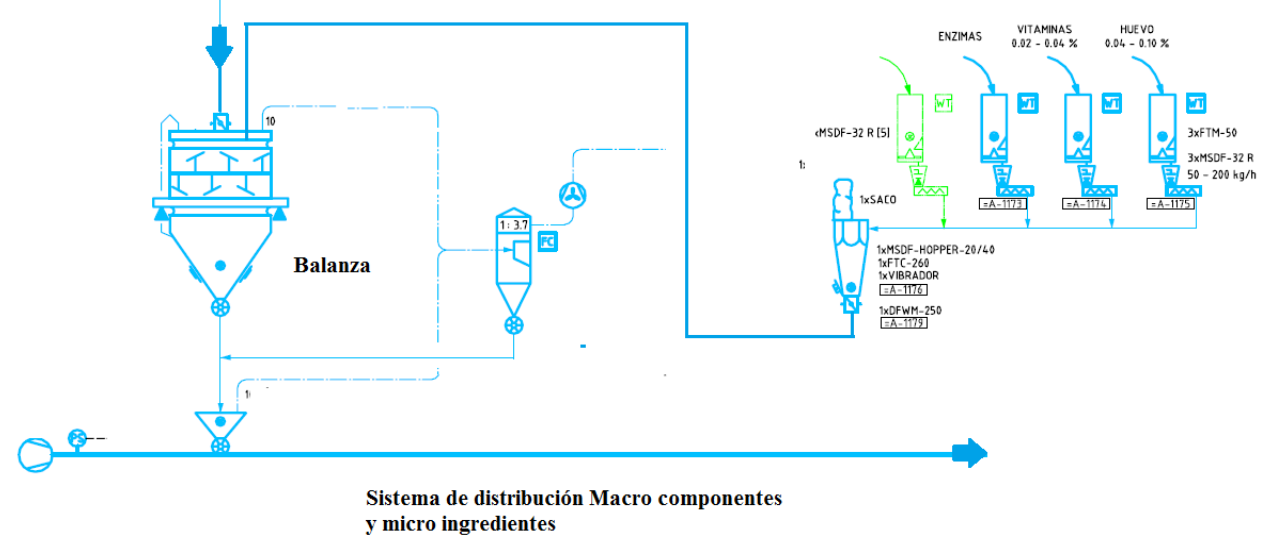

Fuente: La empresa

\section{Silos de recepción de materia prima y rotostar}

Los silos sirven como pulmón para almacenar la materia prima formulada y dar continuidad de operación a las líneas de producción y el rotostar separará partículas que no cumplan con la granulometría especificada. La figura 19 muestra la disposición los silos de cada línea de proceso.

Figura 19: Silos de materia prima

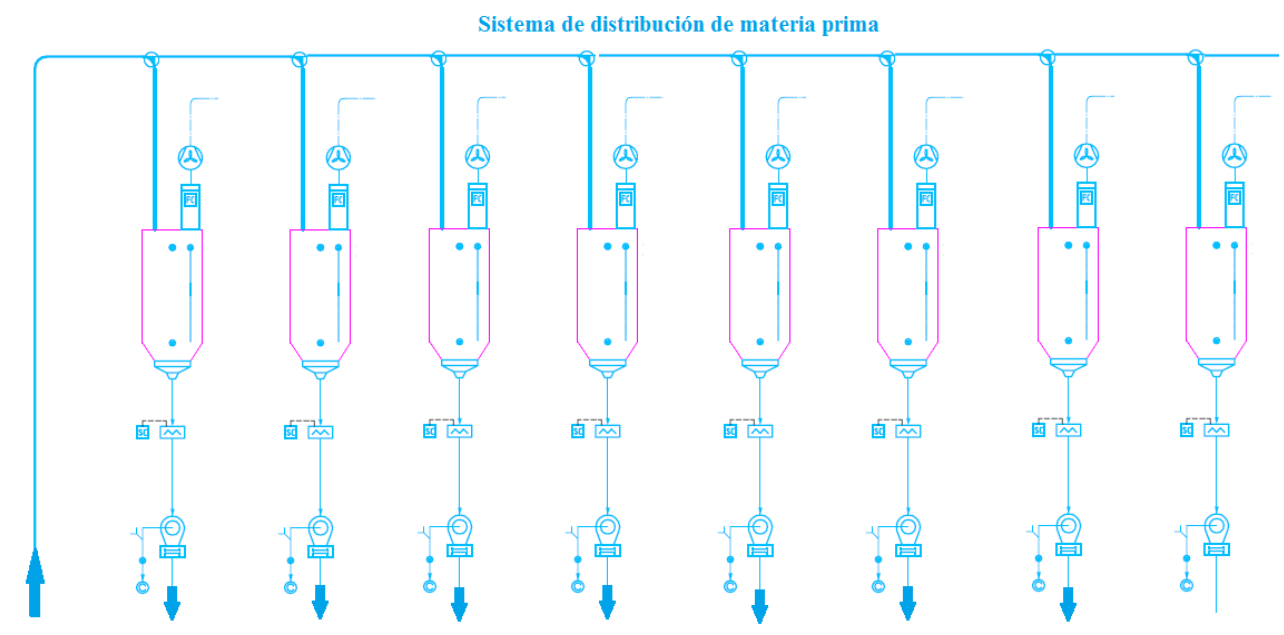

Fuente: La empresa

\section{Sistemas de dosificación de agua y sémola}

La dosificación de agua y sémola se realizan a través de sistemas que permite controlar la temperatura y la cantidad de acuerdo con una formulación. Un filtrado de $5 \mu$ y una lámpara 
ultravioleta permiten que el agua ingrese en estado inocuo a la pre-amasadora. La relación de proporcionalidad que existe entre el agua y la sémola son importantes para garantizar una presión constante en el proceso. En este sentido, para entender cuál es la a relación de agua y harina que se ingresa al sistema se muestra la siguiente ecuación.

$\mathrm{Pa}=\mathrm{Ph} *((\mathrm{Hf}-\mathrm{Hi}) /(100-\mathrm{Hf}))$

$\mathrm{Pa}=$ Peso del agua para adicionar $[\mathrm{Kg}]$ o [litros]

$\mathrm{Ph}=$ Peso de la harina $[\mathrm{Kg}]$

$\mathrm{Hi}=$ Humedad inicial de la harina [\%]

Hf $=$ Humedad final del amasado [\%]

La figura 20 muestra ambos sistemas de dosificación.

Figura 20: Sistema de dosificación de agua y sémola

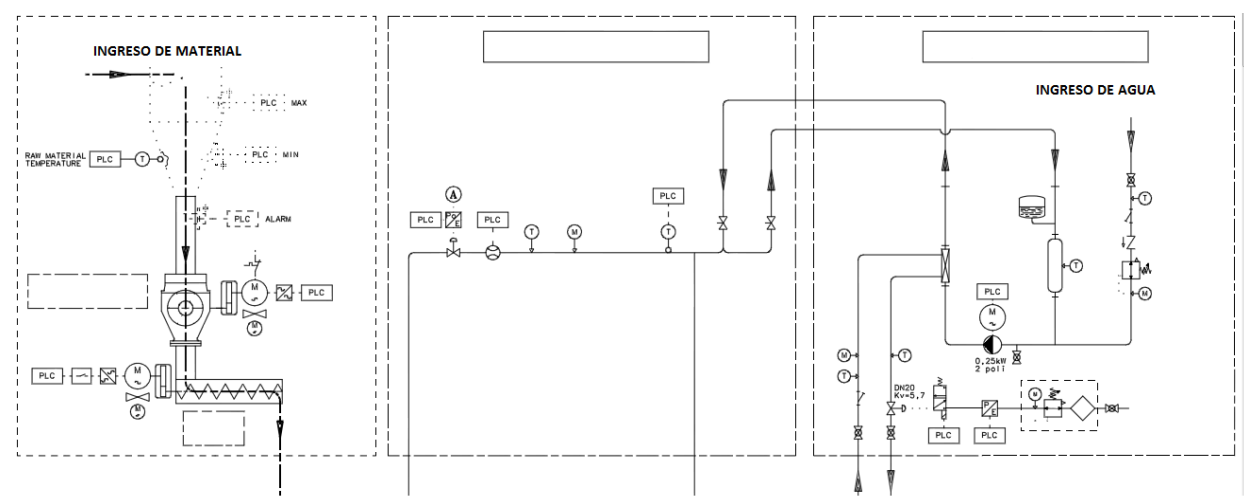

Fuente: La empresa

\section{Prensa}

El agua y la sémola ingresan a un pre-mezclador donde se homogeniza el producto para ser entregado a la mezcladora la cual se encuentra con una presión de vacío mayor - $670 \mathrm{mHg}$, por un periodo de 15 minutos avanza hasta llegar a la tina de distribución que permite alimentar a los tornillos de compresión. Estos presionan la pasta a través de un molde que permite dar la forma del producto. Las variables del proceso como la temperatura de amasado, presión de vacío, presión de compresión y nivel de producto están relacionados a 
el formato en proceso los cuales están definidos en una receta. Se puede visualizar en la figura 21 .

Figura 21: Prensa

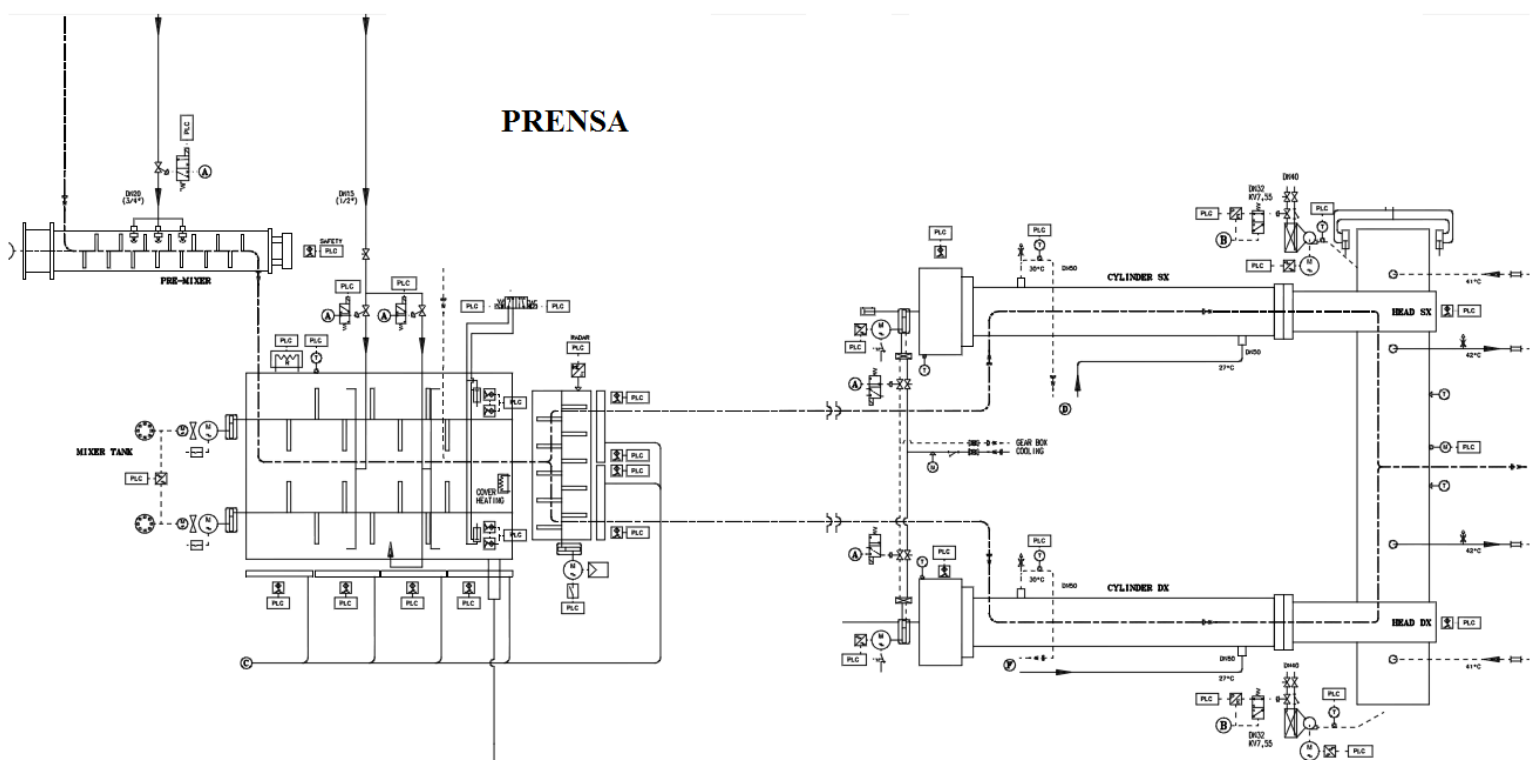

Fuente: La empresa

\section{Extendedor}

En esta etapa, que se muestra en la figura 22, el producto trefilado es colgado en cañas para ser transportado por las diferentes etapas de proceso, un sistema de corte uniformiza el tamaño. Los excedentes son retornados al proceso de mezclado a través de un triturador. 
Figura 22: Extendedor

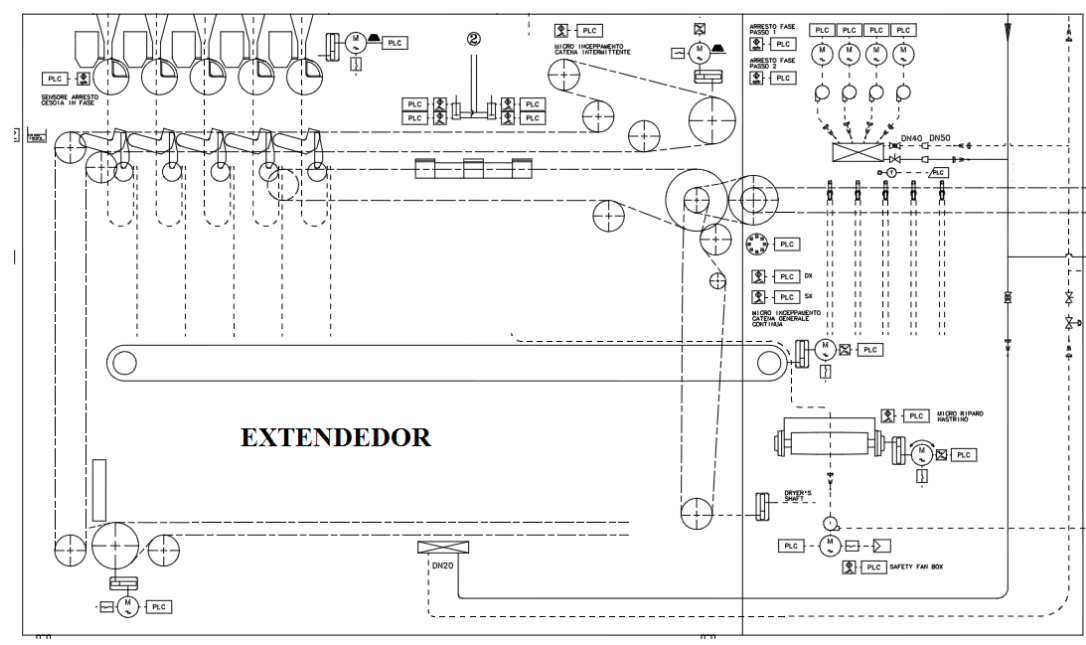

Fuente: La empresa

\section{Pre secado}

El pre secado es una etapa donde se extrae un $50 \%$ de la humedad. Las variables que se controlan para obtener este valor están relacionadas a la humedad, temperatura y velocidad. En consecuencia, la temperatura tiene una relación directa con la humedad y está se transfiere al producto a través de radiadores, la relación de estas dos variables y las curvas de secado obedece a un diagrama de secado específico que está determinado por el modelo del equipo, las características tecnológicas del proceso y las características de la máquina. En el caso mostrado se trata de un modelo de secador de procedencia italiana para procesos de líneas continuas. 
Figura 23: Diagrama de secado para pasta larga

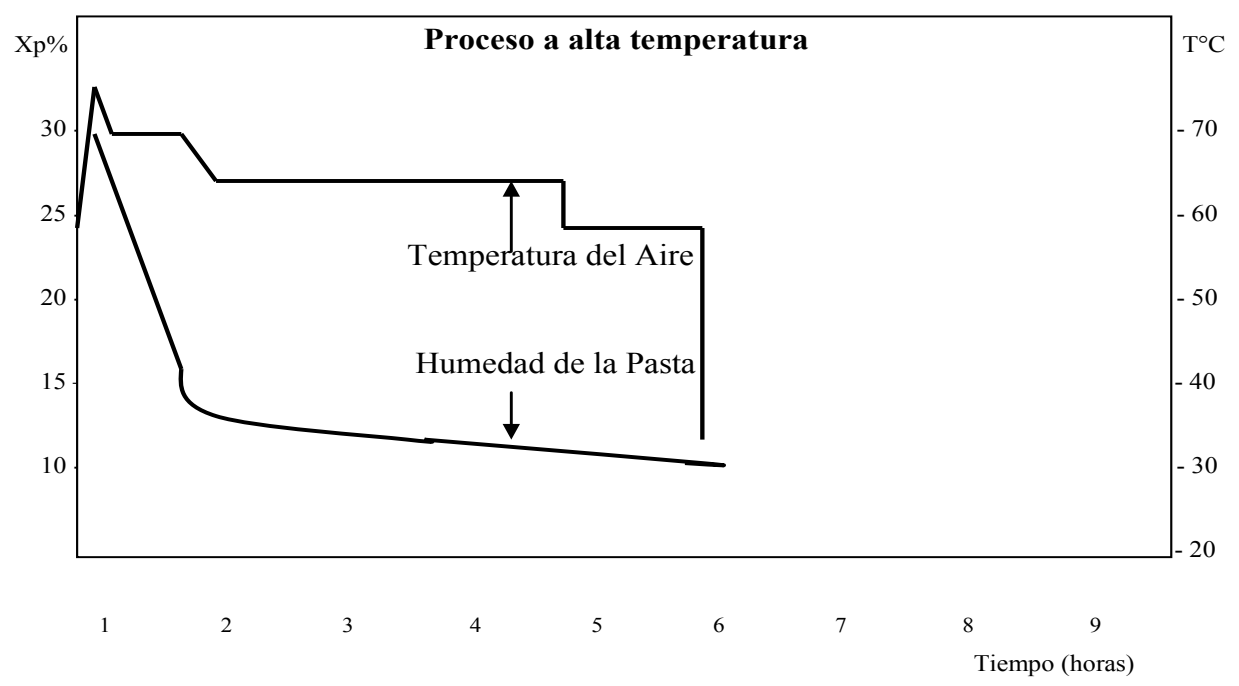

Fuente: Mondelli 2013

En la figura 23 se muestra el diagrama del secado, proporcionado por los fabricantes de plantas de proceso continuo, con curvas que indican los valores progresivos de la humedad de la pasta en relación con los parámetros del proceso, representados por la temperatura, humedad relativa y el tiempo del proceso. Estas condiciones de proceso se obtienen a través de sistemas automatizados y lazos de control de tipo cerrado como se muestra en la figura 24

Figura 24: Pre secado

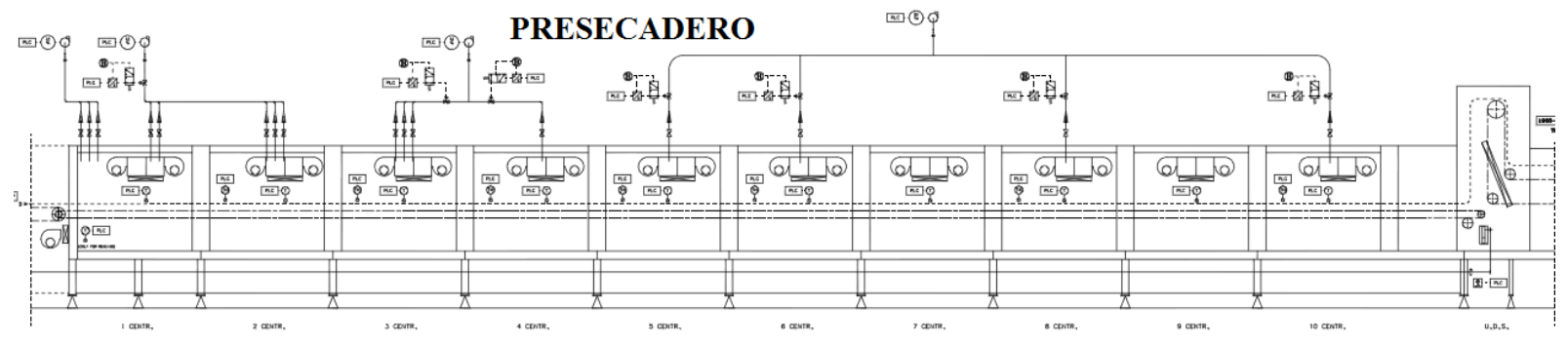

Fuente: La empresa 


\section{Secadero}

El secadero extrae 3\% más de la humedad total del producto como se observa en el gráfico 25 la temperatura del aire es cada vez menor. Por lo tanto, la humedad que se extrae disminuye. Los niveles de secado están determinados por la capacidad de producción para este caso se cuenta con 5 niveles de secado.

Figura 25: Secadero de 5 pisos

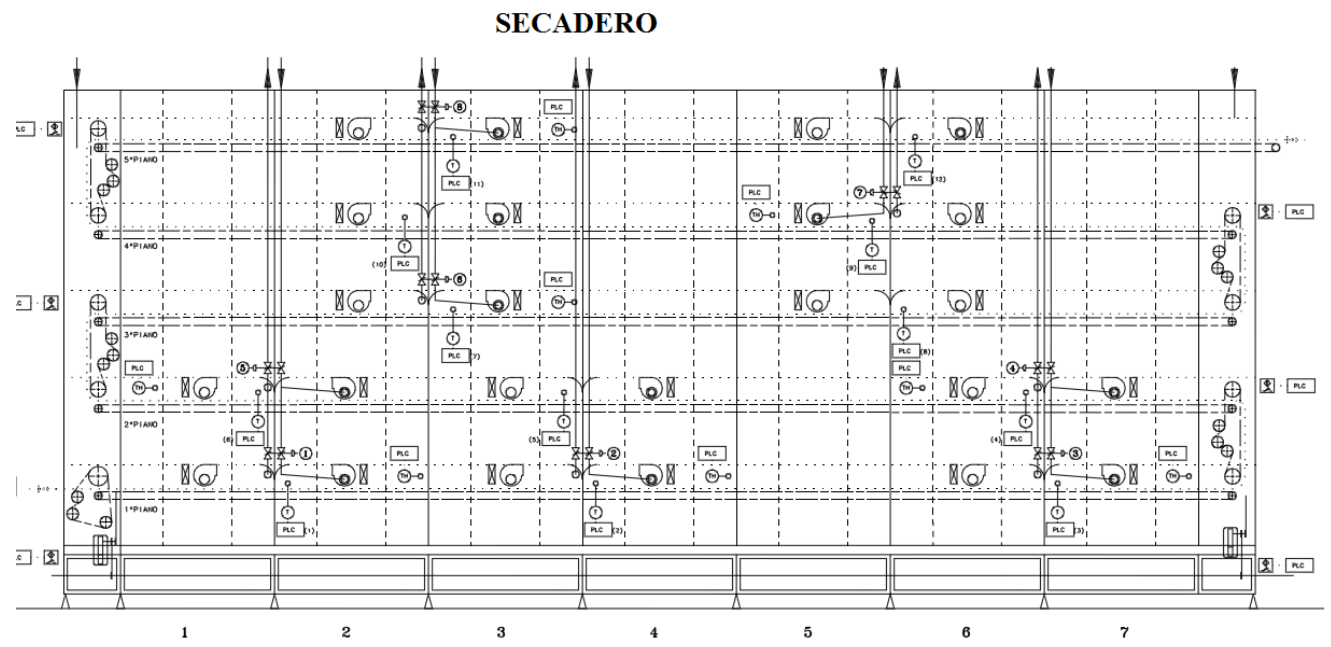

Fuente: La empresa

\section{Humidificador y enfriador}

El humidificador rocía a la pasta un baño de vapor de agua que es generado por un vaporizador de forma controlada y de acuerdo con valores especificados en la receta. Es decir, se agrega humedad al producto. El objetivo es estabilizar y permitir que la humedad se distribuya en forma uniforme. La siguiente etapa se encarga de enfriar el producto a una temperatura cercana a la del medio ambiente, este equipo cuenta con centrales de termorregulación alimentadas con un sistema de agua fría, figura 26. 
Figura 26: Humidificador y enfriador

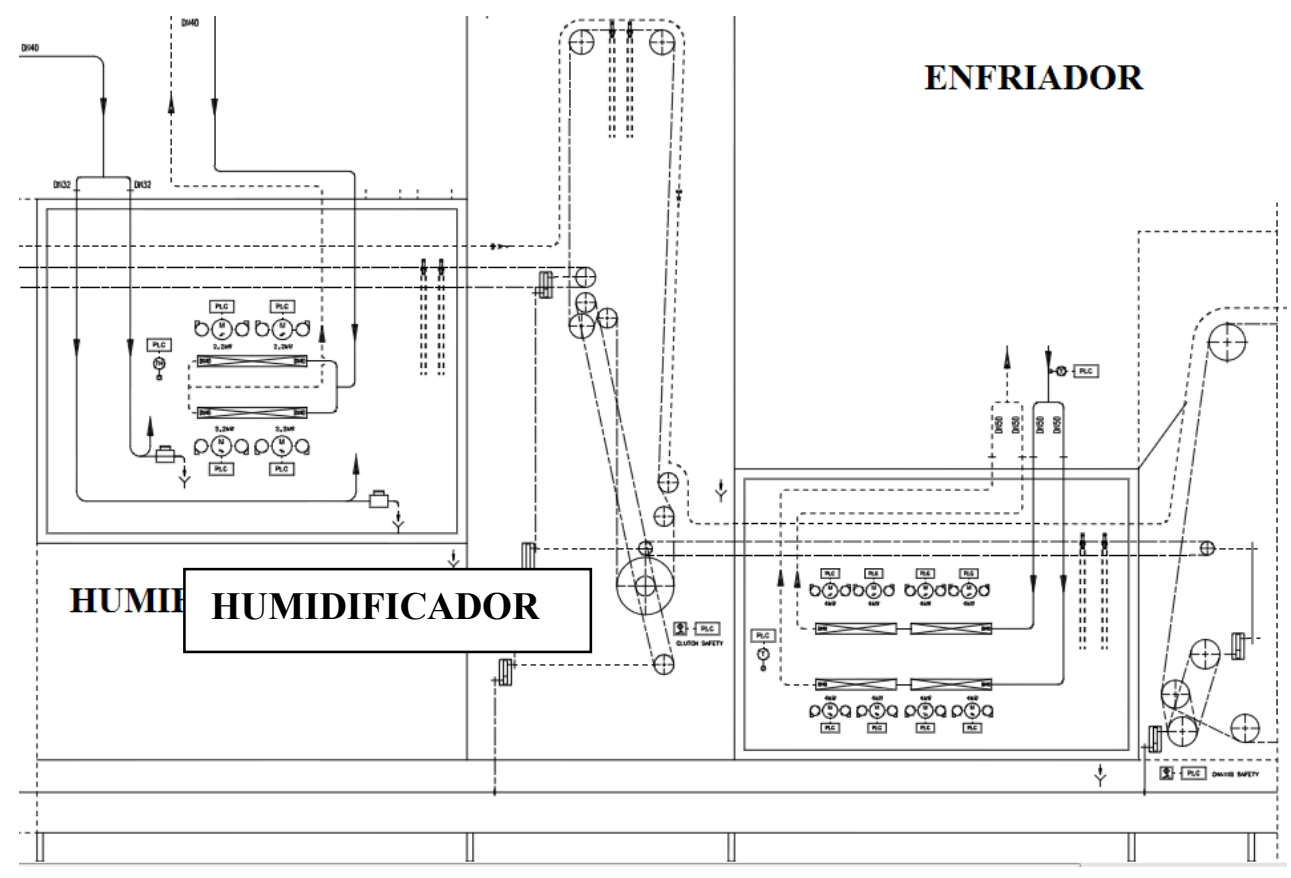

Fuente: La empresa

\section{Cortador}

El sistema de cortado divide la pasta en dos partes iguales y retira los extremos. De manera que, la pasta adquiere las dimensiones establecidas, luego se junta en un sistema de descarga y es enviado a través de elevadores hacia las envasadoras. Este sistema cuenta con tres cuchillas de corte que permiten retirar los extremos, el excedente es triturado y enviada hacia un silo de almacenamiento para su reproceso, figura 27. 
Figura 27: Sistema de corte

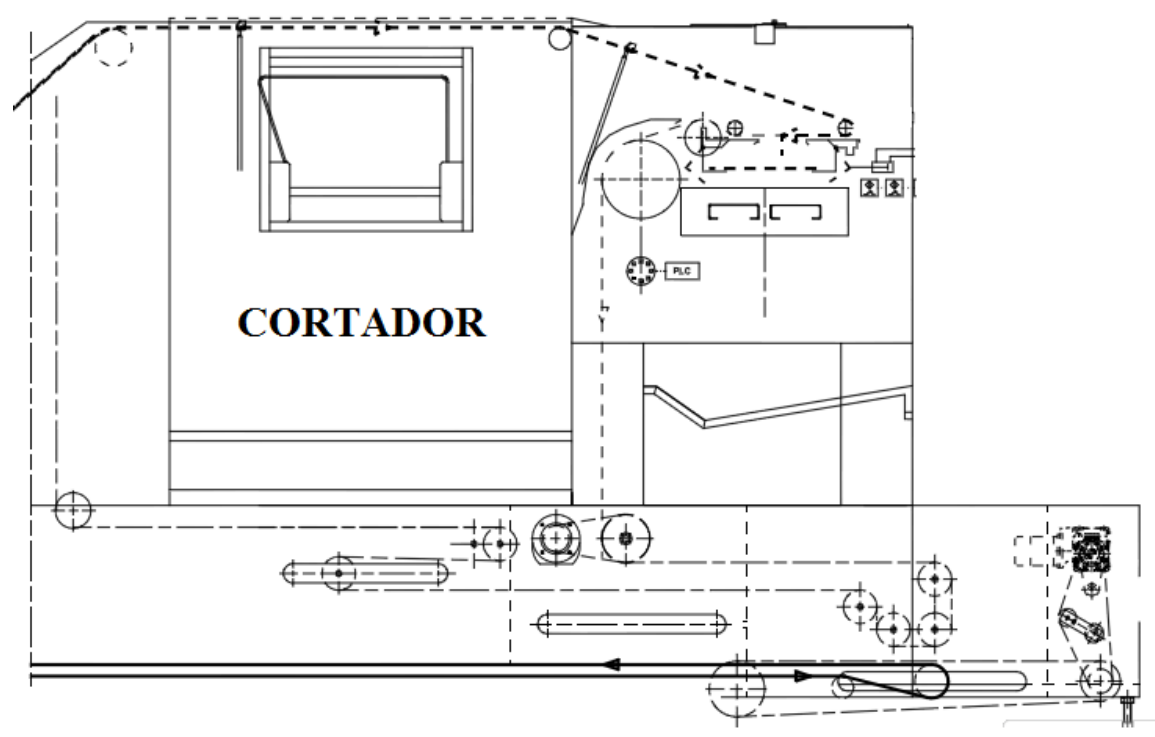

Fuente: La empresa

\section{Envasado}

El proceso de envasado se realiza con envasadoras automáticas que agregan el empaque primario y forman las unidades de acuerdo con la especificación de peso. Además, este proceso cuenta con sistemas que controlan el peso en línea y detectores de metal que rechazan aquellas unidades que no cumplen con las especificaciones.

\section{Enfardelado}

El enfardelado junta las unidades en grupos mayores y agrega un plástico termo contraíble que al pasar por un horno las fija formando una unidad mayor.

\section{Paletizado}

El proceso de paletizado consta en agrupar fardos sobre un pallet de madera. La cantidad de fardos a paletizar está definida por cada Stock-keeping unit o SKU (número de referencia). Una vez completado es embalado con stretch film y se codifica EAN (número de artículo europeo). Finalmente, es enviado al almacén de producto terminado para su distribución. 


\subsection{Determinación de la Problemática}

Para la determinación de la problemática del incumplimiento del programa de producción primero se explica cómo se interrelaciona el planeamiento de la demanda con la programación de la producción y luego se expone las consideraciones y los valores encontrados en tablas y gráficos.

\subsubsection{Planeamiento de la demanda}

Atender al mercado requiere un conocimiento integral de todos los procesos que interactúan en la cadena de suministro. En este sentido, la empresa dedica muchos recursos para realizar una adecuada gestión, el objetivo satisfacer las necesidades de los clientes, en la figura 28 se grafica la secuencia lógica.

- El proceso empieza con la gestión de los proveedores locales y del exterior.

- La gestión de compras tiene un área especializada encargada de realizar las compras locales e internacionales.

- La gestión de los almacenes de materias primas e insumos tienen el objetivo de garantizar la disponibilidad de los materiales.

- Producción es el área encarga de realizar la fabricación de los fideos y tiene como soporte el área de mantenimiento y calidad.

- La producción es almacenada de manera temporal en el almacén de producto terminado (APT)

- Los traslados internos se realizan a los centros de distribución.

- El centro de distribución consolida los pedidos nacionales e internacionales

- El transporte tiene el objetivo de realizar la distribución del fideo a las sucursales

- Las sucursales realizan la preparación de los pedidos de acuerdo con las necesidades de los clientes 
- Finalmente, la distribución del producto a los clientes en unidades menores

Figura 28: Cadena de suministro

\section{Cadena de Suministro}

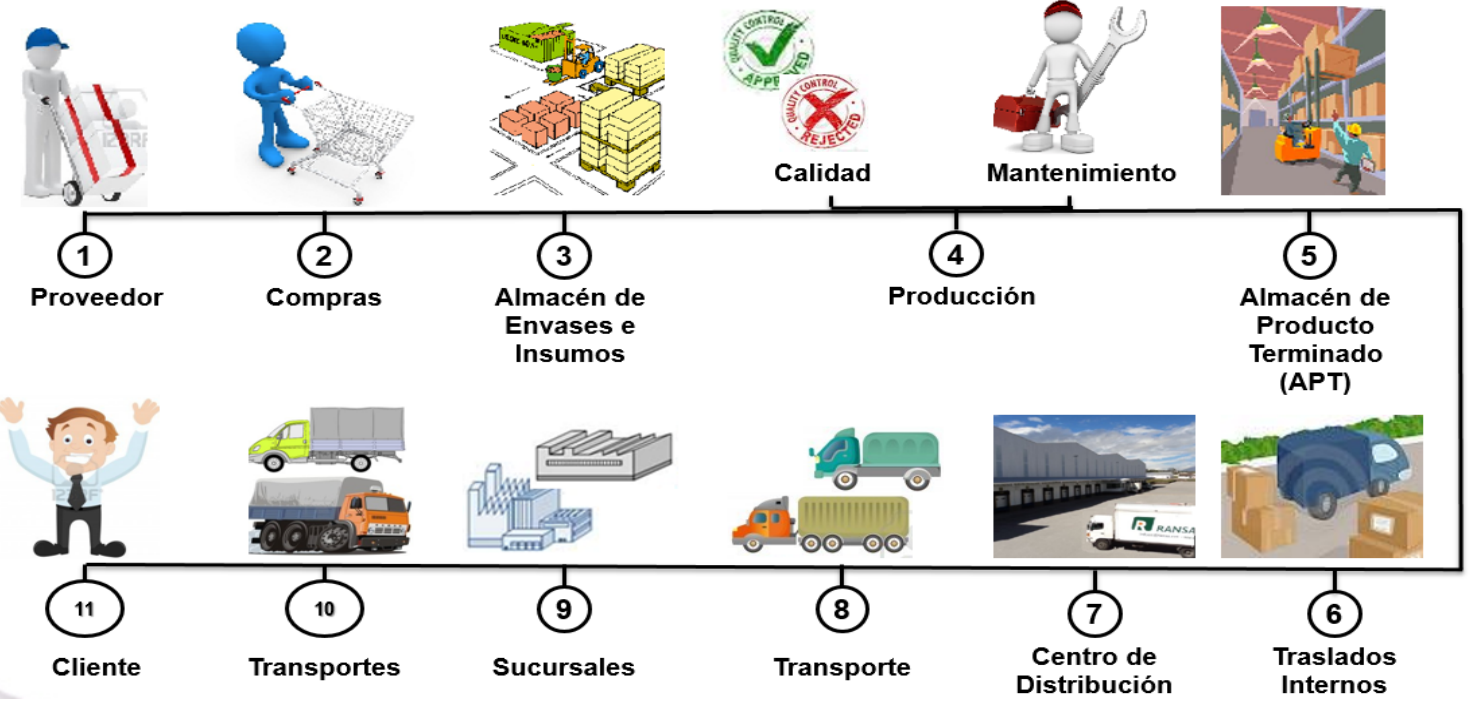

Fuente: La empresa

Asegurar la disponibilidad de los productos para atender los requerimientos de los clientes optimizando los costos productivos logísticos y financieros requiere de una estrategia organizacional del planeamiento de la demanda. El planeamiento integrado que a desarrollado la organizaciòn aplica a todas las unidades de negocio se muestra en la figura 29. En primer lugar, el nivel estrategico se toma encuenta los planes del negocio, evalua las capacidades de las plantas y los planes de inversion. En segundo lugar, en el nivel tactico se realiza la planificacion y cordinacion esta enfocado en gestionar proactivamente potenciales problemas evaluando continuamente los factores dinamicos. Finalmente, el nivel operativo aterriza en la ejecucion de contratos semanales y un programa diario de la produccion.

Figura 29: Planeamiento Integrado 


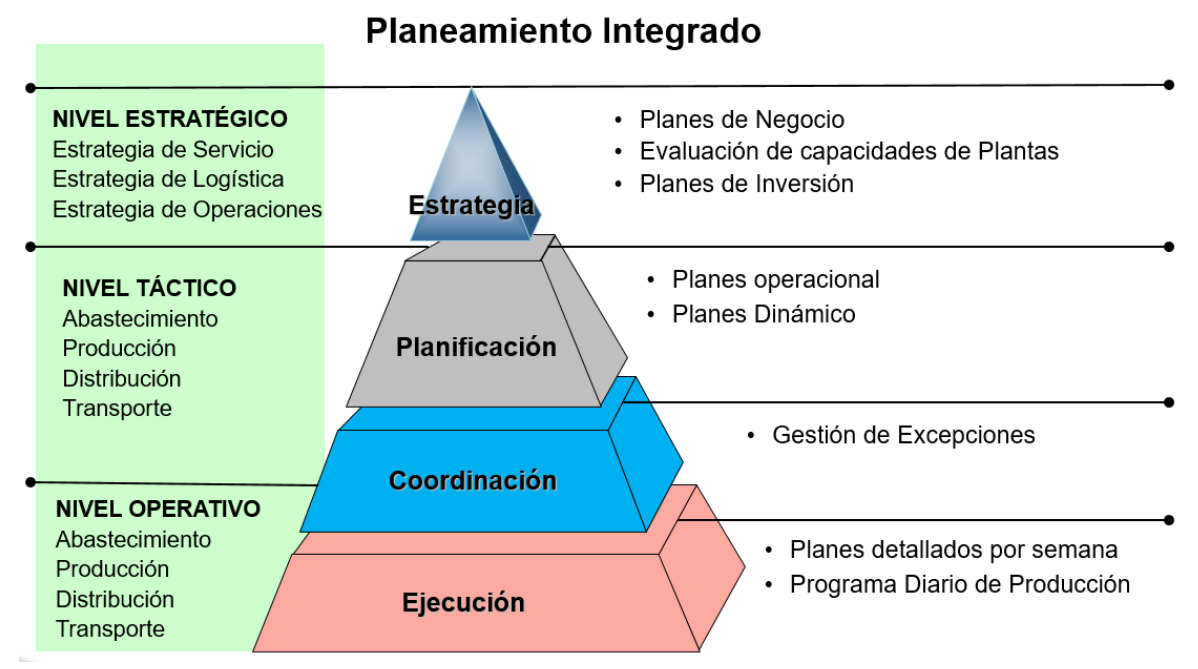

Fuente: La empresa

Para realizar una adecuado pronostico de la demanda la organizaciòn cuenta con sistema informatico que le ayudan a evaluar la información cuantitativa. Además, se toma en consideración los sucesos o eventos que pueden afectar este calculo. En la figura 30 se grafica la interrelacion entre la información.

Figura 30: Interrelación de la información

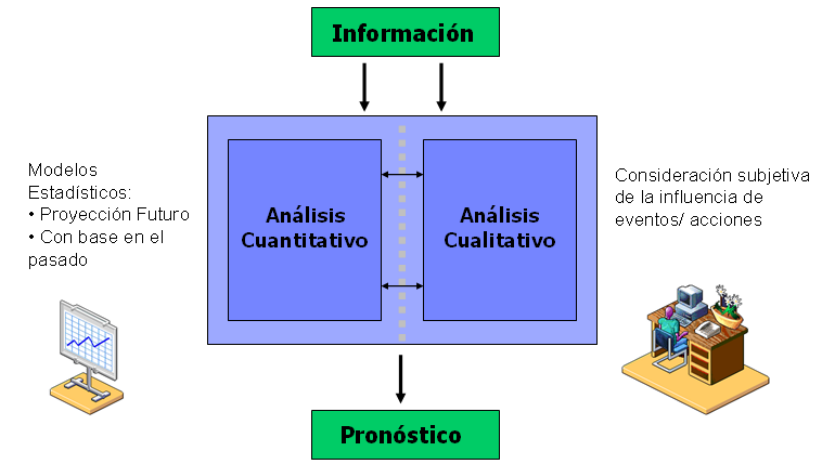

Fuente: La empresa

El análisis cuantitativo esta soportado bajo sistemas de información SAP SCM - DP (Demand Planning) y SNP (Supply Network Planning) que analizan los datos maestros y los transaccionales de la cadena en la figura 31 se muestra el proceso.

Figura 31: Proceso Supply Network Planning 


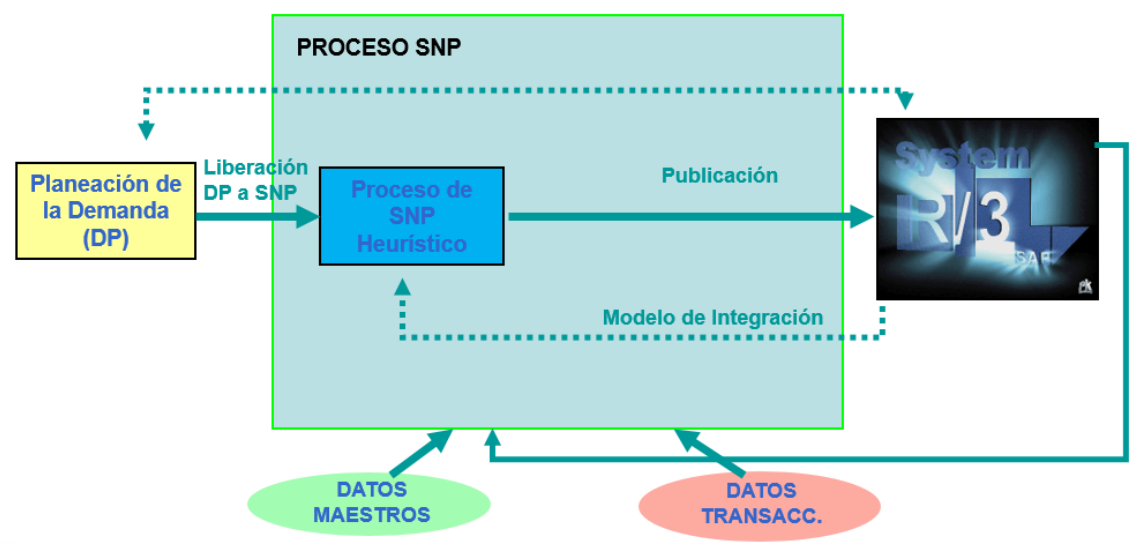

Fuente: La empresa

El proceso de la planificacion empieza cuando se corre el sistema SMC - DP este pronostico se revisa y se adapta de acuerdo a las actividades comerciales esta informacion es revisada por los gerentes zonales que llegan a un consenso de los planes de venta, los gerentes de marca del area de marketing revisan estos datos y se agenda la reunion de demanda el resultado es el plan de ventas inicial, la canfirmacion del plan de ventas se da cuando se recive la retro alimentacion de finanzas esta informacion se ingresa al SNP que genera el plan de distribucion de produccion mensual y semanal que asu vez genera el plan de abastecimientos en la figura 32 se muestra el proceso total del planeamiento. 
Figura 32: Proceso total del planeamiento

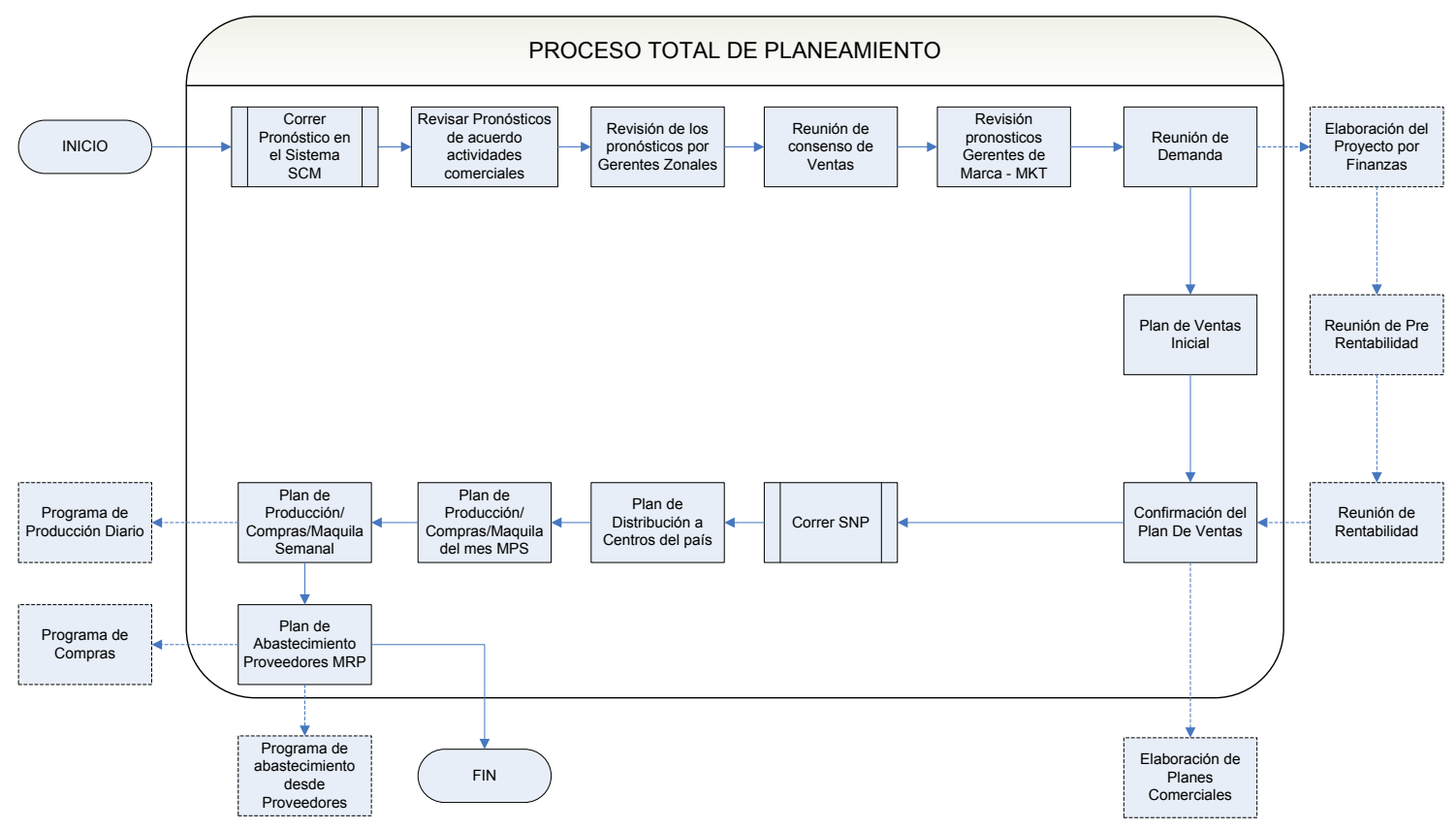

Fuente: La empresa

La función del planeamiento de la demanda se ha asignado a un planificador y su ámbito de acción es la interacción con las diferentes áreas y procesos para realizar un plan de producción acorde con requerimientos como las materias primas, insumos, capacidades de planta, transporte, etc. En la figura 33 se muestra el planeamiento integral

Figura 33: Planeamiento integral de la demanda

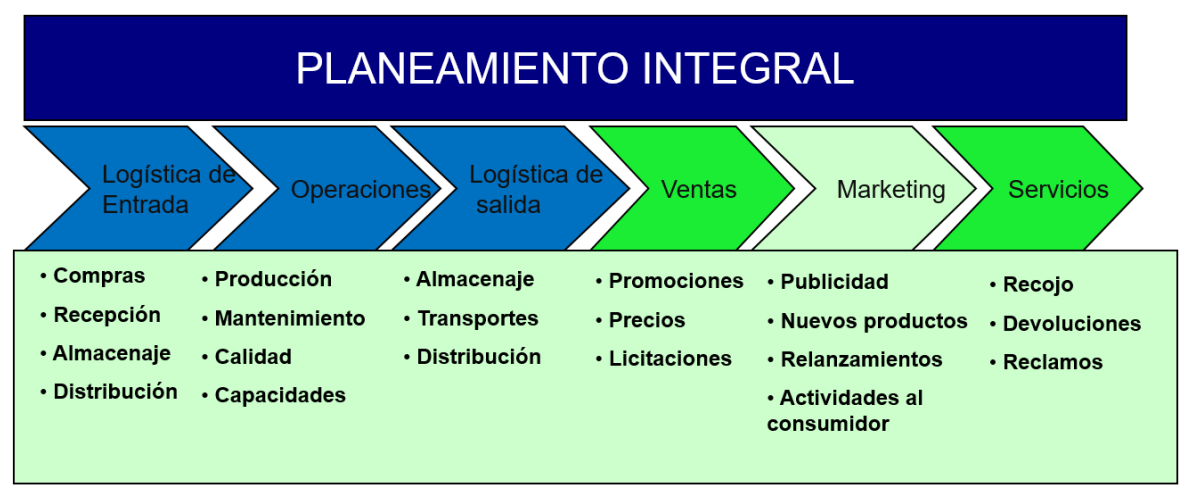

Fuente: La empresa 
El planificador para ejecutar esta labor tiene procedimientos y un proceso a seguir para realizar el plan de producción representado en la figura 34, el proceso de elaboración del plan de producción empieza con la revisión en la primera semana del mes de los planes de venta a nivel nacional y región, el mismo debe ser validada por DP , luego se corre el proceso de planeamiento de suministro SNP en base a los requerimientos del producto terminado, si es correcto se valida el plan a nivel SKU en su defecto se realizara el traspaso de planes a SNP, se validan el cierre de órdenes de fabricación anteriores para evitar duplicidad se corre el proceso SAP/SNP que genera el plan de producción estos valores se ajustan por excepciones de capacidad de producción se valida la razonabilidad de los días giro de producto terminado al cierre de mes se carga el plan de producción ajustado al SAP/SNP se actualiza el plan maestro de producción MPS para insumos y producto en proceso HALB se confirma la disponibilidad de los materiales si es correcto se genera el plan de producción en su defecto se realizaran los ajustes por excepciones. El programa puede cambiarse de acuerdo con el avance de la demanda. Estos cambios se comunican al equipo involucrado para su aplicación. Si afecta a la disponibilidad de productos para la venta se informa además al área comercial. En la siguiente figura se muestra el proceso.

Figura 34: Proceso de elaboración del plan de producción 


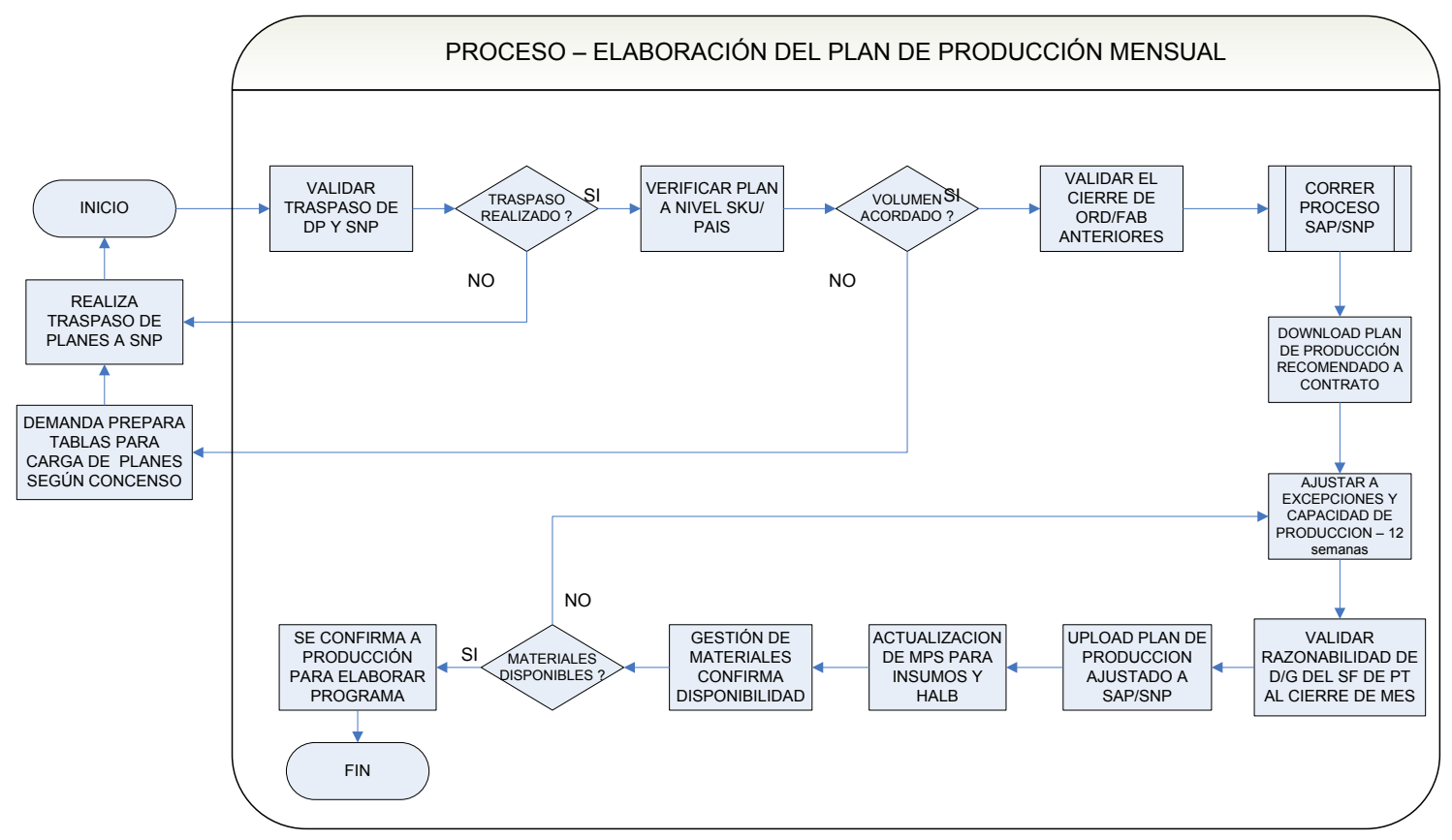

Fuente: La empresa

En conclusión, El área de Planeamiento Industrial después de procesar toda esta información y siguiendo los procesos antes descritos genera el pronóstico de la demanda, es importante mencionar que considera los diferentes factores del horizonte de la planificación, niveles de inventario, pronóstico de ventas, capacidad de producción, materiales. Por consiguiente, planifica la producción de los diferentes SKU en forma semanal y es entregado al área de producción, un contrato establece la conformidad de todas las áreas para el cumplimiento.

\subsubsection{Preparación ejecución y cumplimiento del programa de producción}

El Controlador de Producción elabora el programa de producción, la preparación se realiza de acuerdo con el contrato semanal basada en la información alcanzada por planeamiento a los pedidos eventuales de ventas, a los niveles de inventarios, a la capacidad de producción, a la disposición de recursos, a las paradas por limpieza y mantenimiento. Se genera la 
plantilla en Excel para el llenado de la producción por la línea de producción, variedad y cantidad en toneladas. Esta planificación se envía vía por correo electrónico a los responsables de Producción, Planeamiento, Almacenes, Desarrollo Pastas y Molino, con ello, queda establecida la confirmación de la elaboración del programa de producción, la cantidad de pallets necesarios y el requerimiento de materia prima, para la ejecución respectiva del programa de producción.

El Jefe de Producción o Coordinador de Producción determinará el cambio de variedad de fideo y la paralización de las líneas, según lo considerado en el programa de producción. Las modificaciones en el programa de producción cambio de secuencias, nuevos ingresos o retiros de productos dentro del programa sólo pueden ser realizadas por el controlador de Producción. Se considera el inicio de la programación de la producción desde la prensa y termina el programa en el mismo lugar con la finalidad de mantener un ciclo de programación.

El Controlador de producción realiza la verificación del cumplimiento diario, semanal y mensual del volumen de producción. Semanalmente el Controlador de Producción realiza la comparación entre lo programado y lo ingresado en el sistema de gestión informático a través de las órdenes de producción. Los incumplimientos en el programa semanal de producción son evaluados entre el Controlador y el Planificador de Producción para realizar su reprogramación respectiva.

\subsubsection{Metodología de estimación del proceso productivo}

La planta cuenta con 9 líneas de proceso con una capacidad instalada de 35 toneladas por hora, cada línea de proceso tiene una capacidad productiva diferente la que es afectada por el formato en proceso. Quiere decir, que la variedad productos que se procesan tienen 
diferentes rendimientos los cuales se encuentran previamente definidos de acuerdo con estadísticas productivas. Esta información es tomada como referencia para calcular la producción, además intervienen las siguientes variables porcentaje de producto no conforme, reproceso. El resultado de esta estimación asigna el tiempo productivo para cada línea y formato en proceso.

\section{Cumplimiento eficaz del programa de producción}

El cumplimiento eficaz del programa de producción es un indicador que permite medir si la producción se ha realizado en el tiempo y oportunidad de acuerdo con el contrato establecido. La métrica es el \% de cumplimiento de fabricación de los diferentes SKU programados por semana con las siguientes condiciones. Si la fabricación de los diferentes productos se encuentra dentro del $90 \%$ a $110 \%$ del volumen planificado se considera $100 \%$ de cumplimiento. Por el contrario, si la producción no se realizó o se encuentra fuera de este rango se considera $0 \%$ de cumplimiento. Por lo tanto, el porcentaje cumplimento eficaz de la producción es igual la sumatoria de todos los SKU cumplidos entre la sumatoria de los SKU programados.

El cumplimiento eficaz del programa de producción acumulado para el año 2013 fue de $49 \%$ y para el 2014 un valor de $46 \%$ con un decremento de 3\%, estos valores son los más bajos de la organización en comparación con las diferentes plantas productivas de otras categorías que tienen valores mayores al 65\%. El mejor cumplimiento se presentó en el mes de diciembre de 2014 con un 59\% y el mes que tuvo el peor cumplimiento el mes de abril con 28\%. En la figura 35 se muestra los resultados del año 2014.

Figura 35: Eficacia del cumplimiento de la producción 


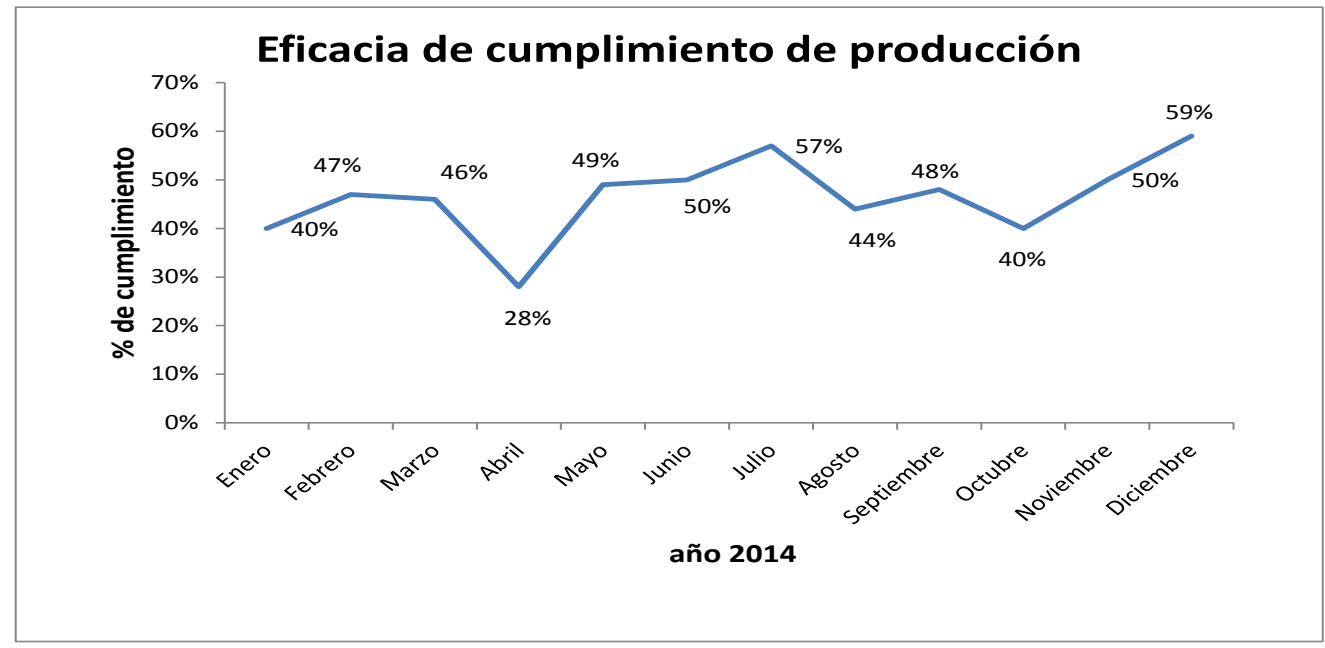

Fuente: Elaboración propia basado en la información de la empresa

El nivel de cumplimiento de entrega de producto al cliente se mide con indicador llamado

Fill Rate para la categoría de pastas fue de 90.84\%. En términos económico esta falta de atención al mercado se traduce que la compañía en el periodo 2014 perdió la oportunidad de vender USD \$ 6546996 a causa de no atender el mercado en oportunidad.

\section{Eficiencia global de los equipos}

La medición de Eficiencia General de los Equipos (OEE) de una planta de producción es un método de medición que permite evaluar el performance productivo, donde integra datos de disponibilidad, eficiencia y calidad. La figura 36 muestra los resultados para el año 2014. 
Figura 36: Eficiencia General de los Equipos

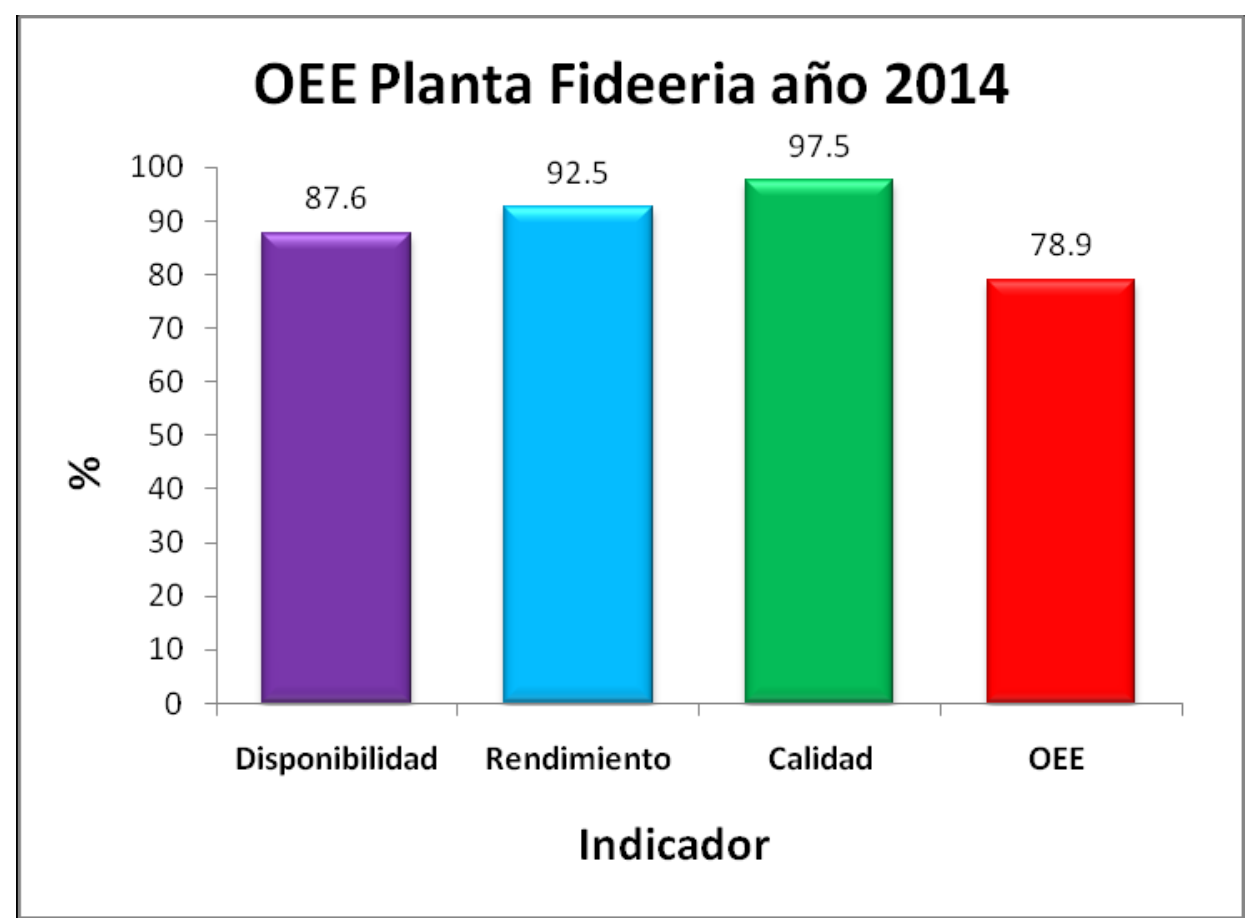

Fuente: Elaboración propia basado en la información de la empresa

La OEE se ve afectada por el deterioro de los factores, de los cuales se puede mencionar fallas de equipo, mantenimiento prolongado, cambios de formato, limpieza de línea, falta de materia prima, producto no conforme, disminución de la capacidad de los equipos de producción.

\section{Tasa de Disponibilidad}

La disponibilidad de los equipos para el periodo 2014 fue de $87.6 \%$ este indicador agrupa los diferentes motivos por los cuales la maquina no se encuentra en producción, el mantenimiento, falla de equipos, mantenimiento programado, paradas imprevistas, limpieza, etc. Es decir, evalúa el tiempo de producción entre el tiempo disponible.

$\underline{\text { Tasa de Rendimiento }}$ 
El rendimiento de las líneas de proceso se ve afectado por diferentes motivos la falta de estandarización, fallas de equipos, falta de capacitación en el personal, cambios de formato excesivos, falta de productividad en el personal y subutilización de los equipos por problemas de mantenibilidad. Uno de los efectos más comunes por las causas antes mencionadas es la disminución de velocidad. Una consecuencia de disminuir la velocidad del proceso se refleja en la perdida de humedad del producto, que termina con un \% humedad relativa por debajo del objetivo de proceso, en el año 2014 solo se llegó al $92.5 \%$ de rendimiento.

\section{$\underline{\text { Tasa de Calidad }}$}

La tasa de calidad un indicador importante en una organización porque refleja la gestión de las áreas de producción, mantenimiento, logística, compras. El resultado para el periodo 2014 se muestra en la figura 37.

Figura 37: Producto No Conforme

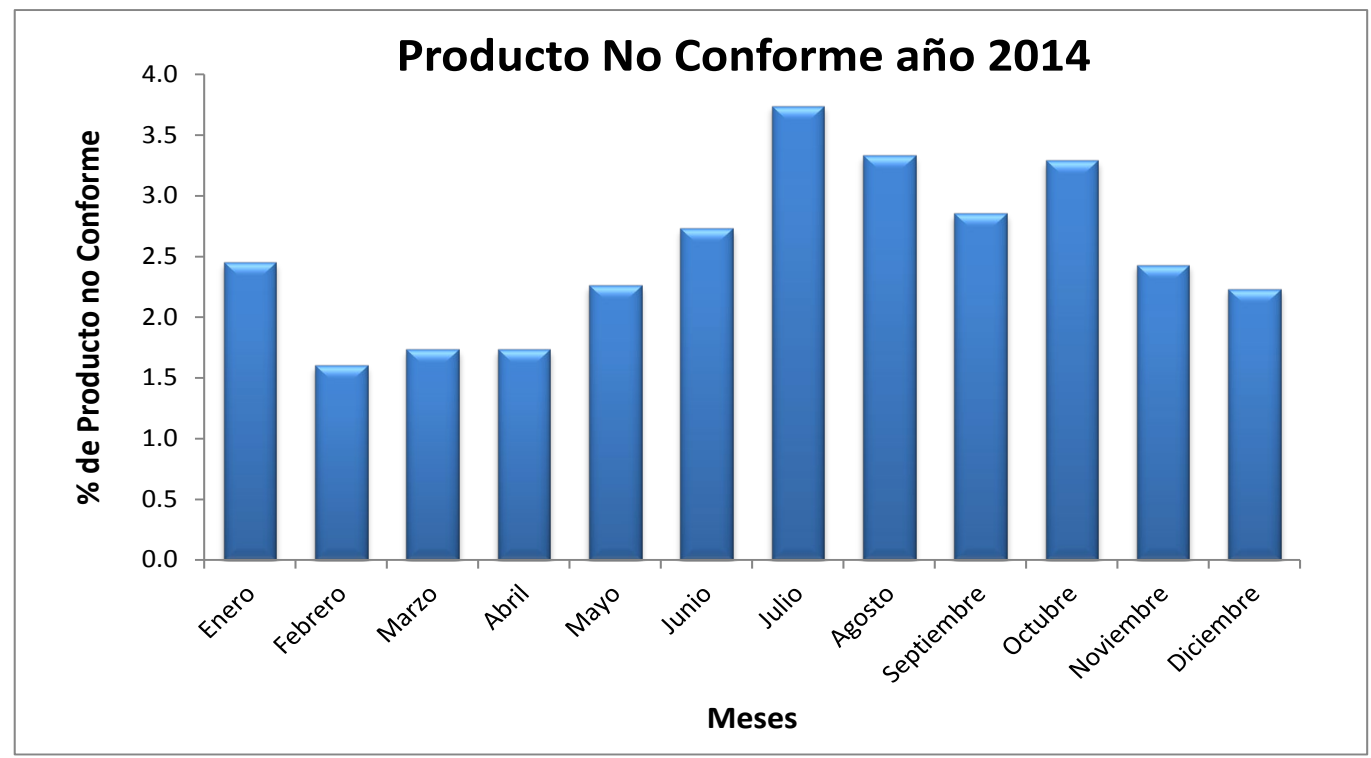


Fuente: Elaboración propia basado en la información de la empresa

Se observa un deterioro importante a partir del mes de mayo, el incremento de los valores del producto no conforme aumenta la incertidumbre en la estimación del tiempo de proceso. Además, de aumentar los costos productivos.

\subsection{Determinación de causas}

\subsubsection{Diagrama de Ishikawa}

Esta herramienta grafica representa las posibles causas raíces del problema de incumplimiento del programa de producción al enfocarse en los diferentes aspectos que interactúan en el problema. En consecuencia, previo a la elaboración del diagrama Ishikawa se realizó una lluvia de ideas con el equipo que participa en el proceso productivo con una idea clara, perseguir la causa raíz basándose exclusivamente en hechos y sin emitir juicios a las personas. En la figura 38 se muestra el diagrama de Ishikawa, diagrama causa-efecto con las causas más importantes. Los diferentes aspectos son analizados en orden de mayor a menor relevancia, para luego ser analizados de manera cuantitativa.

Método. - Producir la cantidad solicitada está estrechamente relacionada a la forma como se calcula las horas productivas. El error de estimación es un problema común por que las variables de cálculo son dinámicas, al no existir un método adecuado se genera errores que obliga al personal realizar cambios no programados.

Máquina. - Los equipos presentan fallas que reducen la capacidad o paran el proceso además si falta alguno de los servicios industriales la producción se detiene.

Mano de obra. - La planta por el nivel de automatización el recurso humano es reducido las actividades se priorizan y se enfocan más en el control del proceso. 
Materiales. - La falta de materia prima e insumos es una consecuencia que se genera por las desviaciones productivas.

Medio Ambiente. - Las Instalaciones tienes las dimensiones necesarias para la operación, sin embargo, producir SKU's no planificados genera ocupación de ubicaciones de almacenamiento externo.

\subsubsection{Análisis de árbol de falla FTA}

En la figura 39 se muestra el análisis de identificación de causas directas e indirectas que afecten el cumplimiento del programa de producción. Las principales causas directas son: el rendimiento de la máquina, los productos defectuosos, la indisponibilidad de la máquina y los errores de estimación de materiales para fabricar el volumen de producción requerido. El rendimiento de la máquina es afectado por la baja y alta velocidad, debido a falta de estándares, metodología y factor personal. La indisponibilidad es afectada por las fallas ya sean eléctricas o mecánicas, y también por los mantenimientos prolongados por razones logísticas. Los errores de estimación son afectados principalmente por el factor humano y falta de metodologías de estandarización. 
Figura 38: Diagrama de Ishikawa de la eficiencia del cumplimiento de la producción

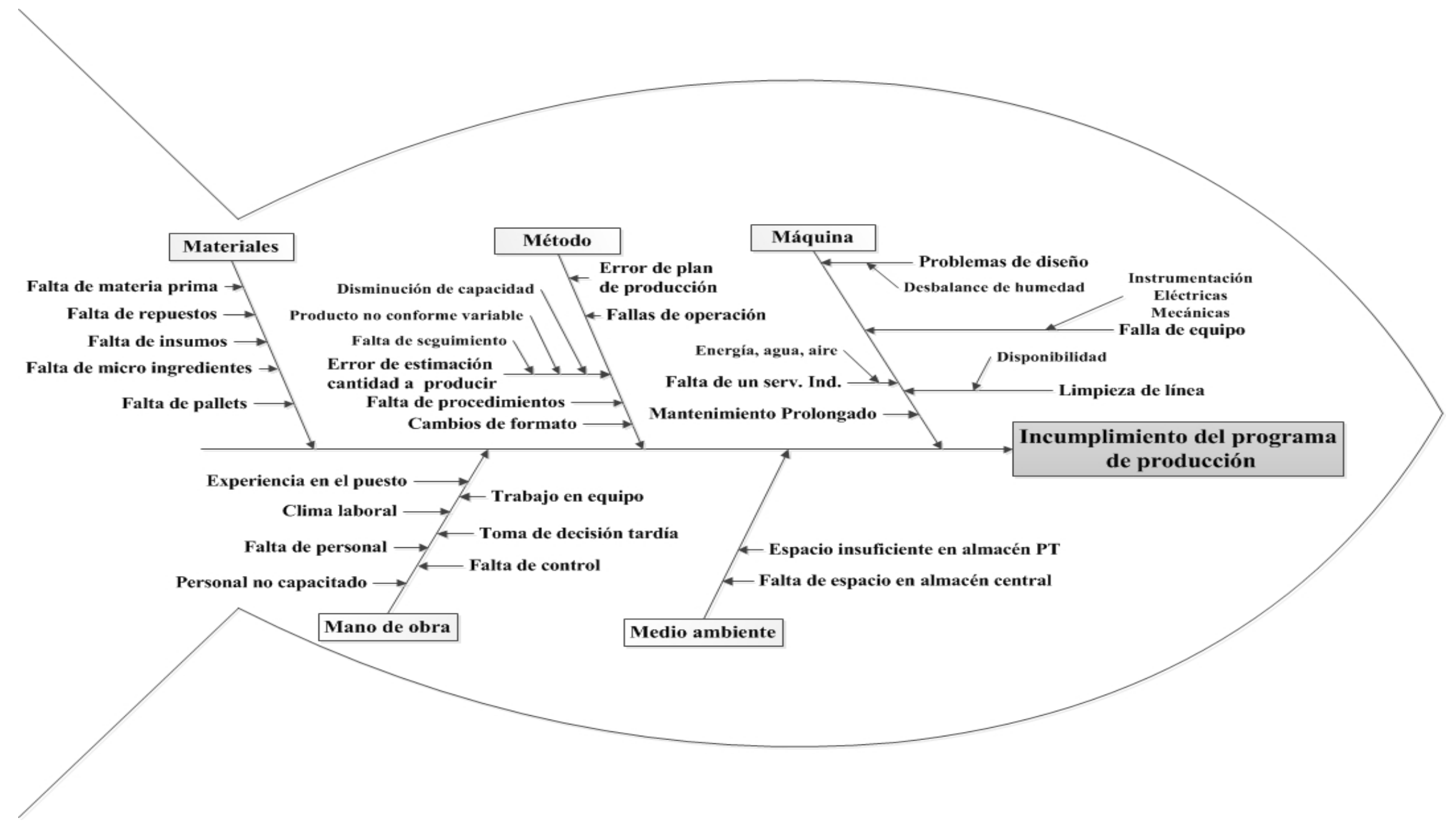

Fuente: Elaboración propia basado en la información de la empresa 
Figura 39: FTA Incumplimiento del programa de producción

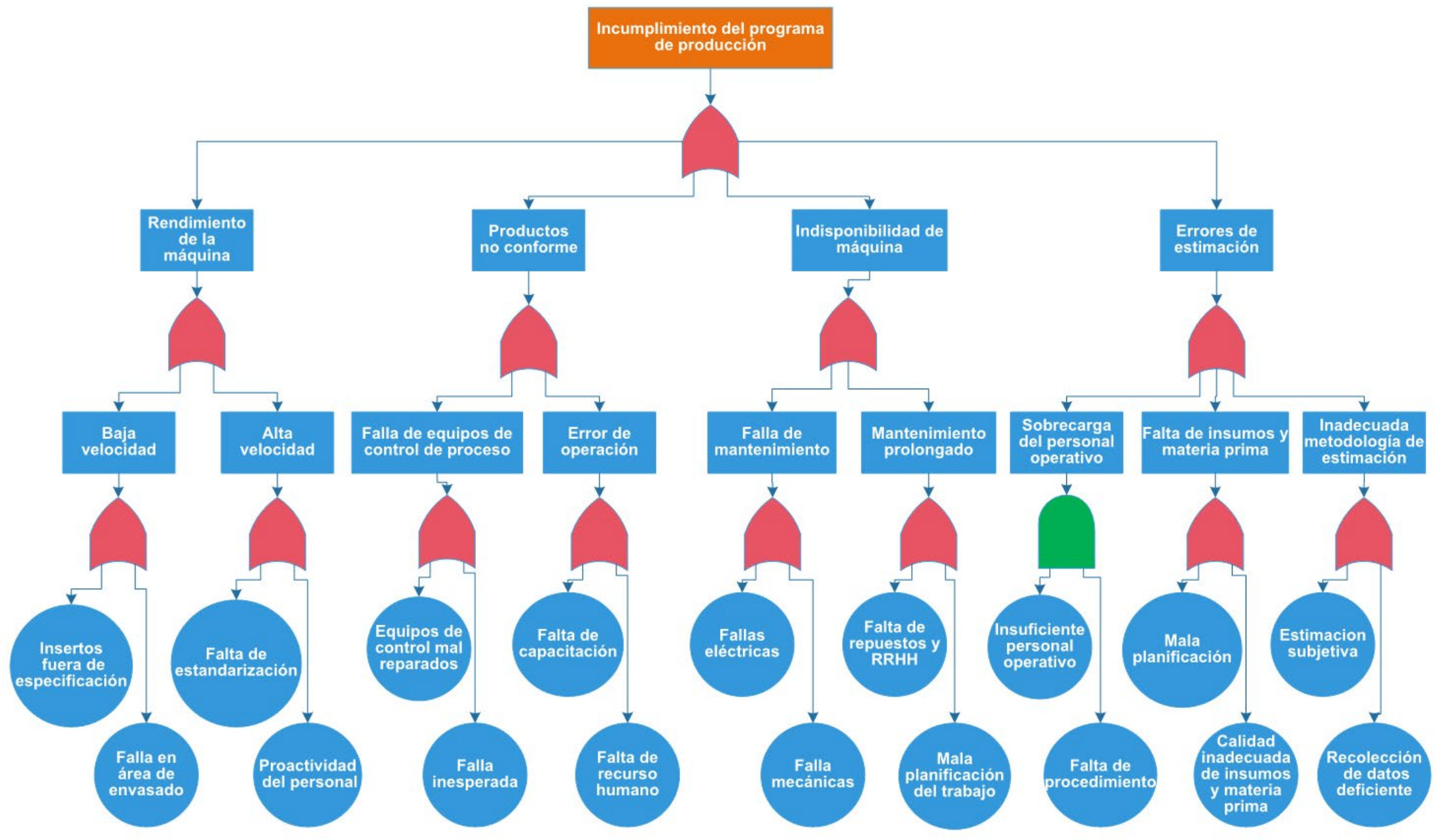

Fuente: Elaboración propia basado en la información de la empresa 


\subsubsection{Diagrama de Pareto}

La producción para el periodo del 2014 fue de 169,894 toneladas, se programaron 1,883

SKU de los cuales 868 fueron fabricados dentro los rangos establecidos lo que representa el $46 \%$ de cumplimiento eficaz. Por lo tanto, el $54 \%$ de la producción no cumple debido a exceso de producción, defecto y falta de producción. En el siguiente cuadro se enumeran la participación de las áreas involucradas del no cumplimiento del programa de producción, figura 40 .

Figura 40: Problemas por áreas que ocasionan el no cumplimiento de la producción

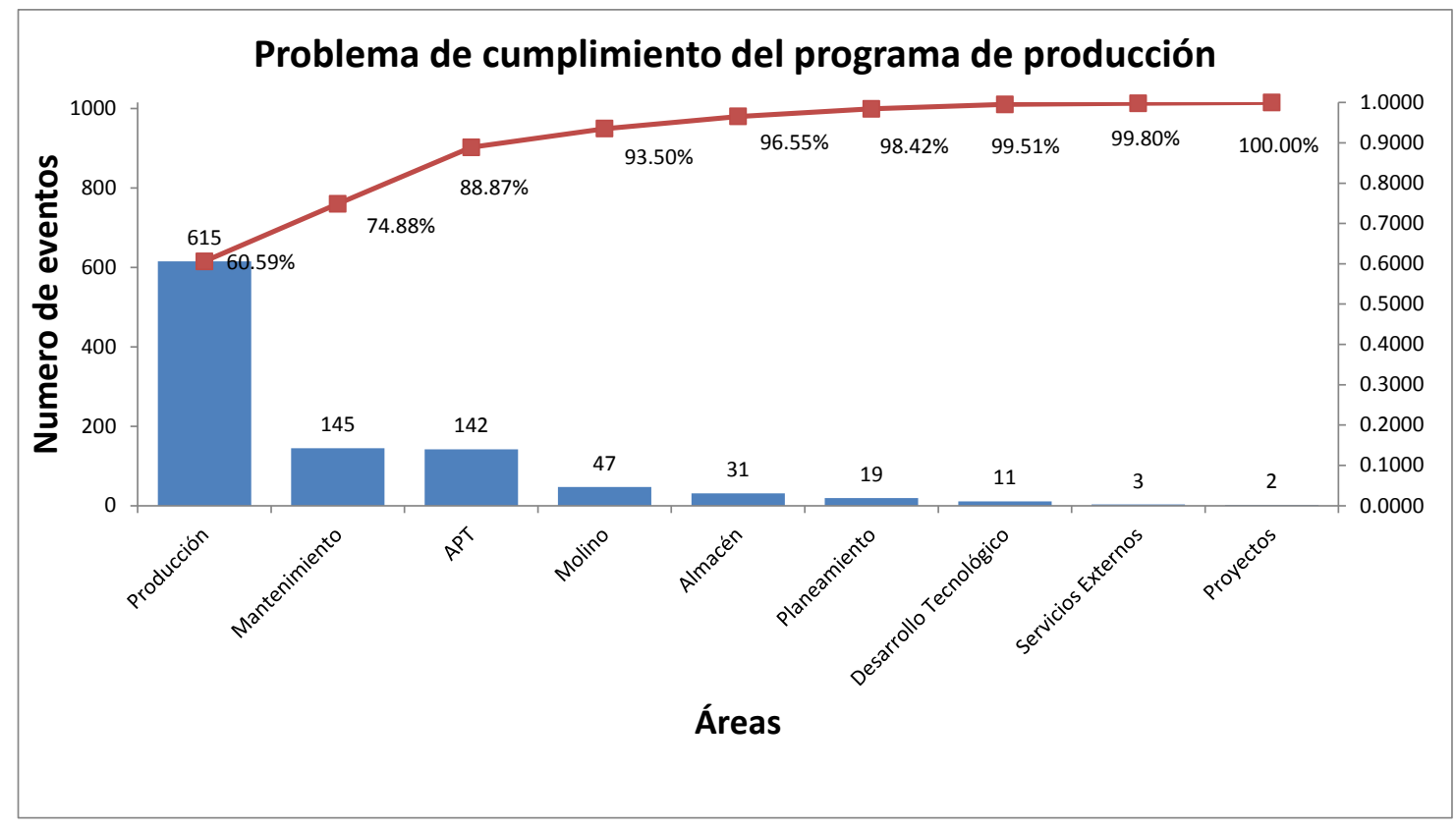

Fuente: Elaboración propia basado en la información de la empresa

En el cuadro se observa que el $88.87 \%$ de los problemas están asociadas a tres áreas del proceso productivo Producción, Mantenimiento y Almacén de Producto Terminado (APT). La principal área donde se encuentran los problemas es producción que representa el $60.59 \%$. 
El área producción es la que se encarga de gestionar el proceso productivo, el no haber podido no cumplir con el programa se debe a diferentes causas que se representan en la figura 41 .

Figura 41: Factores de que afectan el cumplimiento de la producción

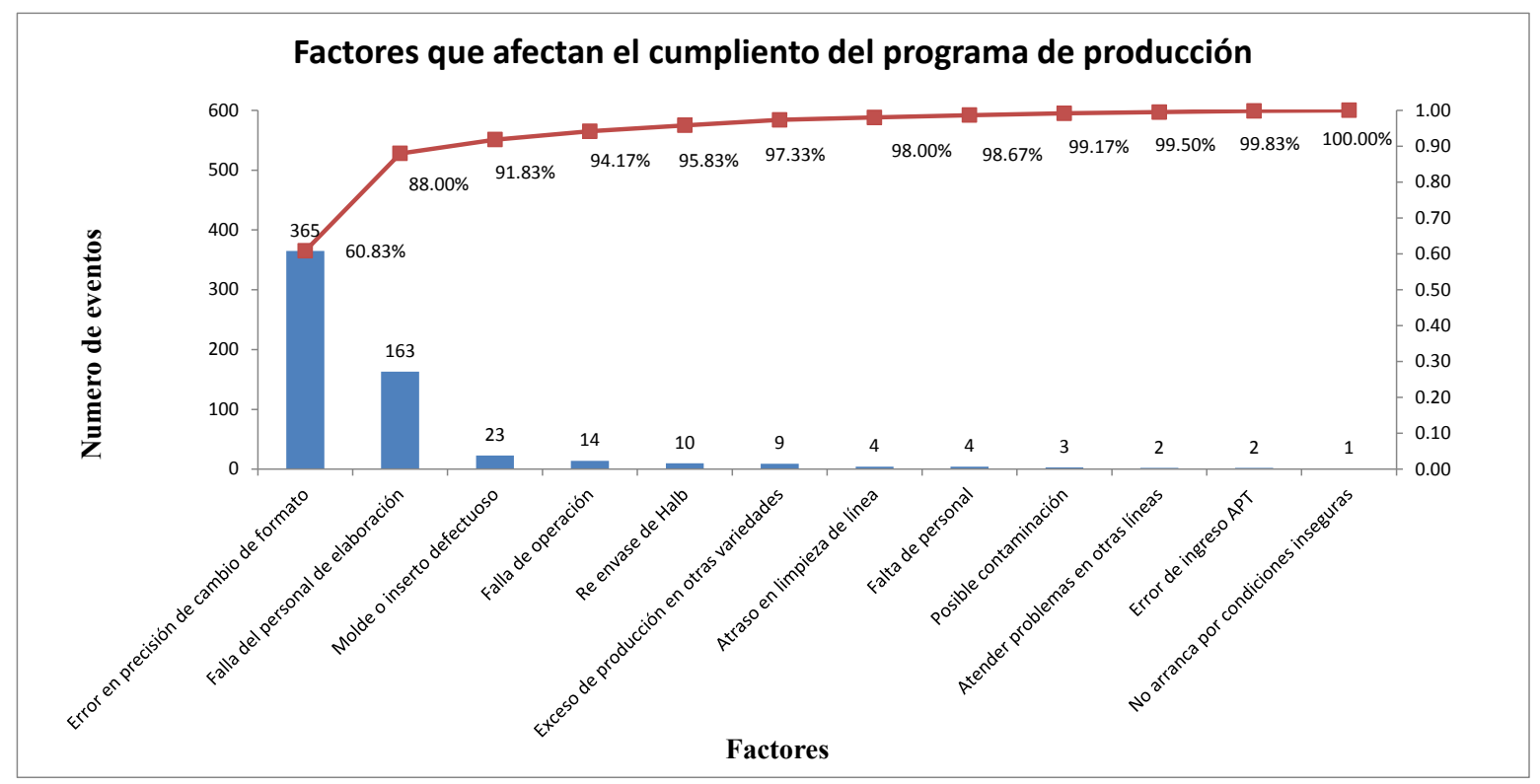

Fuente: Elaboración propia basado en la información de la empresa

En el grafico se observa que el $88 \%$ de los problemas se encuentra en las siguientes causas error de precisión de cambio de formato y fallas del personal de producción. La metodología utilizada sumada al personal reducido que gestiona el proceso no permite mejorar este indicador. El indicador de cumplimiento eficaz de la producción evalúa tres situaciones productivas exceso, déficit, cumplimiento.

\subsubsection{Histograma}

Analizar las diferentes situaciones productivas permitirá plantear soluciones adecuadas. En el siguiente grafico se muestra la producción de un mes de trabajo donde se evalúa los SKU 
programados y las toneladas producidas. Producir más de lo planificado genera sobre costos por almacenamiento y transporte, además, le quita oportunidad de proceso a otro formato. Por el contrario, el déficit ocasiona ventas perdidas, figura 42.

Figura 42: Distribución del porcentaje de cumplimiento por SKU

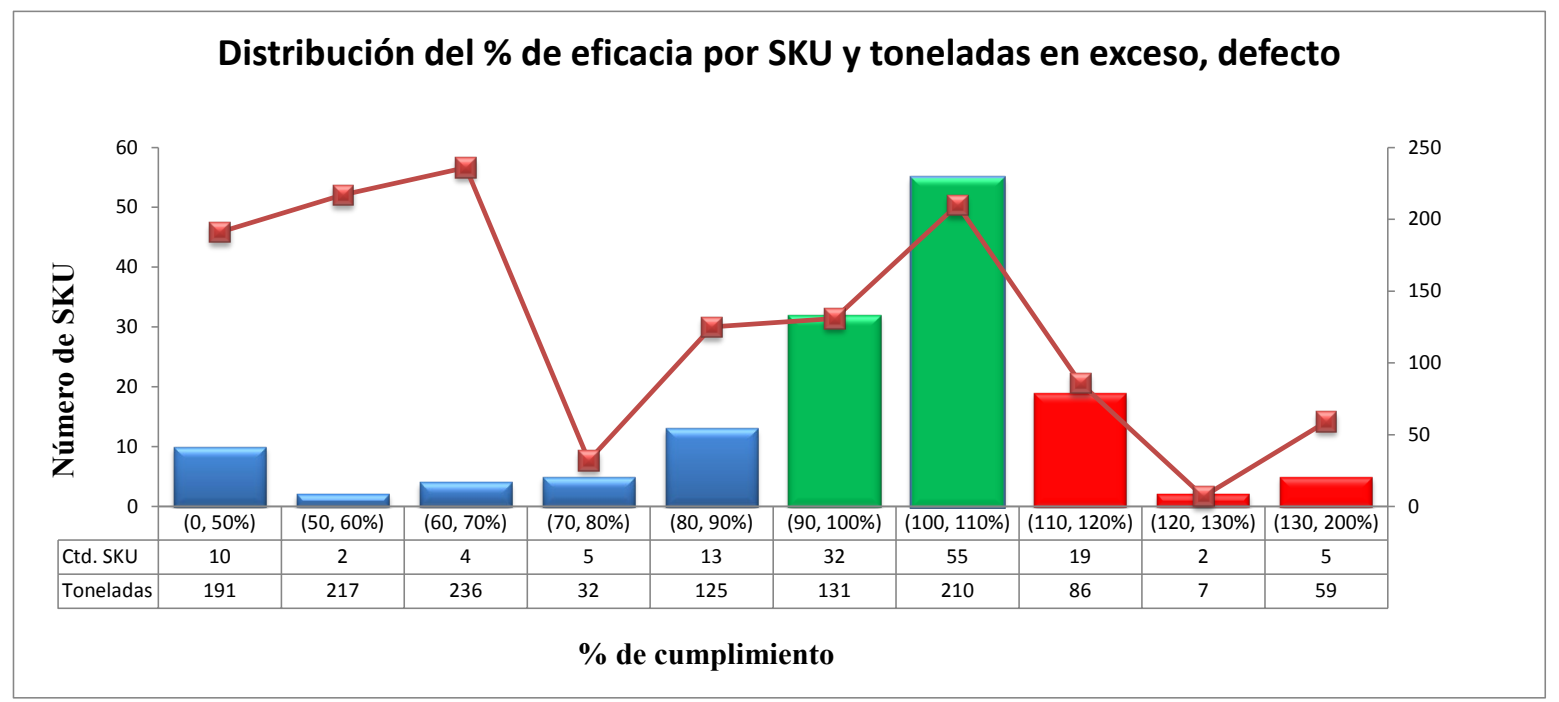

Fuente: Elaboración propia basado en la información de la empresa

Se programaron para un mes de trabajo 147 SKU de los cuales 34 se encuentran con un déficit de producción, 87 se cumplieron y 26 se encuentran con sobre producción. Desde la perspectiva de cantidad se ha producido 801 toneladas con déficit, 152 toneladas dentro de los límites del indicador y 341 toneladas con exceso. Las consecuencias de estas desviaciones generan el incremento del stock, mayor número de posiciones de almacenamiento, mayor costo financiero y estresan la cadena de suministro. En ese sentido, las herramientas de la metodología Lean Manufacturing serán las más adecuadas para optimizar las operaciones del proceso de fabricación de fideos.

\subsection{Análisis de la capacidad del proceso}

Un análisis de la capacidad productiva nos permitirá evaluar si la problemática de la falta de cumplimiento del eficaz del programa de producción se debe a una equivocada 
estimación de las capacidades en la siguiente tabla N ${ }^{\circ} 4$ se presenta una muestra de los datos recolectados de un año productivo.

Tabla 4: Distribución del porcentaje de cumplimiento por SKU

\begin{tabular}{|c|c|c|c|c|c|c|c|c|c|}
\hline \multicolumn{10}{|c|}{ Año 2014} \\
\hline \multirow[b]{2}{*}{ Semana } & \multicolumn{3}{|c|}{ Toneladas } & \multirow{2}{*}{$\begin{array}{c}\text { Cumplimiento } \\
\text { Real/Contrato } \\
\text { semanal }\end{array}$} & \multirow{2}{*}{$\begin{array}{c}\text { Horas } \\
\text { perdidas }\end{array}$} & \multirow{2}{*}{$\begin{array}{l}\text { Toneladas } \\
\text { perdidas }\end{array}$} & \multirow{2}{*}{$\begin{array}{c}\text { SKU } \\
\text { CUMPLIDOS }\end{array}$} & \multirow{2}{*}{$\begin{array}{c}\text { SKU } \\
\text { PROGRAMADOS }\end{array}$} & \multirow{2}{*}{$\begin{array}{c}\text { Eficacia de la } \\
\text { Producción }\end{array}$} \\
\hline & MPS & $\begin{array}{l}\text { Contratos } \\
\text { semanales }\end{array}$ & Real & & & & & & \\
\hline Semana 1 & 9501 & 1434 & 1506.77 & $105.1 \%$ & 20.29 & 23.5 & 5 & 14 & $35.7 \%$ \\
\hline Semana 2 & 9501 & 2008 & 1984.93 & $98.9 \%$ & 33.11 & 100.4 & 13 & 26 & $50.0 \%$ \\
\hline Semana 3 & 9501 & 2016 & $\begin{array}{l}1487.42 \\
\end{array}$ & $73.8 \%$ & 31.32 & 528.6 & 13 & 36 & $36.1 \%$ \\
\hline Semana 4 & 9501 & 2518 & 1751.83 & $69.6 \%$ & 85.72 & 766.2 & 11 & 37 & $29.7 \%$ \\
\hline Semana 5 & 9501 & 1467.78 & 1343.53 & $91.5 \%$ & 109.99 & 146.6 & 12 & 22 & $54.5 \%$ \\
\hline Semana 6 & 9870 & 2686 & 2337.72 & $87.0 \%$ & 96.23 & 367.5 & 25 & 40 & $62.5 \%$ \\
\hline Semana 7 & 9870 & 2378 & 2321.29 & $97.6 \%$ & 48.68 & 91.7 & 18 & 35 & $51.4 \%$ \\
\hline Semana 8 & 9870 & 2600 & 2105.25 & $81.0 \%$ & 173.87 & 512.0 & 17 & 36 & $47.2 \%$ \\
\hline Semana 9 & 9870 & 2189 & 1869.26 & $85.4 \%$ & 39.83 & 332.7 & 9 & 30 & $30.0 \%$ \\
\hline Semana 10 & 9945 & 2575 & 1965.09 & $76.3 \%$ & 236.37 & 609.9 & 14 & 37 & $37.8 \%$ \\
\hline . & …........... & ….......... & …........... & .............. & ….......... & …........... & …........... & .............. & . \\
\hline Semana 40 & 14732 & 3046 & 3013.27 & $98.9 \%$ & 97.49 & 58.5 & 20 & 34 & $58.8 \%$ \\
\hline Semana 41 & 14732 & 2690 & 2105.23 & $78.3 \%$ & 106.26 & 616.2 & 13 & 50 & $26.0 \%$ \\
\hline Semana 42 & 14732 & 3531 & 2717.38 & $77.0 \%$ & 46.5 & 836.6 & 17 & 60 & $28.3 \%$ \\
\hline Semana 43 & 14732 & 3407 & 3025.65 & $88.8 \%$ & 34.52 & 436.4 & 19 & 51 & $37.3 \%$ \\
\hline Semana 44 & 14732 & 2542 & 2383.33 & $93.8 \%$ & 11.43 & 195.6 & 24 & 40 & $60.0 \%$ \\
\hline Semana 45 & 13514 & 3214 & 3050.26 & $94.9 \%$ & 39.06 & 226.6 & 24 & 44 & $54.5 \%$ \\
\hline Semana 46 & 13514 & 3667 & 3217.31 & $87.7 \%$ & \begin{tabular}{l|}
181.22 \\
\end{tabular} & 562.9 & 14 & 44 & $31.8 \%$ \\
\hline Semana 47 & 13514 & 3618 & 3217.56 & $88.9 \%$ & 74.42 & 400.4 & 26 & 50 & $52.0 \%$ \\
\hline Semana 48 & 13514 & 3623 & 3661.58 & $101.1 \%$ & 49 & 22.4 & 30 & 51 & $58.8 \%$ \\
\hline Semana 49 & 12533 & 3466 & 3654.30 & $105.4 \%$ & 74.12 & 71.4 & 33 & 49 & $67.3 \%$ \\
\hline Semana 50 & 12533 & 2913 & 2803.52 & $96.2 \%$ & 145.64 & 242.1 & 22 & 37 & $59.5 \%$ \\
\hline Semana 51 & 12533 & 2913 & 2803.52 & $96.2 \%$ & 145.64 & 242.1 & 22 & 37 & $59.5 \%$ \\
\hline Semana 52 & 12533 & 1848 & 1672.57 & $90.5 \%$ & \begin{tabular}{l|}
146.07 \\
\end{tabular} & 234.9 & 9 & 20 & $45.0 \%$ \\
\hline
\end{tabular}

Fuente: Elaboración propia basado en la información de la empresa

Al realizar una evaluación entre la capacidad productiva de toneladas programadas versus las producidas podemos ver que existen valores de hasta $105 \%$ esto quiere decir las capacidades están bien definidas y el incumplimiento de la eficacia de la producción se debe a otros factores. En este sentido, analizaremos la capacidad productiva. En la figura 43 se muestra la evaluación de intervalos de tolerancia a un nivel de confianza del 95\% para determinar los límites de control inferior y superior, estos datos se utilizarán en el análisis de capacidad del proceso.

Figura 43: Gráfica de intervalos de tolerancia 


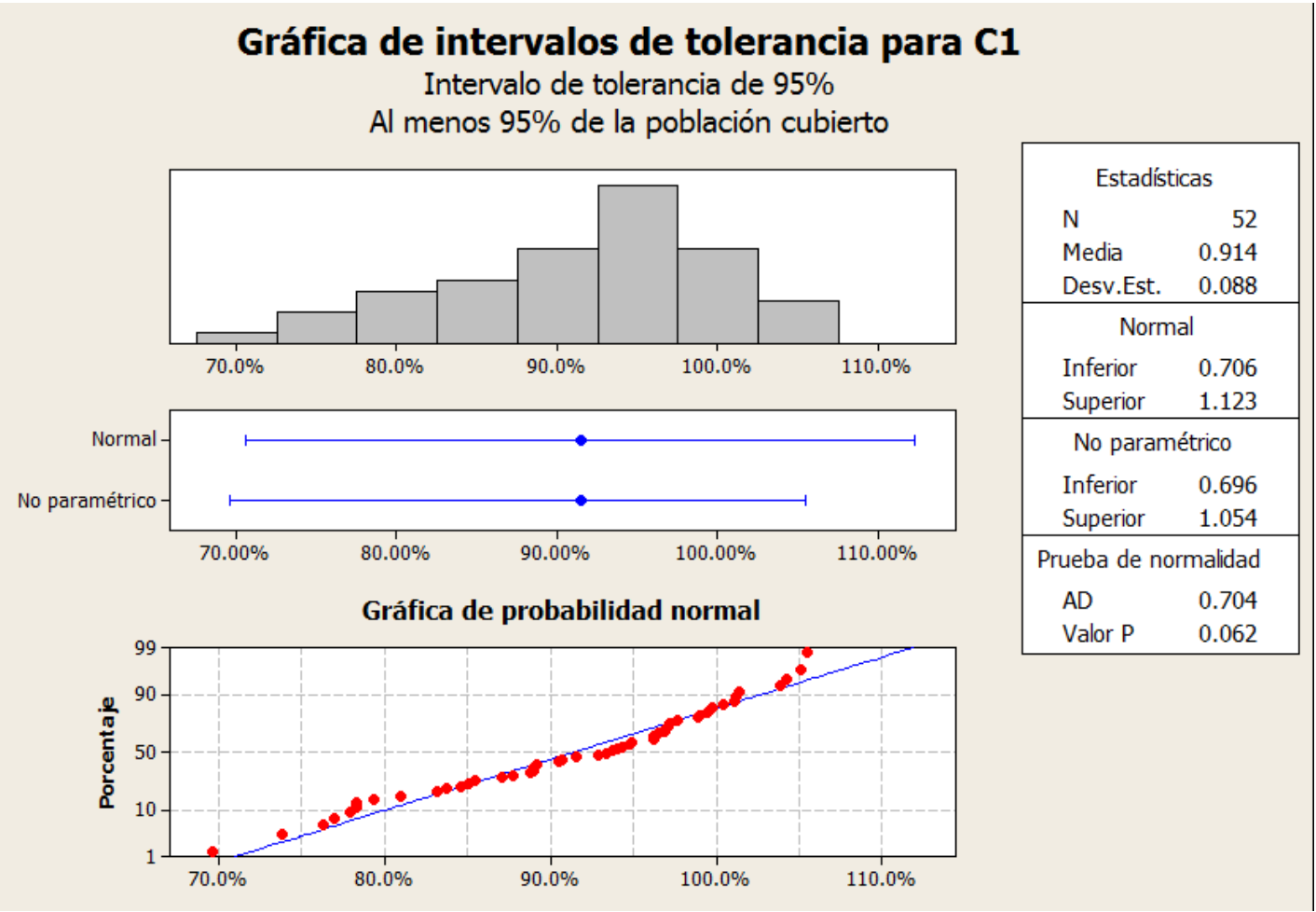

Fuente: Elaboración propia basado en la información de la empresa

A partir de la información obtenida en la tabla N.$^{\circ} 4$ y definidos los intervalos de tolerancia se realiza un análisis estadístico con ayuda del software Minitab en la figura N. ${ }^{\circ} 44$ se muestran los resultados. 
Figura 44: Gráfica de Capacidad de Proceso

\section{Capacidad de proceso Sixpack de C1}

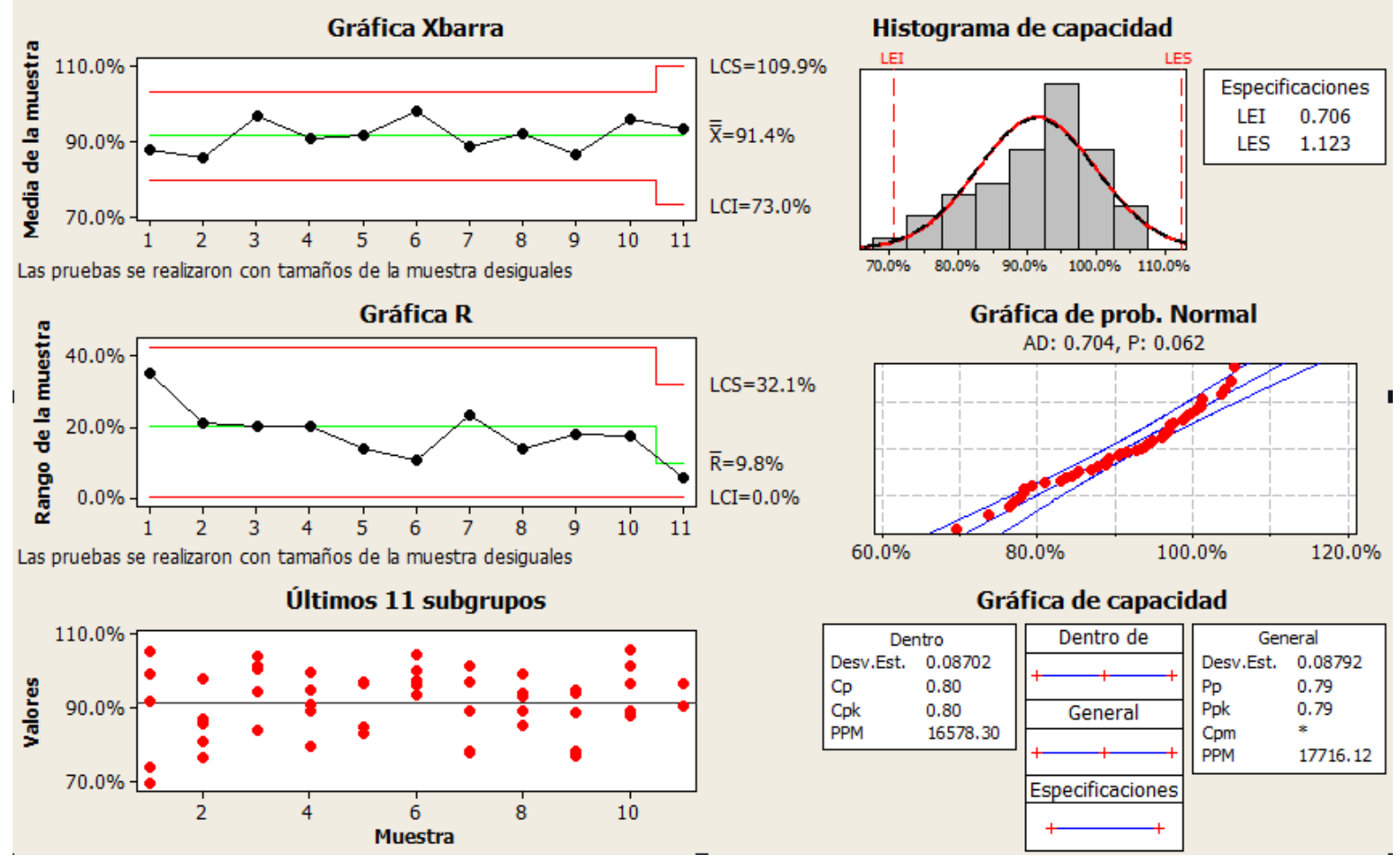

Fuente: Elaboración propia basado en la información de la empresa

De acuerdo con los resultados obtenidos en la gráfica de capacidad del proceso se puede concluir lo siguiente:

- En la gráfica de probabilidad se observa que el valor de $\mathrm{p}$ es mayor a $0.05 \mathrm{y}$ los puntos de los datos casi siguen una línea recta. Esto significa que se acepta la hipótesis nula, por lo tanto, los datos pertenecen a una población distribuida normalmente.

- El proceso se considera capaz si el valor de Cp es mayor a 1.33 en la gráfica se observa que este valor es 0.80 menor al establecido. Por lo tanto, este proceso tiene oportunidades de mejora 
- En la gráfica Xbarra examina la media del proceso y nos permite evaluar la estabilidad del proceso se observa que los puntos varían aleatoriamente alrededor de la línea central y se encuentran dentro los límites de control, además, no se observan patrones, rachas.

- La gráfica rangos móviles muestra que los puntos varían aleatoriamente alrededor de la línea central y se encuentran dentro los límites de control.

- El histograma de capacidad se evalúa la forma de la dispersión de los datos y estos se encuentran sesgados hacia la derecha.

\subsection{Impacto del Problema}

\subsubsection{Impacto Económico y Operativo}

El problema identificado genera una serie de costos y actividades adicionales asociados al incumplimiento del indicador de eficacia de producción. El impacto económico y operativo se ve reflejado en los diferentes indicadores de gestión que lleva la compañía. El Fill Rate mide el nivel de cumplimiento de entregas de producto al cliente para el año 2014 fue 90.4\% por este motivo la compañía perdió la oportunidad de vender \$ 6546 996. Los excesos de producción generan la necesidad de almacenar SKU que el cliente no requiere en este periodo se ha producido 4211 toneladas en exceso por arriba del $110 \%$ de lo planificado esto significó un costo adicional de \$25,990.47 al año por alquiler de almacén. Las actividades adicionales que se generan por el exceso y defecto de la producción estresan la cadena productiva el impacto operativo se refleja en las diferentes áreas que participan, estas deben tomar acciones preventivas y correctivas en su gestión para garantizar que el proceso no se interrumpa, se enumera las más importantes. 
- El área almacenes para asegurar el abastecimiento de los insumos en promedio maneja 39 días giro con un valor de inventario de más de 2.5 millones de soles.

- Incremento del stock de materia prima en 30\% para asegurar las diferentes formulaciones.

- En el área productiva realiza cambios de formato no planificados para evitar desabastecer el mercado.

- Paradas por falta de espacio para almacenar, falta de insumos o materia prima sumaron 181 eventos en el año.

- Necesidad de 4528 ubicaciones y pallets adicionales para almacenaje de producto no planificado

- Gestión logística adicional de traslado para 4211 toneladas

Además, el incumplimiento del programa de producción incrementa la generación de producto no conforme esto se debe principalmente a la interrupción del proceso. Quiere decir, los cambios de formato y las paradas no planificadas incrementan este valor, que para el año en análisis fue de $2.5 \%$ esto representó para la compañía incrementar a sus costos en $\$ 940$ 180. Finalmente, el mayor impacto es poner en riesgo la fidelidad de los clientes, al no cumplir con las entregas de los pedidos en el tiempo acordado, el cliente puede suplir su necesidad con los productos de la competencia o alternativos. Además, el costo adicional por este problema resta competitividad a la empresa. 


\section{CAPITULO 3. METODOLOGÍA SOLUCIÓN AL PROBLEMA}

En el presente capítulo se analizarán las alternativas de solución a la problemática diagnosticada en el capítulo anterior, estas opciones de solución se basan en la teoría presentada en el primer del capítulo. Del análisis realizado en el capítulo II, se encontró que el principal problema de la planta es el incumplimiento del programa de producción, para lo cual se propone la implementación de una mejora que aplicará conceptos de manufactura esbelta para el área de producción de fideos. Las herramientas de la manufactura esbelta que se emplearán permitirán mejorar el cumplimiento de programa de producción, reducir el producto no conforme, optimizar la capacidad de la planta y optimizar el uso de los recursos. Para alcanzar estos objetivos se identificarán y evaluarán cuáles son las herramientas más idóneas en el funcionamiento global del sistema de producción esbelto. Para ello, se considera la situación actual de la empresa y los beneficios que aporta la implementación de cada herramienta.

\subsection{Evaluación de aplicación de herramientas de Manufactura} Esbelta

Para poder evaluar que herramienta de la manufactura esbelta es la más idónea de implementar ajustada a la situación actual de la empresa. Se muestra en la siguiente tabla 5 , en base al análisis del capítulo I, el beneficio que tiene cada herramienta relacionado con la 
etapa de aplicación al implementarlas, clasificadas en tres grupos: Inicio implementación manufactura esbelta; verificación y control de procesos; y evaluación y mejora continua.

Tabla 5: Etapa de aplicación de Herramientas de Manufactura Esbelta

\begin{tabular}{|c|c|c|}
\hline Herramientas & Beneficios & Aplicación \\
\hline $\begin{array}{l}\text { Mapeo de la cadena } \\
\text { del valor }\end{array}$ & $\begin{array}{l}\text { Visión panorámica de toda la } \\
\text { cadena de valor }\end{array}$ & \multirow{4}{*}{$\begin{array}{l}\text { Inicio } \\
\text { Implementación } \\
\text { Manufactura Esbelta }\end{array}$} \\
\hline Las cinco "eses" & $\begin{array}{lll}\text { Clasificar, } & \text { ordenar, limpiar, } \\
\text { estandarizar y mantener los } \\
\text { anteriores. }\end{array}$ & \\
\hline SMED & Cambio rápido de formatos & \\
\hline Poka Yoke & Corrección de error & \\
\hline TPM & $\begin{array}{llll}\text { Maximizar efectividad de } & \text { los } \\
\text { equipos } & & & \\
\end{array}$ & \multirow{5}{*}{$\begin{array}{l}\text { Verificación y } \\
\text { control de procesos }\end{array}$} \\
\hline Six Sigma & Reducir variación del proceso & \\
\hline Justo a tiempo & $\begin{array}{llrr}\text { Optimizar } & \text { un } & \text { sistema } & \text { de } \\
\text { producción } & \text { con } & \text { elementos } \\
\text { necesarios } & & & \\
\end{array}$ & \\
\hline Kanban & Control de inventarios & \\
\hline Takt Time & $\begin{array}{l}\text { Sincronizar la producción con la } \\
\text { demanda }\end{array}$ & \\
\hline Kaizen & $\begin{array}{l}\text { Mejora continua, hacer más } \\
\text { con menos costo }\end{array}$ & \multirow[t]{2}{*}{$\begin{array}{l}\text { Verificación } \quad y \\
\text { control de procesos }\end{array}$} \\
\hline Six Sigma & Reducir variación del proceso & \\
\hline
\end{tabular}

Fuente: Elaboración propia

La etapa de aplicación "Inicio Implementación Manufactura esbelta" engloba las herramientas de Mapeo de la cadena del valor, las cinco "eses", SMED y Poka Yoke. Estas herramientas son consideradas en esta etapa puesto que permite a las empresas dar los primeros pasos en involucrarse y disfrutar los beneficios del pensamiento esbelto. Con el 
Mapeo de la cadena del valor para entender y examinar el proceso, esta herramienta permitirá identificar gráficamente donde y porque ocurren fallas importantes para luego poder tomar decisiones al respecto. Las 5 S' es una herramienta que logrará áreas de trabajo seguras, organizadas y limpias y su implementación es básica y útil para poder continuar con las siguientes herramientas. La implementación de la herramienta SMED optimizará los tiempos de preparación de los equipos para cambios de formato y favorecerá cumplir lotes más pequeños. Finalmente, Poka Yoke es un método que busca obtener un proceso donde los errores no vuelvan a suceder ya que la mejora es que ese error sea imposible de realizar.

La segunda etapa "Verificación y control de Procesos" contiene herramientas que permitirán a las empresas emplear métodos para lograr una producción cumpliendo los pedidos en tiempo, cantidad, calidad y minimizando los siete desperdicios. Por ello, el Six Sigma, ayuda a reducir la variación del proceso; TPM, maximiza la efectividad de los equipos; JIT, busca que la producción se adapte y sea flexible a la variación de la demanda del mercado; Kanban, reduce los inventarios en proceso; y Takt Time, sincroniza la producción con la demanda.

La tercera etapa "Evaluación y mejora continua", se enfoca a la estandarización de los procesos y al personal, además que debe ser conformado por un equipo multifuncional. La herramienta considerada en esta etapa es Kaizen y en parte Six Sigma porque tiene una subherramienta DMAIC. Kaizen se centraliza en la mejora de cada proceso y esta debe ser continua. 
En síntesis, en la figura 45 se puede representar la relación y flujo de las herramientas de Manufactura Esbelta que tienen entre sí. Además, te ayuda a tener una perspectiva de cómo abordar la implementación de estas herramientas. Complementado la figura, se recomienda si una empresa es nueva y necesita aplicar desde cero la manufactura esbelta debe empezar por VSM y 5 S'. Una vez culminada la primera etapa puede pasar a implementar las herramientas del segundo grupo y finalmente para que su sistema sea estandarizado debe aplicar las herramientas de la tercera etapa, donde la principal herramienta es Kaizen.

Figura 45: Relación de secuencia de implementación herramientas de Manufactura Esbelta

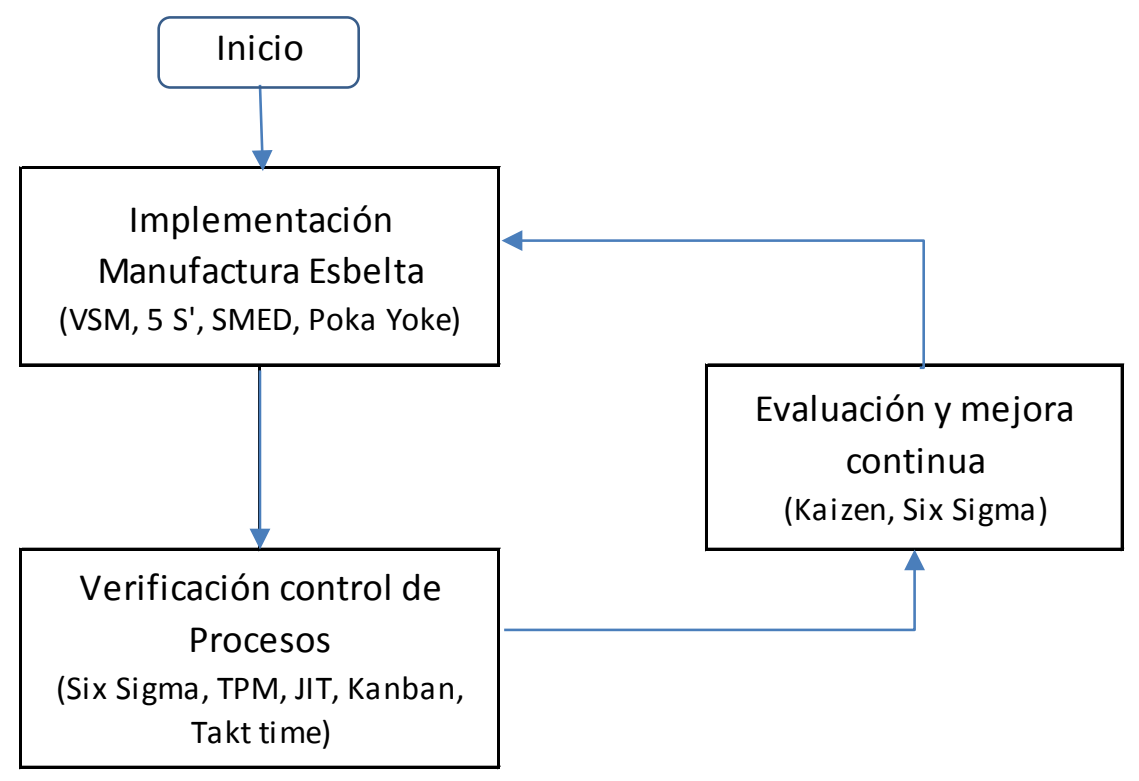

Fuente: Elaboración propia

La empresa actualmente está aplicando varias herramientas de la manufactura esbelta sobre todo la más básica, que es la herramienta de cinco "eses", la misma se evidencia en el capítulo anterior porque no hay causas directas relacionadas a clasificar, ordenar y limpiar. Por lo que la empresa tiene áreas de trabajo seguras, organizadas y limpias. Además, la empresa cuenta con un proceso de producción de fideos continua en el que se ha minimizado los desperdicios de tiempo de espera, transporte y movimientos. 
Considerando la situación actual de la empresa, en la tabla 6 se muestra los indicadores principales del proceso de producción de fideos, los cuales son los principales afectados por los defectos analizados en el capítulo 2, los mismos se relacionan con las herramientas de la manufactura esbelta para poder identificar la oportunidad de mejora.

Tabla 6: Oportunidades que ofrece las Herramientas de Manufactura Esbelta

\begin{tabular}{|c|c|c|}
\hline Indicador & Herramientas & Oportunidad de mejora \\
\hline $\begin{array}{l}\text { OEE, Producto No } \\
\text { Conforme }\end{array}$ & $\begin{array}{l}\text { Poka Yoke, Six } \\
\text { Sigma }\end{array}$ & $\begin{array}{l}\text { - Eliminar perdidas y minimizar costos } \\
\text { en la producción. } \\
\text { - Reducir productos no conformes. } \\
\text { Reducir producto para reproceso } \\
\text { - Eliminar errores que afectan el } \\
\text { proceso de la producción. }\end{array}$ \\
\hline Indisponibilidad & TPM & $\begin{array}{l}\text { - } \text { Mejorar la confiabilidad de equipo } \\
\text { - Minimizar fallas no previstas de los } \\
\text { equipos. } \\
\text { - Asegurar capacidad de producción }\end{array}$ \\
\hline $\begin{array}{l}\text { Cumplimiento del programa } \\
\text { de producción }\end{array}$ & $\begin{array}{l}\text { Poka Yoke } \\
\text { SMED } \\
\text { A3 }\end{array}$ & $\begin{array}{l}\text { - Evitar que se cometa un error en el } \\
\text { proceso en la estimación de la } \\
\text { producción } \\
\text { - Evitar retrasos en la producción } \\
\text { - Asegurar la cantidad de pedido } \\
\text { programada }\end{array}$ \\
\hline
\end{tabular}

Fuente: Elaboración propia

Luego de identificar las herramientas que generarían oportunidades de mejora, las cuales son Poka Yoke, Six Sigma, TPM y SMED, en base a la necesidad actual de la empresa, a la situación o nivel de aplicación de la manufactura esbelta, y a seguir las recomendaciones identificadas en el flujo o secuencia de implementación de la manufactura esbelta. Pasamos 
a definir o elegir las herramientas que generaran mayor impacto y beneficio para el problema planteado, para lo cual se muestra en la tabla 7 , en el que se valora cualitativamente el impacto o beneficio que puede brindar la herramienta para solucionar los principales problemas identificados en el capítulo anterior. La valoración se da en un rango de calificación cualitativa de uno a diez. Los valores menores a 6 el impacto es menor, los mayores a 6 tienen mayor impacto.

Tabla 7: Aplicación de herramientas de Manufactura Esbelta por problema

\begin{tabular}{|c|c|c|c|c|c|c|}
\hline Problemas & $5 \mathrm{~S}$ & A3 & SMED & Poka Yoke & TPM & Six Sigma \\
\hline $\begin{array}{l}\text { Error en precisión de cambio de } \\
\text { formato }\end{array}$ & 0 & 4 & 5 & 9 & 0 & 5 \\
\hline Falla del personal de elaboración & 2 & 4 & 2 & 8 & 0 & 5 \\
\hline Molde o inserto defectuoso & 1 & 4 & 0 & 2 & 4 & 3 \\
\hline Falla en la operación de los equipos & 0 & 3 & 0 & 5 & 3 & 0 \\
\hline Re-envase de producto semi-terminado & 0 & 0 & 2 & 0 & 0 & 0 \\
\hline $\begin{array}{l}\text { Falla de los operadores en el control } \\
\text { del proceso }\end{array}$ & 0 & 0 & 0 & 8 & 0 & 5 \\
\hline Atraso en limpieza de línea & 1 & 0 & 7 & 0 & 0 & 0 \\
\hline Falta de personal & 0 & 0 & 0 & 0 & 0 & 0 \\
\hline Posible contaminación & 5 & 5 & 0 & 3 & 4 & 0 \\
\hline Atender problemas en otras líneas & 0 & 0 & 0 & 4 & 4 & 0 \\
\hline $\begin{array}{l}\text { Error de ingreso de cantidad producida } \\
\text { a almacén de producto terminado }\end{array}$ & 0 & 0 & 0 & 5 & 0 & 0 \\
\hline No arranca por condiciones inseguras & 4 & 4 & 0 & 0 & 0 & 0 \\
\hline Mantenimiento prolongado & 0 & 2 & 0 & 0 & 0 & 0 \\
\hline Fallas de equipo & 0 & 5 & 0 & 0 & 8 & 0 \\
\hline Total & 13 & 31 & 16 & 44 & 23 & 18 \\
\hline
\end{tabular}

\section{Fuente: Elaboración propia}

Por lo tanto, la propuesta de mejora se centrará en la implementación principalmente de la herramienta "Poka Yoke" y el Reporte A3 para minimizar los errores en cambio de 
precisión de formato, fallas del personal en el proceso de elaboración de fideos y fallas del personal en el control del proceso de producción de fideos que apunten en reducir los desperdicios y permitan mejorar los resultados de cumplimiento del programa de producción.

\subsection{Plan de mejora del proceso de Producción}

El objetivo de esta propuesta de mejora es optimizar el proceso de producción de fideos para lo cual se debe incrementar el porcentaje del cumplimiento de producción, enfoque a partir de la información mostrada en el capítulo anterior y también en el capítulo I porque hay una tendencia mundial de la necesidad imperativa de ser más competitivos en costos, productividad y calidad para seguir creciendo como empresa y lograr la visión proyectada.

En el siguiente gráfico 46, se muestra el objetivo de la propuesta de mejora en el que la empresa mejora el subproceso que ha generado mayor impacto en el no cumplimiento del programa de producción, al eliminar como factor crítico la mano de obra, materiales y el método. Puesto que, uno de los problemas principales encontrados en el capítulo anterior es que en el proceso de recepcionar y mezclar los insumos con la harina, se han presentado errores por factores de mano de obra en el cálculo erróneo de los tiempos del lote de producción, lo cual genera incumplimiento en la cantidad y tiempo de entrega del pedido programado para producir.

Figura 46: Propuesta de Diagrama SIPOC de producción de fideos 


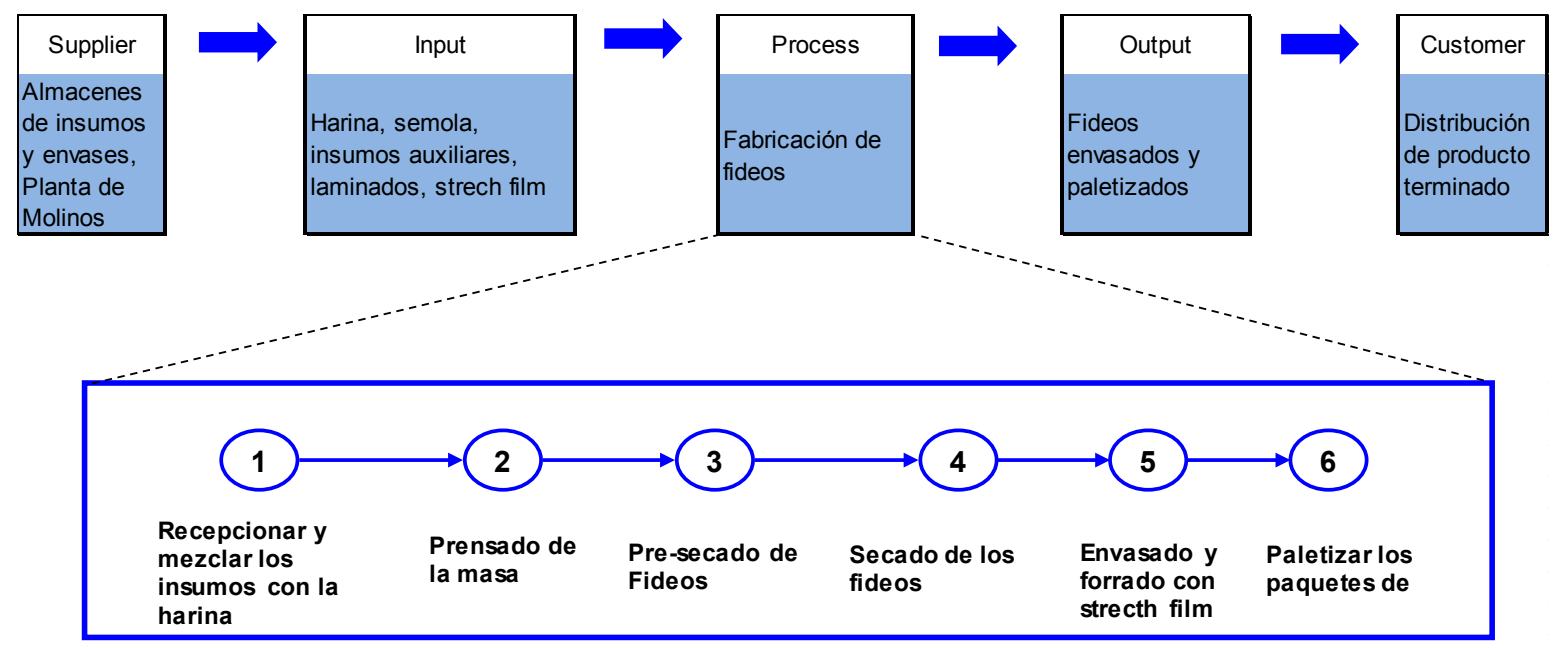

\begin{tabular}{|c|c|c|c|c|c|c|}
\hline \multicolumn{7}{|c|}{ Factores Criticos } \\
\hline & MO & MAT & MET & MAQ & MED & MA \\
\hline 1 & , & & & $x$ & $x$ & \\
\hline 2 & & & $x$ & $x$ & $x$ & \\
\hline 3 & & & $x$ & $x$ & $x$ & \\
\hline 4 & & & $x$ & $x$ & $x$ & \\
\hline 5 & $x$ & $x$ & $x$ & $x$ & & \\
\hline 6 & $x$ & & $x$ & $x$ & & \\
\hline
\end{tabular}

\begin{tabular}{|clll|}
\hline Leyenda & & & \\
MO & Mano de Obra & MAQ & Maquinaria \\
MAT & Materiales & MED & Medición \\
MET & Método & MA & Medio Ambiente \\
\hline
\end{tabular}

Fuente: Elaboración propia basado en la información de la empresa

Para lograr los objetivos propuestos se recomienda la implementación de las herramientas de manufactura esbelta identificadas como las que aportaran más en minimizar los problemas que generan mayor impacto en el efecto del no cumplimiento del programa de producción. Para ello hay que modificar algunos estándares en el proceso de producción actual, además de involucrar a todos los colaboradores que participan en el proceso, alinearlos a los objetivos planteados mostrándoles las ventajas y oportunidades de mejora para la empresa y los colaboradores. Con el fin de interiorizar la mentalidad de cambio se debe trabajar con ellos desde el principio mostrándoles los beneficios que les brindará estas herramientas. En este sentido, es importante involucrar a la gerencia del área de Calidad, 
mantenimiento, y producción, porque ellos serán un gran apoyo en transmitir y unir a todos los trabajadores para el logro de los objetivos.

Para lograr una transformación en la organización y lograr aplicar practicas lean se debe considerar incrementar la productividad, cambiar la forma de trabajar asegurando el cumplimiento de estándares y mejores prácticas con la participación de todo el personal para generar una conciencia lean que permita desarrollar el compromiso de la mejora continua y la proactividad. El proceso de implementación está diseñado para ser realizado en 17 semanas. Se nombrará al gerente de producción como líder de este cambio, el cual ya tiene conocimiento y compartirá sus experiencias anteriores en el pensamiento esbelto en la figura 47 el proceso de implementación.

Figura 47: Proceso de implementación de lean

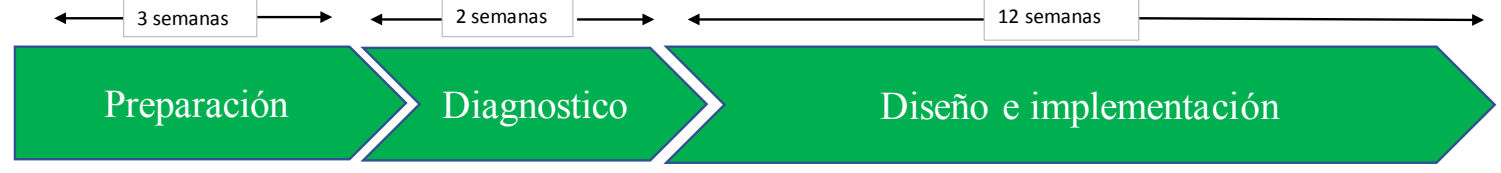

Fuente: Elaboración propia

\section{Preparación}

En esta primera etapa se debe estructurar el despliegue de la metodología encabezado por la alta dirección de la organización.

- Comunicar a la planta el despliegue del programa Lean

- Generar compromiso del liderazgo con el equipo

- Definir el equipo de trabajo involucrado en la implementación

- Generar los requerimientos de información y capacitación del equipo 
- Definir objetivos a ser logrados durante el despliegue (mayor productividad, eficacia de producción, eficiencia, etc.)

- Implementar la logística para que el equipo empiece a trabajar

\section{Diagnostico}

En la segunda etapa se debe definir las actividades a realizar y los documentos de control.

- Analizar las pérdidas desde un aspecto técnico identificando la causa raíz

- Análisis de OEE

- Análisis de producto no conforme

- Análisis de eficacia de producción

- Análisis de capacidad del proceso

- Identificar y estudiar los costos asociados al problema

- Definir el alcance de la aspiración de desempeño

- Organizar las iniciativas de mejora con un nivel de detalle que permita la ejecución y evaluación de la captura

- Definir los indicadores de gestión

Los documentos de control

- Resumen las principales perdías con la causa raíz

- Descomposición de los costos

- Lista de las principales oportunidades valorizadas

- Plan de trabajo para las iniciativas informe A3

- Tablero de control

\section{Diseño e implementación}


- Diseñar con un nivel de detalle todas las iniciativas que aporten a las mejoras

- Implementar iniciativas de mejora siguiendo la metodología A3

- Desplegar y aplicar los nuevos estándares de procesos al resto de la organización

La implementación de la metodología requiere de un plan de trabajo con responsables en el siguiente GANT se muestran las actividades y el tiempo necesario para desarrollar cada tarea. El equipo estará conformador por un ingeniero industrial quien será el líder de la implementación de la metodología Lean y soportado por los jefes de producción, calidad y mantenimiento.

Figura 48: GANT implementación de Lean

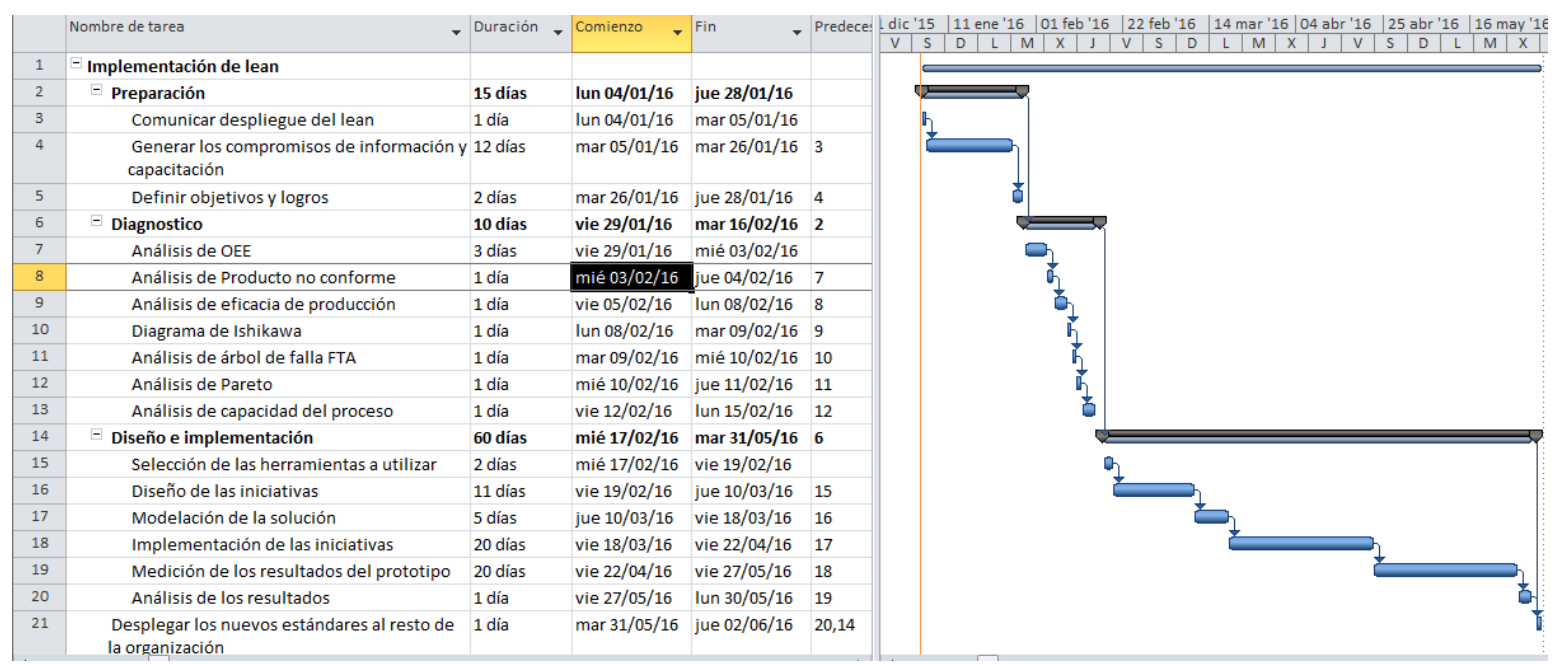

Fuente: Elaboración propia

\subsection{Uso de herramienta de Manufactura Esbelta}

En la actualidad las empresas se encuentran en constante búsqueda de iniciativas que les permitan ser flexibles e innovadoras para cumplir con las expectativas de los clientes. En este sentido, la optimización de los procesos es un foco primordial que genera ahorros importantes en la gestión. La implementación de una metodología que permita atender al cliente en forma oportuna, así como optimizar sus recursos dependerá de las estrategias de 
la organización. Para el caso de la planta de Fideos se utilizará las herramientas de la manufactura esbelta y de ingeniería, cada una tiene un objetivo y son esenciales en el funcionamiento global del sistema de producción esbelto, considerando la situación actual y los beneficios que se requerirían, para ello es necesario evaluarlas y elegir las más idóneas

\subsubsection{POKA YOKE}

Poka - Yoke es una herramienta que se aplica para eliminar defectos y errores antes de que estos puedan ocurrir. La implementación permite anticiparse al error o una vez producido el error tomar acciones correctivas como parar, controlar o generar una alarma. La acción más correcta dependerá de las condiciones operativas y la criticidad del proceso

\subsubsection{Implementación de mecanismos Poka - Yoke}

Para la implementación de mecanismos Poka - Yoke se debe gestionar el compromiso de las personas involucradas para ser capacitadas en los principios básicos del Poka - Yoke desarrollando un programa de formación con lecciones claves de los conceptos, características y beneficios y se debe definir los objetivos generales y específicos.

\section{Objetivo general de la capacitación}

Dar a conocer la herramienta Poka Yoke como mecanismos de previsión y eliminación de errores aplicando técnicas prácticas.

\section{Objetivos específicos}

- Entender el significado Poka -Yoke

- Entender la diferencia entre defecto y error

- Identificar los errores más comunes

- Entender el Ciclo de Deming (PDCA) 


\subsubsection{Método para desarrollar dispositivos Poka - Yoke}

\section{Metodología}

- Documento con información de los conceptos y metodología para la utilización de la herramienta Poka - Yoke

- Capacitación de sesiones teórico practico que permitan interiorizar los conceptos

- Verificación de los conceptos aprendidos

- Formación de equipos multidisciplinarios

La presente propuesta de mejora pretende incrementar de $46 \%$ a un $85 \%$ del cumplimiento del programa de producción, este valor está alineado con los objetivos de la organización en los diferentes centros productivos. En el capítulo anterior se diagnosticó las áreas y las causas que afectan el cumplimiento del programa de producción, en la tabla 8 se muestran los porcentajes de las diferentes áreas que aportan en la problemática.

Tabla 8: Numero de eventos que afectan el cumplimiento del programa de producción

\begin{tabular}{|l|c|c|}
\hline \multicolumn{1}{|c|}{ Área } & $\begin{array}{c}\text { Numero de } \\
\text { Eventos }\end{array}$ & $\%$ \\
\hline Producción & 615 & $60.59 \%$ \\
\hline Mantenimiento & 145 & $14.29 \%$ \\
\hline Almacén de Producto Terminado & 142 & $13.99 \%$ \\
\hline Molino & 47 & $4.63 \%$ \\
\hline Almacén & 31 & $3.05 \%$ \\
\hline Planeamiento & 19 & $1.87 \%$ \\
\hline Desarrollo tecnológico & 11 & $1.08 \%$ \\
\hline Servicios externos & 3 & $0.30 \%$ \\
\hline Proyectos & 2 & $0.20 \%$ \\
\hline
\end{tabular}

Fuente: Elaboración propia basado en la información de la empresa

En la tabla producción representa el 60.59\%, mantenimiento 14.29\%, Almacén de producto terminado $13.99 \%$ y otros $11.13 \%$. Se debe resaltar que, los problemas de almacén y almacén de producto terminado (APT) están asociados a las desviaciones productivas que incrementan el stock lo que ocasiona falta de posiciones en los almacenes, pallets e insumos. En este sentido, las herramientas seleccionadas para la solución de la 
problemática de acuerdo con las características identificadas en el capítulo anterior se muestran en la figura 49.

Figura 49: Impacto de las herramientas en la solución de la problemática

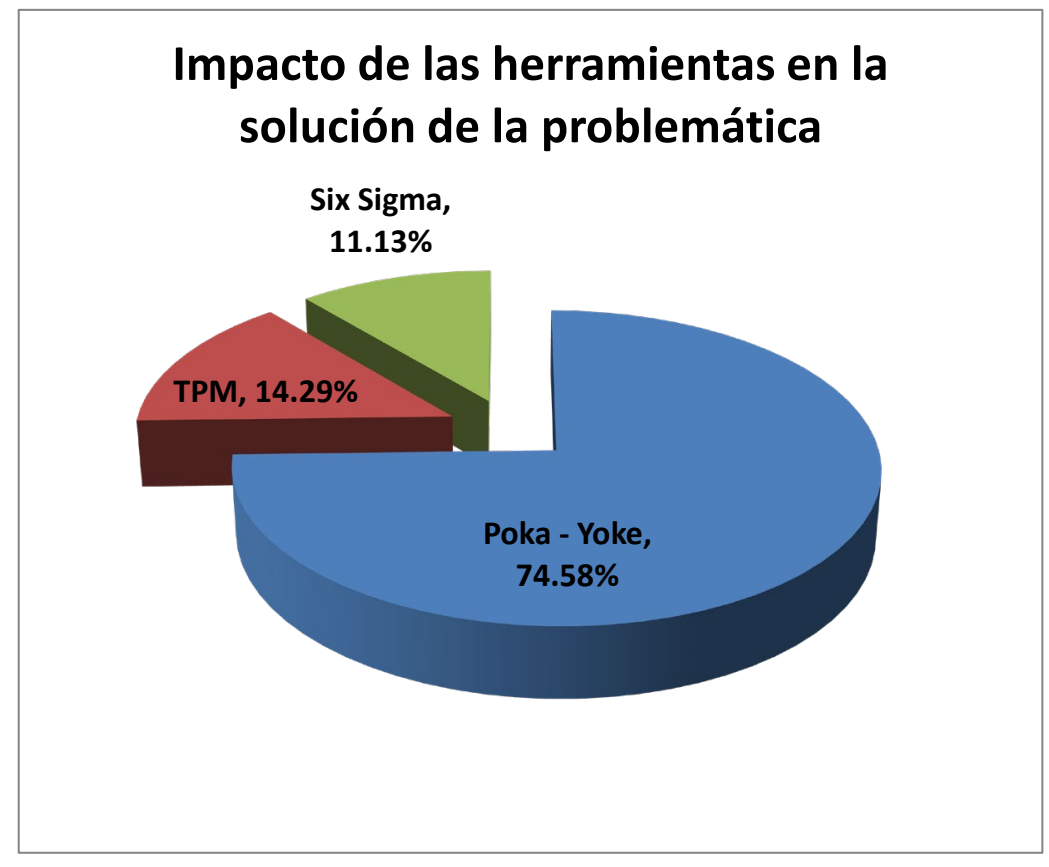

Fuente: Elaboración propia

Los impactos de la implementación de las diferentes herramientas de la metodología lean permitirá mejorar los problemas de las diferentes áreas del proceso, se estima que Poka Yoke permitirá mejorar un $74.58 \%$. Quiere decir, solucionará los problemas de estimación de la producción y de almacenamiento al producir los volúmenes planificados. Los problemas asociados a fallas de mantenimiento serán tratados con el TPM (Mantenimiento Productivo Total) realizando una mejor planificación y gestión de mantenimiento esto representa un 14.29\%. Finalmente, el 11.13\% utilizando Six Sigma focalizado en la reducción de la variación del proceso. En consecuencia, producir lo planificado significa eliminar los problemas de falta de metería prima, insumos, almacenamiento y modificaciones de programa de producción esto representa el $84.14 \%$ de las causas identificadas que tienen relación directa con la oportunidad de mejora.

El proceso de fabricación de pastas es totalmente automatizado desde la recepción de materia prima hasta el paletizado, todos los procesos se gestionan a través de un sistema de supervisión, control y adquisición de datos (SCADA) y controladores lógicos programables (PLC). La infraestructura permite implementar de manera fácil y con costos menores 
sistemas Poka Yoke que permitan eliminar errores. La problemática de estimación de la producción está relacionada a que algunas variables son dinámicas lo que genera el descontrol sobre todo cuando se elabora ordenes pequeñas o muy grandes.

\subsubsection{Sistema de distribución de materia prima}

El sistema de distribución se encarga de formular y enviar las materias primas y los microingredientes a cada línea de proceso. Los diferentes productos tienen recetas específicas que son formuladas por el sistema de distribución. Esta se realiza por batch de 1 tonelada, la proporción de cada materia prima y micro ingrediente se encuentra previamente establecido en el sistema. Una vez formulado el batch es enviado por un sistema de transporte neumático a cada línea de proceso, la figura 50 muestra las balanzas del macro, microcomponentes y el sistema de envío.

Figura 50: Proceso de Recepción Materia Prima

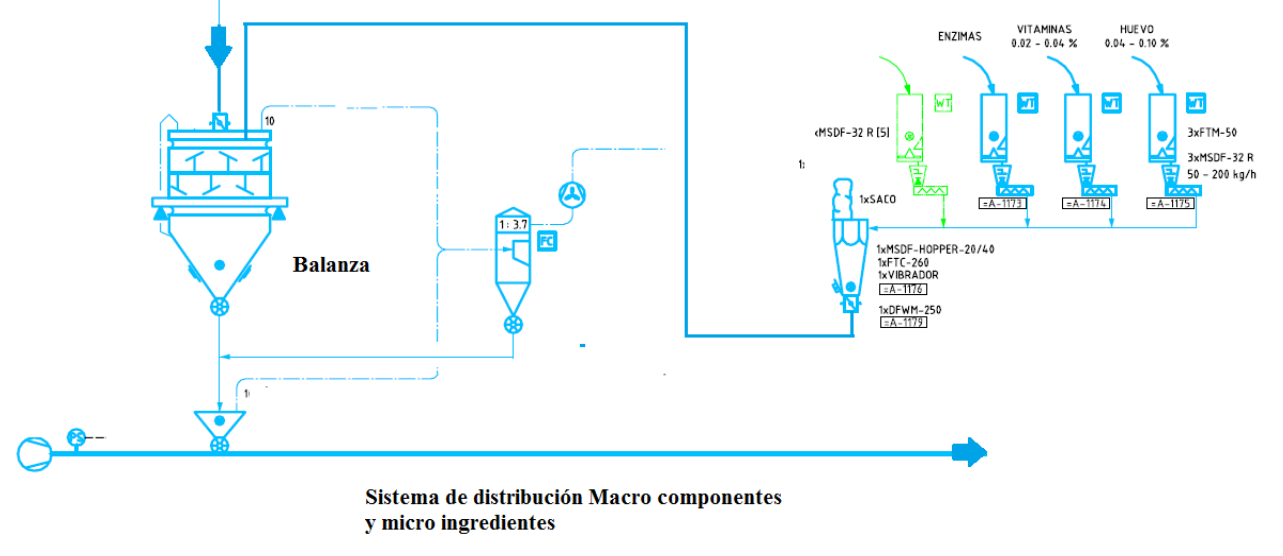

Fuente: Elaboración propia basado en la información de la empresa

La infraestructura y el nivel de automatización del proceso permiten realizar mejoras en la gestión del proceso la aplicación del Poka - Yoke en el área de formulación de la materia prima eliminará los defectos y errores de estimación en la producción.

\subsubsection{Identificación de variables}

- Cantidad por producir. - volumen de producción especificada en el contrato semanal para cada formato de fideo. 
- Porcentaje de reproceso. - Este porcentaje se produce cuando se corta los extremos del fideo para obtener el formato fideo largo. Este residuo retorna a la línea de producción como reproceso.

- Humedad de la materia prima. - Las materias primas principales son harinas y sémolas y tienen una humedad específica definida en los estándares de calidad.

- Humedad del producto final. - La humedad del fideo es controlada en todo el proceso $y$ al final se tiene un valor conocido

- Producto no conforme. - Producto que no cumple con los atributos de calidad y que sólo puede derivarse como chatarra. El producto no conforme es debido a condiciones operativas y de máquina; y son valores conocidos por cada línea de proceso y formato (fideo corto o largo).

- Rendimiento de las líneas de producción. - El rendimiento de cada línea es variado depende de varios factores como la velocidad, el desgaste de los insertos, la humedad del producto final.

- Tiempo de proceso. - El tiempo de proceso para cada línea difiere y está relacionado al formato en proceso, este tiempo se mide desde que ingresa la materia prima a la prensa y sale en el deshiladero.

- Fallas de equipo. - Las fallas de equipo son aquellas que generan la perdida de la funcionalidad total o parcial del equipo, estas son aleatorias y con tiempos de parada diversos.

- Mantenimiento Prolongado. - Mantenimiento designa actividades y acciones que tienen la finalidad de mantener o restaurar de las condiciones operativas de las máquinas con el objetivo de restablecer su funcionalidad. Debido a las actividades no previstas, falta de repuestos o recursos el mantenimiento se prolonga más del tiempo planificado.

- Recurso Humano. - El factor humano es una variable importante en el seguimiento y control de la producción la carga de trabajo es un factor importante que afecta el desempeño de sus actividades. 
- Factores externos. - La falta de un servicio afectan la continuidad de la producción entre los principales se tiene el agua de proceso, agua caliente, agua fría, energía eléctrica, aire comprimido.

- Materia Prima. - La falta de materia prima interrumpe el proceso productivo y al retornar las condiciones operativas se pierde el control del tiempo de proceso.

Son doce variables que intervienen en la estimación del proceso productivo y la complejidad para establecer y ejecutar un modelo matemático que permita realizar un cálculo correcto es difícil. Por la reducida cantidad de personal responsable de los cambios de formato. Más aun, existen variables aleatorias como la falta de materia prima, factores externos, recurso humano, mantenimiento prolongado, fallas de equipo, rendimiento y tiempo del proceso que requieren un seguimiento especial. Para la solución de la problemática se debe implementar un sistema que elimine las variables aleatorias.

La implementación de un sistema Poka - Yoke permitirá tener el control de la producción eliminando los errores de estimación del personal. Para lograr el objetivo se diseña un algoritmo matemático, un sistema lógico y una interface hombre máquina que permite avisar al personal cuando la producción está por concluir y parar el proceso de envío de materia prima cuando la producción ha terminado, a través de avisos luminosos y auditivos el personal será informado de los estados y cantidades producidas. Esta mejora será implementada en el SCADA y el procesador lógico programable del sistema de dosificación de materia prima. Este sistema gestiona la preparación y distribución de materia prima a cada línea de proceso en cantidades conocidas y estándares ( 1 tonelada). 


\subsubsection{Diseño de algoritmo matemático}

Para realizar una estimación correcta se elimina las variables aleatorias y se trabaja con variables conocidas y necesarias para realizar un cálculo correcto.

- $\quad$ Cantidad por producir $=\mathrm{CP}$

- Porcentaje de reproceso $=\mathrm{PR}$

- Porcentaje de humedad de la materia prima $=$ PHMP

- Porcentaje de la humedad del producto final $=$ PHPF

- Producto no conforme $=$ PNC

- Producto conforme $=\mathrm{PC}$

- $\quad$ Cantidad de batch $=\mathrm{CB}$

Fórmula para estimar la cantidad de batch formato corto

$$
\begin{gathered}
\mathrm{CB}=\text { REDONDEAR.MAS }((\mathrm{CP} *(\mathrm{PNC} / \mathrm{PC})+\mathrm{CP}) *(\mathrm{PHMP}-\mathrm{PHPT}) /(100 \%-(\mathrm{PHMP}- \\
\mathrm{PHPT})))+(\mathrm{CP} *(\mathrm{PNC} / \mathrm{PC})+\mathrm{CP})
\end{gathered}
$$

Las formulas antes descritas permiten calcular la cantidad de batch necesarios para cumplir con la cantidad a producir, cada batch representa una tonelada de materia prima que al transformarse en producto final ha mermado por la disminución de la humedad, el porcentaje de producto no conforme y el porcentaje de reproceso. La diferencia entre formatos largos y cortos es el porcentaje de reproceso que no aplica para el segundo producto. En este sentido, para que no exista conflicto en la formulación al final de la estimación se realiza un redondeo a más para que el número de batch sea entero. 


\subsubsection{Propuesta diseño de la lógica de control}

Para la correcta implementación de la mejora se desarrolla el siguiente diagrama que permitirá entender la lógica de la secuencia. 
Figura 51: Propuesta Lógica de Control

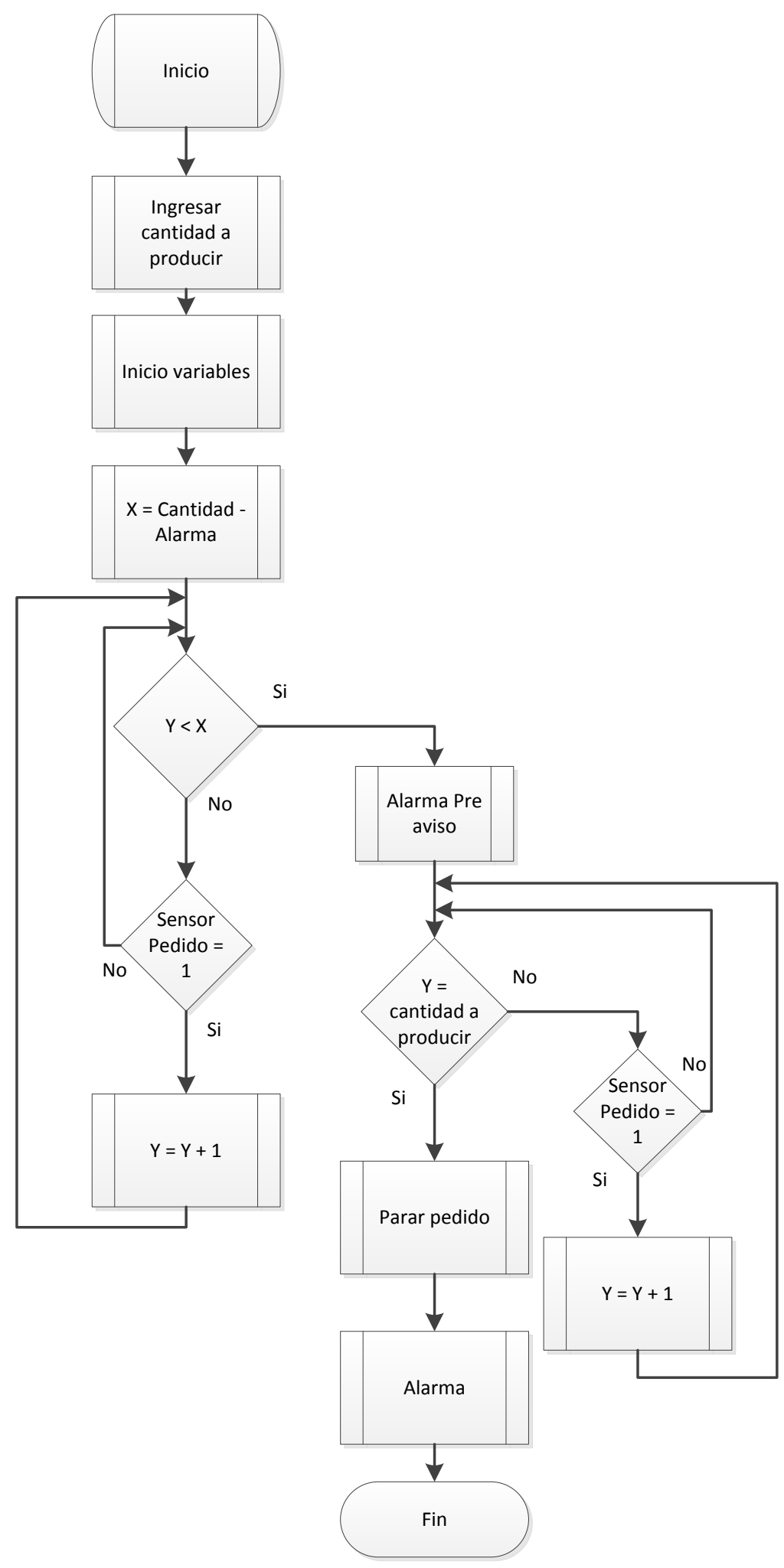

Fuente: Elaboración propia 


\subsection{Informe A3}

Una herramienta visual del Lean Manufacturing que se plantea implementar en la planta de fideos es la que se presenta en la figura 52 Informe A3 el cual permitirá sistematizar y aterrizar el desarrollo de las contramedidas a los problemas. Este modelo ayudará en la solución de los problemas en forma directa y concreta. La publicación de este informe permitirá crear una cultura, evidenciar los problemas resueltos y servirá de motivación al personal.

Figura 52: Informe $A 3$

Informe A3

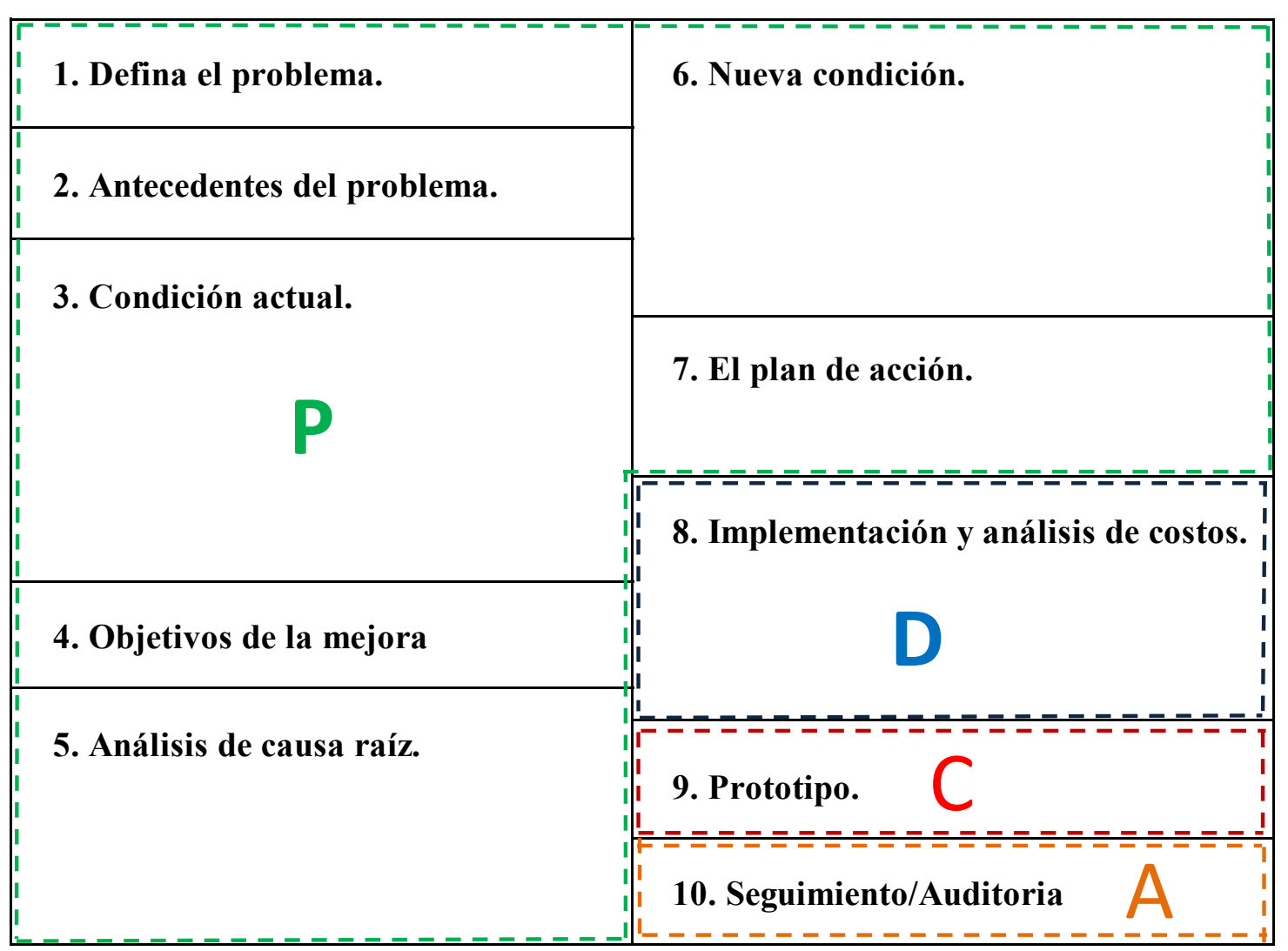

Fuente: Elaboración propia basado en The A3 Problem Solving Report: A 10 Step Scientific method to help solve problems. 
Para implementar esta herramienta el compromiso de la dirección es fundamental y debe invertir en el desarrollo del recurso humano. El primer paso para empezar con la implementación es capacitar al personal de mando medio Ingenieros de mantenimiento y monitores de turno; Esta herramienta tiene una serie de pasos a seguir para su implementación

\section{Defina el problema.}

¿Cuál es el contexto estratégico y operacional para entender el problema a que indicador afecta Seguridad, Calidad, Productividad?

\section{Antecedentes del problema.}

Observar el proceso en su contexto actual realizar un mapa del proceso y cuantificar el problema

\section{Condición actual.}

Un dibujo o imagen que transmita una comprensión completa de la situación actual es esencial para inferir las qué mejoras pueden ser necesarias

\section{Objetivos de mejora}

Defina los objetivos de la mejora estos deben ser concretos y estar alineados con la estrategia de la compañía además de ser SMART (específicos, medibles, alcanzables, relevantes y oportunos).

\section{Análisis de causa raíz.}

Involucrar a las personas que participan en el proceso, recoger sus ideas y desarrolla las posibles medidas a aplicar. Se debe evaluar y generar un consenso sobre las 
posibles soluciones soportados por fundamentos técnicos, utilice los 5 porque y espina de pescado esto dependerá de la complejidad del problema.

\section{Nueva condición.}

Un dibujo o imagen que transmita una completa comprensión de lo que la situación se vería una vez que se implemente la mejora.

\section{El plan de acción.}

Desarrolla el plan de acción con las contramedidas detalladas, determinando responsables, así como los indicadores a mejorar.

\section{Implementación y análisis de costos.}

Un listado concreto tareas que conduzcan a la mejora, junto con líneas de tiempo, resultados y los costos asociados a la implementación. Estas acciones deben tener un componente esencial relacionado al proceso científico, debe tener un sustento técnico.

\section{Prototipo.}

Implemente un pequeño piloto y evalué si los resultados son parecidos a los esperados.

\section{Seguimiento/Auditoria}

Evaluar los resultados (típicamente 30-90 días), recomendaciones de las lecciones aprendidas que sirvan como mejora para los próximos informes A3.

Ejemplo de la aplicación de la metodología A3 en la figura 53

Figura 53: Informe A3 desgaste de tubos formadores 
Informe A3

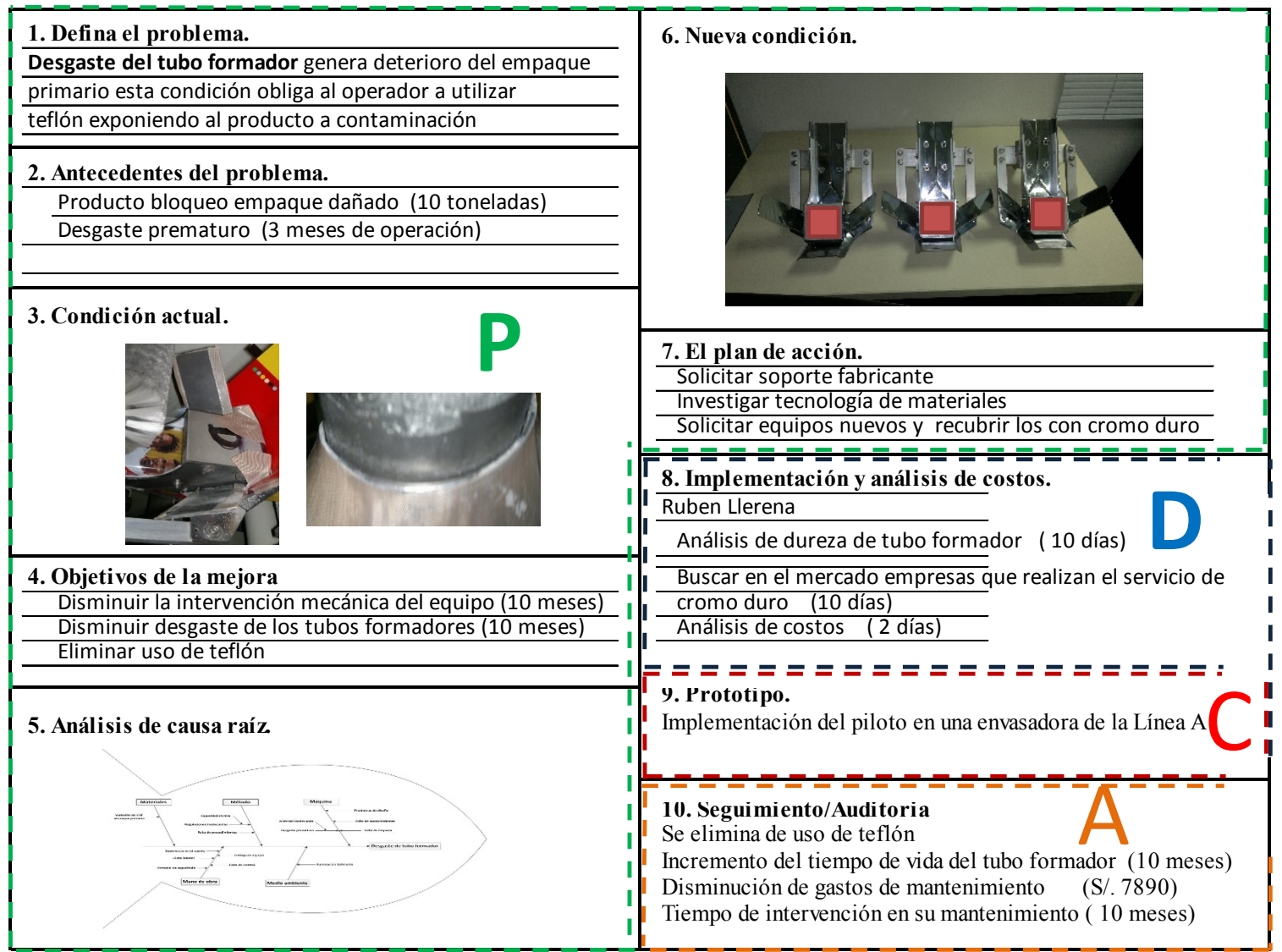

Fuente: Elaboración propia

\subsection{Indicadores de gestión}

Los indicadores aportarán a la medición y evaluación objetiva el éxito de la mejora del proceso de producción. Se emplearán los indicadores que el gerente de producción ha planteado mejorar. En adelante se detallan los indicadores principales que ayudaran la implementación de las herramientas de mejora. 
Figura 54: Indicador OEE

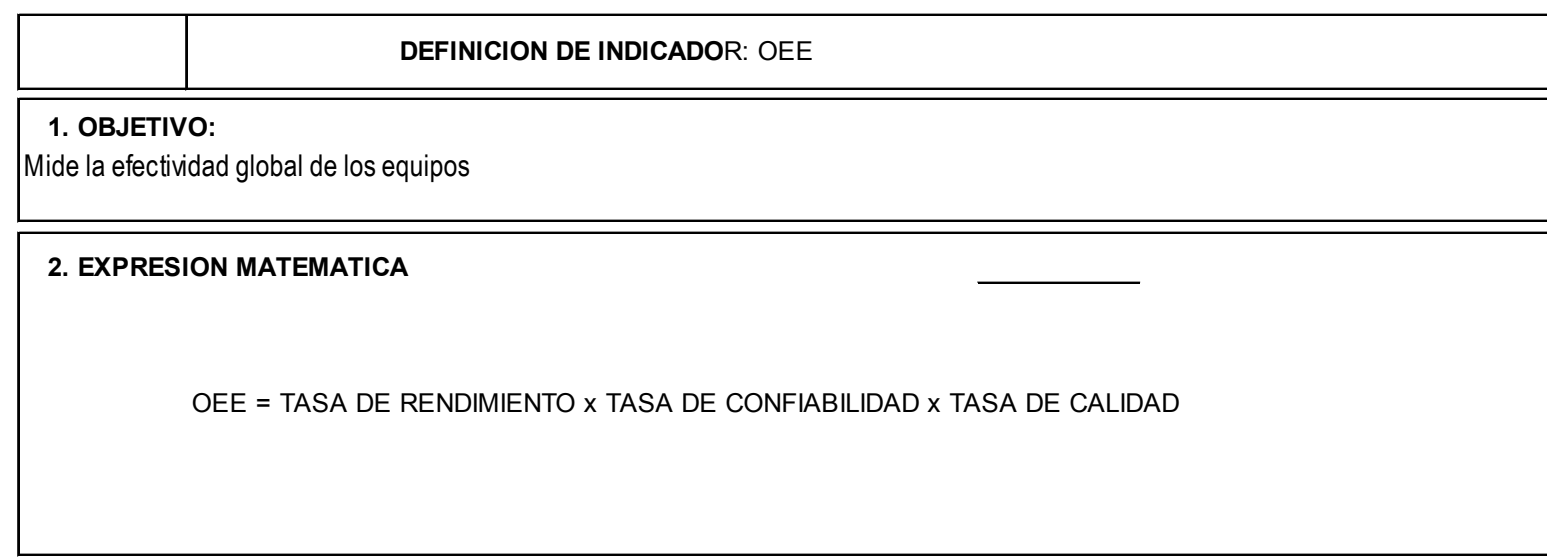

3. NIVEL DE REFERENCIA: $80 \%$

$90 \%$ a más

$80 \%-90 \%$

Menos del $80 \%$

4.- RESPONSABLE : Gerente de Producción

5. PUNTO DE LECTURA E INSTRUMENTO

Punto de lectura: Sistema SAP

6.- FRECUENCIA DE MEDICION Y REPORTE

Medición: Diaria

Reporte: Mensual

7. CONSIDERACIONES DE GESTION

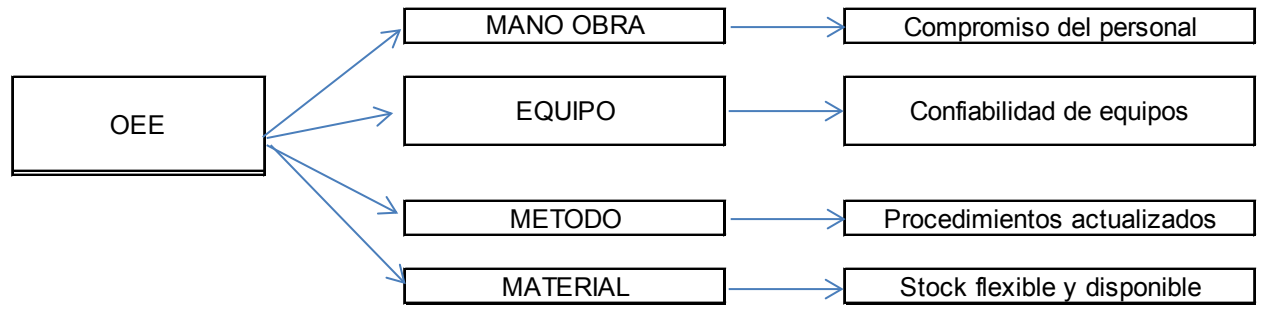

Este indicador engloba la efíciencia del proceso de producción, de los siguientes indicadores:

- Falta de insumo, materia prima o envases

- Falta de repuestos para las máquinas de producción

- Número y duración de falla de equipos

- Cantidad de producto no conformes 
- Demora en tiempo de cambios de formato

- Reducción de velocidad de producción

- Falta de paletas y espacio para almacenar producto terminado.

Figura 55: Indicador Cumplimiento de Producción

\begin{tabular}{|c|c|}
\hline & DEFINICION DE INDICADOR: CUMPLIMIENTO DE PRODUCCIÓN \\
\hline $\begin{array}{l}\text { 1. OBJETIVO: } \\
\text { Mide el cumplimiento en cantidad y }\end{array}$ & y tiempo de los pedidos programados semanalmente \\
\hline $\begin{array}{l}\text { 2. EXPRESION MATEMATICA } \\
\text { Cumplimiento de } \mathrm{Pr}\end{array}$ & Producción = $\frac{\text { Cantidad de SKUS cumplidos en fecha y cantidad }}{\text { Cantidad total de SKU's programados para la semana }}$ \\
\hline
\end{tabular}

3. NIVEL DE REFERENCIA: $\quad 70 \%$

\begin{tabular}{l}
$90 \%$ a más $\quad 70 \%-90 \% \quad$ Menos del $70 \%$ \\
\hline
\end{tabular}

4.- RESPONSABLE : Gerente de Producción

5. PUNTO DE LECTURA E INSTRUMENTO

Punto de lectura: Al termino de la semana verificando y cuantificando las ordenes cumplidad versus las programadas

6.- FRECUENCIA DE MEDICION Y REPORTE

Medición: Diaria

Reporte: Mensual

7. CONSIDERACIONES DE GESTION

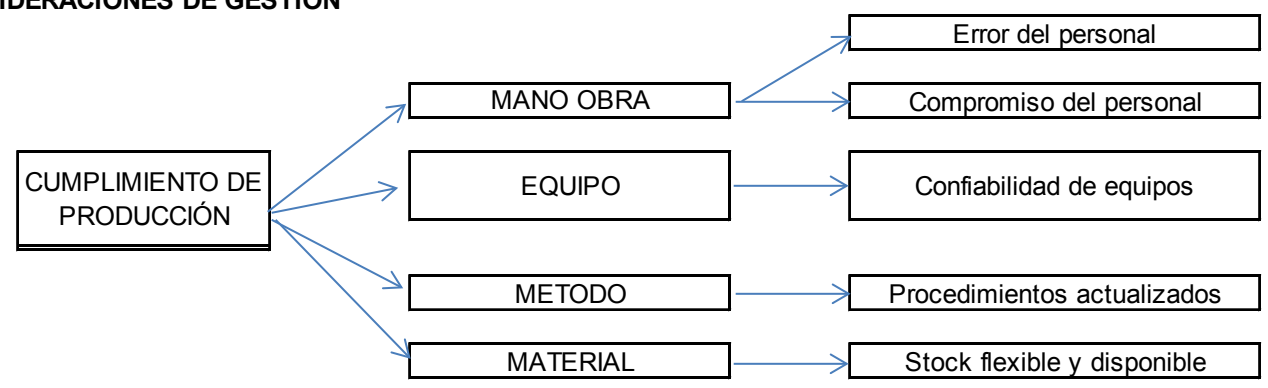

El cumplimiento de producción mide principalmente y evita los desperdicios por exceso de producción.

\section{Objetivos:}

- Mejorar el cumplimiento de producción a $85 \%$ 


\subsection{Validación de la propuesta de mejora}

La validación de la iniciativa de mejora se realizar de dos formas. La primera, a través de la herramienta de Lean VSM dinámico que se basa en el principio de la simulación de modelos y la segunda con la implementación de un prototipo en la línea más crítica.

\subsubsection{Simulación del proceso}

Una de las herramientas de la manufactura esbelta es el mapeo de la cadena de valor que permite crear mapas del flujo de la información, materiales muy útiles en procesos de manufactura. Para analizar procesos complejos como el planteado se utiliza el mapeo de la cadena de valor tipo dinámico, que se basa en la simulación de modelos que se ajustan a la realidad. En consecuencia, esta modelación permitirá evaluar un estado actual y un futuro del proceso analizado. En este sentido, utilizando el software de simulación Arena de Rockwell Automation se analizará el proceso de fabricación de fideos. De este proceso se tomará una línea, en el cual las actividades que forman parte del proceso mencionado se expresan en el siguiente flujograma: 
Figura 56: flujo del proceso

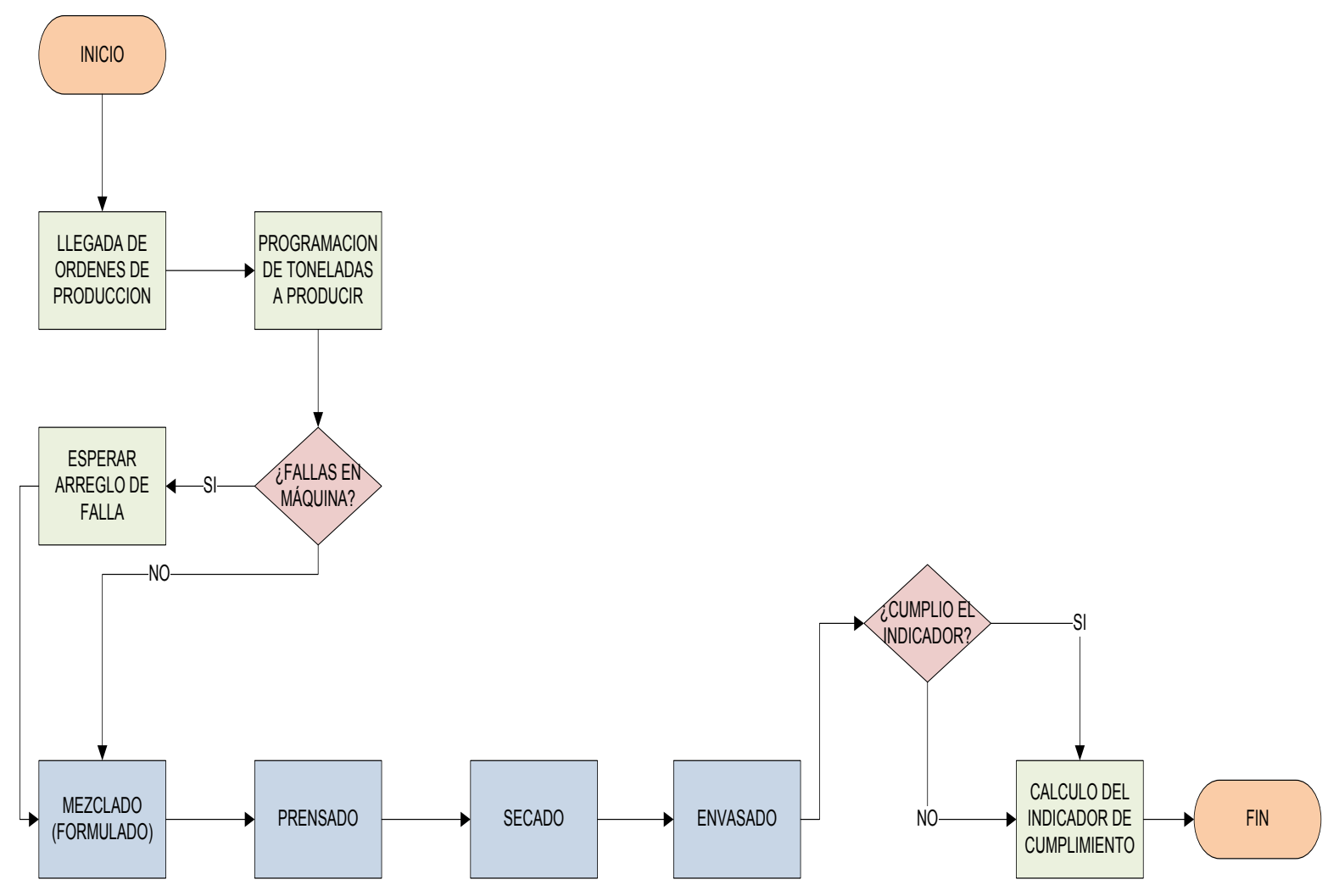

Fuente: Elaboración propia basado en la información de la empresa

\subsubsection{Descripción del problema y propuestas de solución}

En el capítulo 2 análisis y diagnóstico del proceso actual se describen la problemática que tiene la empresa respecto a los resultados deficientes del indicador de cumplimiento eficaz del programa de producción. Este es un indicador que permite medir si la producción se ha realizado en el tiempo y oportunidad. Si la fabricación de los diferentes productos se encuentra dentro del $90 \%$ a $110 \%$ del volumen planificado se considera $100 \%$ de cumplimiento. Por el contrario, si la producción no se realizó o se encuentra fuera de este rango se considera $0 \%$ de cumplimiento. Los principales problemas se encuentran en la metodología de estimación del área productiva y la mantenibilidad de los equipos. 
La propuesta está basada en el empleo de herramientas de manufactura esbelta, que ayudaran a gestionar mejor el proceso, aumentando el porcentaje de producto entregado en oportunidad y tiempo. Además, permitirá evaluar cuál es el impacto de la indisponibilidad de los equipos, las acciones de mejora a realizar son las siguientes:

- Capacitación

- Conformar equipos de trabajo

- Aplicación de la herramienta de manufactura esbelta.

Estas acciones se simularán a partir del proceso actual y luego, en base a las propuestas mencionadas se realizará un escenario propuesto, sobre el proceso actual, para evaluar los resultados y validar las mejoras propuestas en la presente tesis.

\subsubsection{Variables de la simulación}

1. Entidades

- Ordenes de producción las cuales se representan por pedidos.

- Cada pedido tiene una cantidad determinada de toneladas a producir, por lo cual, si bien la entidad principal es el pedido, cada pedido está compuesto por toneladas de fideo que a su vez son entidades que pasarán a lo largo del proceso, y saldrán como toneladas producidas, esta cantidad de toneladas se define como X1.

- Tiempos entre Arribos y Cantidad de Arribos

Esta variable representa el intervalo de tiempo en que van ocurriendo los pedidos u órdenes de producción. Esta variable de tiempo será la entrada al proceso. A su vez, se definirá otra variable que represente la cantidad de toneladas que tiene cada pedido. En este caso definiremos dos variables a simular: $\mathrm{X} 2$ y X3.

- Tiempos de Servicio 
Estas variables representan a los tiempos de cada una de las actividades del proceso, las cuales se definirán como un Xi.

- $\quad \mathrm{X} 4=$ Tiempo de Mezclado

- $\quad \mathrm{X} 5=$ Tiempo de Prensado

- X6= Tiempo de Secado

- $\quad \mathrm{X} 7=$ Tiempo de Envasado

- Tiempo Medio Entre Fallas y Tiempo Medio Para Reparar

Estos indicadores de mantenimiento representan los problemas asociados a la mantenibilidad de los equipos. El intervalo de tiempo en que van ocurriendo las fallas de las máquinas en el proceso, mediante $\mathrm{X} 8$ y con respecto al tiempo que toma reparar una falla se representará con X9. Estas variables afectarán al funcionamiento del proceso, ya que una parada o falla significa que la línea de producción se detendrá.

- Actividad Manual

Dentro del proceso ocurren actividades que interviene el criterio de los operadores de las máquinas que al iniciar el proceso definen el tiempo aproximado a producir esto está asociado a las capacidades de cada máquina y está estrechamente relacionado con la cantidad de toneladas a producir. Esto quiere decir, definen en qué momento deben cortar el proceso una vez iniciado. Esta variable se define como X10.

- Porcentaje de humedad

El porcentaje de humedad es una variable aleatoria depende de la continuidad del proceso y del control de los parámetros del proceso. Esta variable afecta la cantidad de toneladas producidas por pedido en menor medida. Esta variable se define como X11.

- Indicadores

Entre los indicadores que consideraremos a analizar tenemos:

- Valor del indicador de cumplimiento 
- Cantidad de pedidos cumplidos

- Cantidad promedio de pedidos que ingresan

- Tiempo de espera promedio por pedido

- Porcentaje de utilización de cada máquina

\subsubsection{Recolección de datos}

Tiempos entre Arribos y Cantidad de Arribos

El tiempo entre arribos dependerá de la cantidad de pedidos o arribos que ocurren en un mes, que es el período que se simulará. La información relacionada a la cantidad de arribos o pedidos en un mes se muestra a continuación, donde se pudo recolectar información de las ocurrencias mínimas, promedio y máxima:

Tabla 9: Número de pedidos

\begin{tabular}{|c|c|c|c|}
\hline Por Mes & Mínimo & Promedio & Máximo \\
\hline Número de Pedidos & 60 & 140 & 180 \\
\hline
\end{tabular}

Fuente: Elaboración propia basado en la información de la empresa

Por lo cual se asumirá que la cantidad de pedidos o arribos sigue una distribución triangular donde X3 =TRIA $(\mathbf{6 0}, \mathbf{1 4 0}, \mathbf{1 8 0})$. En la simulación definiremos una variable llamada "Valor2" = X3

Definiremos luego Valor $1=28 * 24 /$ Valor 2 que es dividir el tiempo total de producción o de ingreso de órdenes correspondiente a 28 días calendario entre el total de pedidos del mes que es X2 o Valor2.

Para obtener el tiempo entre llegadas o arribos, como en la realidad es continuo la entrada de pedidos entre uno y otro pedido, se representa este hecho tomando a "Valor1" como el 
tiempo entre llegadas, ya que al terminar un pedido llegará otro para completar el tiempo total de 28 días. Sin embargo, como a veces hay reformulaciones entre pedidos o algún tema administrativo o de producción definiremos el tiempo entre llegadas como:

\section{$\mathrm{X} 2=$ Valor1 +0.5 horas}

Además, la cantidad máxima de entidades o pedidos a llegar en el mes será X2 =Valor2, ya que después de ese valor, no llegarán más pedidos.

\section{Cantidad de toneladas por pedido}

Se tomó una muestra de 100 observaciones con la cantidad de toneladas de 100 pedidos. Los datos se muestran a continuación: 
Tabla 10: Cantidad de toneladas por órdenes de producción

\begin{tabular}{|c|c|c|c|c|c|c|c|}
\hline Observación & $\begin{array}{c}\text { Cantidad de Toneladas } \\
\text { a producir }\end{array}$ & Observación & $\begin{array}{c}\text { Cantidad de Toneladas } \\
\text { a producir } \\
\end{array}$ & Observación & \begin{tabular}{|c|} 
Cantidad de \\
Toneladas a producir
\end{tabular} & Observación & \begin{tabular}{|c|} 
Cantidad de \\
Toneladas a producir
\end{tabular} \\
\hline 1 & 32 & 26 & 26 & 51 & 21 & 76 & 23 \\
\hline 2 & 46 & 27 & 26 & 52 & 39 & 77 & 19 \\
\hline 4 & 19 & 29 & 45 & 54 & 24 & 79 & 47 \\
\hline 5 & 26 & 30 & 16 & 55 & 46 & 80 & 32 \\
\hline 6 & 19 & 31 & 34 & 56 & 15 & 81 & 37 \\
\hline 9 & 28 & 34 & 24 & 59 & 28 & 84 & 40 \\
\hline 10 & 16 & 35 & 36 & 60 & 46 & 85 & 47 \\
\hline 11 & 37 & 36 & 47 & 61 & 25 & 86 & 34 \\
\hline 12 & 45 & 37 & 28 & 62 & 21 & 87 & 45 \\
\hline 13 & 47 & 38 & 27 & 63 & 33 & 88 & 19 \\
\hline 14 & 37 & 39 & 42 & 64 & 37 & 89 & 38 \\
\hline 19 & 45 & 44 & 35 & 69 & 28 & 94 & 22 \\
\hline 20 & 26 & 45 & 23 & 70 & 43 & 95 & 24 \\
\hline 21 & 37 & 46 & 16 & 71 & 15 & 96 & 37 \\
\hline 22 & 47 & 47 & 15 & 72 & 18 & 97 & 20 \\
\hline 23 & 21 & 48 & 45 & 73 & 23 & 98 & 15 \\
\hline 24 & 31 & 49 & 17 & 74 & 15 & 99 & 20 \\
\hline 25 & 22 & 50 & 41 & 75 & 20 & 100 & 24 \\
\hline
\end{tabular}

Fuente: Elaboración propia basado en la información de la empresa

Esta información se trasladó a un formato tipo texto tabulado, para luego ingresar los datos al complemento del software arena: Input analyzer. El resultado del análisis se grafica en la figura 57, la distribución estadística que se ajusta a los datos es la siguiente:

Figura 57: Distribución de la cantidad a producir

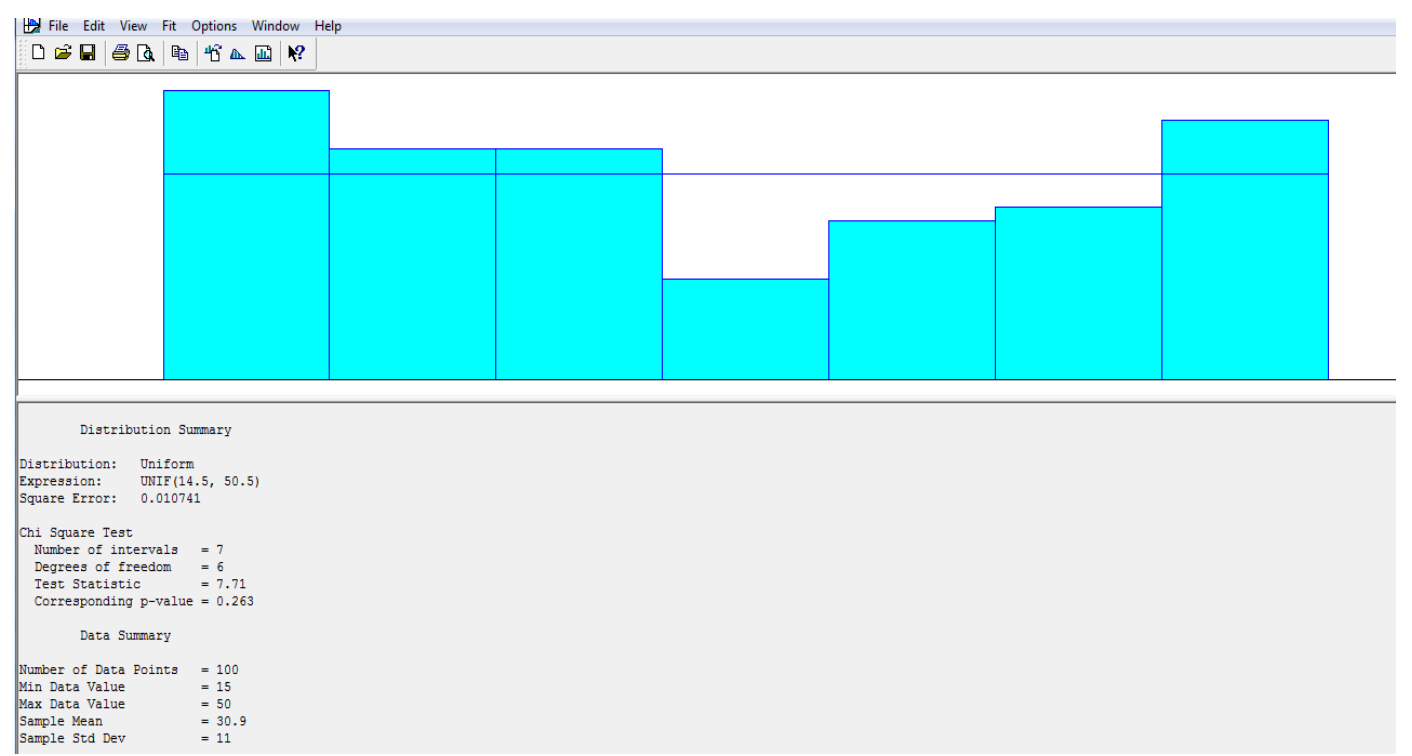

Fuente: Elaboración propia basado en la información de la empresa 
La distribución recomendada por arena es la UNIFORME con parámetros 14.5, 50.5. Como la cantidad de toneladas es entera, definiremos a X1, que es la cantidad de toneladas por pedido, como:

\section{$\mathrm{X} 1=\mathrm{UNIF}(\mathbf{1 4 , 5 0 )}$}

$\underline{\text { Tiempos de Servicio }}$

Los tiempos de servicio se tienen de manera constante para el proceso de producción de fideos de tipo largo, en la línea de producción 1. Dichos tiempos, que toman en procesar una tonelada, son los siguientes:

Tabla 11: Tiempos para procesar una tonelada

\begin{tabular}{|l|c|}
\hline \multicolumn{1}{|c|}{ Proceso } & Minutos $\mathrm{Xt}$ \\
\hline Mezclado & 1 \\
\hline Prensado & 3.7 \\
\hline Secado & 81.25 \\
\hline Envasado & 5 \\
\hline
\end{tabular}

Fuente: Elaboración propia basado en la información de la empresa

Como los tiempos se dan de manera constante definimos las variables de tiempo de servicio como:

- $\mathrm{X} 4=$ CONSTANTE (1) minutos

- $\mathrm{X} 5=$ CONSTANTE (3.7) minutos

- $\mathrm{X} 6=$ CONSTANTE (81.25) minutos

- $\mathrm{X} 7=\mathrm{CONSTANTE}(5)$ minutos

\section{Tiempo Medio Entre Fallas y Tiempo Medio Para Reparar}

Los tiempos entre fallas ocurren en dos sectores del proceso: En prensado y envasado. Pero la ocurrencia de estas fallas se da en un rango entre uno o dos días, lo cual representa cada 24 y 36 horas, para ambos tipos de fallas: 
Tabla 12: Tiempo medio entre fallas

\begin{tabular}{|l|c|c|}
\cline { 3 - 3 } \multicolumn{1}{c|}{} & \multicolumn{2}{c|}{ Tiempo en Horas } \\
\hline $\begin{array}{l}\text { Tiempo Medio Entre } \\
\text { Fallas }\end{array}$ & Mínimo & Máximo \\
\hline Producción & 24 & 48 \\
\hline Envasado & 24 & 48 \\
\hline
\end{tabular}

Fuente: Elaboración propia basado en la información de la empresa

Por lo cual el tiempo entre fallas se representará como una distribución uniforme:

$\mathbf{X 8}=\mathbf{U N I F}(\mathbf{2 4 , 4 8})$ tanto para las fallas de prensa como de envasado. En arena se definirá 2 variables de fallas: Falla 1 y Falla 2 donde ambas serán igual a X8.

El tiempo de reparación de fallas o la demora que tiene una falla tiene distintos tiempos, de los cuales se pudo obtener información al respecto de los tiempos mínimos, máximos y promedios tal como se muestra en la siguiente tabla:

Tabla 13: Tiempo medio para reparar

\begin{tabular}{|lc|c|c|c|}
\cline { 2 - 5 } \multicolumn{1}{c|}{} & \multicolumn{3}{c|}{ Tiempo en minutos } \\
\hline $\begin{array}{l}\text { Tiempo Medio Para } \\
\text { Reparar }\end{array}$ & Mínimo & Promedio & Máximo \\
\hline Producción & 10 & 30 & 240 \\
\hline Envasado & 5 & 40 & 240 \\
\hline
\end{tabular}

Fuente: Elaboración propia basado en la información de la empresa

Por lo cual el tiempo entre fallas se representará como una distribución triangular:

X9 = TRIA $(\mathbf{1 0 , 3 0 , 2 4 0 )}$ para las fallas de producción (Falla 1) y TRIA $(\mathbf{5}, \mathbf{4 0 , 2 4 0 )}$ para las fallas de envasado (Falla 2).

\section{Actividad Manual}

El criterio de los operadores para operar las máquinas, cortarlas antes o después del tiempo programado se ha estimado en base a la información del proceso, y el rango se encuentra entre un $80 \%$ a un $120 \%$. Es decir, $20 \%$ por encima o por debajo del pedido. Esto se ha 
definido para representar el "error humano" que se comete en el proceso actual. Dicha variable la representaremos como X11= UNIF $(\mathbf{0 . 8}, \mathbf{1 . 2})$.

Este porcentaje se multiplicará por la cantidad de toneladas del pedido, para representar dicho "error" y asemejarlo al comportamiento real del proceso.

\section{$\underline{\text { Porcentaje de humedad }}$}

En base a lo trabajado en el proceso, el porcentaje de humedad que hace reducir la cantidad de toneladas producidas en el proceso oscila entre $2 \%$ y $5 \%$. Por lo cual la cantidad que queda de toneladas utilizables para el pedido se multiplicará por $97.5 \%$ a $98 \%$ con lo cual el porcentaje de humedad lo definimos por X12 $=\mathbf{1} * \mathbf{U N I F}(\mathbf{0 . 9 7 , 0 . 9 8 )}$

\section{Indicador de Cumplimiento}

El principal indicador del proceso es el de cumplimiento que se define por lo siguiente:

\section{IC = Pedidos cumplidos /Total de Pedidos}

A su vez los pedidos cumplidos son aquellos que su Porcentaje de Cumplimento está entre 0.9 y 1.1. El porcentaje de cumplimiento se define por:

\section{PCT_CUMP= Toneladas Producidas/Toneladas del pedido}

En la simulación del proceso actual se buscará evaluar el Indicador de Cumplimiento (IC) y que su resultado, en base a la recolección de datos se asemeje a lo que ocurre en el proceso actual. Si dicho resultado es confiable, podremos usar el proceso simulado para proponer las mejoras planteadas en la tesis. 


\subsubsection{Ejecución de la Simulación}

Para simular el proceso actual de producción, de la línea 1, en la producción de fideos se usará el software ARENA. Para ello se hará uso de los siguientes módulos propios de la programación en Arena:

- Create: Utilizado para la creación de entidades.

- Process: Para representar los tiempos de proceso de las diversas actividades que usan recursos y consumen tiempos, por donde las entidades pasarán.

- Decide: Modulo utilizado para indicar una decisión que conlleva a dos o más caminos dependiendo la decisión que se toma en el proceso.

- Assign: Sirve para definir atributos y variables a usar en el proceso, propias de las entidades o que se utilizarán para calcular un indicador.

- Separate: Módulo que permite CLONAR entidades, en base a una entidad original.

- Hold: Módulo que permite bloquear el ingreso de entidades a una parte del proceso, debido a que un recurso se encuentra ocupado, o en falla.

- Failures: Módulo que permite indicar los tiempos entre fallas y los tiempos que demora una falla.

- Statistics: Módulo que permite almacenar estadísticas en cada corrida de simulación que se desee realizar.

\section{Entidades y Tiempo entre llegadas}

Para diseñar las entidades de órdenes de producción o pedidos se utiliza un Create que se basará en un tiempo determinado en la recolección de datos como X2 y X3. A su vez para obtener X2 y X3 se usa dos variables llamadas "Valor1" y "Valor2" que permiten tener los parámetros de:

- Cantidad de pedidos en el mes.

- Cada cuanto ingresará un pedido al proceso. 
Para el cálculo de Valor 1 y Valor 2 se utiliza un create, un assign y un dispose para dar la aleatoriedad al valor de los pedidos que ingresarán en un mes. Posterior a ello con ese resultado se elabora el Create principal que recibe el pedido de producción.

Figura 58: Cálculo de Valor 1 y Valor 2

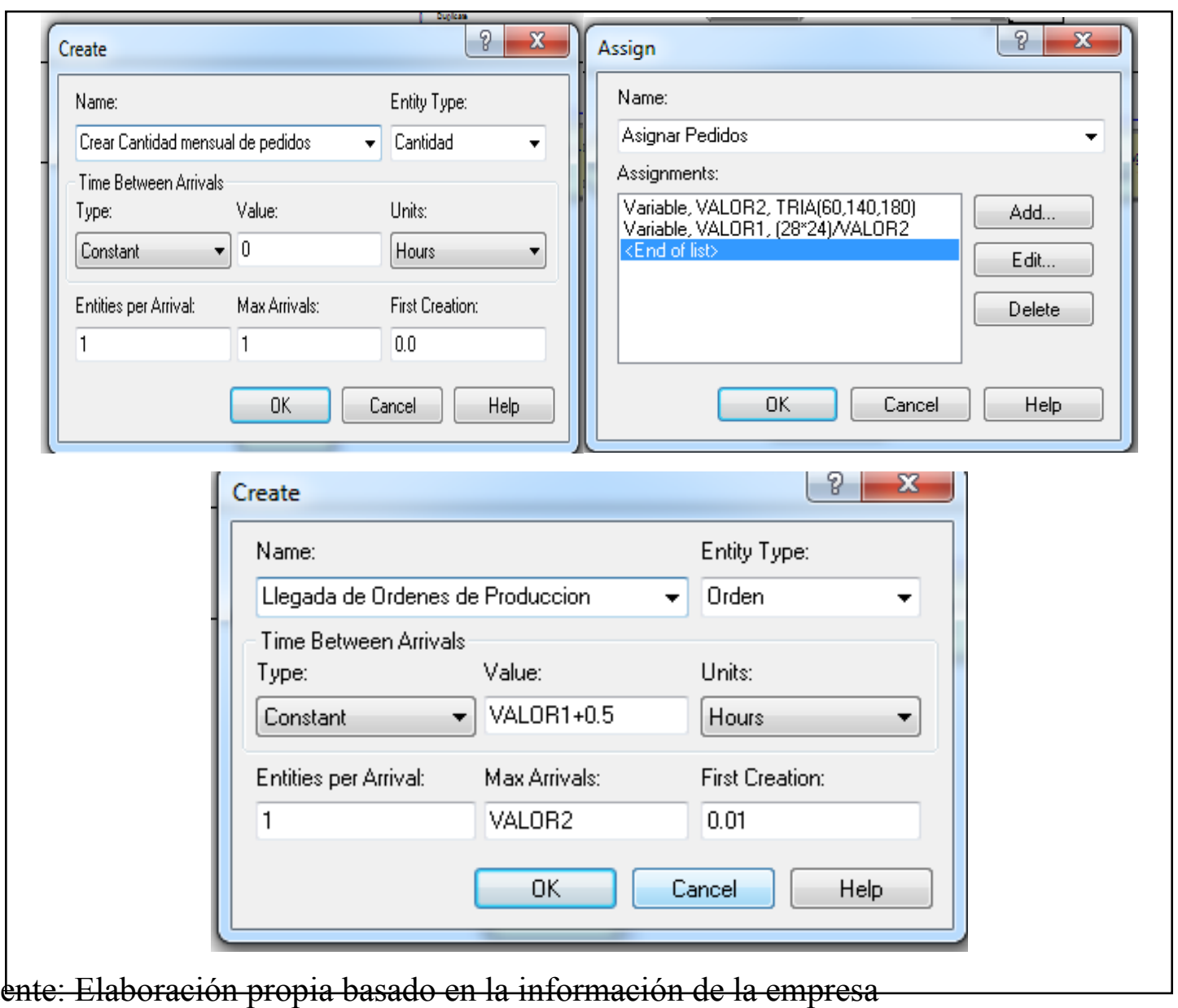

Fuente: Elaboración propia basado en la información de la empresa

\section{Cantidad de Pedidos y Atributos}

En el caso de X1 que representa la variable de la cantidad de pedidos, se definen en un Assign y también otras variables secundarias y atributos como:

- $\quad$ Ton_ $\mathrm{P}=$ Toneladas que contiene el pedido, que es $\mathrm{X} 1=\mathrm{UNIF}(14,50)$

- $\quad \mathrm{PCT}=$ Porcentaje de error humano, que es $\mathrm{X} 11=\operatorname{UNIF}(0.8,1.2)$

- Ton_PR= Toneladas de producción que se harán en el proceso, que es la multiplicación del porcentaje por las toneladas del pedido. 
- Hora Llegada= Atributo que almacena la hora en que llega el pedido.

- Tiempo_P $=$ Es el tiempo de producción estimado para el pedido, en base a la capacidad por hora de 4 toneladas

- Pedidos $=$ Cantidad de pedidos que van ingresando al proceso.

- $\quad$ Código $=$ Es un atributo que marca un código para el pedido que está ingresando. Esto con la finalidad de detectar cuál es el último pedido.

Figura 59: Asignación de valores Assign

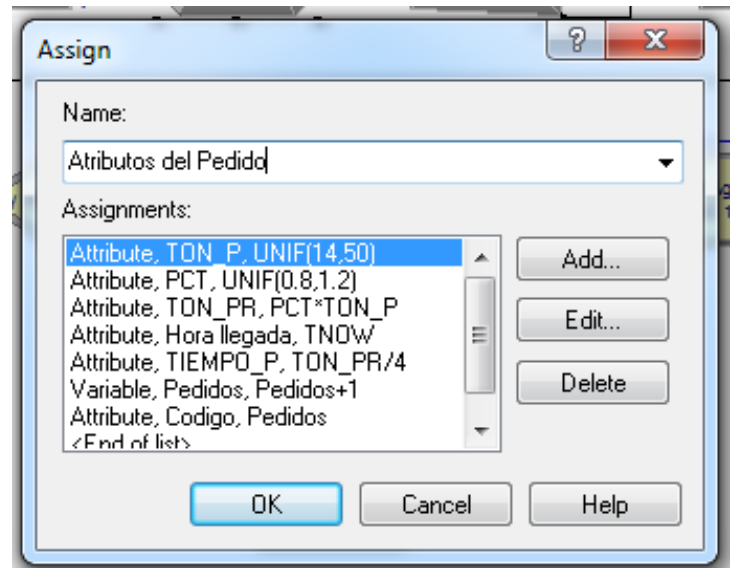

Fuente: Elaboración propia basado en la información de la empresa

\section{$\underline{\text { Creación de Toneladas del Pedido }}$}

Ton_Pr es la variable que define la cantidad de toneladas a producir, ya definidas por los operarios en esta parte del proceso. Pero como la entidad inicial es "PEDIDO" y es una sola, se debe convertir a una cantidad mayor, que son las toneladas, por lo cual se usa el módulo Separate para CLONAR la entidad pedido, y que todas las toneladas de dicho pedido mantengan su característica y atributos. 
Figura 60: Asignación de valores Separate

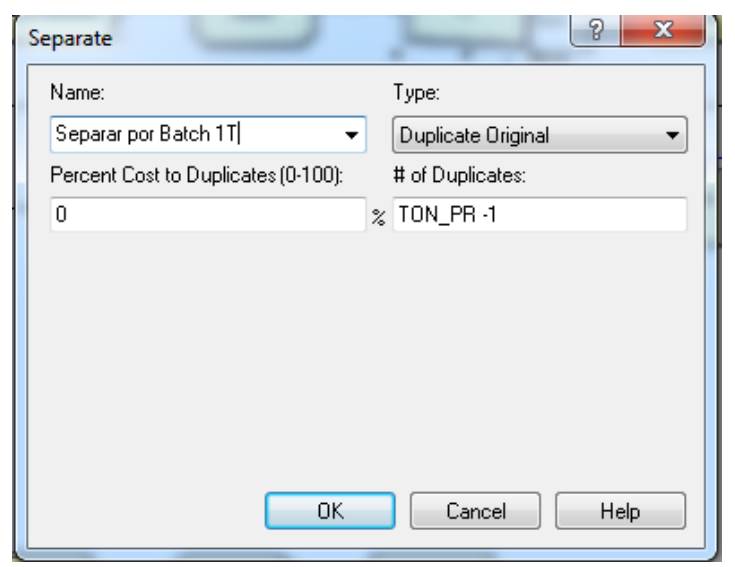

Fuente: Elaboración propia basado en la información de la empresa

\section{Bloqueo de entidades}

Si bien al proceso deben ingresar cierta cantidad de toneladas, estas entran por batch o una por una, siempre y cuando no halla fallas, y las máquinas se encuentren libres. A su vez, como el proceso es continuo, se debe asegurar que cuando se libere una actividad del proceso, inmediatamente llegue el siguiente batch. Esta condición lo realizamos con el módulo hold en diversas partes del proceso a simular.

Figura 61: Asignación de valores Hold

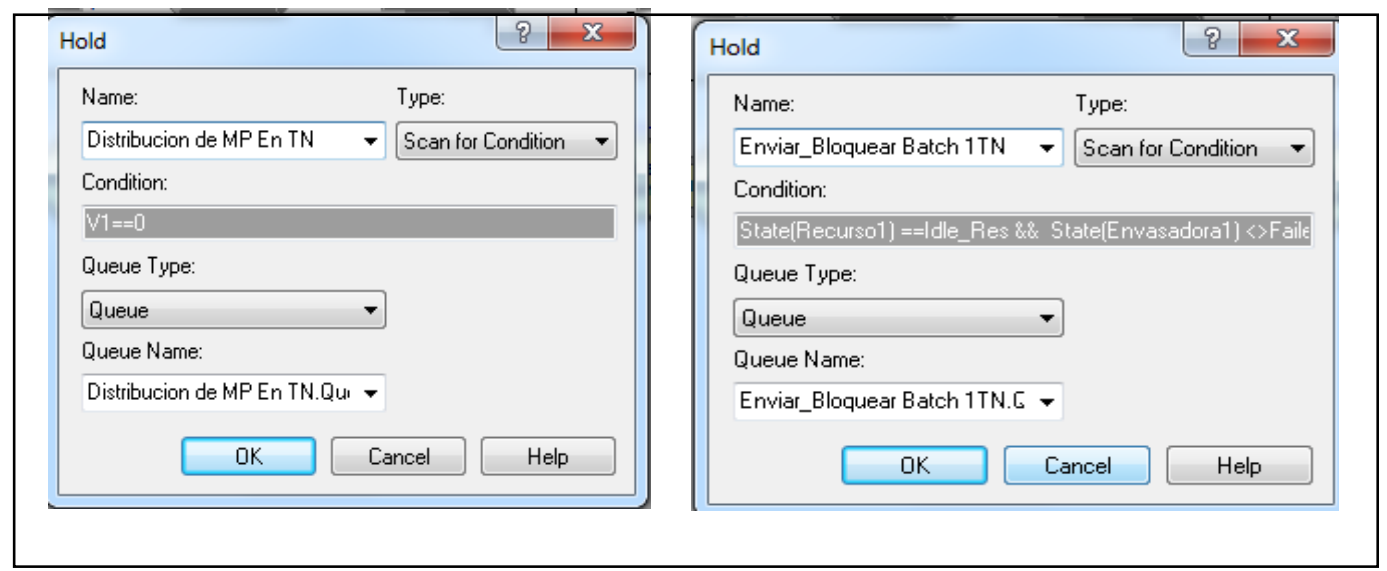

Fuente: Elaboración propia basado en la información de la empresa

Decisión si todas las toneladas se producen 
Puede ocurrir que, en una parte del proceso, por fallas u otros factores, se planificaron cierta cantidad de toneladas a producir, pero se corta el proceso para que ingrese otro pedido o las horas programadas para elaborar dichas toneladas ya se excedieron. Si esto pasa, dicha tonelada o batch no ingresa al proceso de producción. Para representar dicho comportamiento se utiliza un módulo decide que evalúa si la hora actual con la hora que el pedido ingreso es menor al tiempo planificado. Si es verdadero se produce, caso contrario no es producida, considerándolo como merma.

Figura 62: Asignación de valores Decide

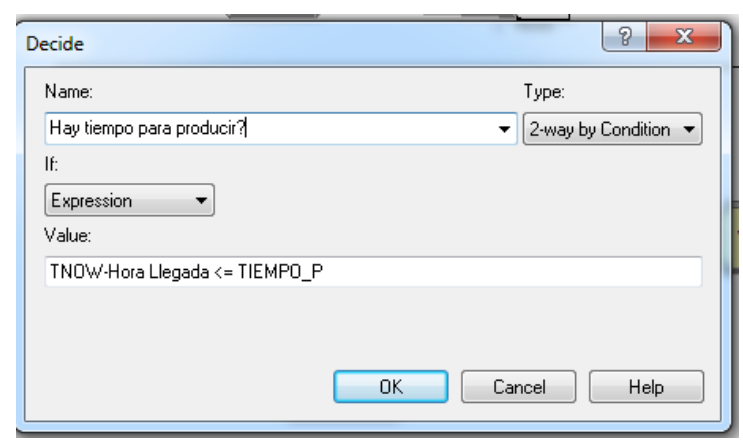

Fuente: Elaboración propia basado en la información de la empresa

$\underline{\text { Tiempos de Servicio }}$

Para los tiempos de servicio se utilizó los módulos process en los cuales se colocará los tiempos definidos con las variables $\mathrm{X} 4, \mathrm{X} 5, \mathrm{X} 6$ y X7 en la recolección de datos. Los recursos utilizados se colocaron como mezcladora, prensadora (Recurso1), secadora, envasadora, en las cuales detrás de dichas máquinas hay un equipo humano, el cual se considera como un solo conjunto de recursos por actividad, el cual en este proceso actual y el propuesto se mantendrán constante. 
Figura 63: Asignación de valores Process

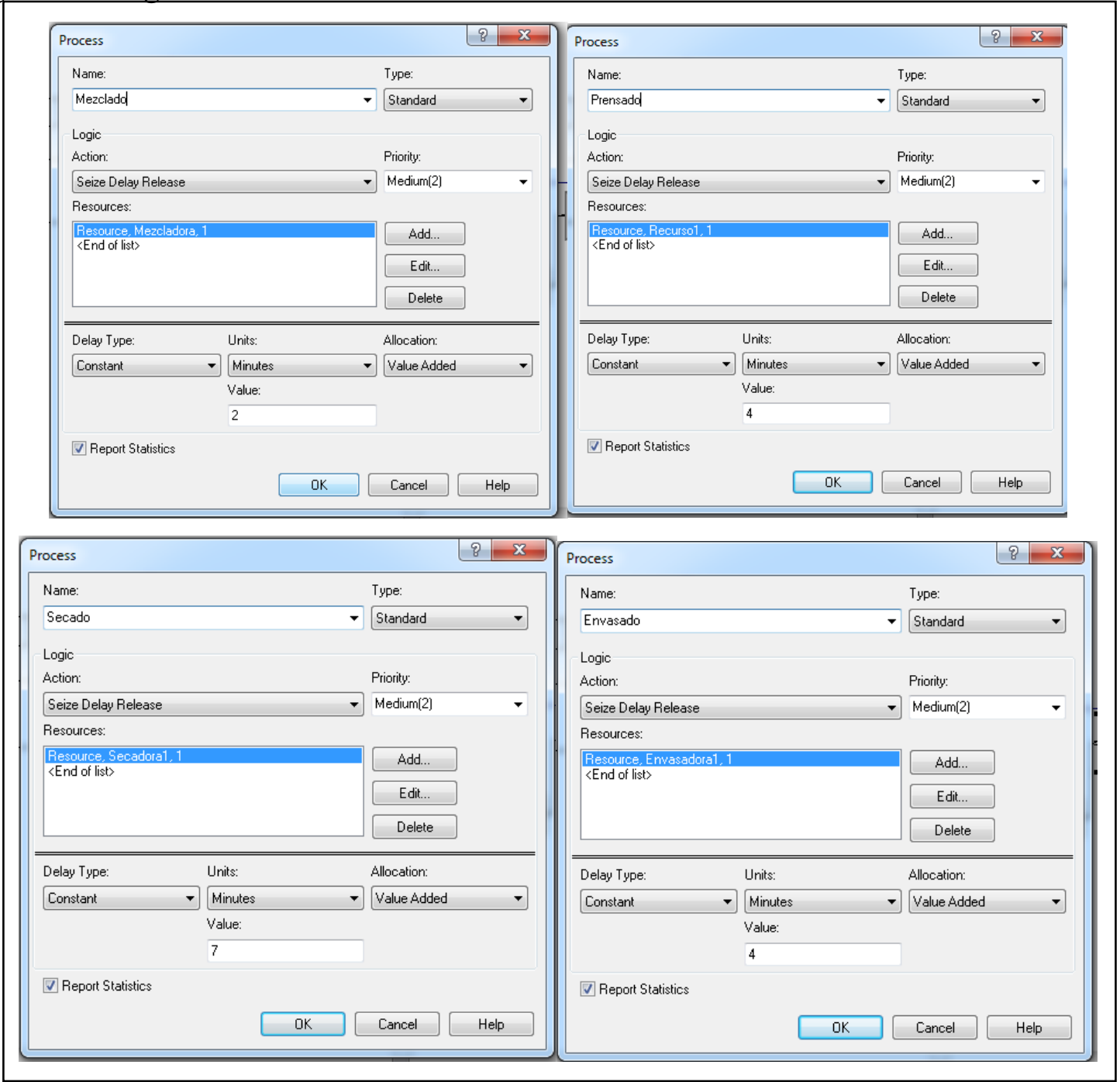

Fuente: Elaboración propia basado en la información de la empresa

Tiempos Medio en Falla y Tiempos Medio Para Reparar

Basados en las distribuciones definidas en la recolección de datos, X8 y X9, se colocan en el módulo "Failures" de Arena, para luego en el módulo "Resources" indicar que recursos tendrán la falla, en este caso, prensa y envasado. Lo expresado se muestra cómo se ingresó en el software de simulación Arena. 
Figura 64: Asignación de valores Variables

\begin{tabular}{|c|c|c|c|c|c|c|}
\hline \multirow[t]{2}{*}{ Failure } & \multicolumn{6}{|c|}{ Advanced Process } \\
\hline & Name & Type & Up Time & Up Time Units & Down Time & Down Time Units \\
\hline 1 V & Falla1 & Time & UNIF $(24,48)$ & Hours & $\operatorname{TRIA}(10,30,240)$ & Minutes \\
\hline 2 & Falla2 & Time & UNIF $(24,48)$ & Hours & $\operatorname{TRIA}(5,40,240)$ & Minutes \\
\hline
\end{tabular}

\begin{tabular}{|c|c|c|c|c|c|c|c|c|c|}
\hline \multicolumn{10}{|c|}{ Resource - Basic Process } \\
\hline & Name & Type & Capacity & Busy/Hour & Idle / Hour & Per Use & StateSet Name & Failures & Report Statistics \\
\hline 1 D & Recurso1 & Fixed Capacity & 1 & 0.0 & 0.0 & 0.0 & & 1 rows & E \\
\hline 2 & Mezcladora & Fixed Capacity & 1 & 0.0 & 0.0 & 0.0 & & 0 rows & E \\
\hline 3 & Secadora1 & Fixed Capacity & 1 & 0.0 & 0.0 & 0.0 & & 0 rows & E \\
\hline 4 & Envasadora1 & Fixed Capacity & 1 & 0.0 & 0.0 & 0.0 & & 1 rows & E \\
\hline
\end{tabular}

Fuente: Elaboración propia basado en la información de la empresa

\section{$\underline{\text { Lógica del último evento }}$}

Para detectar que la simulación finalizó, se elaboró una lógica del proceso en la cual se ubica el último pedido con el atributo "Código". Si el código es igual a la cantidad de pedidos del mes, simulada al inicio del proceso, indica que ya la simulación está por terminar. Luego para determinar que se está fabricando la última tonelada o batch de dicho pedido, con la variable auxiliar WIP, que indica cuantas entidades hay en el proceso, si dicho WIP es $=1$ indica que es la última tonelada. Esta lógica sirve para finalizar el cálculo del indicador de cumplimiento y finalizar la simulación.

Figura 65: Diagrama de bloques para el cálculo

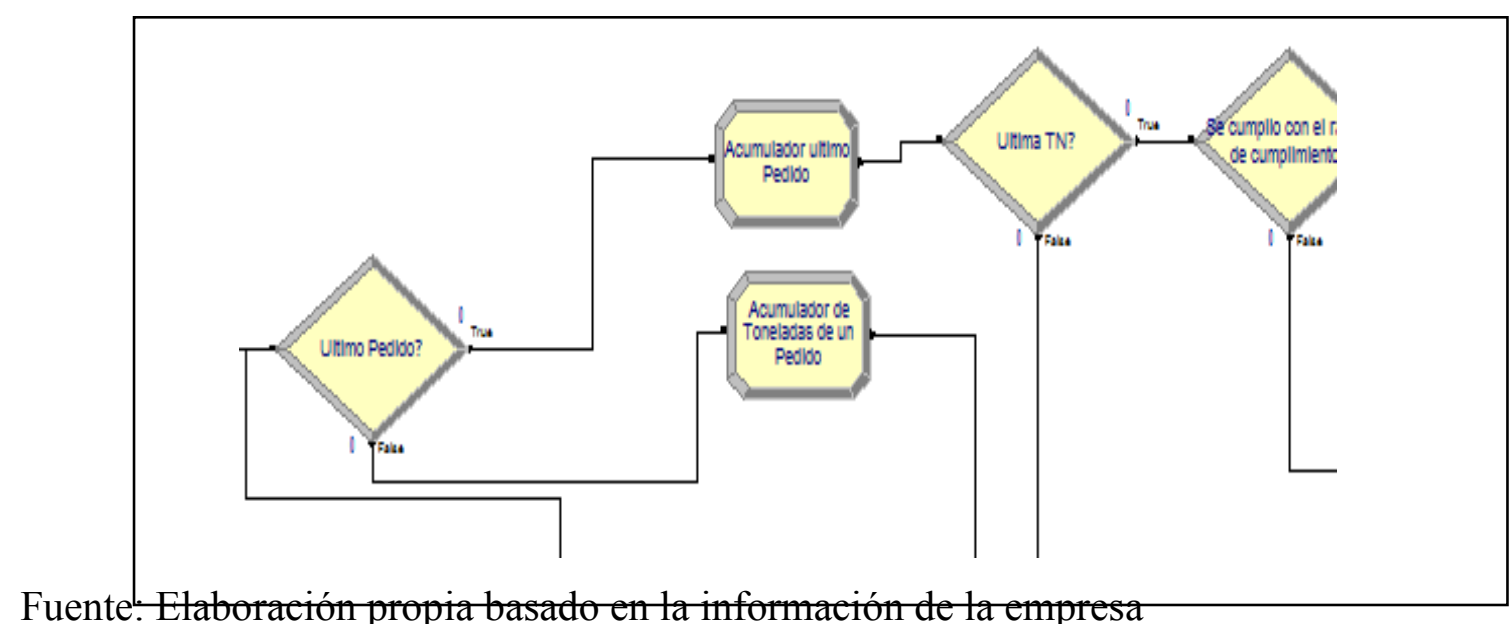

$\underline{\text { Indicador de Cumplimiento }}$ 
Para calcular el indicador principal del proceso que es el indicador de cumplimiento que indica si las toneladas producidas están entre el 90\% y $110 \%$ de las toneladas requeridas por el pedido, se utiliza módulos Assign para el cálculo de variables auxiliares que determinen el valor de PCT_CUMP, en base a una acumulación del total de toneladas producidas, que está definido por TOTAL_TN, las cuales indican cuantas toneladas realmente se han producido de un MISMO PEDIDO. Si se cumple con el rango, se aumenta un contador "Cumplido1" y si es el último pedido que cumple, se aumenta el contador “cumplido2". Al final el cálculo del indicador de cumplimento se da por la fórmula definida en la recolección de datos:

\section{IC $=($ Cumplido1 + Cumplido2 $) /$ Pedidos}

Figura 66: Asignación de variables para calcular indicador principal

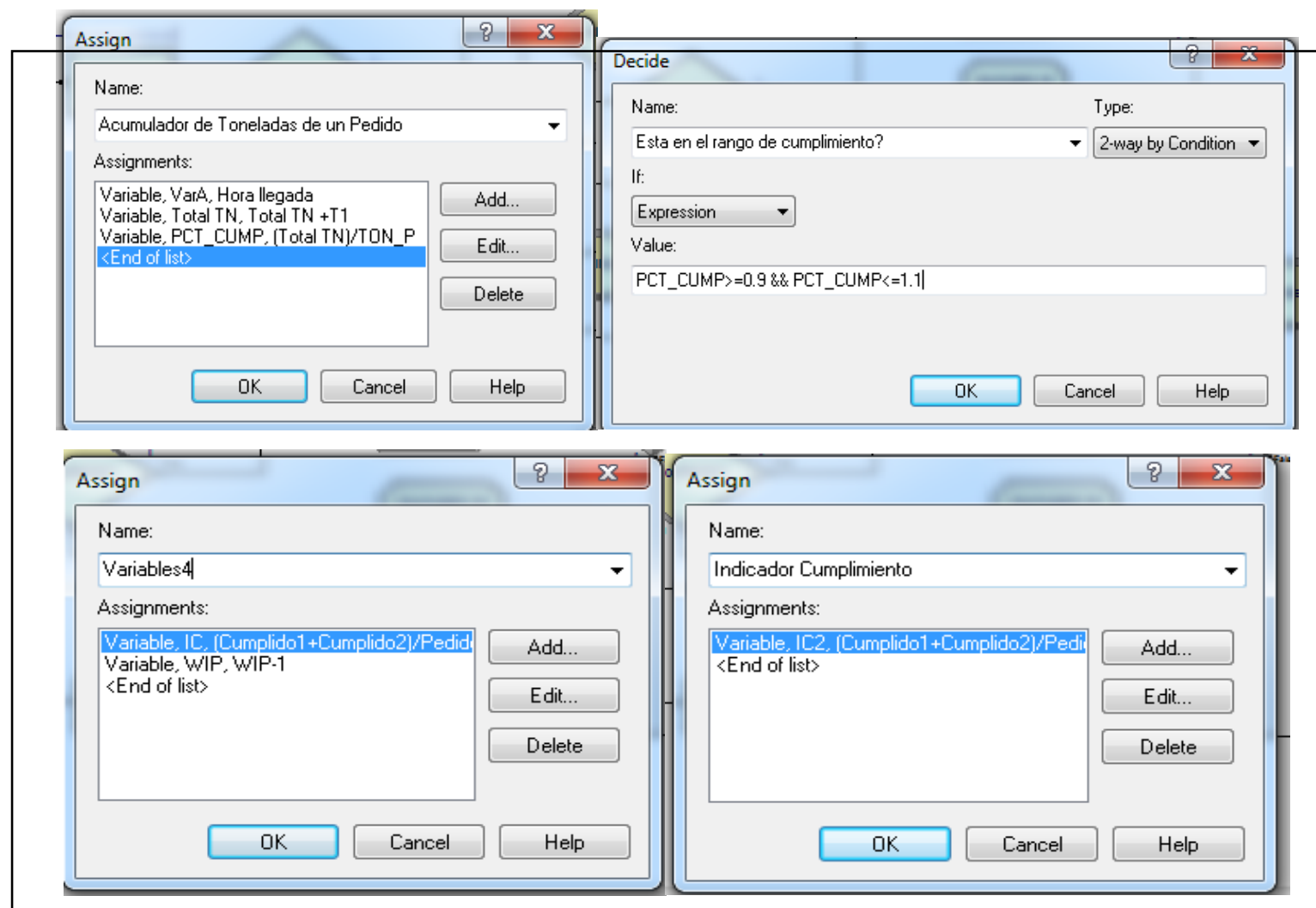

Fuente: Elaboración propia basado en la información de la empresa

Condiciones de Simulación 
Se trabajó con 30 réplicas de simulación, que representan 30 meses simulados, en base a las condiciones definidas en el proceso en Arena. Las unidades están expresadas en horas, y para los reportes se usa la categoría SIMAN que es un archivo de texto. Cada réplica con el valor del indicador de cumplimiento final, de entidades en proceso, y de pedidos atendidos se almacenará en un archivo para guardar estadísticas y validar un posible intervalo de confianza.

Figura 67: Asignación de condiciones de simulación

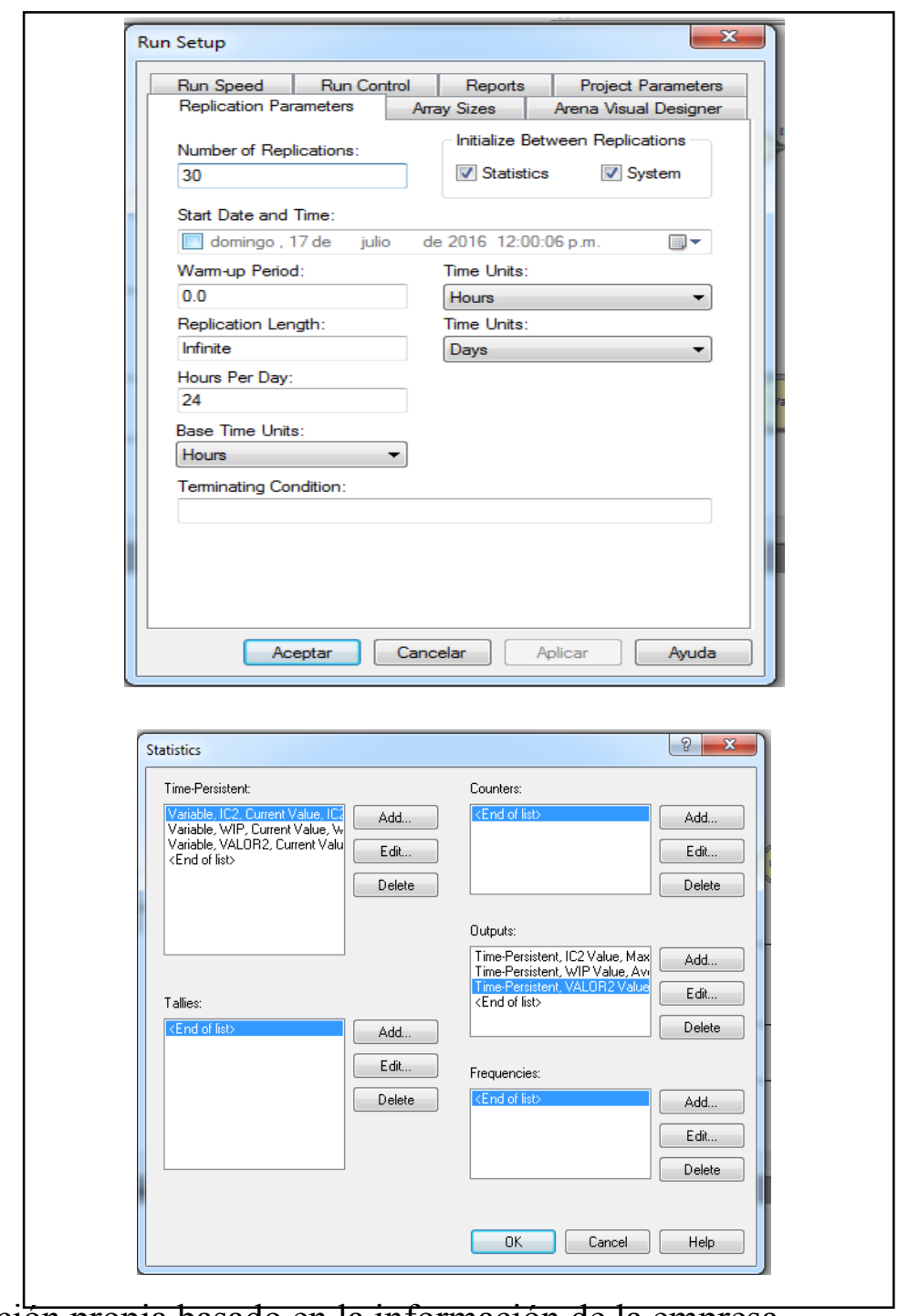

Fuente: Elaboración propia basado en la información de la empresa 
Luego, el proceso en Arena, con las condiciones de simulación explicadas y aproximándose al comportamiento del proceso actual de producción de fideos para una línea de producción queda como el siguiente flujo:

Figura 68: Flujo del proceso simulada con Arena

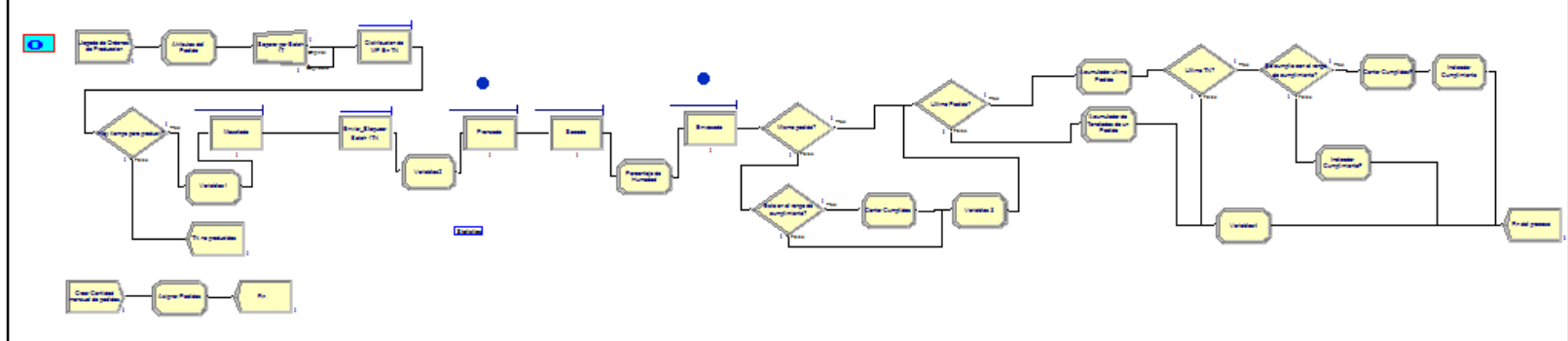

Fuente: Elaboración propia basado en la información de la empresa

\subsubsection{Resultados de la simulación del proceso actual}

Realizando 30 simulaciones, los resultados que muestra en el reporte SIMAN, formato del software Arena, arrojó los siguientes resultados principales (Outputs) asociados al proceso actual de producción de fideos:

- Pedidos Promedio

129.30

- Indicador Cumplimiento

0.50803

- $\quad \mathrm{TN}$ en el sistema

2.3530

- Orden.NumberIn (TN a producir)

4044.1

- Tn Producidas

4023.8

- Envasadora1.ScheduledUtilization

0.35338

- Mezcladora.ScheduledUtilization

0.17669

- Secadora1.ScheduledUtilization

0.61841

- Recurso1.ScheduledUtilization (Prensa) 0.35338 
La simulación tomó 6.5 minutos para ejecutar las 30 réplicas. Un tiempo considerado regular, debido a que se "clona" entidades y se procesa una gran cantidad de ellas, lo cual hace que el proceso sea largo en la simulación. Con respecto a los principales indicadores que se observan en la parte final del reporte se tiene los siguientes resultados promedios de las 30 réplicas:

- La cantidad de pedidos u órdenes de producción son en promedio 129 al mes para la línea 1 de producción de fideos.

- El indicador de cumplimiento IC que es el principal indicador por calcular, en el proceso actual toma un valor promedio de $50.8 \%$ con lo cual se valida que el resultado se encuentra cerca a lo que ocurre a la realidad, con lo cual podemos decir que el proceso simulado en Arena refleja mucha similitud a lo que ocurre con el proceso planteado en la tesis y su resultado asociado al principal indicador, que es el cumplimiento de las órdenes o pedidos.

- Las toneladas promedio en el sistema que siempre se están procesando es de 2.35 toneladas o batch que pueden estar en cualquier parte del proceso.

- En promedio en cada simulación (cada mes) se debían producir 4044 toneladas o batchs, pero por temas de fallas se producían sólo 4023 toneladas, con lo cual se entiende que algunos pedidos no se cumplieron en su totalidad.

- La utilización neta de las maquinarias es aproximadamente de $18 \%$ para la mezcladora, $35 \%$ la envasadora y prensadora, $62 \%$ para la secadora.

\subsubsection{Tamaño de Réplicas}

Para validar la confiabilidad de que las 30 simulaciones son confiables, observamos el resultado general de los 3 indicadores principales, donde se indica el Half-Width:

\section{Promedio Half-Width}

- Pedidos Promedio

- Indicador de Cumplimiento
129.3

0.508
7.9801

.0184 
- $\quad$ TN en el sistema

El half-Width es el tamaño del error o la mitad del intervalo de confianza al 95\% del indicador que se esté analizando.

En el estudio de simulación definiremos que la desviación o diferencia de los resultados no difieran en más del 10\% del promedio que se obtenga

- Pedidos promedio

- Indicador de cumplimiento

- $\quad$ TN en el sistema

$$
129.3 * 0.10=12.93
$$$$
0.508 * 0.10=0.058
$$

$2.353 * 0.10=0.235$

Los half width son menores en los 3 casos. $7.9801<12.93$ para los pedidos promedio, $0.0184<0.058$ para el indicador de cumplimiento y $0.1298<0.235$ para las toneladas en el sistema con lo cual podemos concluir que el tamaño de 30 réplicas nos da una confianza del 95\% en los resultados obtenidos de los principales indicadores analizados.

\subsubsection{Diseño y resultados del proceso propuesto}

La propuesta de mejora se centrará en la implementación principalmente de la herramienta "Poka Yoke" y balance de masa, donde se realizarán las siguientes acciones:

- Inicio Implementación Manufactura Esbelta.

- Verificación y control de Procesos

- Evaluación y mejora continua

Estas acciones permitirán que la desviación actual que se comete al momento de planificar los batch y toneladas de producción disminuyan o sean de un intervalo de ocurrencia más corto, ya que se calcula en base a la cantidad a producir y que esta se encuentre dentro de los rangos de 0.90 y 1.1 . 
Se estimó que el rango de error humano que se comete en el proceso actual, para el proceso propuesto disminuya a

$$
\text { X11= UNIF (0.92, 1.08). }
$$

Estos cambios los ingresaremos al nuevo al diagrama mejorado, creando un nuevo proceso propuesto. Específicamente en el módulo ASSIGN al inicio del proceso se realiza la modificación indicada, basada en la propuesta de mejora. Posterior a ello se ejecutará la simulación para evaluar los resultados que tiene lograr que el error humano por cálculos errados disminuya y cuál es su efecto en los principales indicadores del proceso.

Figura 69: Ingreso de variables en Assign al nuevo diagrama mejorado

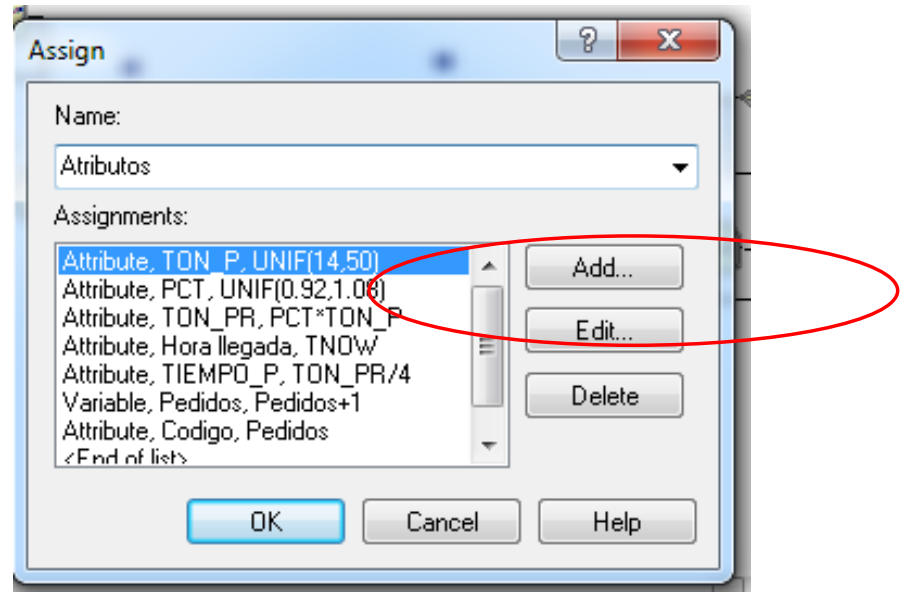

Fuente: Elaboración propia basado en la información de la empresa

Realizando 30 simulaciones, los resultados que muestra en el reporte SIMAN, formato del software Arena, arrojó los siguientes resultados principales (Outputs) asociados al proceso actual de producción de fideos:

- Pedidos Promedio

- Indicador Cumplimiento

0.85959

- $\mathrm{TN}$ en el sistema

2.3251 . 
- Orden. NumberIn (TN a producir)

- Tn Producidas

- Envasadora1.ScheduledUtilization

- Mezcladora. ScheduledUtilization

- Secadora1.ScheduledUtilization

- Recurso1.ScheduledUtilization (Prensa) 0.34983
4005.6

3989.4

0.34983

0.17492

0.61221

La simulación tomó 6 minutos para ejecutar las 30 réplicas. Un tiempo considerado regular, debido a que se "clona" entidades y se procesa una gran cantidad de ellas, lo cual hace que el proceso sea largo en la simulación. Con respecto a los principales indicadores que se observan en la parte final del reporte se tiene las siguientes interpretaciones:

- La cantidad de pedidos u órdenes de producción son en promedio 129 al mes para la línea 1 de producción de fideos. Esto se mantiene con la anterior simulación, validando los resultados de ambos escenarios.

- El indicador de cumplimiento IC en el proceso PROPUESTO toma un valor promedio de 0.859 o $85.9 \%$ con lo cual se valida que el proceso propuesto mejora en casi $36 \%$ el cumplimiento actual, demostrando que el proceso propuesto presenta un mejor escenario para el cumplimiento efectivo de las ordenes de producción o pedidos.

- La utilización neta de las maquinarias es aproximadamente de $18 \%$ para la mezcladora, $35 \%$ la envasadora y prensadora, $61 \%$ para la secadora. La utilización de las maquinas sigue manteniéndose casi igual.

\subsubsection{Implementación del prototipo}

Para validar y estimar el impacto de la propuesta de mejora se está implementando un prototipo en una de las líneas de producción de fideos, es una la línea que tiene la mayor cantidad de cambios de formato, hasta 5 cambios de formato al día, de capacidad nominal 
de 4 t/hr, y produce fideos de formato cortos. Para empezar, se analiza las principales variables identificadas en el proceso, tal como se muestra en la figura 14 del capítulo II.

\section{Humedad de la materia prima}

La humedad relativa (HR) de la materia prima, que es la harina, se encuentra especificada de acuerdo con formulación determinada por el área de desarrollo, y esta debe ser de 14.5 $\%$ HR, esta variable es controlada en el proceso, para lo cual el área de calidad muestrea cada lote de harina que ingresa al proceso para validar esta información. La humedad relativa de la harina controladas al ingreso del proceso dio como resultado en promedio $14.56 \%$ HR con una desviación estándar de 0.195 .

\section{Producto no conforme}

No toda la producción es $100 \%$ conforme, esta pérdida es mínima en el proceso actual y para identificarla se realizó la medición en el último año del porcentaje de producto no conforme; se encontró que en promedio es de $2.53 \%$ de producto no conforme, con una desviación estándar de 0.68 .

\section{Humedad final del producto terminado}

La humedad final del producto es la variable característica que debe tener el producto terminado al término del proceso de secado y previo a la etapa de envasado. El valor de la humedad final según especificaciones de desarrollo y calidad no debe ser superior a $12.5 \%$ HR para asegurar la calidad del producto. Por tal, este valor es muestreado frecuentemente. El valor promedio del último año de operación estimado fue de $12.02 \% \mathrm{HR}$ con una desviación estándar de 0.07 


\section{Porcentaje de reproceso (formatos Largos)}

Los fideos de formato largo luego de ser secados (figura 70) son cortados en longitudes estándares para ser envasados, de estos cortes resulta trozos de fideos sobrante, a estos sobrantes o excesos de fideos se denominan horquillas, la horquilla es un producto para reproceso. La cantidad de horquillas, en promedio es de $7.6 \%$ respecto al total de producción. Esta cantidad de horquillas se puede reprocesar, para lo cual se muele el fideo y se regresa a la etapa de mezclado. El producto se recupera por eso se denomina porcentaje de reproceso.

Figura 70: Secado de fideos

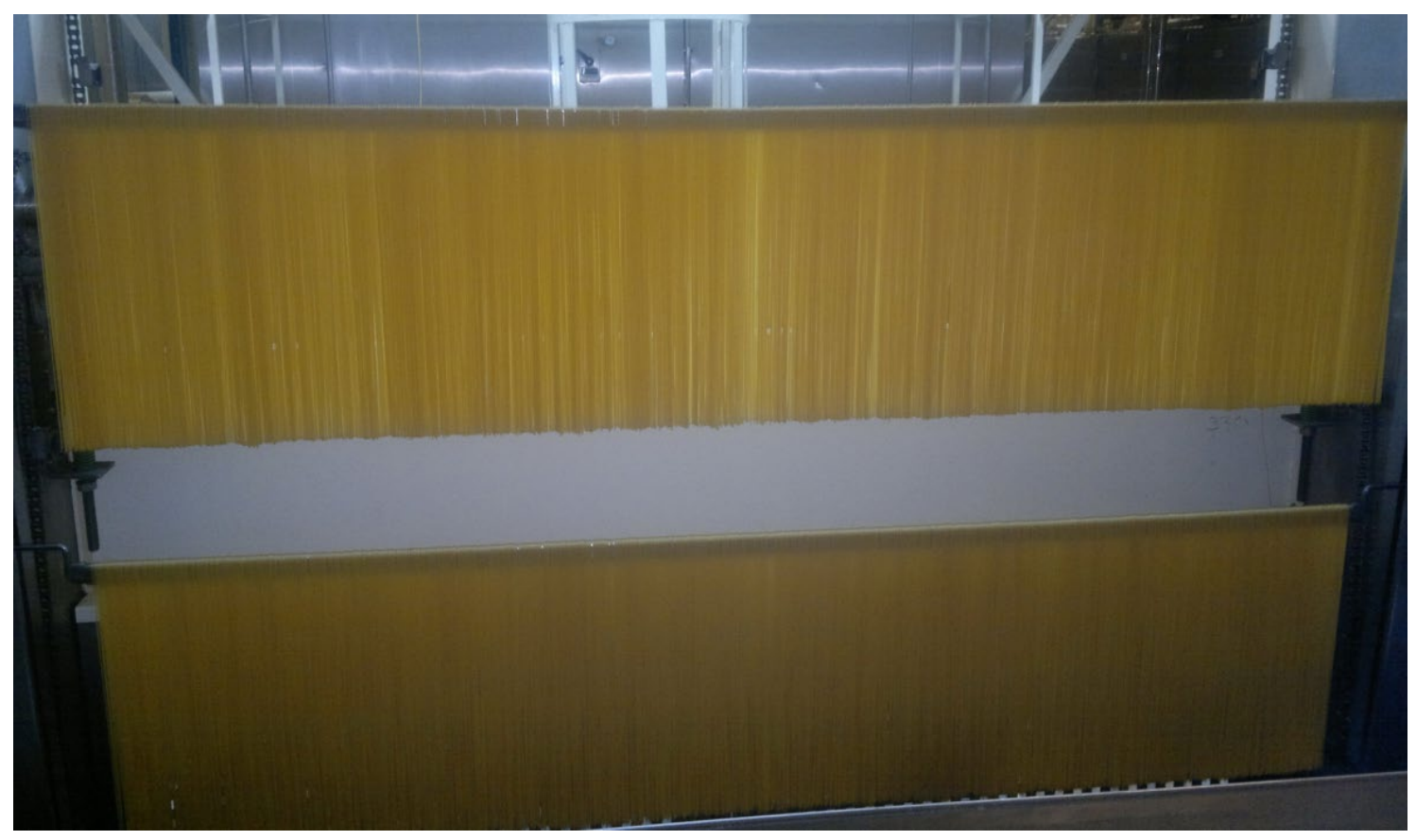

Fuente: La empresa

\section{Balance de masa}

Para gestionar los procesos industriales y tener un control adecuado se realiza diferentes análisis como de la productividad del trabajo, productividad del capital, productividad de los materiales entre otros. El balance de la masa es una expresión de conservación de la 
materia y es utilizada para controlar los desempeños de los materiales. En este sentido, los materiales que ingresan a un proceso productivo deben ser igual a los que salen de él, en la siguiente figura 71 se muestra el balance de masa del proceso de fabricación de fideos.

Figura 71: Balance de masa del proceso de producción de fideos

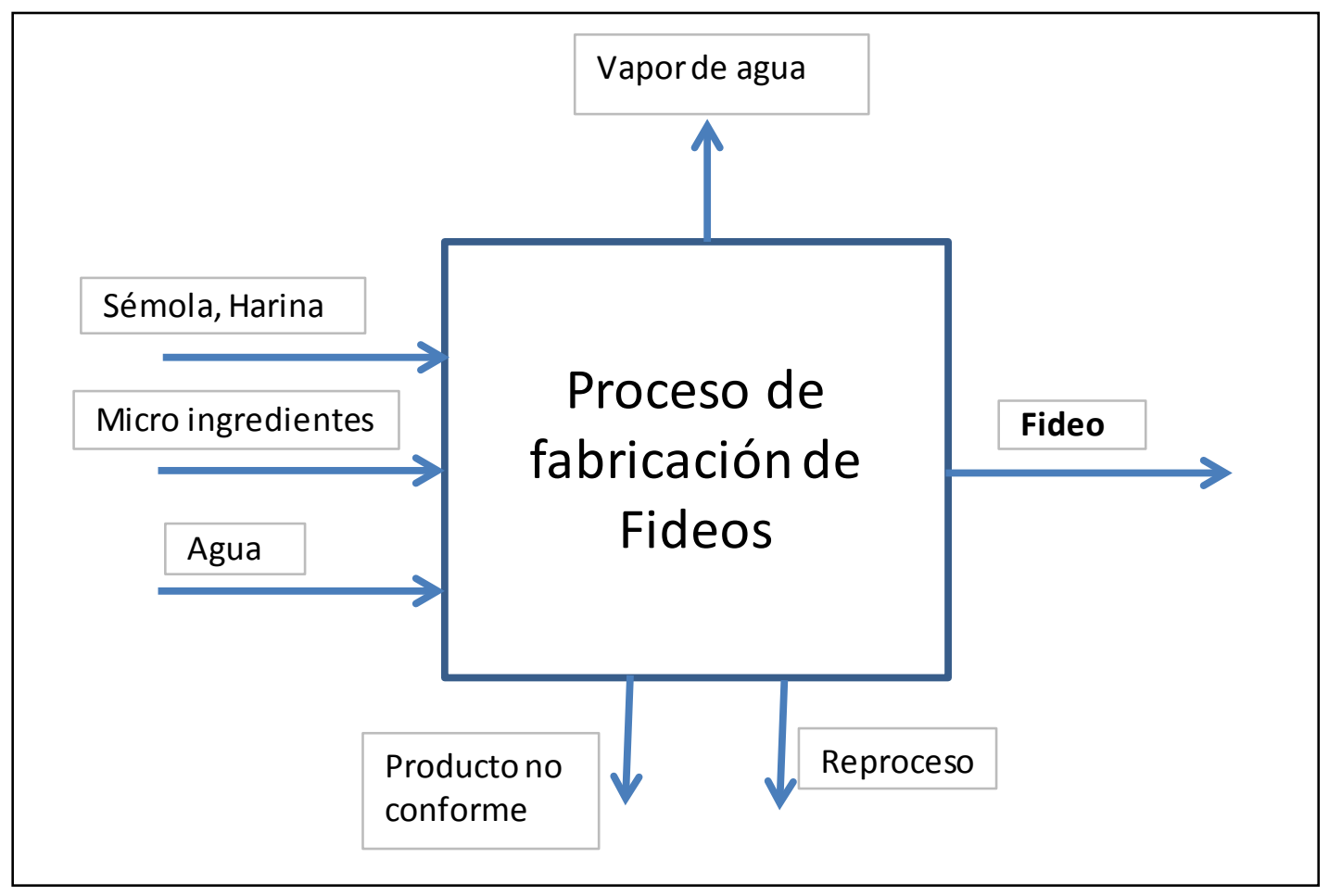

Fuente: Elaboración propia basado en la información de la empresa

En el esquema se muestra los materiales que ingresan al proceso de fabricación de fideos sémola, harina, micro ingredientes y agua; y se obtiene como salida vapor de agua, producto no conforme, producto para reproceso y fideo. Para explicar la relación se utiliza como ejemplo la cantidad de necesidad de fabricar $14000 \mathrm{~kg}$ de fideos. Para lo cual se desea estimar que cantidad de materia prima (sémola, harina) es necesaria. En el cálculo no se considera los micros ingredientes por que la cantidad es despreciable en proporción a la formulación y el agua que se agrega para formar el producto se evapora durante el proceso. La materia prima que ingresa al proceso tiene como humedad relativa inicial de $14.5 \%$, tal 
como se explicó en el análisis de variables, esta humedad relativa durante el proceso de secado bajará a $12 \% \mathrm{HR}$, por lo tanto, hay una pérdida de peso de $2.5 \%$, luego el producto final no es $100 \%$ conforme, de acuerdo con la evaluación de variables se obtendría una producción conforme al $97.5 \%$, es decir una pérdida de $2.5 \%$. En ese sentido, para poder cumplir con la necesidad de $14000 \mathrm{Kg}$ de fideo de formato corto, habría que sumar el volumen que se pierde en la humedad y en el producto no conforme. No se considera adicionar la pérdida por producto en reproceso, ya que en este caso es la línea de fideos de formato corto, donde no hay horquillas. La siguiente figura 72 muestra el ejemplo como se estima el volumen de la materia prima para producir $14000 \mathrm{~kg}$ de fideos a partir del análisis del proceso. 
Figura 72: Estimación del volumen de harina

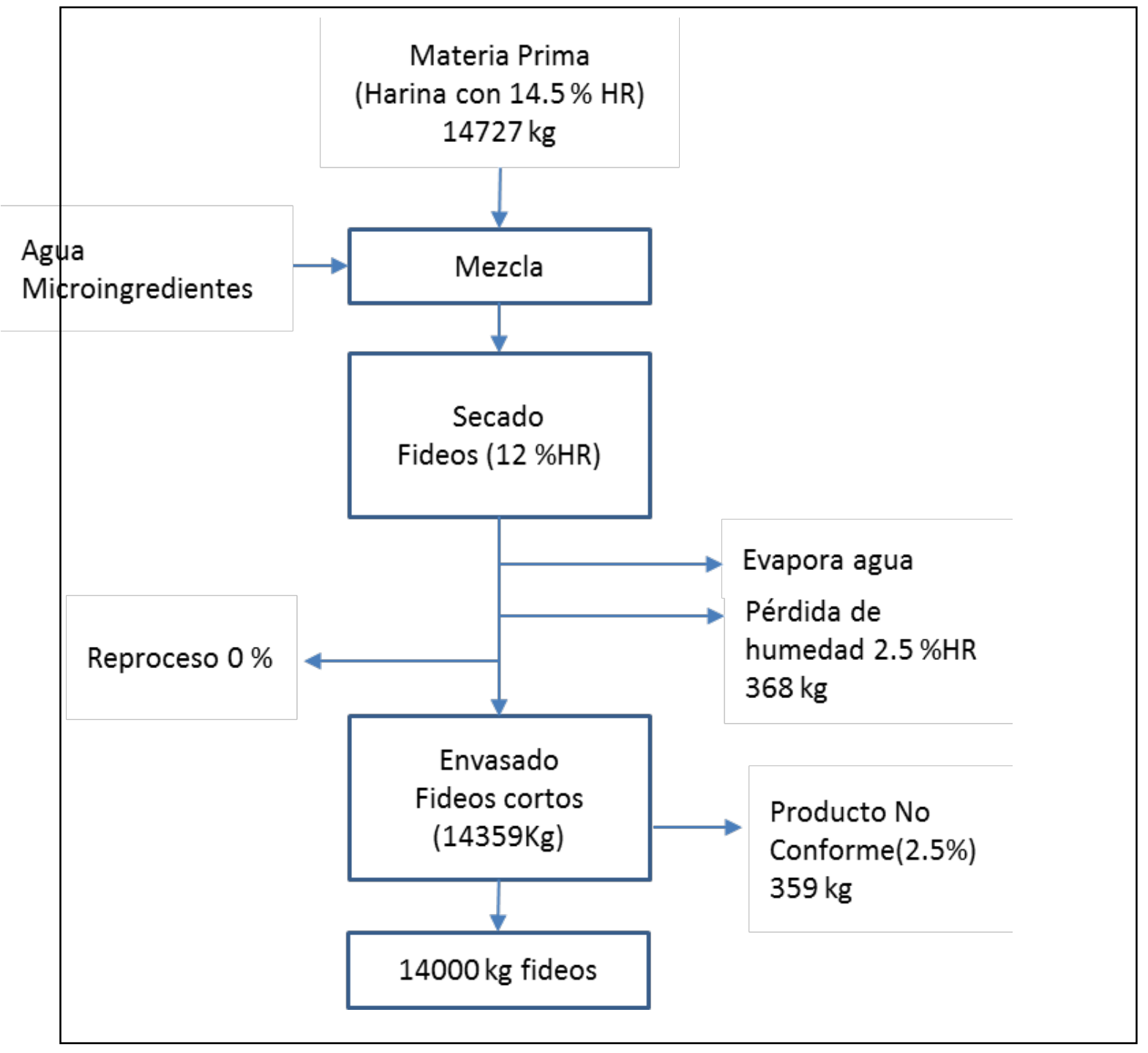

Fuente: Elaboración propia basado en la información de la empresa

Entonces, considerando lo explicado líneas arriba la estimación del volumen de la materia prima es el siguiente:

Materia prima $=14000 \mathrm{~kg}+359 \mathrm{~kg}$ (perdida por producto no conforme) +368 (pérdida por humedad)

Materia prima $=14727 \mathrm{~kg}$

Finalmente, como los batch de materia prima están determinados en toneladas, el volumen final tendrá que redondearse a $15000 \mathrm{~kg}$, en otras palabras 15 batchs. 


\subsection{Implementación de la Mejora}

Para la correcta implementación de la mejora se define el alcance, los costos y los tiempos de la implementación. El objetivo realizar un trabajo con calidad, identificar los riesgos, los interesados y las restricciones permitirá tener planes de acción que minimicen la probabilidad de error. En el siguiente diagrama Gantt (figura 73) se muestra los tiempos necesarios para la implementación del sistema Poka Yoke.

\section{Diagrama de Gantt}

Figura 73: Diagrama de Gantt

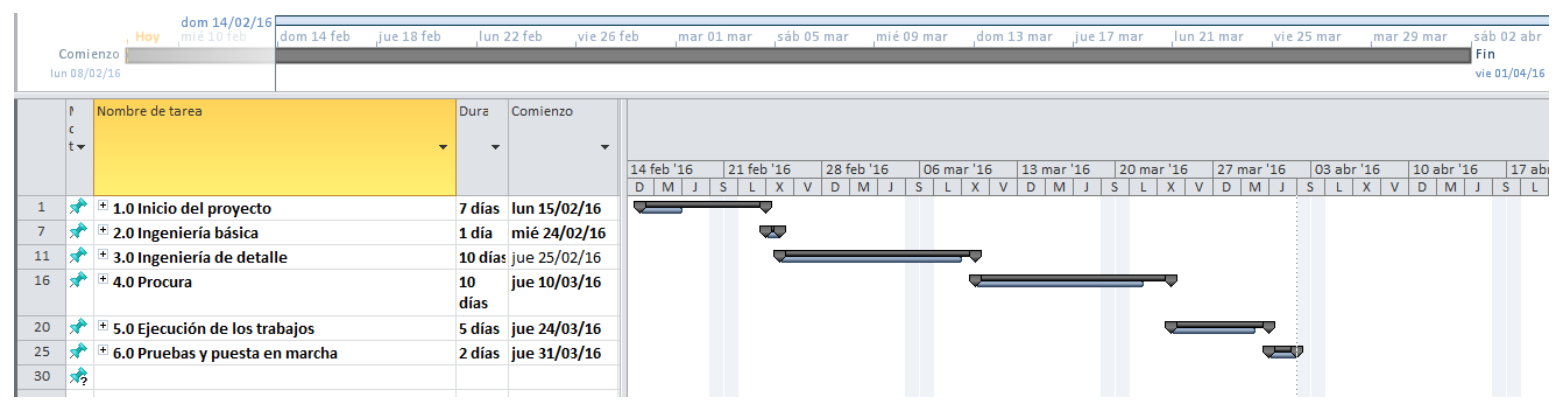

Fuente: Elaboración propia

\section{Lista de actividades}

En la siguiente figura se detalla la lista de actividades y las fechas tentativas para la implementación de la mejora. 
Figura 74: Plan de actividades

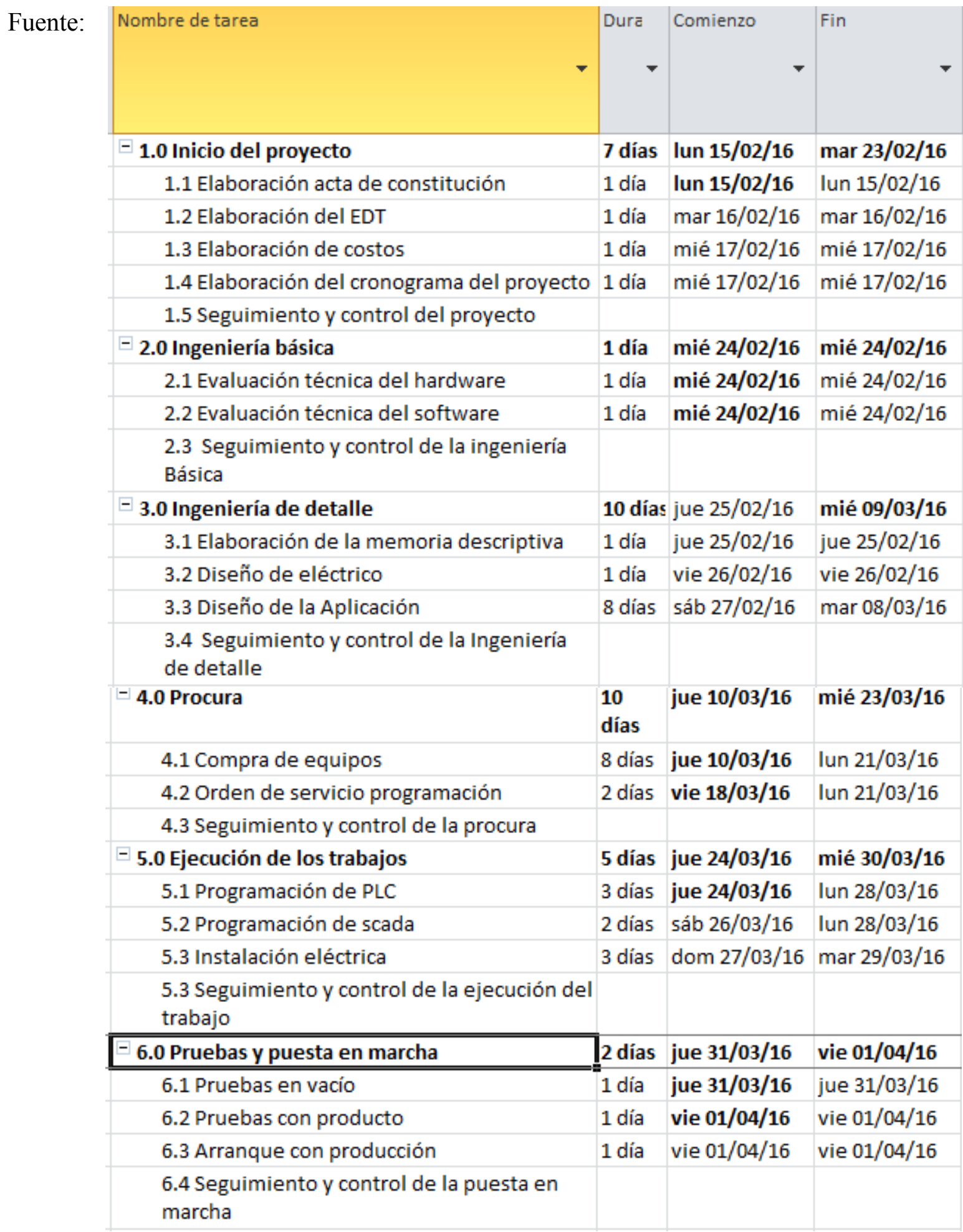

Elaboración propia 
El cálculo de los batch se realizará en una hoja Excel con un entorno que permita calcular y almacenar los datos. Esta tendrá desarrollada una macro que permita integrar el algoritmo matemático para realizar el balance de masa. Los diferentes campos se han desarrollado con el concepto Poka Yoke para eliminar los posibles errores al momento de realizar el cálculo. En este sentido, los diferentes campos tienen restricciones y bloqueos de acuerdo con el nivel del usuario.

- Campo línea. - Es un combo donde se selecciona una de las nueve líneas (A, B, C, D, E, F, G, H, I)

- Campo fecha. - No editable toma la fecha del sistema,

- Campo turno. - Es un combo seleccionable (MAÑANA, TARDE, NOCHE)

- Campo orden. - Permite ingresar solo datos numéricos

- Campo Cantidad. - Permite ingresar solo datos numéricos

- Campo \%PNC. - No editable toma datos de la matriz

- Campo \% Reproceso. - No editable toma datos de la matriz

- Campo \%HR Producto Final. - No editable toma datos de la matriz

- Campo Numero de Batch. - No editable realiza el calculo

- Campo Responsable. - Combo seleccionable (nombre de los operadores)

- Botón Grabar. - Ejecuta la macro y guarda los datos

- Botón Borrar. - borra los campos editables

En la siguiente figura 75 el diseño del entorno de ingreso de datos 
Figura 75: Calculo de Batch

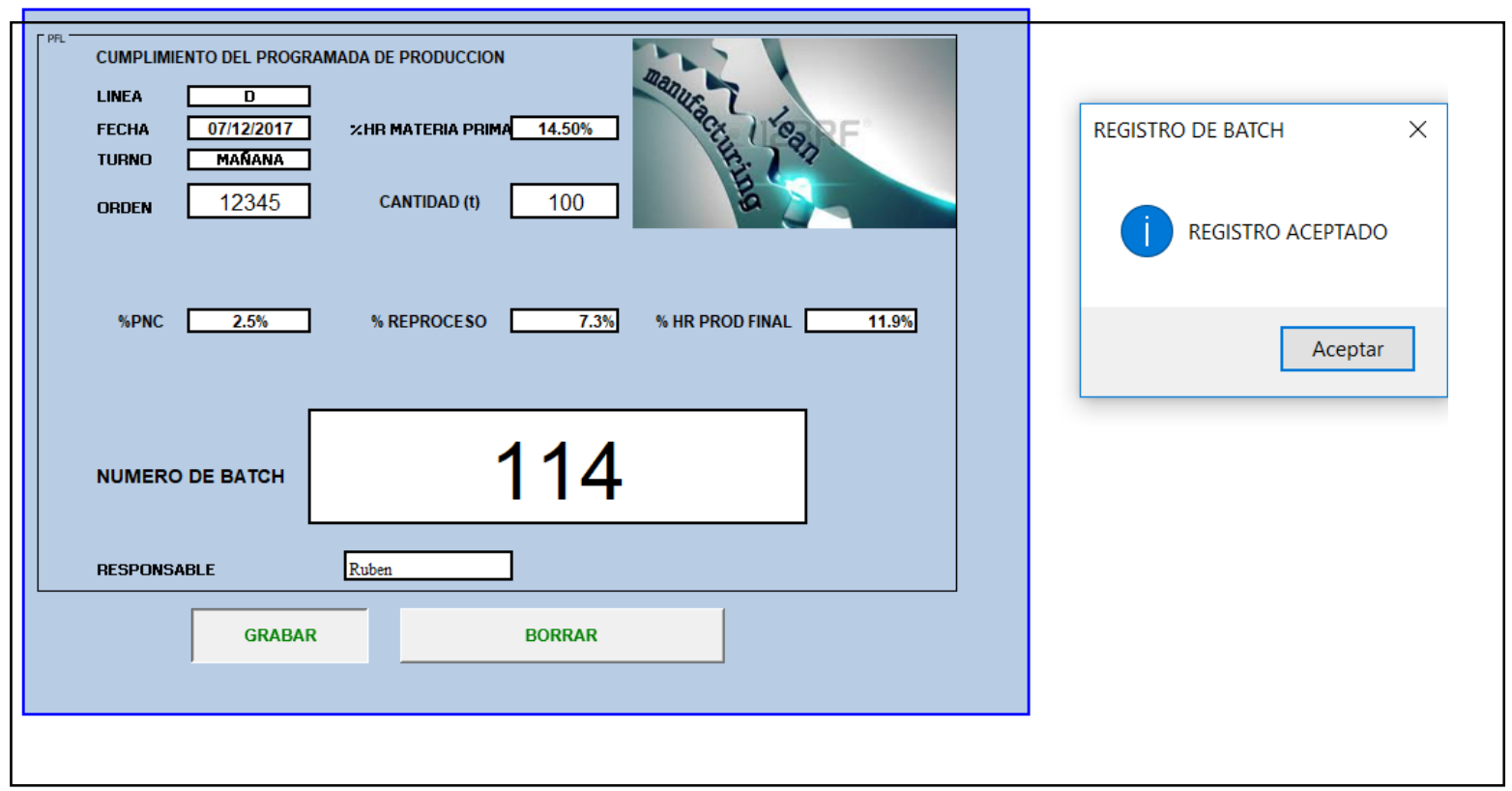

Elaboración propia

Las variables que dependen de cada línea serán editadas con un nivel de acceso mayor supervisor o coordinador en la siguiente tabla se definen los valores.

Tabla 14: Variables de proceso a definir

\begin{tabular}{|c|c|c|c|c|}
\hline TURNOS & LINEAS & $\begin{array}{c}\% \\
\text { PNC }\end{array}$ & $\begin{array}{c}\% \\
\text { REPROCESO }\end{array}$ & $\begin{array}{c}\% \text { HR Prod } \\
\text { Final }\end{array}$ \\
\hline MAÑANA & $\mathrm{A}$ & $2.5 \%$ & $7.80 \%$ & $12.500 \%$ \\
\hline TARDE & $\mathrm{B}$ & $2.2 \%$ & $7.20 \%$ & $12.000 \%$ \\
\hline NOCHE & $\mathrm{C}$ & $2.3 \%$ & $7.50 \%$ & $11.800 \%$ \\
\hline & $\mathrm{D}$ & $2.5 \%$ & $7.30 \%$ & $11.900 \%$ \\
\hline & $\mathrm{E}$ & $2.6 \%$ & $7.40 \%$ & $12.300 \%$ \\
\hline & $\mathrm{F}$ & $2.5 \%$ & $8.00 \%$ & $12.000 \%$ \\
\hline & $\mathrm{G}$ & $2.5 \%$ & $0.00 \%$ & $12.000 \%$ \\
\hline & $\mathrm{H}$ & $2.5 \%$ & $0.00 \%$ & $11.600 \%$ \\
\hline & $\mathrm{I}$ & $2.5 \%$ & $0.00 \%$ & $11.700 \%$ \\
\hline
\end{tabular}

Elaboración propia

Los datos serán almacenados en una hoja que permitirá realizar el análisis y la trazabilidad de los cálculos realizados en la tabla 15 se muestran los campos 
Tabla 15: Registro de Variables de proceso

\begin{tabular}{|c|c|c|c|c|c|c|c|c|c|c|}
\hline LINEA & FECHA & $\begin{array}{c}\text { \%HR MATERIA } \\
\text { PRIMA }\end{array}$ & TURNO & $\begin{array}{c}\text { ORDEN } \\
\text { FABRICACION }\end{array}$ & $\begin{array}{l}\text { NECESIDAD } \\
\text { DE PROD }\end{array}$ & PNC & $\%$ REPROCESO & \%HR PROD FINAL & $\begin{array}{l}\text { CANTIDAD DE } \\
\text { BATCH }\end{array}$ & RESPONSABLE \\
\hline A & $07 / 04 / 2016$ & 0.145 & MAÑANA & 12345 & 100 & 0.025 & 0.078 & 0.125 & 114 & Ruben \\
\hline B & $07 / 04 / 2016$ & 0.145 & MAÑANA & 12345 & 40 & 0.022 & 0.072 & 0.12 & 46 & Ruben \\
\hline $\mathrm{C}$ & $07 / 04 / 2016$ & 0.145 & MAÑANA & 12346 & 50 & 0.023 & 0.075 & 0.118 & 57 & Ruben \\
\hline C & $07 / 04 / 2016$ & 0.145 & MAÑANA & 12349 & 50 & 0.023 & 0.075 & 0.118 & 57 & Ruben \\
\hline $\mathrm{D}$ & $07 / 04 / 2016$ & 0.145 & MAÑANA & 12348 & 80 & 0.025 & 0.073 & 0.119 & 91 & Ruben \\
\hline 1 & $07 / 04 / 2016$ & 0.145 & MAÑANA & 12348 & 17 & 0.025 & 0 & 0.117 & 18 & Ruben \\
\hline $\mathrm{I}$ & $07 / 04 / 2016$ & 0.145 & MANNANA & 123423 & 20 & 0.025 & 0 & 0.117 & 22 & Ruben \\
\hline & & & & & & & & & & \\
\hline & & & & & & & & & & \\
\hline & & & & & & & & & & \\
\hline & & & & & & & & & & \\
\hline & & & & & & & & & & \\
\hline & & & & & & & & & & \\
\hline & & & & & & & & & & \\
\hline & & & & & & & & & & \\
\hline & & & & & & & & & & \\
\hline & & & & & & & & & & \\
\hline & & & & & & & & & & \\
\hline & & & & & & & & & & \\
\hline & & & & & & & & & & \\
\hline & & & & & & & & & & \\
\hline & & & & & & & & & & \\
\hline & & & & & & & & & & \\
\hline & & & & & & & & & & \\
\hline & & & & & & & & & & \\
\hline & & & & & & & & & & \\
\hline & & & & & & & & & & \\
\hline
\end{tabular}

Elaboración propia

\subsubsection{Medición de resultado de la implementación del prototipo}

El volumen de producción programado en la semana específica las cantidades de cada formato a producir, esta información es suministrada por el área de planificación y en consenso con el área de producción se fijan las cantidades, luego estos datos se registran en una hoja Excel, en él se realiza el cálculo del número de batchs con las consideraciones detalladas líneas arriba, luego de estimar el número de batchs necesarios para cumplir con el requerimiento se ingresa manualmente el número batchs para cumplir con la orden en el programa del PLC a través del SCADA. En consecuencia, la secuencia lógica implementada contrala la cantidad de materia prima enviada a la línea que al llegar a un valor próximo al fijado este envía una alarma visual para que el operador pueda gestionar su tiempo y atender el cambio cuando llegue a cumplir el numero fijado que finalizara el proceso de envió. Este sistema evita al operador realice estimaciones de la cantidad 
producida y que cometa errores de cálculo y control del proceso. En adelante, cuando se logré la aprobación y medición completa de los resultados, esta mejora debe automatizarse en todas las líneas de producción, para lo cual será necesario un desarrollo en la programación y automatización del programa del PLC e interface del SCADA. El siguiente cuadro muestra los primeros resultados. 
Tabla 16: Registro de cumplimiento de programa de producción

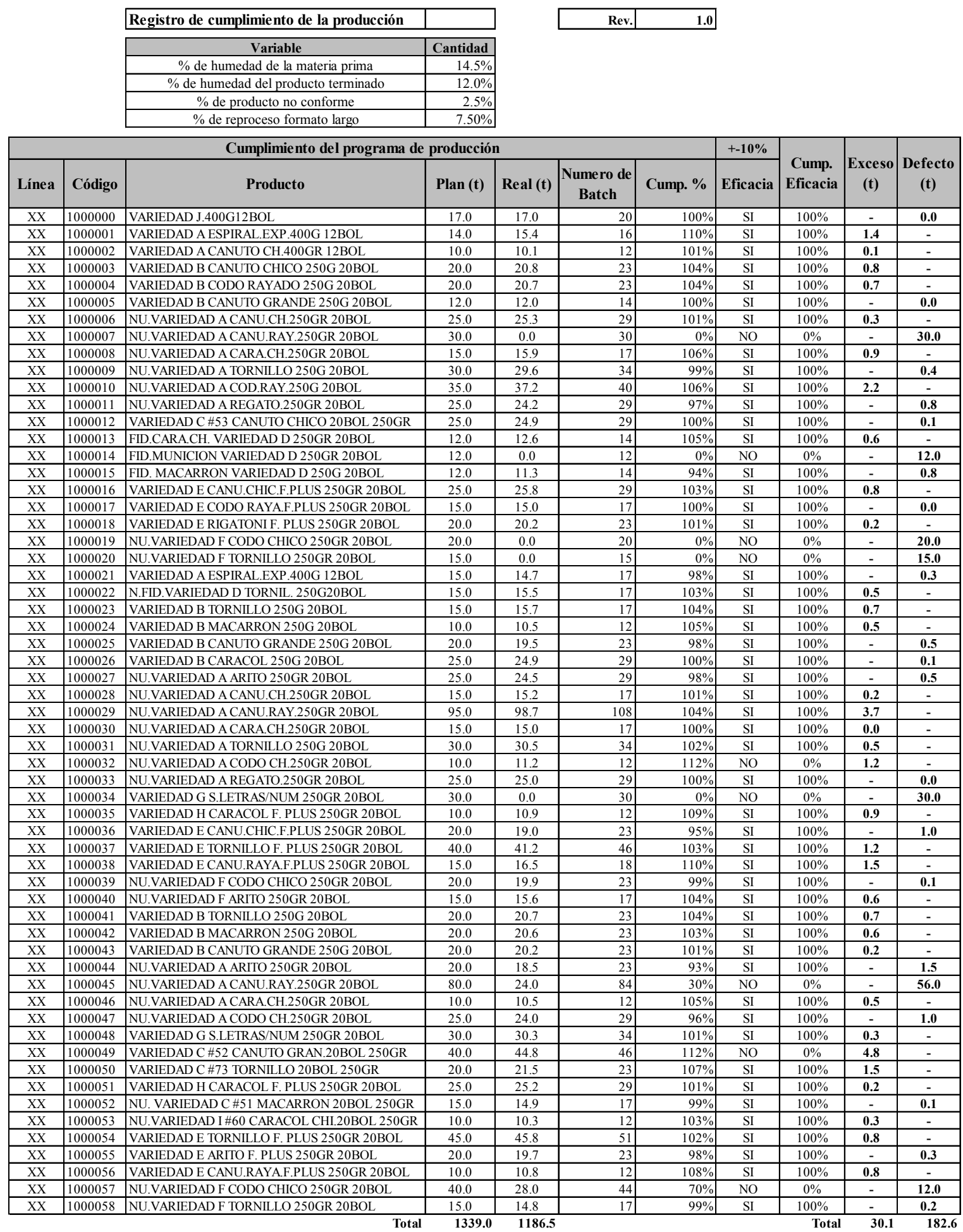

Fuente: Elaboración propia basado en la información de la empresa 
La tabla 16 muestra los resultados de la implementación del prototipo en un mes de operación donde la columna de cumplimiento muestra una mejora importante. En esta evaluación se programaron 59 órdenes de producción de los cuales 50 se encuentran dentro lo esperado, quiere decir, dentro los límites de la cantidad planificada y 9 de ellos no cumplen. Se realiza el cálculo del indicador del porcentaje de cumplimiento eficaz de la producción.

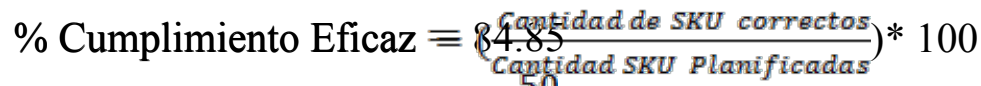

$\%$ Cumplimiento Eficaz $=\left(\frac{50}{59}\right) * 100$

Estos resultados permiten realizar una comparación con los obtenidos en el año 2014 referente a la producción, exceso y defecto. Es claro que, no cumplir con el volumen de producción afectan el Fill Rate y producir en exceso genera costos adicionales en almacenamiento de materias primas, insumos y producto terminado, en la siguiente tabla se muestra los resultados comparativos.

Tabla 17: Comparación resultados de primer prototipo

\begin{tabular}{|l|c|c|r|r|r|r|r|}
\hline \multicolumn{1}{|c|}{ Resultados } & Plan (t) & Real (t) & \multicolumn{1}{c|}{$\begin{array}{c}\text { Exceso } \\
(\mathbf{t})\end{array}$} & $\begin{array}{c}\text { Defecto } \\
(\mathbf{t})\end{array}$ & \% Exceso & \% Defecto & Total \\
\hline $\begin{array}{l}\text { Situación } \\
\text { anterior }\end{array}$ & $9,438.00$ & $8,363.46$ & 667.43 & $2,282.43$ & $7.1 \%$ & $24.2 \%$ & $31.3 \%$ \\
\hline $\begin{array}{l}\text { Situación co } \\
\text { mejora } \\
\text { (prototipo) }\end{array}$ & $1,339.00$ & $1,186.50$ & 30.12 & 182.62 & $2.2 \%$ & $13.6 \%$ & $15.9 \%$ \\
\hline
\end{tabular}

Fuente: Elaboración propia basado en la información de la empresa

En la tabla 17 se muestra los resultados de la línea de producción de fideos de pasta corta para un periodo de un año línea donde se implementó el prototipo, en la situación anterior 
de una planificación de 9,438 toneladas solo se entregó en los plazos establecido 8,363.46 toneladas. Además, se entregaron con exceso 667.43 toneladas y no se entregaron 2,282.43 toneladas. El porcentaje por exceso representa el $7.1 \%$ de lo planificado y defecto $24.2 \%$ en total se ha tenido un error $31.3 \%$

Mientras que, para la situación de mejora, después de implementar el prototipo en un periodo de un mes, se ha reducido el error por exceso es solo el $2.2 \%$, y por defecto $13.6 \%$ con un error total de $15.9 \%$. En conclusión, los resultados preliminares del prototipo implementado son contundentes demuestran una mejora importante en la gestión de la producción. Sin embargo, es importante realizar una simulación para el modelo de máquina que fabrica la pasta larga, estas líneas tienen menor perturbación con respecto a cambios de formatos. El resultado de este análisis sumado a los resultados del prototipo permitirá tener una conclusión de la propuesta de solución planteada.

\subsection{Análisis económico}

Para evaluar el impacto económico que se genera por el no cumplimiento del programa de producción se realiza una estimación con una valorización por cada formato y toneladas no entregadas a tiempo. Con un nivel de eficacia del cumplimiento de la producción de $46 \%$ se estima una pérdida de \$ 6546 996, tal como se muestra en la tabla 18. 
Tabla 18: Costos de la pérdida

\begin{tabular}{|c|c|c|c|c|}
\hline \multirow[b]{2}{*}{ Semana } & \multicolumn{2}{|c|}{ Toneladas } & \multirow[b]{2}{*}{$\begin{array}{c}\text { Cumplimiento } \\
\text { programa }\end{array}$} & \multirow{2}{*}{$\begin{array}{l}\text { Valorización } \\
\text { Perdida USD }\end{array}$} \\
\hline & $\begin{array}{c}\text { Programa } \\
\text { semanal }\end{array}$ & Real & & \\
\hline Semana 1 & 1,434 & 1,507 & $105.1 \%$ & 10,400 \\
\hline Semana 2 & 2,008 & 1,985 & $98.9 \%$ & 44,096 \\
\hline Semana 3 & 2,016 & 1,487 & $73.8 \%$ & 232,768 \\
\hline Semana 4 & 2,518 & 1,752 & $69.6 \%$ & 337,324 \\
\hline Semana 5 & 1,468 & 1,344 & $91.5 \%$ & 64,397 \\
\hline Semana 6 & 2,686 & 2,338 & $87.0 \%$ & 161,695 \\
\hline \begin{tabular}{|l|} 
Semana 7 \\
\end{tabular} & 2,378 & 2,321 & $97.6 \%$ & 40,535 \\
\hline & & & & \\
\hline Semana 29 & 2,740 & 2,558 & $93.4 \%$ & 90,665 \\
\hline Semana 30 & 1,708 & 1,642 & $96.2 \%$ & 77,382 \\
\hline Semana 31 & 1,271 & 990 & $77.9 \%$ & 124,397 \\
\hline Semana 32 & 2,384 & 2,416 & $101.3 \%$ & 52,426 \\
\hline & & & & \\
\hline Semana 45 & 3,214 & 3,050 & $94.9 \%$ & 100,298 \\
\hline \begin{tabular}{|l|} 
Semana 46 \\
\end{tabular} & 3,667 & 3,217 & $87.7 \%$ & 248,399 \\
\hline Semana 47 & 3,618 & 3,218 & $88.9 \%$ & 176,941 \\
\hline Semana 48 & 3,623 & 3,662 & $101.1 \%$ & 9,846 \\
\hline \begin{tabular}{|l|} 
Semana 49 \\
\end{tabular} & 3,466 & 3,654 & $105.4 \%$ & 31,616 \\
\hline Semana 50 & 2,913 & 2,804 & $96.2 \%$ & 106,762 \\
\hline \begin{tabular}{|l|} 
Semana 51 \\
\end{tabular} & 2,913 & 2,804 & $96.2 \%$ & 106,762 \\
\hline \begin{tabular}{|l|} 
Semana 52 \\
\end{tabular} & 1,848 & 1,673 & $90.5 \%$ & 103,965 \\
\hline
\end{tabular}

Fuente: Elaboración propia basado en la información de la empresa

Un costo más tangible que la compañía ha tenido que asumir para este periodo es el sobre costo por el almacenamiento de producción en exceso, por arriba del $110 \%$ de lo planificado, esto significó una pérdida anual de \$25 990.47 en la tabla 19 se muestra los detalles.

Tabla 19: Costos de la pérdida por sobre producción 


\begin{tabular}{|l|r|r|r|r|}
\hline \multicolumn{1}{|c|}{ Mes } & Toneladas & $\begin{array}{c}\text { Ubicaciones } \\
\text { necesarias por } \\
\text { mes }\end{array}$ & $\begin{array}{c}\text { Costo } \\
\text { Almacenar (\$) }\end{array}$ & $\begin{array}{c}\text { Costos } \\
\text { Total (\$) }\end{array}$ \\
\hline enero & 349 & 375 & 5.74 & 2154.0 \\
\hline febrero & 423 & 455 & 5.74 & 2610.8 \\
\hline marzo & 342 & 368 & 5.74 & 2110.8 \\
\hline abril & 251 & 270 & 5.74 & 1549.2 \\
\hline mayo & 176 & 189 & 5.74 & 1086.3 \\
\hline junio & 304 & 327 & 5.74 & 1876.3 \\
\hline julio & 538 & 578 & 5.74 & 3320.6 \\
\hline agosto & 375 & 403 & 5.74 & 2314.5 \\
\hline septiembre & 355 & 382 & 5.74 & 2191.1 \\
\hline octubre & 503 & 541 & 5.74 & 3104.5 \\
\hline noviembre & 233 & 251 & 5.74 & 1438.1 \\
\hline diciembre & 362 & 389 & 5.74 & 2234.3 \\
\hline \multicolumn{1}{|r|}{ Total } & $\mathbf{4 2 1 1}$ & $\mathbf{4 5 2 8}$ & & $\mathbf{2 5 , 9 9 0 . 4 7}$ \\
\hline
\end{tabular}

Fuente: Elaboración propia basado en la información de la empresa

Para realizar la gestión de distribución los paquetes de fideos son agrupados en unidades mayores pallet y pueden albergar en promedio $930 \mathrm{Kg}$ de peso, cada pallet necesita una posición de almacenaje. La eliminación de estos sobrecostos permitirá generar ahorros importantes en el área de distribución y almacenamiento.

Los costos asociados a la implementación de la propuesta de mejora de acuerdo con el alcance y las actividades descritas en el diagrama Gantt se muestran en la siguiente tabla 20.

Tabla 20: Costos de la mejora 


\begin{tabular}{|l|c|}
\hline \multicolumn{1}{|c|}{ Detalle de costos } & Costo $\$$ \\
\hline Ingeniería Básica & 1500 \\
\hline Ingeniería de detalle & 3000 \\
\hline Programación & 10000 \\
\hline Equipos & 3000 \\
\hline Instalación Eléctrica & 2000 \\
\hline Capacitación & 19000 \\
\hline Imprevistos & 5775 \\
\hline \multicolumn{1}{|r|}{ Total } & $\mathbf{4 4 2 7 5}$ \\
\hline
\end{tabular}

Fuente: elaboración propia basado en información de la empresa

La inversión tiene un costo de \$44 275 aquí se encuentran los costos asociados a la implementación de las herramientas de Manufactura Esbelta, así como los costos asociadas a la capacitación. En el siguiente cuadro se detallan los costos del material didáctico

Tabla 21: Costos de material didáctico

\begin{tabular}{|c|c|}
\hline Detalle del costo & Costo $\$$ \\
\hline Diseño y conceptualización grafica afiches vinilos infografía & 950.3 \\
\hline Pieza impresa en propalcote $1.8 \mathrm{~m} \times 1 \mathrm{~m}$ & 89.5 \\
\hline Banner horizontal en vinilo laminado $1 \mathrm{~m} \times 5 \mathrm{~m}$ & 108 \\
\hline Vinil adhesivo laminado $2 \mathrm{~m} \times 2 \mathrm{~m}$ & 88.9 \\
\hline Banner horizontal en vinilo laminado $0.90 \mathrm{~m}$ alto $\times 5 \mathrm{~m}$ & 108 \\
\hline Vinilo adhesivo en celtex $.20 \mathrm{~m} \times 1.60 \mathrm{~m}$ & 89.5 \\
\hline Banner horizontal en vinilo laminado $1.50 \mathrm{~m}$ alto $\times 5 \mathrm{~m}$ & 160.5 \\
\hline Banner horizontal en vinilo laminado $1 \mathrm{~m}$ alto $\times 1.70 \mathrm{~m}$ & 50.9 \\
\hline Pizarras acrílicas $1.5 \mathrm{~m} \times 2.5 \mathrm{~m}$ & 460 \\
\hline Impresiones & 895 \\
\hline Material didáctico & 495 \\
\hline Instalación & 771.6 \\
\hline Computadora Laptop + licencias & 4500 \\
\hline Licencia SAP & 2000 \\
\hline
\end{tabular}

Fuente: elaboración propia basado en información de la empresa

Un análisis económico que justifica la inversión es tomar el valor de pérdida por el incumplimiento de la producción o las pérdidas de venta en un año, son valores que superan 
ampliamente la inversión. Sin embargo, el costo tangible asociado al almacenamiento de producto no planificado que la compañía tuvo que pagar fue de \$25 990.47 para el periodo 2014. Esto significa que se necesitó 4528 posiciones más con una desviación estándar de 1352 a un costo por posición de $\$ 5.74$ al mes. En el siguiente análisis (tabla 22) se demuestra la factibilidad de la inversión con una evaluación del flujo de caja considerando que el Costo de Oportunidad del Capital (COK) de 13\% definido por la compañía para todas sus inversiones.

Tabla 22: Flujo de Caja

\begin{tabular}{|c|c|c|c|c|c|c|}
\hline \multicolumn{7}{|l|}{ Supuestos } \\
\hline Cantidad de posiciones (Q) & $0 \%$ & 4,523 & 4,523 & 4,523 & 4,523 & 4,523 \\
\hline Precio (P) & $0 \%$ & 5.74 & 5.74 & 5.74 & 5.74 & 5.74 \\
\hline Costo unitario $(\mathrm{CU})$ & $0 \%$ & 0.00 & 0.00 & 0.00 & 0.00 & 0.00 \\
\hline Depreciación & 44,275 & $8,855.00$ & $8,855.00$ & $8,855.00$ & $8,855.00$ & $8,855.00$ \\
\hline & $30 \%$ & & & & & \\
\hline \multirow[t]{2}{*}{ Costo de Oportunidad del Capital (COK) } & $13 \%$ & & & & & \\
\hline & $\mathbf{0}$ & 1 & 2 & 3 & 4 & 5 \\
\hline Ventas & & $25,967.06$ & $25,967.06$ & $25,967.06$ & $25,967.06$ & $25,967.06$ \\
\hline$(-)$ Costos & & 0.00 & 0.00 & 0.00 & 0.00 & 0.00 \\
\hline ( - ) Depreciación & & $-8,855.00$ & $-8,855.00$ & $-8,855.00$ & $-8,855.00$ & $-8,855.00$ \\
\hline$(=)$ UAII = EBIT & & $17,112.06$ & $17,112.06$ & $17,112.06$ & $17,112.06$ & $17,112.06$ \\
\hline ( - ) Impuestos & & $-5,133.62$ & $-5,133.62$ & $-5,133.62$ & $-5,133.62$ & $-5,133.62$ \\
\hline$(+)$ Depreciación & & $8,855.00$ & $8,855.00$ & $8,855.00$ & $8,855.00$ & $8,855.00$ \\
\hline Flujo Económico de Operación (FEO) & & $20,833.44$ & $20,833.44$ & $20,833.44$ & $20,833.44$ & $20,833.44$ \\
\hline Gastos netos de capital & $-44,275.00$ & & & & & \\
\hline Flujo de Caja de Libre Disponibilidad (FCLD) & $-44,275.00$ & $20,833.44$ & $20,833.44$ & $20,833.44$ & $20,833.44$ & $20,833.44$ \\
\hline VAN & $29,001.02$ & & & & & \\
\hline TIR & $37 \%$ & & & & & \\
\hline
\end{tabular}

Fuente: Elaboración propia basado en Sapag 2001

En el flujo de caja se puede inferir que el proyecto de mejora es rentable debido a que el resultado del Valor Actual Neto (VAN) es positivo; la utilidad al final del ejercicio es de \$ 29,001.02. Por otro lado, la Tasa de Retorno de la inversión es de 37\% superior al Costo de Oportunidad del Capital que es de $13 \%$. Esto quiere decir, que el proyecto es rentable y la inversión no tiene riesgo. 
Este proyecto es totalmente factible según los resultados del VAN y TIR, sin embargo, es necesario evaluar a través de una herramienta de simulación los riesgos asociados, este análisis se realizará utilizando el @Riks de Excel. Uno de los elementos más importantes de la simulación es determinar adecuadamente la distribución de probabilidad de los datos. En consecuencia, se utiliza la herramienta de análisis de datos Input Analyzer para determinar a qué tipo de distribución pertenecen estos datos, se verifica que las ubicaciones necesarias para almacenar la producción excesiva siguen una distribución normal con un $\mathrm{p}$ valor mayor a 0.15 en las figuras 76 y 77 se muestran los resultados de la simulación del Valor Actual Neto.

Figura 76: Gráfica de distribución del Análisis del Valor Actual Neto

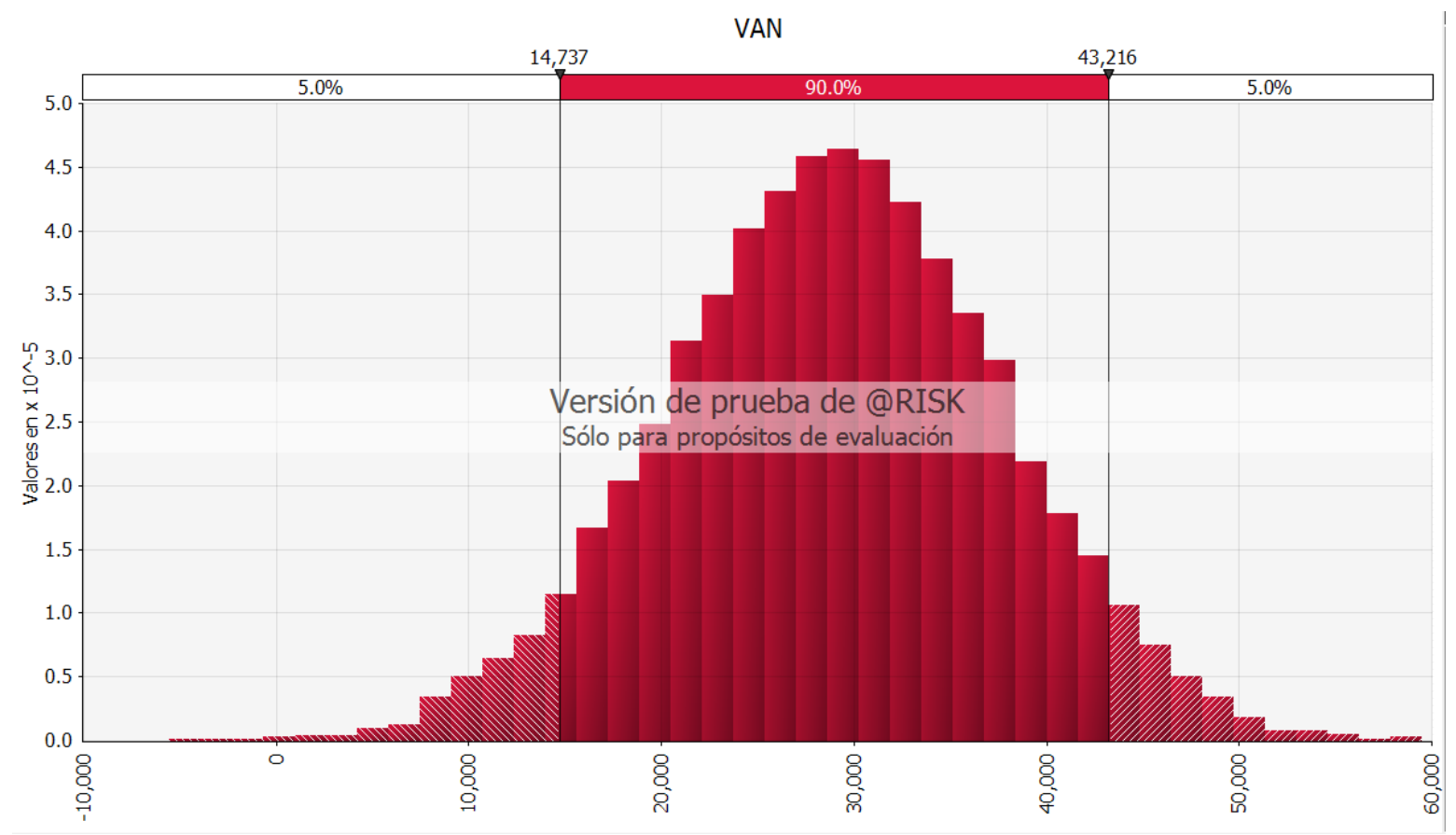

Fuente: Elaboración propia basado en información de la empresa

Figura 77: Gráfica Acumulativa ascendente del Análisis del Valor Actual Neto 


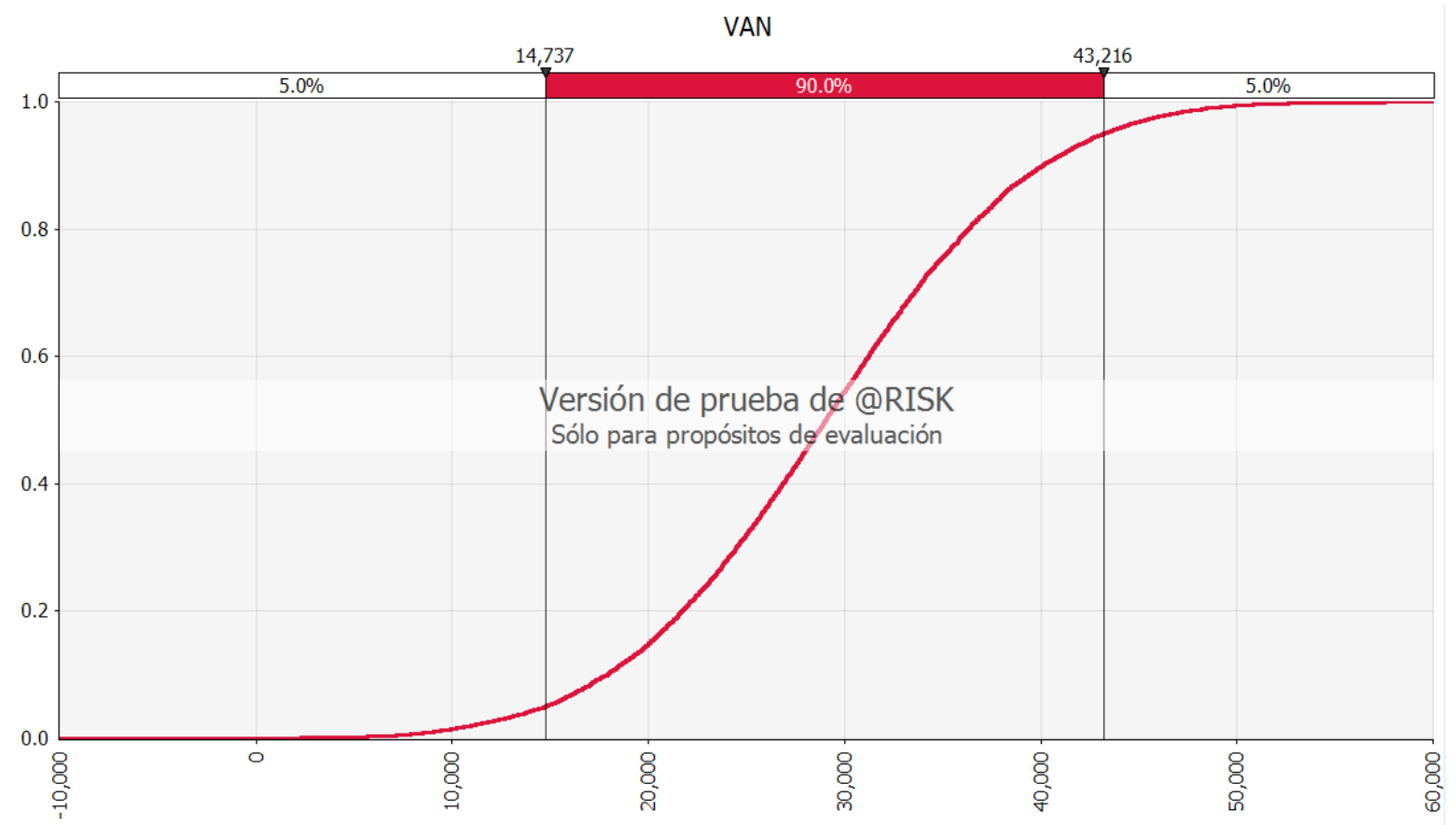

Fuente: Elaboración propia basado en información de la empresa

En las figuras 76 y 77 histograma y grafico acumulativo muestra el rango de posibles resultados de la probabilidad, donde se observa que el Valor Actual Neto es positivo, además, se puede afirmar que con un intervalo de confianza del 90\% los valores del VAN estarán comprendidos entre el siguiente rango de valores (14 737, 43 216) estos resultados sumado a los datos estadísticos en la tabla 23 validan la inversión.

Tabla 23: Resultados estadísticos VAN

\begin{tabular}{lr} 
Valor Actual Neto (VAN) \\
\hline & \\
Mínimo & $-5,523.00$ \\
Máximo & $59,507.15$ \\
Media & $29,001.03$ \\
Desv Est & $8,646.33$ \\
Iteraciones & $10,000.00$
\end{tabular}

Fuente: Elaboración propia basado en información de la empresa 
El otro indicador de la factibilidad de la inversión no menos importante es el TIR en las figuras 78 y 79 los resultados de la simulación.

Figura 78: Gráfica de distribución del Análisis de la Tasa de Retorno Interno

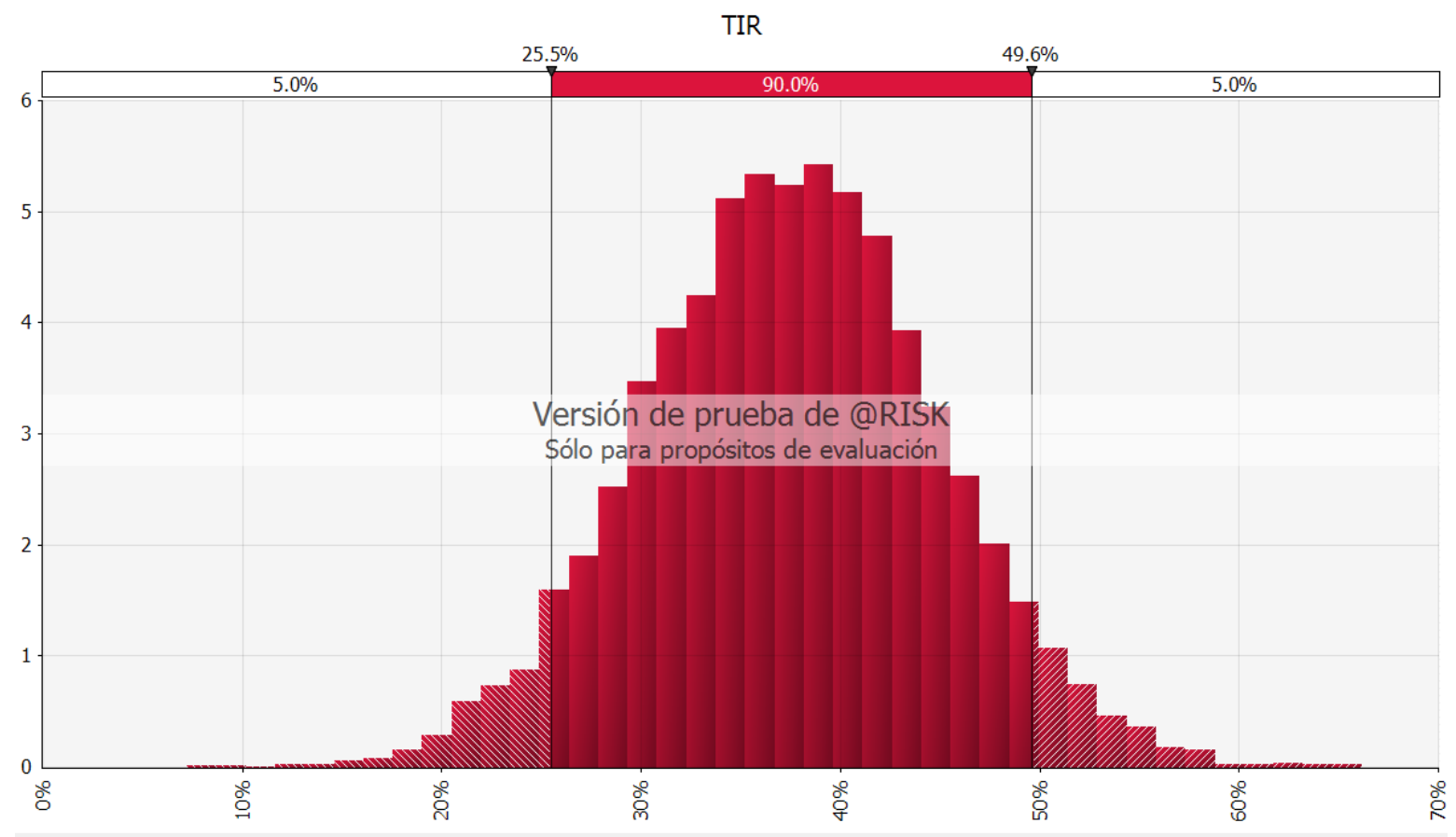

Fuente: Elaboración propia basado en información de la empresa

Figura 79: Gráfica Acumulativa ascendente del Análisis de la Tasa de Retorno Interno 


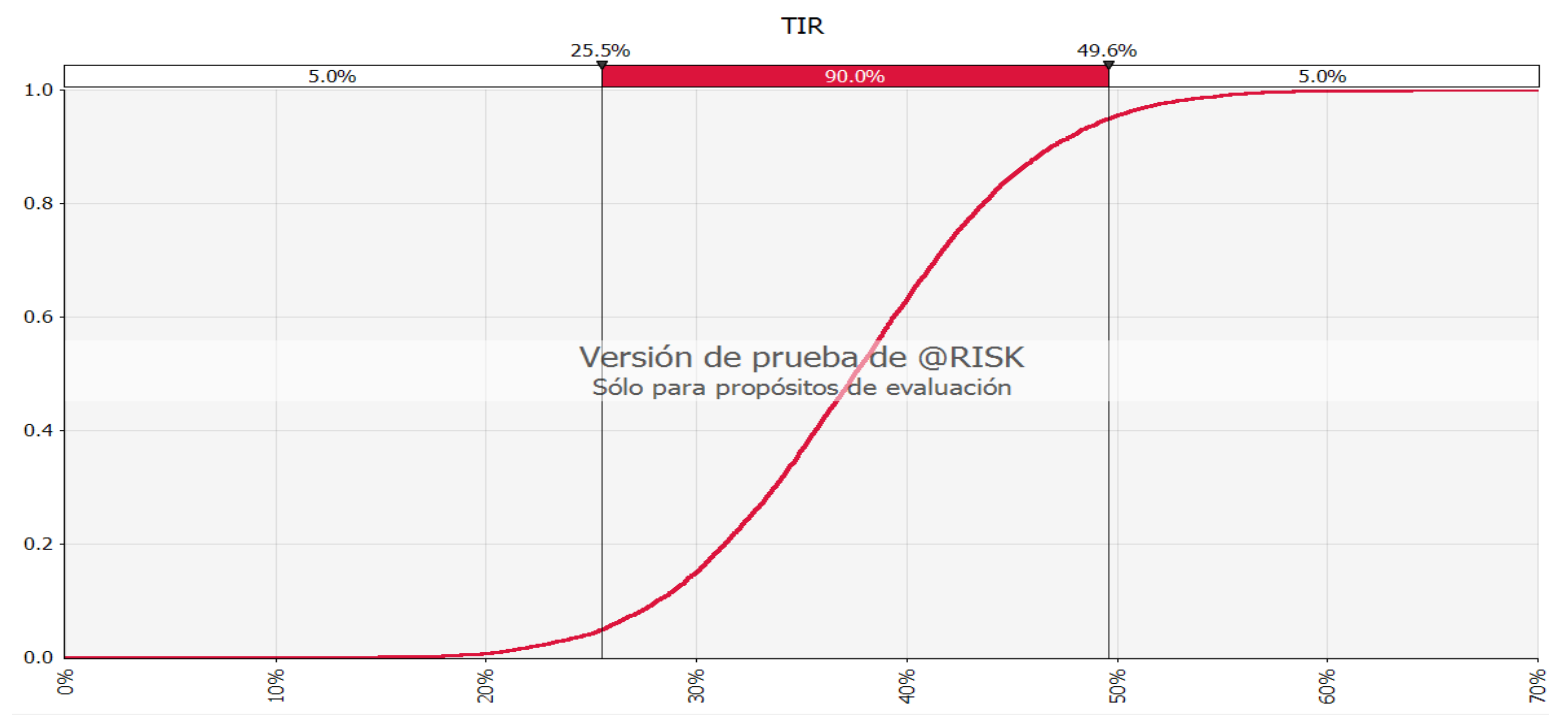

Fuente: Elaboración propia basado en información de la empresa

En las figuras 78 y 79 histograma y grafico acumulativo del TIR se muestra el rango de posibles resultados que la probabilidad puede tomar. En ese sentido, se puede afirmar que con un intervalo $90 \%$ de confianza los valores de la Tasa de Retorno de la Inversión estarán comprendidos entre el siguiente rango de valores $(25.5 \%, 49.6 \%)$ y en la tabla 24 los valores estadísticos de la simulación los cuales confirman la factibilidad de la inversión. Tabla 24: Resultados estadísticos TIR

\begin{tabular}{lr} 
Tasa Interna de Retorno (TIR) \\
\hline Mínimo & $7.241 \%$ \\
Máximo & $66.17 \%$ \\
Media & $37.53 \%$ \\
Desv Est & $7.34 \%$ \\
Iteraciones & $10,000.00$
\end{tabular}

Fuente: Elaboración propia basado en información de la empresa 


\section{CAPITULO 4. CONCLUSIONES Y RECOMENDACIONES}

En el presente capitulo se presenta las siguientes conclusiones y recomendaciones, como resultado al análisis de lo evaluado en la presente tesis.

\subsection{Conclusiones}

- La aplicación de la Manufactura Esbelta en una organización permite crear una cultura y esta debe abarcar todas las áreas y a todos los colaboradores.

- La Manufactura Esbelta encamina a la organización a ser más eficiente y pone de manifiesto que el valor está dado por el cliente y no por la empresa, de esta forma orienta los esfuerzo para satisfacerlos.

- El uso de las diferentes herramientas de diagnóstico de la Manufactura Esbelta pone en manifiestos las MUDAS con mayor impacto en el proceso de producción de fideos que son la sobreproducción e inventarios.

- El uso de la herramienta Poka Yoke a través de soluciones integrales permitirá eliminar los errores causados por el factor humano que afectaba el cumplimiento de la producción de fideos, ocasionando sobreproducción, inventarios y ventas pérdidas.

- La implementación del Reporte A3 permitirá seguir una metodología en la solución de las oportunidades de mejora.

- Con la implementación de la propuesta de mejora se logrará incrementar el nivel de cumplimiento de entrega a los clientes de $90 \%$ a $95 \%$ de Fill Rate.

- La implementación de la propuesta de mejora genera ahorros importantes de 25 mil dólares por año aproximadamente, al optimizar el inventario de las áreas logísticas de la 
organización como almacenaje de producto terminado, materia prima, insumos, transporte y recurso humano.

- El prototipo implementado en una de las líneas de manufactura de fideos cortado, que es la que tiene mayor cantidad de cambios de formato, ha validado la propuesta de mejora, puesto que se logró un incremento importante del indicador de cumplimiento del programa de producción semanal de $33.67 \%$ a $84.85 \%$

- La modelación a través del software Arena a la línea de producción de fideos de formato largo ha permitido validar los resultados desde otra perspectiva, con una cantidad de 30 réplicas, el resultado del indicador de cumplimiento eficaz de la producción en promedio fue de $50.8 \%$ para el proceso actual y $85.9 \%$ con la implementación de la propuesta de mejora. Se debe resaltar que solo existen dos modelos de máquina y los procesos son exactamente iguales por lo que es extensible implementar esta mejora a todas las máquinas de producción de fideos.

- El análisis económico demuestra que la inversión es viable; el Valor Actual Neto es positivo y la Taza de Retorno de la Inversión superan el Costo de Oportunidad del Inversionista.

- Los resultados obtenidos utilizando el software de modelación@ @risk validad la propuesta económica, los resultados del VAN Y TIR en los diferentes escenarios son favorables.

- Finalmente, en líneas Generales se afirma la hipótesis planteada, debido a que la implementación del proyecto de mejora permitirá optimizar los recursos e incrementar el nivel de cumplimiento en tiempo y oportunidad de los productos.

\subsection{Recomendaciones}

- Se recomienda implementar la herramienta Mantenimiento Productivo Total para incrementar la disponibilidad de los equipos ya que se observa que aún existe oportunidad de incrementar el indicador de cumplimiento Eficaz de la producción.

- Se recomienda la implementación de un sistema de capacitación progresivo al personal en temas tecnológicos del proceso productivo. 
- Se propone el intercambio de personal con otras sedes la organización que tienen procesos similares. Con ello, se logrará captar y transferir conocimientos a favor de la empresa.

- Se recomienda mejorar el nivel de la planificación del área de mantenimiento con el objetivo de mejorar la indisponibilidad de los equipos.

- Para lograr la implementación de una propuesta de mejora en un proceso productivo se debe argumentar con propiedad los beneficios y posibles resultados. Conocer los aspectos técnicos, los alcances y repercusiones que implicará la mejora permitirá tener una mejor visión. Sin Embargo, sin una adecuada gestión no se lograrán los objetivos trazados. 


\section{BIBLIOGRAFÍA}

AGUILAR, Pedro (2012) Un modelo de clasificación de inventarios para incrementar el nivel de servicio al cliente y la rentabilidad de la empresa (Consulta 10 de julio de 2016) http://web.b.ebscohost.com/ehost/pdfviewer/pdfviewer?sid=f3efa6e0-a3d3-47c0-abbe2a9363d14e10\%40sessionmgr102\&vid=17\&hid=107

ALAMILLO, Alfonso y otros (2011) Innovación mediante equipos de trabajo México (Consulta 1 de noviembre de 2015)

(http://web.b.ebscohost.com/ehost/pdfviewer/pdfviewer?sid=37b206ec-5846-45a9-abc936f1332ec677\%40sessionmgr198\&vid=36\&hid=105)

ALDAPE, Alfonso (2011) Innovación Mediante Equipos de Trabajo (Consulta 1 de noviembre de 2015)

http:/web.b.ebscohost.com/ehost/detail/detail?vid=7\&sid=30042eb1-ded9-4787-852d-

37d18ffacdd9\%40sessionmgr107\&hid=115\&bdata $=$ Jmxhbmc9ZXM\%3d \#AN=67655163\& $\mathrm{db}=$ fua

ARRIETA, Juan y otros (2010) Benchmarking sobre manufactura esbelta (lean Manufacturing) en el sector de la confección en la ciudad de Medellín, Colombia (Consulta 1 de noviembre de 2015)

http://web.a.ebscohost.com/ehost/detail/detail?vid=8\&sid=62e77223-1588-485b-94e9-

91530ecdc24d\%40sessionmgr4002\&hid=4214\&bdata=Jmxhbmc9ZXM\%3d\#AN=5138154 $5 \& \mathrm{db}=\mathrm{bth}$

BASSUK, James y WASHINGTON, Ida (2013) The A3 Problem Solving Report: A 10Step Scientific Method to Execute Performance Improvements in an Academic Research Vivarium (Consulta 1 de febrero de 2016) 
http://web.a.ebscohost.com/ehost/detail/detail?vid=3\&sid=f3b49481-deb1-4126-a4154db8bb4de62e\%40sessionmgr4001\&hid=4214\&bdata $=$ Jmxhbmc9ZXM\%3d\#AN=9447872 $2 \& d b=a 9 h$

CARDOZO, Edyamira y otros (2011) Las Pequeñas y Medianas Empresas Agroalimentarias en Venezuela y el Desarrollo Sustentable: Enfoque basado en los Principios de Manufactura Esbelta (Consulta 1 de noviembre de 2015) http://web.a.ebscohost.com/ehost/detail/detail?vid=5\&sid=62e77223-1588-485b-94e991530ecdc24d\%40sessionmgr4002\&hid=4214\&bdata $=$ Jmxhbmc9ZXM\%3d\#AN=8613724 $6 \& \mathrm{db}=$ fua

DELGADO, Frank y GALLO, Eliseo (2011) Manufactura Esbelta por medio de optimización de sistemas de manufactura (Consulta 1 de noviembre de 2015) (http://web.b.ebscohost.com/ehost/pdfviewer/pdfviewer?vid=3\&sid=37b206ec-5846-45a9abc9-36f1332ec677\%40sessionmgr198\&hid=105)

DELGADO, Nicolás (2011) Propuesta del mejoramiento de la metodología de Manufactura Esbelta por medio de optimización de sistemas de manufactura y modelación de eventos discretos (Consulta 10 de noviembre de 2015)

(http://web.a.ebscohost.com/ehost/detail/detail?vid=74\&sid=3d953c1f-5077-48b0-b666c78b8a9a47a0\%40sessionmgr4002\&hid=4114\&bdata=Jmxhbmc9ZXM\%3d\#db=fua\&AN= 85708507)

FERNANDEZ, Oscar (2006) ¿Tercera revolución industrial? Reflexiones desde la lógica del "empirismo convencional" (Consulta 11 de noviembre de 2015) (http://web.b.ebscohost.com/ehost/pdfviewer/pdfviewer?vid=3\&sid=e6274db2-6f3b-43e2b8db-ee0e36ff8c75\%40sessionmgr113\&hid=107)

GARCIA, Jorge y otros (2012) Factores claves del éxito asociados a Kaizen (Consulta 20 noviembre de 2015) http://200.21.217.140/index.php/revistaciencia/article/viewFile/335/209 
GRYBOWSKA, K y GAJDZIK, B (2012) Optimization of equipment setup processes in enterprises (Consulta 10 de noviembre de 2015)

http://web.a.ebscohost.com/ehost/detail/detail? vid=67\&sid=3d953c1f-5077-48b0-b666c78b8a9a47a0\%40sessionmgr4002\&hid=4114\&bdata=Jmxhbmc9ZXM\%3d\#AN=8228438 $2 \& d b=a 9 h$

GUZMÁN, Omar y otros (2015) "Beneficios de la mejora continua a través de la implementación de la herramienta del mapa de flujo de valor" Caso práctico: Empresa ubicada en Apodaca. (Consulta 15 de noviembre de 2015).

(http://udo.mx/portaludo2/images/archivos/catedracumex/ponencias/Universidad\%20Aut\% C3\%B3noma\%20de\%20Nuevo\%20Le\%C3\%B3n/Ing.\%20Omar\%20Guzm\%C3\%A1n\%20 Garc\%C3\%ADa/Ponencia\%20Beneficios\%20de\%201a\%20mejora\%20continua \%20a\%20tr av\%C3\%A9s\%20de\%20la\%20implementaci\%C3\%B3n\%20de\%20la\%20herramienta\%20d el\%20mapa\%20de\%20flujo\%20de\%20valor.pdf)

HASRULNIZZAM, Wan y otros (2015) Translating OEE Measure into Manufacturing Sustainability (Consulta 1 de mayo de 2016) http://web.b.ebscohost.com/ehost/pdfviewer/pdfviewer?sid=9603fe8c-fcea-4670-805f$18 \mathrm{a} 5 \mathrm{~b} 25 \mathrm{c} 529 \mathrm{~d} \% 40$ sessionmgr $103 \& \mathrm{vid}=4 \& \mathrm{hid}=105$

HERNÁNDEZ, Juan y otros (2013) Lean Manufacturing Conceptos, técnicas e implantación (Consulta 15 de noviembre de 2015).

http://api.eoi.es/api_v1_dev.php/fedora/asset/eoi:80094/EOI_LeanManufacturing_2013.pdf

LÓPEZ, Iván y otros (2012) Implementación del método anteriores (Consulta 28 de noviembre de 2015)

(http://www.edutecne.utn.edu.ar/coini_2013/trabajos/COA12_TC.pdf) 
LÓPEZ, María y LÓPEZ, Patricia (2014) Uso secuencial de herramientas de control de calidad en procesos productivos: una aplicación en el sector agroalimentario (Consulta 1 de noviembre de 2015)

http://web.a.ebscohost.com/ehost/detail/detail?vid=37\&sid=45ea0282-0206-4794-936fbc11bd6779c4\%40sessionmgr4003\&hid=4212\&bdata=Jmxhbmc9ZXM\%3d\#db=fua\&AN $=102022168$

MARÍN-GARCÍA, Juan y MARTÍNEZ, Rafael (2013) Barreras y facilitadores de la implantación del TPM (Consulta 10 de abril de 2016) http://web.a.ebscohost.com/ehost/pdfviewer/pdfviewer?sid=09792b9a-23eb-45d7-a6b6$6673 \mathrm{~d} 42 \mathrm{adcf} 2 \% 40$ sessionmgr4001\&vid $=9 \& \mathrm{hid}=4214$

MADARIAGA, Francisco (2013) Lean Manufacturing: Exposición adaptada a la fabricación repetitiva de familias de productos mediante procesos discretos (Consulta 4 de noviembre de 2015)

https://books.google.com.pe/books?id=mBgDGYRQzXMC\&printsec=frontcover\&dq=lean + manufacturing\&hl=es419\&sa=X\&ved=0CCEQ6AEwAWoVChMIyo3MyI6PyQIVATomCh3jYgLc\#v=onepage $\& \mathrm{q}=$ lean $\% 20$ manufacturing $\& \mathrm{f}=$ false

MEDIANEIRA, Nara (2014) Herramientas para la mejoría de la calidad y productividad (Consulta 1 de noviembre de 2015)

(http://revistas.ua.pt/index.php/estudosdoisca/article/view/2866)

MIGUEL, Jorge (2013) Sistema de implementación de Manufactura Esbelta (Consulta 10 de noviembre de 2015) http://eprints.uanl.mx/7916/1/1080259485.pdf

MONGE, Carlos y otros (2013) Impacto de la Manufactura Esbelta, Manufactura Sustentable y Mejora Continua en la Eficiencia Operacional y Responsabilidad Ambiental en México (Consulta 1 de noviembre de 2015) 
http://web.a.ebscohost.com/ehost/detail/detail?vid=5\&sid=3ba7d7de-1c10-4928-8ecb$5700872 \mathrm{cb} 9 \mathrm{bb} \% 40$ sessionmgr4003\&hid=4112\&bdata=Jmxhbmc9ZXM\%3d\#AN=933264 $69 \& \mathrm{db}=$ fua

MORALES, Alberto y otros (2014) Modelo de un sistema de producción esbelto con redes de Petri para apoyar la toma de decisiones (Consulta 1 de noviembre de 2015) http://web.a.ebscohost.com/ehost/detail/detail?vid=14\&sid=3ba7d7de-1c10-4928-8ecb5700872cb9bb\%40sessionmgr4003\&hid=4112\&bdata=Jmxhbmc9ZXM\%3d\#AN=102306 $173 \& \mathrm{db}=$ fua

NOGUERAS, David (2012) Qué hay realmente de nuevo en Lean IT? (Consulta 1 de noviembre de 2015) http://web.a.ebscohost.com/ehost/detail/detail?vid=16\&sid=3ba7d7de-1c10-4928-8ecb5700872cb9bb\%40sessionmgr4003\&hid=4112\&bdata=Jmxhbmc9ZXM\%3d\#db=fua\&AN $=77897886$

OLSEN, Eric y otros (2014) Extending the A3: A Study of Kaizen and Problem Solving (Consulta 10 de abril de 2016)

http://web.b.ebscohost.com/ehost/pdfviewer/pdfviewer?vid=1\&sid=ea91f5a9-1 cdc-4d3aa907-098ba306181f\%40sessionmgr104\&hid=123

PÉREZ, Jorge y otros (2010) Uso de herramientas de mejoramiento y su incidencia en costos, fallas y factores de éxito de grandes y medianas empresas industriales del Valle de Aburrá (Consulta 10 de noviembre de 2015) http://www.scielo.br/pdf/gp/v17n3/12.pdf

PÉREZ, Jorge (2011) El avión de la muda: herramienta de apoyo a la enseñanzaaprendizaje práctica de la manufactura esbelta, (Consulta 25 de mayo de 2015) http://www.scielo.org.co/pdf/rfiua/n58/n58a18.pdf 
ROCA, Alfredo (2014) Control Automático de Procesos Industriales (Consulta 22 de julio de 2016) https://books.google.com.pe/books?id=xmMWBQAAQBAJ\&pg=PA85\&dq=diagrama + de + bloques + en + balance + de + materia $\&$ hl $=$ es $\& s a=X \&$ redir_esc $=y \# v=$ onepage $\& q=$ diagrama $\%$ 20de $\% 20$ bloques $\% 20$ en $\% 20$ balance $\% 20 \mathrm{de} \% 20$ materia $\& \mathrm{f}=$ false

ROF, Letitia (2011) Kaizen Costing and its role in the management of an entity (Consulta 10 de noviembre de 2015)

http://web.a.ebscohost.com/ehost/detail/detail?vid=36\&sid=3d953c1f-5077-48b0-b666c78b8a9a47a0\%40sessionmgr4002\&hid=4114\&bdata $=$ Jmxhbmc9ZXM\%3d\#db=bth\&AN= 63890743

RUIZ DE ARBULO, Patxi (2007) La gestión de costes en Lean Manufacturing. $1^{\mathrm{a}}$ ed. España: Netbiblo

SÁNCHEZ, Guillermo y otros (2012) KANBAN allocation in a serial suply chain (Consulta 1 de abril de 2016) http://web.a.ebscohost.com/ehost/pdfviewer/pdfviewer?vid=25\&sid=fce8caca-7b83-439e97cb-f82e2194af48\%40sessionmgr4005\&hid=4214

SÁNCHEZ, José (2012) Proyect Managenent Models: Lean Thought Proyect Managenent (Consulta 10 de noviembre de 2015)

http://web.b.ebscohost.com/ehost/results?sid=83139cd5-5c42-4098-a666133b8b074285\%40sessionmgr198\&vid=26\&hid $=115 \&$ bquery $=$ pensamiento + lean $\&$ bdata $=$ JmRiPWE5aCZkYj1uZGgmZGI9YnRoJmRiPXVmaCZkYj1paWgmZGI9ZGRoJmRiPW VoaCZkYj1laWgmZGI9OGdoJmRiPWtoaCZkYj1 loamgmZGI9aGxoJmRiPWx4aCZkYj1s aWgmZGI9ZjZoJmRiPWx0aCZkYj1uZmgmZGI9YndoJmRiPXNpaCZkYj1zM2gmZGI9c 2VyJmRiPW5sZWJrJmRiPWZ1YSZkYj1lbnQmZGI9MjJoJmNsaTA9RFQxJmNsdjA9Mj AxMDAxLTIwMTUxMiZsYW5nPWVzJnR5cGU9MA\%3d\%3d 
SANCHIS, Raquel y otros (2011) Gestión de la calidad total y mantenimiento productivo total en la fabricación de alto rendimiento (Consulta 1 de noviembre de 2015). http://web.a.ebscohost.com/ehost/detail/detail? vid=72\&sid=abc82341-03f2-42ce-b03bc7b40644ddc8\%40sessionmgr4005\&hid=4212\&bdata=Jmxhbmc9ZXM\%3d\#db=fua\&AN $=69540602$

SCHMIDT, Stefan (2013) Preventive Methods in logistics Poka - Yoke and failure mode and effect analysis (FMEA) (Consulta 1 de noviembre de 2015). http://web.a.ebscohost.com/ehost/detail/detail?vid=24\&sid=abc82341-03f2-42ce-b03bc7b40644ddc8\%40sessionmgr4005\&hid=4212\&bdata=Jmxhbmc9ZXM\%3d\#AN=1021489 $89 \& \mathrm{db}=\mathrm{a} 9 \mathrm{~h}$

SOUSA, Lourdes (2014) Eficiencia con las 5'S Limpieza y orden eficientes, clave del desarrollo japonés (Consulta 1 de noviembre de 2015) http://web.a.ebscohost.com/ehost/pdfviewer/pdfviewer?sid=45ea0282-0206-4794-936fbc11bd6779c4\%40sessionmgr4003\&vid=14\&hid=4212

TAMÀS, Pèter (2016) Application of value stream Mapping at flexible Manufacturing Systems (consulta 10 de mayo 2016).

http://web.a.ebscohost.com/ehost/pdfviewer/pdfviewer?sid=49da7e42-c731-4b5d-b9470fb3626ee1 c6\%40sessionmgr4004\&vid=4\&hid=4107

TEJADA, Anne (2011) Mejoras de Lean Manufacturing en los sistemas productivos (Consulta 1 de noviembre de 2015).

http://web.a.ebscohost.com/ehost/detail/detail?vid=11\&sid=3ba7d7de-1 c10-4928-8ecb$5700872 \mathrm{cb} 9 \mathrm{bb} \% 40$ sessionmgr4003\&hid=4112\&bdata $=$ Jmxhbmc9ZXM\%3d \#db=fua\&AN $=67763924$

TOLEDANO, Asier y otros (2009) Las claves del éxito Toyota. Lean, más que un conjunto de herramientas y técnicas, Cuadernos de Gestión Vol. 9. № 2 (Año 2009), pp. 111-122 
http://web.a.ebscohost.com/ehost/detail/detail?vid=4\&sid=9c3f708f-c427-4ceb-bc54b9b2a6007e27\%40sessionmgr4005\&hid=4109\&bdata=Jmxhbmc9ZXM\%3d\#db=fua\&AN $=48735284$

YACUZZI, Enrique y otros (2013) Aplicaciones del JIT en argentina (Consulta 10 de noviembre de 2015)

http://web.a.ebscohost.com/ehost/detail/detail?vid=15\&sid=45ea0282-0206-4794-936fbc1 1bd6779c4\%40sessionmgr4003\&hid=4212\&bdata=Jmxhbmc9ZXM\%3d\#db=a9h\&AN $=88914861$

UPADHYE, Nitin y otros (2010) Lean Manufacturing para el Desarrollo Sostenible (Consulta 1 de noviembre de 2015)

http://web.a.ebscohost.com/ehost/detail/detail?vid=14\&sid=913fd371-f444-406a-a8fdf017da0a630b\%40sessionmgr4002\&hid=4107\&bdata $=$ Jmxhbmc9ZXM\%3d $\# \mathrm{db}=$ ent\&AN= 51408911 


\section{GLOSARIO DE TERMINOS}

Cultura: Conjunto de principios, creencias y normas de conducta aceptadas, que determinan como de realizan las cosas en una organización.

Estocásticos: Teoría estadística de los procesos cuya evolución en el tiempo es aleatoria.

Lean Manufacturing: Manufactura esbelta o manufactura delgada su fin es reducir las actividades que no agregan valor de los procesos para agilizarlos.

Procesos: Conjunto de actividades que interactúan para producir un producto o proceso

Tasa de Retorno de la Inversión (TIR): Es una medida de la rentabilidad de un proyecto de inversión, que muestra el interés más alto a la que el proyecto no genera pérdidas o ganancias es decir el valor actual neto igual a cero.

Valor Actual Neto (VAN): Es la sumatoria de los valores positivos (ingresos) y de valores negativos (costos) que se producen en diferentes momentos.

Ventaja Competitiva: La ventaja competitiva se da cuando una organización cuenta con una mejor posición respecto a sus rivales para asegurar la fidelidad de sus clientes. Esta ventaja está asociada a las actividades que realiza la empresa en su cadena de valor, a menores costos que sus adversarios. 


\section{Anexos \\ MEMORIA DESCRIPTIVA DE PROCESO \\ SISTEMA DE CONTROL DE BATCH \\ PLANTA FIDEERÍA - 2016 - V1}

Actualmente la planta de Fideeria cuenta con líneas continuas de producción de alta capacidad de pasta larga y pasta corta. El sistema de dosificación es por batch totalmente automatizado y este realiza la gestión de formulación para todas las líneas de producción. El nuevo sistema de control de batch será insertado en la lógica del PLC y el SCADA y tendrá como finalidad controlar la cantidad de materia prima a ser enviada de acuerdo con un valor ingresado. En consecuencia, tendrá la capacidad generar las alarmas correspondientes o de parar la dosificación de acuerdo con las habilitaciones definidas por el operador.

\section{Lógica de control PLC}

El sistema debe tener la capacidad de realizar la nueva gestión por cada línea de proceso en forma independiente, las nuevas funciones deberán ser programadas en boques diferentes a los existentes. El número de batch a controlar será ingresado por medio del SCADA además el sistema debe contemplar un campo que permita definir la cantidad de batch previos a cumplir con el objetivo, esto debe permitir generar las alarmas correspondientes y parar la dosificación cumplido el objetivo, en el siguiente grafico la lógica de funcionamiento. 
Figura 80: Gráfica de sistema de control de Batch

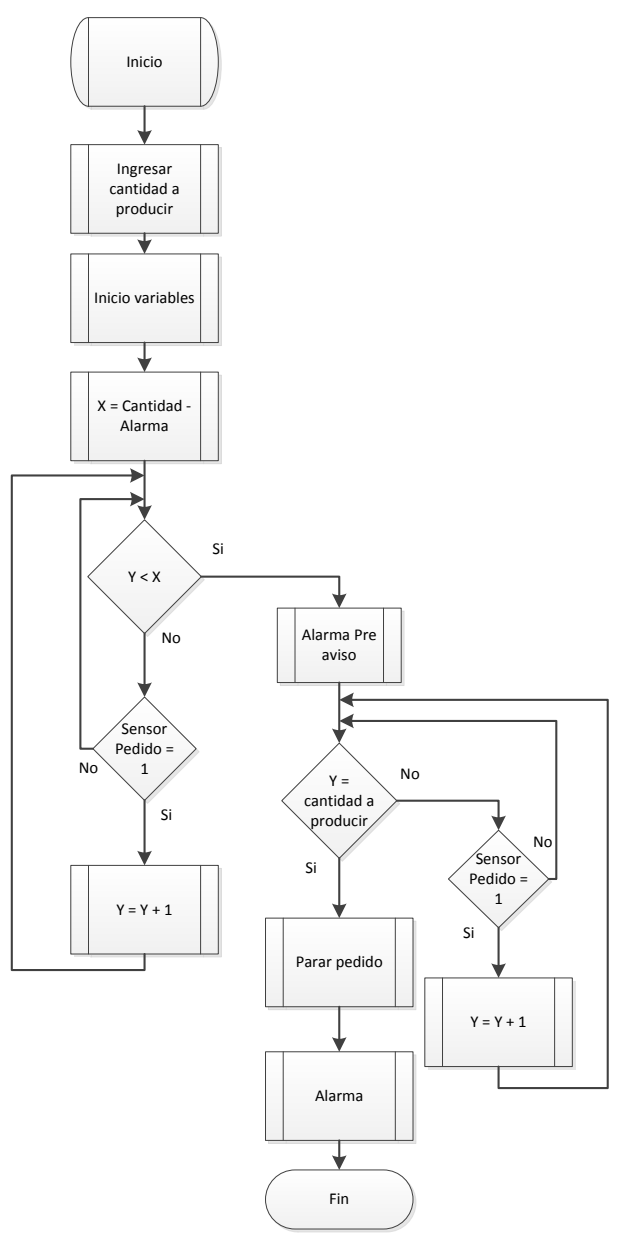

Fuente: Elaboración propia basado en información de la empresa

El sistema debe tener la flexibilidad de usar o prescindir de las nuevas funciones, esta habilitación es por cada línea de proceso. La señal de referencia para el contador de batch se tomará del sensor de pedido señal existente como se muestra en el grafico siguiente. 
Figura 81: Gráfica de sensor de contador

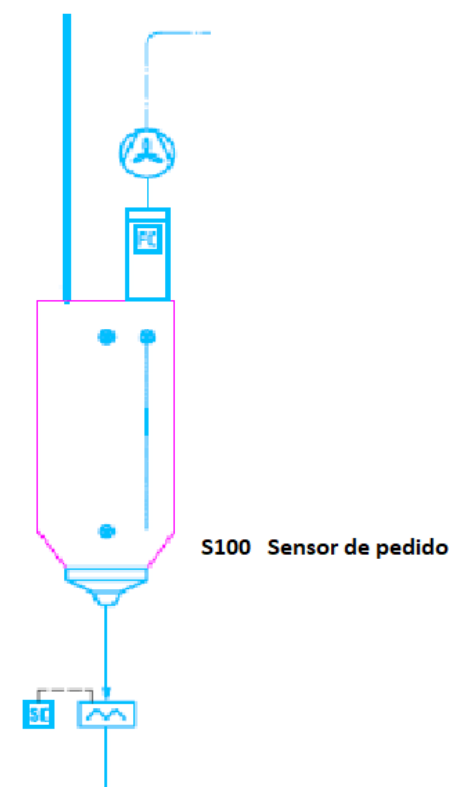

Fuente: Elaboración propia basado en información de la empresa

En la siguiente tabla la lista de sensores por cada línea de proceso Tabla 25: Sensores del proceso batch

\begin{tabular}{|l|c|c|c|c|c|c|c|c|c|}
\hline Silo Línea & A & B & C & D & E & F & G & H & I \\
\hline TAG Sensor & S100 & S200 & S300 & S400 & S500 & S600 & S700 & S 800 & S900 \\
\hline
\end{tabular}

Fuente: Elaboración propia basado en información de la empresa

Las alarmas generadas por este nuevo proceso serán independientes a las existentes sin embargo el sistema de reconocimiento y reset deben ser integradas en las actuales botoneras de campo y SCADA. En consecuencia, para la alarma sonora y visual serán asignadas salidas digitales libres existentes del PLC.

$\underline{\text { SCADA }}$ 
Se creará una nueva pantalla que permita ingresar en número de batch a producir por cada línea de producción. El ingreso de datos debe tener restricciones que solo permitan ingreso de números y en un rango configurable con mínimos y máximos, el botón de grabar debe tener confirmación de la acción. Se modificara la pantalla donde se encuentra la gestión de envíos y se agregara el Valor de proceso (PV) y el punto objetivo se control (SP) por cada línea de producción. Además, el sistema debe tener la capacidad de realizar la trazabilidad quiere decir que por cada línea de proceso se debe grabar las variables SP y PV en el historiador del SCADA en la siguiente imagen se muestra el diseño de las pantallas Figura 82: Gráfica de pantallas de control de Batch

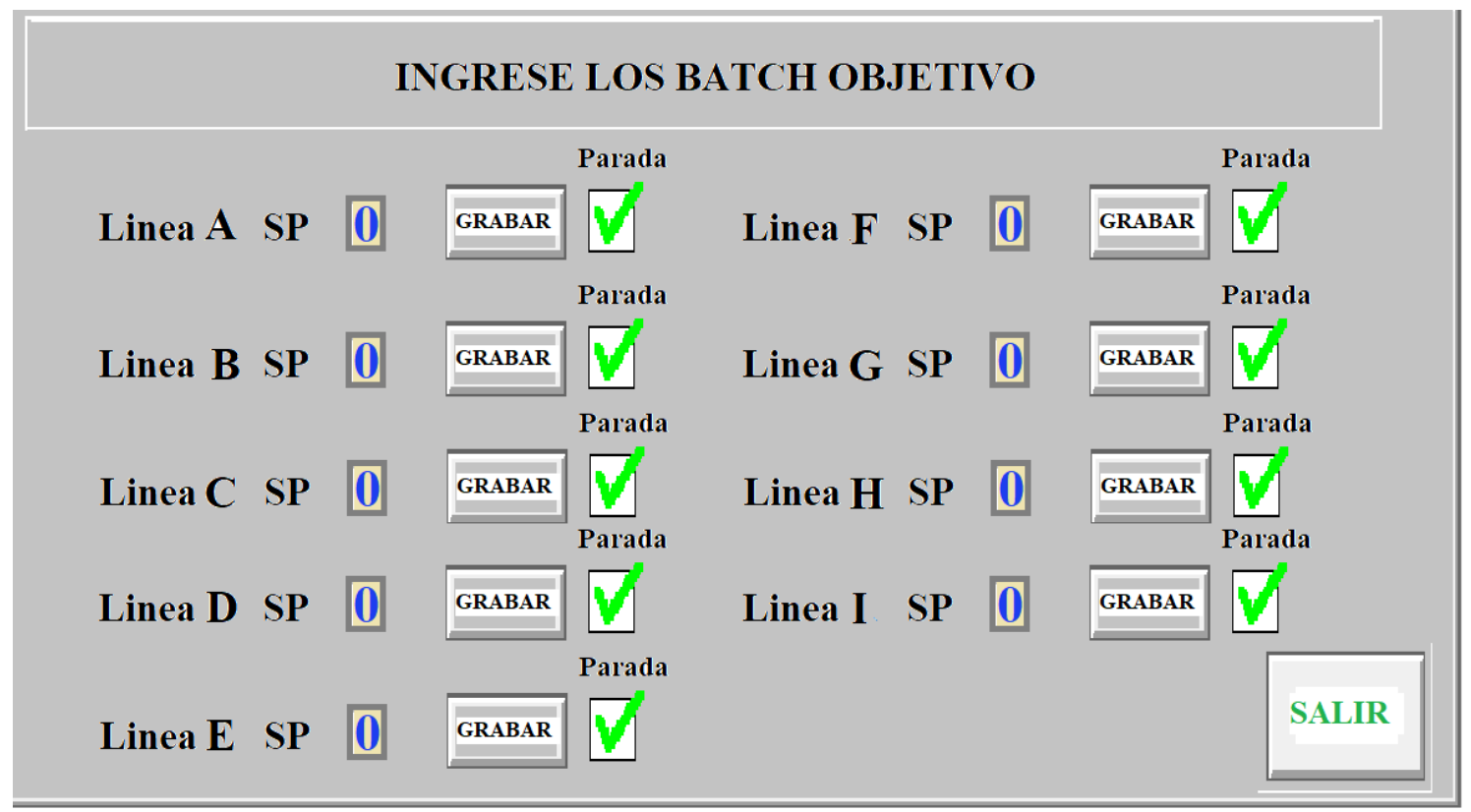




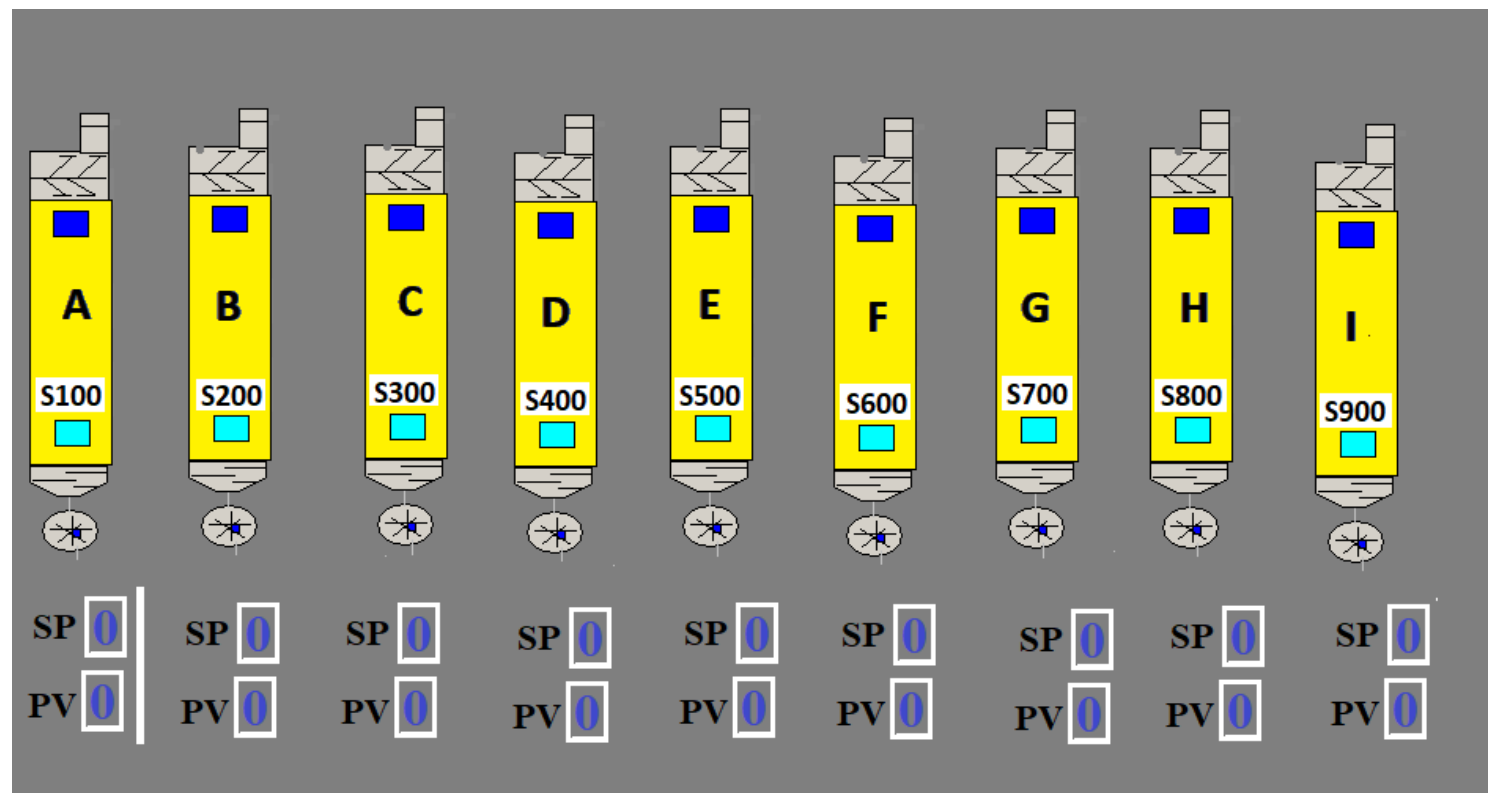

Fuente: Elaboración propia basado en información de la empresa 